


\section{EXHIBITIONS FOR SOCIAL JUSTICE}

Exhibitions for Social Justice assesses the state of curatorial work for social justice in the Americas and Europe today. Analyzing best practices and new curatorial work to support all those working on exhibitions, Gonzales expounds curatorial practices that lie the nexus of contemporary museology and neurology. From sharing authority, to inspiring action and building solidarity, the book demonstrates how curators can make the most of visitors' physical and mental experience of exhibitions.

Drawing on ethnographic and archival work at over twenty institutions with nearly eighty museum professionals, as well as scholarship in the public humanities, visual culture, cultural studies, memory studies, and brain science, this project steps back from the detailed institutional histories of how exhibitions come to be. Instead, it builds a set of curatorial practices by examining the work behind the finished product in the gallery.

Demonstrating that museums have the power to help our society become more hospitable, equitable, and sustainable, Exhibitions for Social Justice will be of interest to scholars and students of museum and heritage studies, gallery studies, arts and heritage management, and politics. It will also be valuable reading for museum professionals and anyone else working with exhibitions who is looking for guidance on how to ensure their work attains maximum impact.

Elena Gonzales is an independent scholar focusing on curatorial work for social justice and the roles of museums in society. She received her doctorate in American Studies at Brown University in 2015 and her Master's in Public Humanities from Brown in 2010. She has curated exhibitions since 2006 and has taught curatorial studies since 2010, becoming a 2012 Ford Dissertation Fellow and a visiting scholar in American Studies at Northwestern University from 2011-2015. She is co-chair of the exhibitions committee at the Evanston Art Center and co-editor of Museums and Civic Discourse: History, Current Practice, and Future Prospects, a digital public humanities project. 


\title{
MUSEUM MEANINGS
}

\author{
Series Editors: Richard Sandell and Christina Kreps
}

Museums have undergone enormous changes in recent decades; an ongoing process of renewal and transformation bringing with it changes in priority, practice and role as well as new expectations, philosophies, imperatives and tensions that continue to attract attention from those working in, and drawing upon, wide-ranging disciplines.

Museum Meanings presents new research that explores diverse aspects of the shifting social, cultural, and political significance of museums and their agency beyond, as well as within, the cultural sphere. Interdisciplinary, cross-cultural and international perspectives and empirical investigation are brought to bear on the exploration of museums' relationships with their various publics (and analysis of the ways in which museums shape - and are shaped by - such interactions).

Theoretical perspectives might be drawn from anthropology, cultural studies, art and art history, learning and communication, media studies, architecture and design and material culture studies amongst others. Museums are understood very broadly - to include art galleries, historic sites, and other cultural heritage institutions - as are their relationships with diverse constituencies.

The focus on the relationship of the museum to its publics shifts the emphasis from objects and collections and the study of museums as text, to studies grounded in the analysis of bodies and sites; identities and communities; ethics, moralities and politics.

\section{Also in the series:}

Colonialism and the Object

Empire, Material Culture and the Museum

Edited by Tim Barringer and Tom Flynn

\section{Museum Activism}

Edited by Robert R. Janes and Richard Sanders

\section{Exhibitions for Social Justice}

Elena Gonzales

www.routledge.com/Museum-Meanings/book-series/SE0349 


\title{
EXHIBITIONS FOR SOCIAL JUSTICE
}

Elena Gonzales

\author{
홀 Routledge \\ 尊 Taylor \& Francis Group \\ LONDON AND NEW YORK
}


First published 2020

by Routledge

2 Park Square, Milton Park, Abingdon, Oxon OX14 4RN

and by Routledge

52 Vanderbilt Avenue, New York, NY 10017

Routledge is an imprint of the Taylor \& Francis Group, an informa business

(C) 2020 Elena Gonzales

The right of Elena Gonzales to be identified as author of this work has been asserted by her in accordance with sections 77 and 78 of the Copyright, Designs and Patents Act 1988.

All rights reserved. No part of this book may be reprinted or reproduced or utilised in any form or by any electronic, mechanical, or other means, now known or hereafter invented, including photocopying and recording, or in any information storage or retrieval system, without permission in writing from the publishers.

Trademark notice: Product or corporate names may be trademarks or registered trademarks, and are used only for identification and explanation without intent to infringe.

British Library Cataloguing-in-Publication Data

A catalogue record for this book is available from the British Library

Library of Congress Cataloging-in-Publication Data

A catalog record has been requested for this book

ISBN: 9781138292611 (hbk)

ISBN: 9781138292598 (pbk)

ISBN: 9781315232812 (ebk)

Typeset in Bembo

by Newgen Publishing UK 
For - Pop I 
$\because$ Taylor \& Francis

Taylor \& Francis Group

http://taylorandfrancis.com 


\section{CONTENTS}

List of figures viii

List of tables $\quad$ xii

List of abbreviations xiii

Acknowledgments xiv

Introduction

1 From empathy to solidarity 15

2 Physical experiences: building memories and empathy 58

3 Inspiring action $\quad 96$

4 Welcome, inclusion, and sharing authority 139

$\begin{array}{lr}\text { Conclusion } & 180\end{array}$

$\begin{array}{ll}\text { Index } & 187\end{array}$ 


\section{FIGURES}

1.1 Incredulità di San Tommaso by Michelangelo Merisi da Caravaggio, 1601-1602, oil on canvas, 42" x 57". Courtesy of Stiftung Preußische Schlösser und Gärten Berlin-Brandenburg/Photographer: Hans Bach.

1.2 View of the plaza and Nelly's house in Verzetsmuseum Jr. at the Verzetsmuseum, photo by author (2017). Courtesy of Verzetsmuseum Amsterdam.

1.3 View of Eva's house in Verzetsmuseum Jr. at the Verzetsmuseum, photo by author (2017). Courtesy of Verzetsmuseum Amsterdam.

1.4 Interior of Jan's house in Verzetsmuseum Jr. at the Verzetsmuseum, photo by author (2017). Courtesy of Verzetsmuseum Amsterdam.

1.5 Interior of Eva's house with coatrack in Verzetsmuseum Jr. at the Verzetsmuseum, photo by author (2017). Courtesy of Verzetsmuseum Amsterdam. 26

1.6 Jane Addams' traveling Medicine Kit and the alternative label by Terri Kapsalis. Photograph by Rachel Glass. Image courtesy of Jane Addams Hull-House Museum, University of Illinois at Chicago.

1.7 “The Big Graph” at Eastern State Penitentiary showing the US having the highest per-capita rate of incarceration (2016). Courtesy of Eastern State Penitentiary Historic Site.

1.8 "The Big Graph" at Eastern State Penitentiary showing the spike in overrepresentation of non-White populations in jail beginning in the 1980s (2016). Courtesy of Eastern State Penitentiary Historic Site.

1.9 Inside Prisons Today at Eastern State Penitentiary (2016). Courtesy of Eastern State Penitentiary Historic Site.

1.10 Anónimo novohispano, "De español y negra produce mulato," Segunda mitad del siglo XVIII, oleo sobre lámina de cobre, $43 \mathrm{~cm}$ x $32 \mathrm{~cm}$, Colección Museo Soumaya. Fundación Carlos Slim, Ciudad de México, México. Photo by Javier Hinojosa, courtesy of the National Museum of Mexican Art with kind permission from Museo Soumaya. 
1.11 “War Targets Poor People of Color," by Favianna Rodríguez and Alfonso Jaramillo, i arte, 2002, offset poster, Permanent Collection of the NMMA 2003.327. Courtesy of Favianna Rodríguez, Alfonso Jaramillo, i arte, and the National Museum of Mexican Art.

1.12 Gallery shot of Who Are We Now? showing (left to right) "Malcolm X \& Steven Biko" by Malaquias Montoya (1992) and "Malcolm as the Phoenix" by Chaz Bojorquez (1993). Image courtesy of National Museum of Mexican Art. 48

2.1 Gallery shot of Unfinished Business: The Right to Play at the Jane Addams Hull-House Museum (2014). Photograph by Simon Pyle. Courtesy of Simon Pyle.

2.2 Gallery shot of the Tuttle Clog in Unfinished Business: Arts Education. Courtesy of Naomi Blumberg and the Jane Addams Hull-House Museum.

2.3 Tahitian Marketplace in Traveling the Pacific at the Field Museum; photo by author (2016). Courtesy of the Field Museum.

2.4 A visitor tries to move a stone block in Inside Ancient Egypt at the Field Museum; photo by author (2016). Courtesy of the Field Museum.

2.5 Photograph by Rachel Herman of Into Body Into Wall by Maria Gaspar at the Jane Addams Hull-House Museum (2015). Courtesy of Maria Gaspar.

2.6 Photograph by Rachel Herman of Into Body Into Wall by Maria Gaspar at the Jane Addams Hull-House Museum (2015), detail of curtain. Courtesy of Maria Gaspar.

2.7 Railcar in the Cleave (2017). Courtesy of Illinois Holocaust Museum \& Education Center. Photo by Jesus Mejia.

2.8 Fiftieth-anniversary commemorative postage stamps of Memín Pinguín (a character created by Yolanda Vargas in 1942) from Mexico (2005). Image courtesy of the National Museum of Mexican Art.

2.9 "La Raza Kózmika” by Alfred J. Quiroz (b. 1944), 2005, acrylic on wood panel, 64" x 95.5" x 3.5", collection of the artist. Photo by Wilson P. Graham. Image courtesy of the National Museum of Mexican Art and Alfred Quiroz.

2.10 "Copa inmigración AKA Deport a Mex Foosball” by Juan and Ricardo Compean, 35" x 30" x 56", 2008, mixed media with foosball table. Courtesy of Juan and Ricardo Compean and the National Museum of Mexican Art.

2.11 “Copa inmigración AKA Deport a Mex Foosball” detail by Juan and Ricardo Compean, 35" x 30" x 56", 2008, mixed media with foosball table. Courtesy of Juan and Ricardo Compean and the National Museum of Mexican Art.

2.12 Census map didactic panel by Angelina Villanueva for Who Are We Now? Roots, Resistance, and Recognition, 2006. Courtesy of the National Museum of Mexican Art.

3.1 Playboy interview with James Earl Ray at Brushy Mountain Penitentiary, 1977. Left to right: Jim McKinley, lead author on the interview; Laurence Gonzales, collaborating author; Ray's attorney; James Earl Ray. Collection of the author.

3.2 Gallery shot from Can You Walk Away? at Lincoln's Cottage, 2012. Take-away element: postcard installation. Courtesy of President Lincoln's Cottage. 
3.3 "Children at St. Michael's Residential School." Photo by Beverly Brown fonds (1937-1945), exhibited in Speaking to Memory: St. Michael's Indian Residential School, 2013-2014, Audrey and Harry Hawthorn Library \& Archives, UBC Museum of Anthropology. Courtesy of UBC Museum of Anthropology, Vancouver, Canada. Beverley Brown fonds. a033945.

3.4 Unofficial Voting Station: Voting for All Who Legally Can't at the Jane Addams Hull-House Museum, featuring "Vox Pop: The Disco Party" by Aram Han Sifuentes (2016). Photo by Sara Pooley. Courtesy of Aram Han Sifuentes.

3.5 Unofficial Voting Station: Voting for All Who Legally Can't at the Jane Addams Hull-House Museum, featuring "Vox Pop:The Disco Party" by Aram Han Sifuentes (2016). Banners read: "Incarcerated, Ex-Convicted, Non-Citizens, Youth, US Territories, No ID; We Too Speak American.” Photo by Sara Pooley. Courtesy of Aram Han Sifuentes.

3.6 Unofficial Voting Station:Voting for All Who Legally Can't at the Jane Addams Hull-House Museum, featuring "Vox Pop:The Disco Party" by Aram Han Sifuentes (2016). Photo by Sara Pooley. Courtesy of Aram Han Sifuentes.

3.7 US Citizenship Test Samplers installed in the library of the Jane Addams Hull-House Museum, 2016. The long sampler on the right is by Han Sifuentes and the smaller ones are by participants in her project. Photo by Sara Pooley. Courtesy of Aram Han Sifuentes.

3.8 US Citizenship Test Samplers installed in the library of the Jane Addams Hull-House Museum, 2016. Detail of sampler by Han Sifuentes. Photo by Sara Pooley. Courtesy of Aram Han Sifuentes.

3.9 US Citizenship Test Samplers installed in upstairs hallway of the Jane Addams Hull-House Museum, 2016. "Question Number: 6. Name: Maita. Age: 54. From: Columbia. Moved to the U.S. in 2003." By Maita. Embroidery on linen or cotton with plastic beads. Size roughly $8 "$ x $10^{\prime \prime}$. Photo by Sara Pooley. Courtesy of Aram Han Sifuentes.

3.10 Kristine Aono, "The Nail that Sticks of the Farthest...," 2017, installation view, IfYou Remember, I'll Remember, February-June 2017, Mary and Leigh Block Museum of Art, Northwestern University, IL. Photo by Caroline Alice Claflin. Courtesy of Kristine Aono.

3.11 Kristine Aono, "The Nail that Sticks of the Farthest...," 2017, installation view, If You Remember, I'll Remember, February-June 2017, Mary and Leigh Block Museum of Art, Northwestern University, IL. Photo by Caroline Alice Claflin. Courtesy of Kristine Aono.

3.12 Kitten and Pussyhat, knitted by Rachel Leibowitz. Photo by Tanya Findlay, 2018. Courtesy of Arran and Tanya Findlay.

3.13 Welcome Blanket view from July 2017, shortly after the opening of the exhibition. Photo by Michael Tropea. Courtesy of the Smart Museum of Art.

3.14 Welcome Blanket view from September 2017. Photo by Michael Tropea. Courtesy of the Smart Museum of Art.

3.15 Welcome Blanket view from September 2017 showing an area where visitors could write welcoming messages to new immigrants to accompany blankets. Photo by Michael Tropea. Courtesy of the Smart Museum of Art. 
3.16 Welcome Blanket view from December 2017, close to the closing of the exhibition. Photo by Michael Tropea. Courtesy of the Smart Museum of Art.

3.17 Welcome Blanket view from December 2017, showing part of the remaining mountain of blankets yet to be opened. Photo by Michael Tropea. Courtesy of the Smart Museum of Art.

3.18 Welcome Blanket view from December 2017 showing an area where visitors could write welcoming messages to new immigrants to accompany blankets. Photo by Michael Tropea. Courtesy of the Smart Museum of Art.

4.1 Alice Kellogg Tyler, Portrait of Mary Rozet Smith, 1898, oil on canvas. Image courtesy of Jane Addams Hull-House Museum, University of Illinois at Chicago.

4.2 "Common Goals, Common Struggles, Common Ground (100 year time line on the African American and Mexican migration into Chicago)" by Rahmaan "Statik" Barnes, installed at the NMMA, 2006, spray paint and acrylic on canvas, 10' x 26'. Courtesy of Rahmaan "Statik" Barnes and the National Museum of Mexican Art.

4.3 Fountain, 1917, replica 1964; Marcel Duchamp 1887-1968; Tate, purchased with assistance from the Friends of the Tate Gallery 1999; (C) Succession Marcel Duchamp/ADAGP, Paris/Artists Rights Society (ARS), New York 2017 and DACS, London 2017; photography: (C) Tate, London 2017. 


\section{TABLES}

4.1 Quick guide to types of spaces 164

4.2 Which tools fit which spaces? 166

4.3 Brainstorming on models of spaces 169

$\begin{array}{lll}4.4 & \text { Brainstorming on use of tools } & 171\end{array}$ 


\section{ABBREVIATIONS}

$\begin{array}{ll}\text { AAM } & \text { American Alliance of Museums } \\ \text { AZA } & \text { Association of Zoos \& Aquariums } \\ \text { CCHW } & \text { Chicago Coalition of Household Workers } \\ \text { CHM } & \text { Chicago History Museum } \\ \text { CHS } & \text { Chicago Historical Society } \\ \text { DoVE } & \text { Dimensions of the Visitor Experience } \\ \text { LPZ } & \text { Lincoln Park Zoo } \\ \text { MAH } & \text { Museum of Art and History, Santa Cruz } \\ \text { MASS Action } & \text { Museum as a Site of Social Action } \\ \text { MCA } & \text { Museum of Contemporary Art, Chicago } \\ \text { MFACM } & \text { Mexican Fine Arts Center Museum } \\ \text { MOA } & \text { Museum of Anthropology,Vancouver } \\ \text { MoT } & \text { Museum of Tolerance } \\ \text { NMAH } & \text { National Museum of American History } \\ \text { NMAI } & \text { National Museum of the American Indian } \\ \text { NMMA } & \text { National Museum of Mexican Art } \\ \text { OBE } & \text { Outcomes-Based Evaluation } \\ \text { PBS } & \text { Public Broadcasting Service } \\ \text { SJAM } & \text { Social Justice Alliance of Museums } \\ \text { SoC } & \text { International Coalition of Sites of Conscience } \\ \text { UBC } & \text { University of British Columbia } \\ \text { UConn } & \text { University of Connecticut } \\ \text { UIC } & \text { University of Illinois at Chicago } \\ \text { USHMM } & \text { United States Holocaust Memorial Museum }\end{array}$




\section{ACKNOWLEDGMENTS}

This book would not have been possible without the generosity of many museum professionals and scholars who shared their time, expertise, and experiences with me. First, I'd like to acknowledge my network of sites in the Chicago area for help with research. At the Chicago History Museum, thank you to Randy Adamsick for always helping me find my way in the museum world and Chicago. Thank you to Peter Alter, Jill Austin, Joy Bivins, Russell Lewis, Phyllis Rabineau (now retired), John Russick, and NancyVillafranca. Thank you Emily Graslie and Alaka Wali for your tireless and fascinating work at the Field Museum. At the Hull-House Museum, thank you to Jennifer Scott, the fearless director. Thank you to the many former staff members who have supported my work: Naomi Blumberg (now of CHM), Lisa Lee (still at UIC), Lisa Junkin López (now of the Juliette Gordon Lowe Birthplace), Heather Radke (curator, audio producer, and public historian), Rima Schultz, Amanda Signore, Teresa Silva (still at UIC), Peg Strobel, and Irina Zadov (now at the Chicago Park District's Art and Nature Department). At the Illinois Holocaust Museum, thank you to Amanda Berrios, Shoshana Buchholz-Miller, Rick Hirschhaut, Emily Mohney, Devon Pyle Vowles (now at the Art Institute), Kelley Szany, and Arielle Weinenger. Clifford Chanin, now the Senior VP for Education and Public Programming at the 9/11 Memorial \& Museum, was instrumental to helping me understand his curatorial project, Legacy of Absence, at the Holocaust Museum. Finally, thank you to the survivors who founded that institution and still pour their energies into it and bravely share their stories. Thank you to Carlos Tortolero at the National Museum of Mexican Art for helping me answer my calling in the museum world and for his faith in me. Raquel Aguiñaga Martínez, you have tirelessly responded to my calls and emails when I know your desk is covered with urgent projects. Thank you! Rebecca Meyers, thank you for always sharing your insights. Talking with you is always an education. Cesáreo Moreno, thank you for being such a caring mentor to me over the last decade and for teaching me to curate. Thank you as well to all of the many staff members of the NMMA, past and present, who have been wonderful colleagues and friends. At the Block Museum, thank you so much Dan Silverstein, who has been a trusted mentor and colleague for nearly fifteen years. And thank you to Lisa Corrin and Susy Bielak for bringing out the best in one of my favorite local 
institutions. At the Smart Museum, thank you to Michael Christiano and John Harness for truly looking beyond the frame of the exhibition format, and for sharing that vision with me. At the University of Illinois at Chicago, thank you to Jennie Brier and Rosa Cabrera for your honest feedback over the years. Thank you, consultants in Chicago, for sharing the big picture with me:Amina Dickerson of Dickerson Global Advisors, Cecilia Garibay of the Garibay Group, and Emily Reusswig at the Chicago Cultural Alliance.

Thank you very much to the artists and copyright holders who have supported my work, both in the research and in being so kind as to share images of their work for this project. To Kristine Aono, Rahmaan "Statik" Barnes, Ricardo and Juan Compean, Maria Gaspar, Alfonso Jaramillo, Ann Lewis, Favianna Rodríguez, Simon Pyle, Alfred Quriroz, Aram Han Sifuentes, Ron Wilkins, and Jayna Zweiman, I know your work will inspire other museum professionals as it has inspired me.Your generosity adds to the richness of this resource we all can share.

Thank you to the colleagues in the world of zoos and aquariums who have so graciously suffered my relative ignorance of your side of the field and helped me to better understand it and learn from your path-breaking work. Jerry Luebke, Jennifer Matiasek, and Jamie Zite-Stumbris at the Brookfield Zoo, thank you for the education! Lindsay Maldonado at the Shedd, best of luck with your new endeavors. Manda Smith and Stephanie Bohr at the Lincoln Park Zoo, thank you for your support. Your work is a model we all can learn from. Thank you to Amy Niedbalski, Erin Tate, and Laura Seger at the St. Louis Zoo for the virtual visit and for sharing your research.

I traveled to Amsterdam to learn from Eveline Sint Nicholaas and Stephanie Archangel at the Rijksmuseum, and I was not disappointed. Language is power. My best wishes to you as you work to make important changes at your institution. Other sites in Amsterdam were also very welcoming and generous with their time. Thank you to Emma Bijloos and Mette Gratama van Andel at the Prince Claus Fund. Thank you Levien Rouw for taking so much time to show me around the Anne Frank House and educate me about your programs and to Menno Metselaar for your support with my visit. My visit to Amsterdam would have been worth it even if I had only visited the Verzetsmuseum. The director, Liesbeth van der Horst, should be very proud of her site's pioneering children's exhibition. Thank you for supporting my work during and after the visit.

This project was the perfect reason to visit a long-time model of interesting curatorial work, the University of British Columbia's Museum of Anthropology. The sheer number of interesting contemporary projects I learned about on my visit from the generous curators was astounding. Thank you, Karen Duffek, Jennifer Kramer, Sue Rowley, Nuno Porto, and the director, Anthony Shelton, for a most interesting visit.

Back in the states, I ventured beyond Chicago to seek the expertise and experience of sites such as the National Underground Railroad Freedom Center. There, Richard Cooper arranged a well-rounded view of the site. Thank you Katie Brammel, Jamie Glavic, Lara Green, Ashley Jordan, Chris Miller, and Tara Riley for patiently sharing your experiences during those meetings and beyond. Thank you to Lauren Donovan Ginsberg and Zac Ginsberg. Not only did you open your gorgeous home for my visit to the Freedom Center to me but, Lauren, you have been my rock for fifteen years in the academic realm. From writing our senior theses to selecting graduate programs, from dissertations to book proposals and so far beyond, you have always been there for me.Thank you for always giving me good advice and the friendship to go with it. 
It became clear even before I arrived at Eastern State Penitentiary that Sean Kelley, Lauren Zalut, and Annie Anderson were my people. I am so excited by the work that you do. Thank you for welcoming me so quickly and forthrightly into your offices and stories.

Thank you to everyone at the International Coalition of Sites of Conscience for your inspiring work, and especially to Julieta Cuéllar (now completing graduate work), Linda Norris, and Liz Silkes for your assistance with research, and Liz Ševčenko, the coalition's founding director, for your vision and path-breaking work. Thank you to Heather Igloliorte, The Incluseum, and Caren Oberg for pointing me toward resources for research.

The team at Lincoln's Cottage should be very proud of their innovative transformation of the site and their ongoing research. Thank you, Erin Carlson Mast and Callie Hawkins for being generous with your findings. Likewise, thank you to the team at the Harriet Beecher Stowe House, Vivian Nabeta, Olivia Sher, and Katherine Kane (now retired). Historic house museums may be small, but they are mighty.

This book has given me the opportunity to approach some of my academic and museological heroes for advice. Thank you Nina Simon and Spencer Crew for your willingness to think about this project with me.Thank you, Deborah Mack, for helping me visit the National Museum of African American History and Culture remotely. I cannot wait to visit in person.

I am very grateful to the individuals beyond the museum field who shared their own stories of experiences in the museum with me. These stories were harder to find and capture with the necessary specificity, making me all the more thankful for Shannon Burke, Sian Charles Harris, Sangye Hawke, Jennifer Jones, and Mark Kohan. Thank you, Clarissa Ceglio, for introducing me to Mark Kohan and the universe of UConn, which has led to so many fruitful and thought-provoking encounters. Thank you to the curator, Katie Fuller, for sharing your experience on Race and Revolution, also at UConn.

Muchísimas gracias a Esther Fernández de Paz por enseñarme tanto sobre la museología cuando era tu estudiante en Sevilla.Y gracias por tu gran amistad tras los últimos casi 20 años. Esther has been a mentor to me across decades and oceans and has helped me summon the bravery to write this book.

Thank you to the librarians who have supported my research: Kathleen Bethel and John Hernández at Northwestern University and Elnina Geiger at the Evanston Public Library. Without all those interlibrary loans, where would I be?

Many thanks everyone at Taylor \& Francis and Routledge for making this book a reality, especially Heidi Lowther and the entire editorial and production teams, including Dan Shutt and Anitta Benice. Christina Kreps and Richard Sandell - two academic idols of mine - had the confidence in me to take on this project for Routledge. Thank you! Christina has long been a trusted mentor and I was very grateful for the opportunity to work closely with her on this project. Special thanks to Elise Howard and Sean Dinces for teaching me about the publishing process.

To all those colleagues and friends who have read part or all of this book in advance, thank you! The comments of an anonymous reviewer strengthened the book at the outset. I am very grateful to Danny Cohen and Danny Greene for insightful critiques on my treatment of Holocaust museums. Ann Lewis helped me examine building empathy and solidarity from an artist's point of view. Amy Lonetree and Micah Salkind guided me on decolonization. Rose Paquet Kinsley of the Incluseum commented on "Inspiring Action." Steve Lubar's critiques are always illuminating. After guiding me through writing my dissertation, he was kind enough to stand by me in this project as well. Morgan Rasmusson provided a fresh set of eyes when 
mine were exhausted. Emmanuel Schanzer, the shining light of your attention has shown me so much. The book is better for your invaluable critiques, but any mistakes are my own.

There is one reader who deserves an extra special thank you. He's the man to whom this book is dedicated, my father, Laurence Gonzales, who always said I would be a writer when I grew up. Pop, thank you not only for patiently reading the chapters again and again, but also for constantly feeding me research tips and stories. I know you think of me when you're reading, traveling, and working on your own projects, and I am so grateful for that. I think of you, too! Thank you for telling me to throw away my first ten-page paper in high school and for teaching me not to be afraid to write and rewrite. I learned from you that writing is a way to think.

Although she wasn't able to read this book, the angel on my shoulder throughout this project has been my mother, Carolyn Lorence, who would have had so many valuable insights to improve this work. Sadly, I must content myself with knowing that her incisive analysis and unsparing editorial skills were a constant part of my education as a writer and scholar right up until her death in 2013. Nevertheless, each day at my desk, her picture is there smiling down on me as I imagine she must be. My sister, Amelia Bartolotta, and her beautiful family have been my sweet cheerleaders and reminded me of my mom's presence.

Several important people helped me care for my two wonderful children while I was writing this book. My incredible husband, Simon Goldbroch, Karina Esquivel (¡Muchísimas gracias!), and Laurence and Debbie Gonzales all deserve my thanks for countless quiet and worry-free hours.

Last on the page, but always first for me, thank you Simon, Emmett, and C.C. Goldbroch. You have made this project possible in different ways. Where others have pushed me deeper into research and writing, you have pulled me back to my most lovely home. Where others have invited me to talk about work, you've invited me to run and flop, pretend, read, sing, and bake. Where others have read my chapters, you've read Hop on Pop to me. Emmett and C.C.: thank you for your snuggles, your performances, for being my good helpers, and for filling my cup to the brim with happiness. Simon, thank you for being my dinnertime king and king of my heart. 
$\because$ Taylor \& Francis

Taylor \& Francis Group

http://taylorandfrancis.com 


\section{INTRODUCTION}

Museums have the power to help our society become more hospitable, equitable, and sustainable. One goal of this book is to support museum professionals and other cultural workers in making and making use of the feelings that arise from visiting exhibitions. Specifically, this book is meant to help make those feelings useful in working for social justice. Likewise, I have endeavored to make this text a useful tool for researchers and students. In order to achieve these aims, I present examples from contemporary museum practice where social justice is one curatorial goal. In particular, I seek out practices that can build detailed, long-lasting memories, that can break down prejudices by helping visitors (and staff) build empathy and solidarity, and that can inspire visitors to take action. When we harness the systems in the human brain to help, this can be even more effective. To this end, I (conservatively) incorporate contemporary neurology into the analysis of curatorial practices whenever possible.

The importance of curatorial work for social justice can be broken down into several main areas, which the practices in this book will reinforce and demonstrate. First and foremost, curatorial work for social justice is one way that museums can contribute positively to the social and environmental sustainability of human life. I join with scholars such as Robert Janes in exploring how museums can foster practices and states of mind in visitors that will positively affect our human prospects into the future. Second, curatorial work for social justice is important because museums are some of society's primary educators, along with families and schools. Given this crucial position, museums have a significant role to play in helping learners of all ages gain the tools they need to examine problems, find solutions, act pro-socially, and engage in respectful, inclusive behavior that is rooted in an understanding of history and cultural diversity. Finally, and selfishly from the standpoint of museums, working for social justice through exhibitions is one important way to enhance the sustainability and relevance of museums. The practices I discuss in this volume, however, are not only about making museums more sustainable. Rather, they are about how museums today are contributing, and can continue to contribute, to shaping our societies to become ones in which risks and rewards are equitably distributed and ones in which a representative variety of voices shape the narratives of the past, present, and future. Finally, I hope to provide some indicators of where future 
studies in this area can further strengthen curatorial work for social justice. This book is only one step in a collective endeavor.

\section{Curatorial work for social justice}

Curatorial work is not limited to curators. Designers and many others have roles that are curatorial in nature - creative, involving research and mining of collections, thinking about visitors' responses, and imagining interpretive strategies. Furthermore, exhibitions are often assembled by teams. In this book, I use the term "curator" inclusively to refer to all those involved in the creative practice of building the multisensory environments that are exhibitions. Sometimes I refer in particular to other professionals by title, and there are important distinctions between positions, especially at the level of each individual institution. But here, my interest is in facilitating curatorial work in its most inclusive sense. To this end, I have designed this book to be useful to practitioners as well as teachers, students, and researchers.

Scholars of social justice divide the field broadly into two categories: distributive justice and retributive justice. ${ }^{1}$ Distributive justice is about the equitable distribution of risks and rewards in society. Retributive justice is about the redress of wrongs. ${ }^{2}$ In the context of exhibitions that work for social justice, distributive justice includes the equitable distribution of historical recognition, inclusion in dominant national identities, and the guarantee of civil and human rights. Retributive justice in exhibitions includes mitigating prejudice and transitional justice efforts to commemorate and prevent atrocities such as genocide.

Transitional justice is an area of study that addresses transitions from authoritarian regimes, wars, and other instances of large-scale violations of human rights. ${ }^{3}$ It is mostly beyond the scope of this study. However, an overview of the ways in which museums have supported and can support transitional justice is a useful addition to the discussion, since they also relate to social justice.

Literature in the field of transitional justice, a subset of retributive justice, has been calling out for the type of work that museums provide. Scholars such as Tristan Anne Borer describe several needs that museums can address. ${ }^{4}$ They include rebuilding communities, fostering conversation about the unthinkable and unspeakable, and placing events in historical context. In general, transitional justice efforts require going beyond what truth and justice commissions do to get at the meaning of the events that have transpired. That is one job of museums.

Transitional justice provides numerous tantalizing openings for museums and historic sites to assist in the work of transitional justice. Museums rebuild communities where chaos and discrimination have overwhelmed democracy. They also tread where governments cannot go. One of the main languages in museums is visual. In The Power of Images, for example, David Freedberg makes the argument that images reach us on a visceral level and that our experiences with them actually begin in a realm beyond words. ${ }^{5}$ Unspeakable horror or beauty may be approached from a variety of media within the museum that can prove helpful emotionally, politically, and socially. Our human ability to think about problems and work toward solutions may be contingent on our ability to talk about them. ${ }^{6}$ Our inability to talk about these problems hampers not only our ability to redress wrongs and prevent further violence, but also the ability of victims of violence to grieve and heal.

Unlike truth commissions, museums and other sites can situate their topics in context. As museums fight to remain relevant, they are trying to connect the past and the present. In the most effective examples these connections are a way of working for good in the present 
by recognizing the persistence of past problems, such as prejudice and discrimination, and learning about possible solutions.

The International Coalition of Sites of Conscience $(\mathrm{SoC})$ is an organization that lies at the intersection of social justice, transitional justice, and museums. The rise of the SoC is but one indicator to the museum world of the importance of topics of justice in the global cultural landscape. The Lower East Side Tenement Museum in New York worked with eight other museums in seven other countries to found the SoC in 1999. ${ }^{7}$ Now the organization counts more than 200 sites, including many museums, among its members. More than half of these are outside the US. In its own words, the SoC is a "global network of historic sites, museums and memory initiatives that connect past struggles to today's movements for human rights." ${ }^{8}$ The organization believes in the political agency of history and the necessity of engaging with the past to form a just present and future. The organization's goal for members is that they take action and inspire action in their visitors. As the director Liz Silkes put it, the coalition is building a movement of organizations working for social justice, "spreading best practices from member to member and community to community."

But the SoC is only the tip of the iceberg. Small community museums and large mainstream museums alike have an eye on positive social change without making this their only purpose. Some of the museums in this study belong to the SoC. Others are notable exceptions that the SoC does not represent. I want to touch on these and other fruitful areas of relevant curatorial work in building an international context for this book.

This book builds on the work of many scholars who have established the possibility of museums working for social justice and then documented that reality. Others have provided diverse examples of curatorial work for social justice. My project steps back from the detailed institutional histories of how exhibitions come to be. Instead, I build a set of curatorial practices by examining the work that goes into the finished product in the gallery.

One of the ways in which museums have been demonstrating their relevance is by realizing their ability to work for social justice. In this project, I take as established the fact that museums can and do work for social justice and that this contributes to their ongoing relevance. ${ }^{10}$ Nevertheless, this is but one role that museums can have in society. Not all museums are suited for playing this, nor should they be obligated to do so. One of the most significant values of the global landscape of museums today is its diversity.

\section{Taking a position}

We all have agency and positions from which we speak. In Interpreting Art in Museums and Galleries, Christopher Whitehead wrote:

Recognition of the fallacy of the neutrality of the gallery space is commonplace now: the gallery is not, and never was, a value-free location ... and to go there is not to leap into some alternative pre-political reality of aesthetic contemplation and reverie. ${ }^{11}$

Steven Dubin asserted that museums either support the status quo or they are actively working for change. This stands to reason. Any institutions that claim to take no position are tacitly taking the position that the status quo is acceptable. ${ }^{12}$ Susan Pearce said it best: "The most dangerous exhibitions are the ones mounted by authors who claim objectivity, and who are therefore unaware of the broader purposes to which their work could be put." ${ }^{13}$ 
We all take positions that reflect the many features of our individual subjectivity. However, some fear that curators could choose to turn history to their own political ends. To say, as critics such as Edward Rothstein have, that culturally specific museums make up history to suit their purposes misses the point. ${ }^{14}$ Culturally specific museums exist partially to refute the arguments of the great imperial museums. They tell alternative versions of their histories, mythologies, and stories and blend the significance of these categories in a way that does not confer privilege on Western epistemologies. This strategy is important to decolonizing museums, as I discuss in Chapter 4.

Culturally specific museums are not the only ones that have sustained this kind of criticism. In the aftermath of apartheid, the South African Truth and Reconciliation Commission pioneered the idea that multiple truths can coexist based on our diverse positions as subjects. ${ }^{15}$ The Truth and Reconciliation Commission defined four kinds of truth: factual or forensic truth, personal or narrative truth, social truth, and restorative truth. Museums use this framework to create complex narratives with multiple voices. Restorative truth is about creating the best truth imaginable for the world of the future. Some would say that restorative truth is nothing more than an excuse for propaganda, and that the notion of multiple truths enables the use of misinformation for any political purpose. I argue that the information the museums in this study provide is not misleading or untrue despite its use, in some cases, for an explicit purpose.

When the museum claims a position and staff members are also allowed to claim their positions, the museum takes a step toward rupturing the false notion of objectivity. This is, in and of itself, an important political intervention and can help exhibitions resonate with visitors. As most storytellers and readers know, visitors will connect more easily to a narrative with authorship and a point of view. Often, getting to resonance involves taking the risk of transparency about the agency and position of the museum. As Nina Simon put it, political meaning and personal value are often connected.

Dishonesty exists on different levels ... We commit errors of omission, telling visitors a fun fact instead of something that might connect more deeply (and perhaps uncomfortably) with their lives. We write museum exhibit labels in a "neutral" tone, ignoring the multiplicity of perspectives on the issue at hand ... We say "they'll figure it out on their own." Sometimes they will. But often they won't ... if you want to matter more, you have to take the risk and make the relevance explicit. ${ }^{16}$

Museums that shy away from openly staking out their position on the issues they discuss in their galleries should recall that even the most traditional institutions use the notion of multiple truths. Throughout its history, the Chicago Historical Society (now CHM) struggled to organize and present multiple truths. In 1929, the museum was in a capital campaign and leaders were discussing the narrative the museum would tell in the new building. The minutes from one meeting recall:

In their search for truth, our present day historians have disrobed many of our national heroes, exposing their weaknesses to the public eye and forgetting to stress their virtues. The story of Washington and the cherry tree is perhaps a myth, but why explode the bubble if in doing so we break down one of those fine childhood stories which has helped many a boy or girl to become a better man or woman? ... in the presentation 
of the life story of our ancestors let us pass lightly over their faults and emblazon their virtues in the skies. ${ }^{17}$

In this foreshadowing of the History Wars, the museum committed to supporting what it viewed as the restorative truth rather than the forensic truth. Later, the same document states this explicitly: "For history ... is read with the mind as well as with the heart. It is, after all, a means and an avenue whereby we may attain the future." ${ }^{18}$ The ideas that administrators of CHS in 1929 had about the future of the city and nation were different from those they have today. Those earlier administrators did not shy away from trying to influence the future. The way those museum professionals acted nearly 100 years ago is surprisingly similar to the way institutions that work for social justice accept their involvement in contemporary politics today.

Over the last century, many have discussed the potential of museums to become sites of social control, both for good and for ill. Since I collect and analyze practices for influencing visitors' feelings and actions, this history is a source of potential criticism for this project. Tony Bennett and Eilean Hooper-Greenhill have argued that museums developed in the nineteenth century as Foucauldian zones of control. ${ }^{19}$ Their organization and narratives were designed to be comprehended by specific citizen populations who could internalize the museums' lessons through their own visual literacy and train themselves to function civically in a way that suited the state.

Museums have also changed in some important ways since the nineteenth century. Bennett's concern with museums' universalist claims are vital and well founded. And some museums still make those claims. Other museums make universalist claims with different political effects. Museums such as the National Museum of Mexican Art (NMMA) use universalism to break down prejudice and bring groups together on common ground. Contemporary museums, especially those working for social justice, are often more interested in sharing authority, creating multiple points of entry into narratives, and building in multiple vantage points and voices throughout.

In "Civic Seeing: Museums and the Organization of Vision," Bennett argues that contemporary museums will meet diverse visitors' needs better if they move to using visual practices with more "give-and-take between different perspectives." ${ }^{20} \mathrm{He}$ goes on to promote interactivity, self-direction, and generally practices in which the visitor can take an active role in the museum. ${ }^{21}$ Many of the curatorial techniques and forms I present in this book do exactly that. Bennett suggests that museums are places where new realities are "constructed and then mobilized." 22 In fact, Bennett bemoans the lack of a "real variety of practice and effect" in contemporary museums striving to reach and include diverse publics. ${ }^{23}$ That variety is precisely what I have sought to present.

Even today, however, some museums are certainly more Foucauldian than others. I agree with Andrea Witcomb that museums, such as the Museum of Tolerance (MoT), that try to control visitors as part of their work for social justice are actually methodologically at crosspurposes with their own content. ${ }^{24}$ The MoT is paradigmatically Foucauldian in ways that, for example, the Jane Addams Hull-House Museum or the Rijksmuseum are not. This is not to say that Hull-House and the Rijksmuseum do not attempt to influence their visitors. Many elements do. No museum is objective or free from interpretation. But in the end, the goals of those museums are not to control the visitor but to engage the visitor in questioning, thinking critically, and remembering - all important topics among the curatorial tools in this book. 
Scholars such as Ivan Karp and Steven Lavine, John Falk, and Andrea Witcomb have argued that visitors have more agency than Bennett and others originally took into account. Indeed, visitors bring an increasing political consciousness and varied senses of identity to the museum visit that inflect and inform their visits. ${ }^{25}$ Far from viewing visitors as passive and subject to easy manipulation, I view them as bringing their many subjectivities to the museum and as sharing authority when invited authentically to do so, as Nina Simon suggests. ${ }^{26}$

From visitors' support to funding from foundations, corporations, and the government, the resources that sustain museums demonstrate that museums serve diverse purposes. They are useful to a broad range of publics, each for its own reasons. The Creation Museum is useful to certain people for certain purposes. The National Civil Rights Museum is useful to others. Some curators and other museum professionals have an instrumental view of their work.

This book is a study of particular museums and exhibitions. The museum workers involved have made clear their goals and positions. Rather than decry their decision to bring a certain utility to their work, we should applaud their transparency about their own positions and those of their exhibitions. One of my tasks is further exploration of how these exhibits have been useful to stakeholders such as neighbors, source communities, and visitors. This exploration illuminates the kinds of influence exhibitions may have on the visitor (whether readers deem that influence to be appropriate or inappropriate).

One way to view my work is as research into how media (in this case exhibitions in museums) affects people (in this case, visitors). In this way, my book is related to Allison Griffiths's Shivers Down Your Spine: Cinema, Museums, and the Immersive View. Not unlike research into subliminal messaging, Griffiths and I analyze tools or technologies that can be used equally for a range of ends. The possible negative uses of museums do not imply that we should not discuss the strengths, weaknesses, and best practices of particular curatorial techniques.

\section{The purposes of museums}

The purposes of museums range from teaching children about science to engaging adults in debates about human rights, from exploring the life of one person to offering a sanctuary where visitors may bask in art for its own sake. Increasingly, though, as Hilde Hein writes, "what distinguishes the museum is its agency, what it does with its resources, and for whom."27 The vast global landscape of museums represents tremendous diversity of audience, content, style, and mission. Nevertheless, many museums, including those accredited by the American Alliance of Museums, for example, share some elements of their missions in common. Most notably, they commit to educate and to be equitably accessible to all. ${ }^{28}$ In addition, museum professionals commonly accept that museums collect, preserve, and interpret materials to diverse publics.

For decades, scholars and practitioners from around the world have been writing about museums being in a state of crisis. ${ }^{29}$ In light of the literature on the museological crisis, museums are returning to the debate that Duncan Cameron, then Director of the Brooklyn Museum, sparked in 1971 regarding whether museums should be temples or forums. ${ }^{30}$ Today, the role of the museum as forum and experimental laboratory is broadly accepted among museum professionals. From James Clifford's characterization of museums as "contact zones" to Elaine Heumann Gurian's vision of them as "congregant spaces" to Elijah Anderson's description of museums as "cosmopolitan canopies," many scholars agree that museums are trying to become safe spaces for everyone to encounter diverse people and ideas. ${ }^{31}$ Cameron 
argued that the social responsibility of museums is to "interpret matters of public importance, no matter how controversial." ${ }^{32}$ This is a small harbinger of the museum work for social justice that would begin to become more popular over the next four decades.

The contemporary practices I study also build on the community museum movement, which began in the late 1960s. This movement took the notion of the museum as a forum or town square one step further. If a town square is a place where people congregate, then a community center or community museum is also a provider of necessary services. When American cities were failing and policymakers were giving up on urban populations, many kinds of firstvoice organizations cropped up to meet communities' needs. (First-voice organizations share culturally specific narratives from the point of view of that cultural group, and I will discuss them further in Chapter 4.) Museums were among these organizations. ${ }^{33}$

In the thick of the debates on multiculturalism of the 1990s, the American Alliance of Museums (then the American Association of Museums;AAM) produced Excellence and Equity, the landmark report that effectively changed the mission of American museums to be educational and equitably accessible. ${ }^{34}$ This report endorsed the activities of institutions such as community museums, which were making themselves accessible to people who felt excluded by museums. Much of the work I write about is an extension of this shift. This book is about the state of the curatorial practices of the museum as "forum" in the twenty-first century.

\section{Neuroscience}

In part, this book is about using truths of the brain and body to craft purposeful exhibitions. Our understanding of how emotion relates to learning and memory has progressed tremendously in the last fifty years. As providers of memorable, emotional learning experiences, we would do well to take some of these lessons into account. However, fascinating new work is constantly being published by neuroscientists. This book does not attempt to comprehensively connect developments in the brain sciences to the field of museum work. Rather, I have selected particular areas, such as the formation of memory, where there is consensus among scientists and a clear connection to our work to try to build a conversation between the two.

I will provide a fuller discussion of key concepts for this book, such as emotion, feeling, group behavior, and empathy in Chapter 1. I have tried to make statements about memory, empathy, and related topics only where there is broad consensus in the field. ${ }^{35}$ I have also tried to tread carefully as a visitor to brain sciences, making use of ideas from a discipline so very different from my own. The neurological work I bring to bear on museums in this book has been well established over the course of, in some cases, more than thirty years. Whenever I use neuroscience, I only cite conservative conclusions. While it is tempting to generalize these conclusions to other areas, I do not extrapolate. Rather, I present the broad consensus and then draw my own conclusions, and I make the delineation between those steps clear.

The science tells us that physical experiences, including emotional ones, help us form lasting memories. Solid memories with emotional valences are more likely to produce empathy. ${ }^{36}$ Empathy leads to action, as scholars and scientists are demonstrating. In one example, Oceja et al. wrote "Research has consistently shown that eliciting empathy for a single individual ... in need results in helping behavior..." 37 I propose museums can help turn visitors' empathy to action and long-lasting memories that, in turn, promote action, through practices such as broader use of touch in museums, careful use of immersive environments, and other emotionally compelling elements, such as first-person narratives. If my theory is true, it could have 
long-lasting implications for cultural work. We could expect to see that visitors experiencing the practices discussed in this book form longer-lasting, more detailed memories, participate more inside the museum, and take more actions related to their visits outside the museum.

In this book, I connect the work of brain scientists with museum professionals' planning for the kinds of experiences we want visitors to have in museums. To do so, I engage with several bodies of literature dealing with memory and emotional responses. This includes work in visual culture, brain science, and works about memory from within the humanities.

\section{Methodology}

True to my background in anthropology and American studies, my research process for this book has been hybrid: ethnographic and archival. I identified museums in the Chicago area where curators were working for social justice through exhibitions. Coastal communities and their museums are often pigeonholed as bastions of liberal progressive activism. Both for convenience (I live near Chicago) and to move the conversation beyond the idea of these practices being specific to those areas, I chose to focus roughly half of my analysis on museums in the middle of the country. They serve audiences from Wisconsin to Alabama and from California to Maryland. I want to speak to a broader audience. I selected sites based on a variety of markers for diversity in the study: type of museum, size, location, the degree to which social justice work is pervasive at the site, the relationship between leaders and curators, and the funding structure.

One of my goals was always to find a small subset of museums at which I could conduct deeper research. Four sites emerged that had all of the necessary qualifications: large experiences with curatorial work for social justice, deep enough archives about the institution and the exhibitions, the human resources to support my presence on site, and the willingness to support my project. These were the Jane Addams Hull-House Museum, the Illinois Holocaust Museum and Education Center, the National Museum of Mexican Art (NMMA), and the Chicago History Museum (CHM). I conducted ethnographic fieldwork with roughly twelve informants belonging to these core sites.

In addition, I chose several other sites abroad and around the US at which to conduct shorter research visits pertaining to specific projects or institutional practices. These sites are the Verzetsmuseum and the Rijksmuseum in Amsterdam, Eastern State Penitentiary in Philadelphia, the Brookfield Zoo, the Lincoln Park Zoo, the John G. Shedd Aquarium, and the Smart Museum of Art in Chicago, the National Underground Railroad Freedom Center in Cincinnati, the Museum of Anthropology in Vancouver, and the Mary and Leigh Block Museum of Art in Evanston. Still more museums, such as the St. Louis Zoo and President Lincoln's Cottage at the Soldier's Home in Washington, DC, have helped me with virtual research visits. Museum professionals at many other institutions such as the National Museum of African American History and Culture and the International Coalition of Sites of Conscience have also allowed me to interview them for this project.

In total, I interviewed nearly eighty museum professionals and other leaders in the field at over twenty institutions for this project. I interviewed each individual one to four times in interviews ranging from one to three hours each. My archival research at the core sites took place in informal residencies of three to six months each.

My primary sources from the archival research phase include the documentation that accompanies exhibitions (grant proposals and reports, agendas, meeting minutes, scripts, graphic design, curatorial and design review presentations, texts, maps, press releases and press 
files, demographic statistics on visitors, photographs, and films), and institutional documentation (strategic plans, vision statements, notes, minutes, agendas, and presentations from board meetings, staff retreats, and other planning sessions, capital campaigns, and building plans). These sources allowed me to reconstruct a contextualized view of how specific exhibitions were created at each institution by situating the exhibitions within an institutional culture and history. When I extrapolate curatorial practices from specific institutions' experience, this context is invaluable because it allows other curators to determine whether the internal conditions of their institutions will also support these practices.

I distilled the findings of the ethnographic and archival research into case studies for the core and additional museums named above, detailing their institutional history, building history, governance, curatorial styles and philosophies, institutional culture, and relationship to social justice. For the core sites, these studies also included reports on an average of five exhibitions at each site. Each included the history of the exhibition, its goals, techniques, processes, and workflows used to create it, results - including experiences with visitors - and long-term implications for the institution. The case studies comprise my primary database for this project.

\section{The scope of this study}

The material in this book is valuable for its richness and detail. I developed the analysis of these museums on the foundation of professional relationships sustained over the course of years (nearly fifteen years in the case of the NMMA and the Block Museum). Since the value of the cases studies that comprise my archive is in their depth, I believe in fully using that archive rather than trying to broaden it solely to increase the sample size. To that end, my additions of sites beyond the original core has been premeditated, based on exciting curatorial projects and practices at those additional sites. That said, there are many sites at which time simply did not allow in-depth research or visits. I hope to give these sites the attention they deserve in a future project.

Like any archive, my case studies are unique and idiosyncratic. The sample size is too small to be universally generalizable. However, curatorial work for social justice and the sites that do this work deserve attention as their own category within the cultural sector. And the great diversity among these sites helps the generalizability of studying them. Moreover, I have set the stories and techniques in this book in an international context (including a broader range of kinds of museological environments). Insights from the sites in Chicago and the US, including needs, challenges, and opportunities, will speak to settings beyond these contexts even though each curator will implement solutions in her own way as individual circumstances and sites require.

\section{The sites in the book}

This book involves stories and studies from over twenty museums and historic sites. Rather than introduce all of them here, I will introduce them in the chapters as they appear. They include four museums where I conducted research residencies (the Jane Addams Hull-House Museum, the Illinois Holocaust Museum and Education Center, the National Museum of Mexican Art, and the Chicago History Museum) as well as eleven museums I visited to interview staff and do targeted research.

Museums working for social justice are often museums that endeavor to connect past and future in a meaningful way. They frequently have specific goals for solving unsolved problems 
or not repeating past wrongs. Thus, memory is very significant for museums working for social justice, just as it is across an industry dealing in memory. Building and maintaining memories and keeping them relevant are all important. Furthermore, the utility of the memories visitors form contribute to the ongoing relevance and sustainability of museums. Funders are increasingly embracing the concept of working for social justice. But for museum professionals who care about social justice, it is equally important that their institutions protecting the labor rights, civil rights, gender equality, and general respect of all their employees as it is to engage productively with funders.

Though the sites in this book are quite diverse, museum professionals and others who work for social justice share common concerns. We are working to make our institutions more inclusive. While all museums care about education, we also care about participation, inspiration, and action - having an effect on visitors' behavior in the world. This might take the form of changing someone's mind, raising awareness about a problem, or encouraging a visitor to take a specific kind of action. There often is and should be an intentional internal vision of what the visitor should "know, feel, and do." The utility of tools such as curatorial practices for good or for ill does not mean they should be ignored. On the contrary, they are already in use. Studying them will allow us to work in as informed and efficacious a manner as possible. Relationships with visitors and the relationships with local publics and other stakeholders should be conducted in a climate of empathy and solidarity with visitors, communities, marginalized populations, and those involved in the museum's narratives.

\section{Chapter overview}

The first three chapters of this book address the ways in which the work of the curatorial team affects the experience of the visitor. First, I examine how the experience in an exhibition can support visitors' development of empathy and, from empathy, solidarity. Then I explore the ways in which visitors can build strong, lasting memories of their experiences in museums, and how curators can support making memories through their work in the gallery. In Chapter 3, I survey diverse examples of exhibitions inspiring visitors to take action and analyze the curatorial practices involved. From the discussion of visitors taking action in Chapter 3, I move in Chapter 4 to a discussion of how museum staff and leaders can take action to make their institutions work better for social justice in and out of the gallery. The book ends with worksheets to help museum professionals evaluate the practices in this book in relationship to their own institutions and put them to use.

\section{Chapter 1: From empathy to solidarity}

I begin where many museums do: stories of individual people. We readily empathize with one person, but usually not with millions, as Holocaust museums well know. If curators hope to inspire people to act - whether inside or out of the museum - then visitors must empathize. If visitors are to be part of any collective action, they must feel solidarity.

In exploring the role of a curatorial strategy that is founded on empathy and solidarity, I ask why empathy is important. I look at two divergent stances for personal and group relationships that we see in museums: hospitality and tolerance. Then, I explore practices that curators can use to help visitors build empathy and solidarity. 


\section{Chapter 2: Physical experiences: building memories and empathy}

Memories combine with the empathy and solidarity discussed in Chapter 1 to make a powerful platform from which visitors can act. In this chapter, I look at physical experiences in the museum, paying special attention to the promises and challenges of immersive environments. I explore what makes some immersive environments successful and others not. What are the roles of keystone objects? What happens when objects or artworks become environments? When and how is it advantageous to slow down or stop an emotional experience?

This chapter also discusses the connection between content in the museum and visitors' own experiences. Often this includes a connection to contemporary events. The possibilities for making content that resonates with visitors are as varied as the visitors themselves. But it's worth examining how a museum's approach to storytelling may include or exclude people from that resonance.

\section{Chapter 3: Inspiring action}

The neurologist Oliver Sacks was 69 when he wrote about his formative experiences in the museums of London: "The museums, especially, allowed me to wander in my own way, at leisure, going from one cabinet to another ... There was something passive, and forced upon one, about sitting in school, whereas in museums one could be active, explore, as in the world." ${ }^{38}$ Perhaps our sense of what constitutes action has changed. But for Sacks, looking back on his childhood, the simple action of exploring in the museum was significant. In this chapter, I take an ample view of action in an effort to examine the many ways in which a visit to an exhibition in a museum might affect a visitor's behavior.

Many museums working for social justice hope to inspire the visitor to take action. At what point in exhibitions do museums call their visitors to action, and what are the implications of these choices? This chapter explores the range of ways in which museums can inspire visitors to take action inside and outside of the museum, and the stakes involved in how museums envision visitors as social actors.

In addition to the issue of social control, addressed above, two related concerns emerge around the notion of inspiring visitors to act. One is that museums working for social justice are simply "preaching to the choir"; that those who visit are self-selecting and were already likely to take action on contemporary issues. While most visitors are self-selecting (school groups being a notable exception), it's unfair to envision the majority of visitors as "the choir." First of all, many of the institutions in this study are mainstream institutions at which a visitor might be surprised to find content around social justice at all. However, even at a museum such as Hull-House, where the visitors are likely to be acquainted with the museum's work in this area, the visitors might be divided into three categories: super-users who are already taking action on all fronts represented within the museum, those who are totally apathetic or uninterested in the topic, and the middle majority of visitors. This middle majority is likely to be at least somewhat interested in the subject matter, informed about some parts of it and not others, and open to making a new connection, thinking about something in a new way, or perhaps even taking action. The second, related concern that critics may have is that an exhibition in a museum is not going to truly transform someone's frame of mind. While it would be wonderful to be able to take White supremacists, expose them to an exhibition, and transform them into open-minded anti-racists, this is neither the topic nor the goal of this book. ${ }^{39}$ 
Rather, my discussion of inspiring action is focused on the middle majority of visitors who are curious but perhaps still passive. This will be different at each institution, and staff members will know their own audiences the best.

I offer a sample of ways in which museums have engaged visitors in action along with a series of vignettes that offer a rare long-term glimpse into how museums can affect the informational environment of visitors. I do not suggest outcomes-based evaluation as a solution for the highly complex question of how exhibitions affect visitors over the long term. But I do hope that future studies will provide more data about whether the curatorial practices discussed here affect visitors' memories, empathetic feelings, and actions in the anticipated ways.

\section{Chapter 4: Welcome, inclusion, and sharing authority}

Empathy arises between individuals. Solidarity arises between groups. Over time, that solidarity can develop into a bond of community. And museums can help us to sufficiently expand the group of people whose fate matters to us so that we're willing to act on their behalf. Museums can break down barriers that separate "us" from "them." My book ends with support for museum professionals as they rupture categories that keep us from helping one another and retain those that band us together.

Sharing authority has taken on great importance in museums in the new century. In this chapter, I discuss three ways to share authority: with visitors, with members of specific communities, and with both. This last can be an important way to bring people together to work for a cause.

The final task of this chapter will be to tether the popular topic of sharing authority to the question of how to use exhibitions to work for social justice. I will discuss museums that have used labels and other forms of address to consolidate visitors into publics with particular shared goals.

\section{Summary}

Two lines connect the collection of curatorial practices in this book. One is the goal of fostering curatorial work that seeks to redress wrongs and equitably distribute risks and rewards in society. The second is the way in which these curatorial practices make use of human bodies' natural systems, the ways in which human brains form memories and the ways in which people build empathy. These tools help curators to intentionally blend content with intellectual resonance and content that produces embodied emotional responses. I have selected curatorial practices that can do this because blending resonance and embodied emotion can help build memories and improve empathy.

In this book, I offer museum professionals ideas and strategies for confronting profound and urgent contemporary problems. One way to do this is developing the broad acceptance of the notion that we ought not to simply tolerate those who are different from ourselves. Museums must model hospitality. Our continued human existence demands that we share resources equitably and learn to care for others. Our existence is interdependent. Let's work together and use the vast resource of the world's museums to mitigate prejudice, inspire collaboration, and redistribute resources. 


\section{Notes}

1 I don't incorporate generative justice into the framework for this book because, while it is an interesting tool for discussing labor justice, it does not yet work as effectively as distributive and retributive justice for discussing concerns such as representation of historical voice.

2 Loretta Capeheart, Social Justice: Theories, Issues, and Movements, Critical Issues in Crime and Society (New Brunswick, NJ: Rutgers University Press, 2007), 45.

3 Tristan Anne Borer, ed., Telling the Truths: Truth Telling and Peace Building in Post-Conflict Societies (Notre Dame, IN: University of Notre Dame Press, 2006), 17.

4 Tristan Anne Borer and RIREC Project on Post-Accord Peace Building, Telling the Truths: Truth Telling and Peace Building in Post-Conflict Societies (Notre Dame, IN: University of Notre Dame Press, 2006), 41, 214-215, 218.

5 Freedberg, David. The Power of Images: Studies in the History and Theory of Response (Chicago, IL: University Of Chicago Press, 1991).

6 This is a contentious area, scientifically speaking, and there is no consensus yet. But scholars in the humanities such as Freedberg, Hamber, Borer, and others agree that tools that bring us beyond the unspeakable can help us solve problems.

7 Interview with Erika Gee. Phone call with the author, December 3, 2009.

8 "International Coalition of Sites of Conscience Home Page," Sites of Conscience (blog), accessed March 20, 2017, www.sitesofconscience.org/en/home/.

9 Elizabeth Silkes, interview with Elizabeth Silkes, Director, International Coalition of Sites of Conscience, Phone, March 20, 2017.

10 Robert R. Janes, Museums in a Troubled World: Irrelevance, Collapse or Renewal, 1st edn (London: Routledge, 2009); Richard Sandell, Museums, Prejudice and the Reframing of Difference (London; New York: Routledge, 2007); Richard Sandell, Museums, Equality, and Social Justice (Abingdon, Oxon; New York: Routledge, 2012); Janet C. Marstine, ed., The Routledge Companion to Museum Ethics: Redefining Ethics for the Twenty-First Century Museum (London; New York: Routledge, 2011).

11 Christopher Whitehead, Interpreting Art in Museums and Galleries (London; New York: Routledge, 2008), xvii, www.routledge.com/books/details/9780415419222/?utm_campaign=interpreting art_museums_022012\&utm_source $=$ adestra\&utm_medium $=$ email.

12 Marcia Tucker in Stephen E. Weil, A Cabinet of Curiosities: Inquiries into Museums and Their Prospects (Washington, DC: Smithsonian Institution Press, 1995), 76, 110; Steven Dubin, Displays of Power (with a new Afterword): Controversy in the American Museum from the Enola Gay to Sensation! (New York: New York University Press, 2001), 3, 11; Richard Sandell, Museums, Prejudice and the Reframing of Difference (London; New York: Routledge, 2007), 177.

13 Susan M. Pearce, Museums and the Appropriation of Culture (London; Atlantic Highlands, NJ: Athlone Press, 1994), 103-128.

14 Edward Rothstein, "Identity Museums Challenge History's Received Truths," The New York Times (December 28, 2010), sec. Arts/Art \& Design. www.nytimes.com/2010/12/29/arts/design/29identity.html.

15 Archbishop Desmond Tutu et al., "Truth and Reconciliation Commission of South Africa Report," 1998, 110-114.

16 Simon and Moscone, The Art of Relevance, 155.

17 "Proceedings: Chicago Historical Society" (Progress Report, Chicago History Museum, Chicago, October 25, 1929), Subseries 1. Board of Trustees; Box 5: Minutes 1928-31; Bound volume: Proceedings, CHS, October 25, 1929, Chicago History Museum., 6. Courtesy of Chicago History Museum.

18 Ibid., 9.

19 Tony Bennett, The Birth of the Museum: History, Theory, Politics (London: Routledge, 1995); Eilean Hooper-Greenhill, Museums and the Shaping of Knowledge (London: Routledge, 1992).

20 Bennett in Sharon Macdonald, A Companion to Museum Studies (Chichester: Wiley-Blackwell, 2011), 264. 
21 Bennett in Macdonald, 277.

22 Tony Bennett, “Civic Laboratories," Cultural Studies 19, no. 5 (September 1, 2005): 525.

23 Bennett, 538.

24 Andrea Witcomb, Re-Imagining The Museum: Beyond the Mausoleum, 1st edn (London; New York: Routledge, 2003).

25 Steven D. Lavine and Ivan Karp, Exhibiting Cultures: The Poetics and Politics of Museum Display (Washington, DC: Smithsonian Institution Press, 1991); John Falk, Identity and the Museum Visitor Experience (Walnut Creek, CA: Left Coast Press, 2009); Andrea Witcomb, Re-Imagining The Museum: Beyond the Mausoleum, 1st edn (London; New York: Routledge, 2003).

26 Nina Simon, The Participatory Museum (Santa Cruz, CA: Museum 2.0, 2010).

27 Hilde Hein in Marstine, The Routledge Companion to Museum Ethics, 7-8.

28 Ellen Hirzy, Excellence and Equity: Education and the Public Dimension of Museums (Washington, DC: American Association of Museums, 1992).

29 See, for example, Peter Vergo, The New Museology (London: Reaktion Books, 1991). Steven Conn, Do Museums Still Need Objects? (Philadelphia, PA: University of Pennsylvania Press, 2009).

30 Duncan Cameron, “The Museum: A Temple or the Forum," Curator 14 (March 1971): 7-74.

31 James Clifford, Routes: Travel and Translation in the Late Twentieth Century (Cambridge, MA: Harvard University Press, 1997); Elaine Heumann Gurian, Civilizing the Museum: The Collected Writings of Elaine Heumann Gurian, 1st edn (London: Routledge, 2006); Elijah Anderson in Betty Farrell et al., "Demographic Transformation and the Future of Museums," Center for the Future of Museums (Washington, DC: American Association of Museums, 2010), 20.

32 Cameron in Anderson Gail Anderson, Reinventing the Museum: Historical and Contemporary Perspectives on the Paradigm Shift (Walnut Creek, CA: AltaMira Press, 2004), 57.

33 See, for example, Fath Davis Ruffins, "Culture Wars Won and Lost: Ethnic Museums on the Mall, Part I:The National Holocaust Museum and the National Museum of the American Indian," Radical History Review 68 (1997): 79-100; Fath Davis Ruffins, "Culture Wars Won and Lost, Part II: The National African-American Museum Project," Radical History Review 1998, no. 70 (December 21, 1998): 78-101.

34 Hirzy, Excellence and Equity.

35 Eric R. Kandel, The Age of Insight: The Quest to Understand the Unconscious in Art, Mind, and Brain: From Vienna 1900 to the Present (New York: Random House, 2012).

36 One example of this is the way in which hippocampal memory plays a role in empathy. Janelle $\mathrm{N}$. Beadle et al., "Empathy in Hippocampal Amnesia," Frontiers in Psychology 4 (2013), https://doi.org/ 10.3389/fpsyg.2013.00069.

37 C.D. Baston in Luis V. Oceja et al., "Empathy, Awareness of Others, and Action: How Feeling Empathy for One-Among-Others Motivates Helping the Others," Basic and Applied Social Psychology 36, no. 2 (March 1, 2014): 111; another example is Carrie L. Masten, Sylvia A. Morelli, and Naomi I. Eisenberger, "An FMRI Investigation of Empathy for 'Social Pain' and Subsequent Prosocial Behavior," NeuroImage 55, no. 1 (March 2011): 381-388.

38 Oliver Sacks, Uncle Tungsten: Memories of a Chemical Boyhood, 1st edn (New York: Knopf, 2001), 57.

39 I have chosen to capitalize both "Black" and "White" when naming racial categories not in order to reify race, but rather to call attention to it as a social construction. While capitalizing Black is commonplace, capitalizing White may seem to unnecessarily elevate Whiteness. This is not my intention, rather, I wish to draw attention to White as a racial category rather than an unmarked "normal" state from which other races diverge.

\section{Bibliography}

Adamsick, Randy. “CHM Diversity, Innovation, Social Justice." Chicago History Museum, 2017. Adamsick, Randy. Development Director, Chicago History Museum. “Letter,” January 8, 2018. 


\section{FROM EMPATHY TO SOLIDARITY}

Without empathy, social justice ceases to exist. In this chapter, I will explore ways of building empathy in the museum and of translating empathy into solidarity. I move through examples that deal with interpersonal human bonding to the creation of community across generations to the relationships among institutions, and finally to the histories that connect our personal identities and grapple us to our communities. First, however, I will introduce the concepts of empathy and groupness.

\section{Empathy and groupness}

Empathy is a common part of our human experience. Most of us empathize with family, friends, and colleagues daily. We also likely feel empathy for people we learn about in the news and on social media and for fictional characters in books, movies, and TV shows. As babies, we learn to knit ourselves into the group - our lifeline - by understanding the feelings of others and responding accordingly. Empathizing is part of how humans bond to one another and is a crucial element of our survival.

Some react negatively to the term "empathy" as a catalyst for museum work. Empathy is not as significant a framing tool outside the US. Linda Norris and Julieta Cuéllar, the Global Networks Team at the International Coalition of Sites of Conscience (SoC), helped me to understand why. ${ }^{1}$ The reaction comes from the sense that this is an elitist framework, that only White, majoritarian institutions need to foster empathy because marginalized populations or those dealing with violence are already in the trenches. In regional networks of SoC, such as the African network and the Latin American and Caribbean network, the primary concern for sites and their local communities is achieving retributive justice - the redress of wrongs. In these contexts, the word "empathy" can connote a lack of experience with hardship. So, the term isn't as popular among sites where the majority of stakeholders have direct experience with violence. They do use it, however, in discussions of making connections to young people. The next generation may not have had these personal experiences with violence, and all regional networks are focused on reaching them. I approach empathy as a necessary element of all human experience and a connector that can bring us together, whether our differences 
in experience are significant or small. In addition, empathy is just the starting point, not the only or final goal for the curatorial work I examine and imagine.

In 1970, the psychologist Henri Tajfel coined the term "groupness" to describe the propensity of humans and other animals to form groups. ${ }^{2}$ This is the social equivalent of something that happens in the body as well. The body distinguishes between self and other - internal and external - in several important ways. This is how it protects itself against dangers including illness and infection. But this is also how the body manages its necessary and constant interactions with the external world, including eating, moving around, socializing, and mating. The body's strategies for delineating the self include the skin, the immune system, the gut (where 80 percent of the immune system resides), and the emotional system. ${ }^{3}$ The emotional system determines how best to relate an individual to the external world. Just as a healthy immune system fights off infection, a healthy emotional response produces choices that strengthen our bonds with close family and friends: helping a friend move, bringing soup to someone with a cold, shoveling the neighbor's sidewalk. Unlike reptiles, which do not rely on groups, our drive to help and protect our group is more powerful than even our drive for self-preservation. Determining the best interactions with other individual selves is a crucial job of the emotional system. What's best for my organism? What's best for the group? For mammals in general and primates in particular, our emotionally determined social strategies are extremely important.

Humans form social groups based on the slightest pretext. In college, housemates or teammates speak a special in-group language. In-jokes evolve into a vocabulary that is opaque to outsiders. Each of us belongs to many groups, some with stronger alliances than others. You might feel some kinship with other people who collect fountain pens, but a much stronger bond with other parents, for example. The strongest bond of all is usually with one's own nuclear family. The formation of groups is necessarily also about exclusion. There is no group without outsiders. We rightly rail against this with interdisciplinary academic programs, crosslistings of books, and academic positions, perhaps by refusing to accept a single sexual, racial, or ethnic identity. But our tendency to create the groups of "us" and "them" is innate.

Groupness is neither good nor bad. It is simply a fact of life. It can be useful, consolidating and strengthening a population against a common enemy. What if this enemy were not another human group, but were a particular problem to be solved? Museums can call new publics - new groups - into being through forms of address. When museums use groupness as a tool, they can and do consolidate publics around issues such as supporting the rights of immigrants, reforming the justice system, or mitigating prejudice against marginalized populations. Although it is difficult for people to empathize with those they feel are outside their group - whatever type of group that may be - museums have a special ability to demonstrate to visitors that they actually do share a group with supposed others.

Clearly, groupness can have harmful effects depending on what groups it reinforces. Philip Zimbardo's Stanford Prison Experiment in 1971 dramatically demonstrated how situational groupness can create behavior that has no correlation to individuals' personalities. In his experiment, normal, healthy, male college students were to participate for two weeks in a mock prison scenario, wherein the students were randomly assigned to play guards or prisoners. Almost immediately, the play-acting went out of control. Guards' abuses of prisoners became intolerable, and Zimbardo's own moral compass faltered. It took a visit from an outsider to convince Zimbardo that the experiment needed to be cut short. ${ }^{4}$ Groupness can strengthen prejudices and marginalization and can result in ideologies that guide and empower large and powerful groups to decimate other groups. The lesson from Zimbardo's work, and Stanley 
Milgram's before him, is that "there but for the grace of God go I."We all have human instincts to make sense out of nonsensical circumstances, to solve problems, and to form groups. We are also trained from birth to obey authority. In the wrong situation, our instincts and training combine to enable good people to act cruelly and evilly.

Dismantling negative forms of groupness will help our civilization survive. It will not rid the world of dangerous situations, "bad barrels," as Zimbardo put it, that create the proverbial "bad apples," but it's a start. Damasio describes groupness (though he doesn't use that term). Then, he substantiates my idea that we can (and need to) think our way out of groupness:

The best of human behavior is not necessarily wired under the control of the genome. The history of our civilization is, to some extent, the history of a persuasive effort to extend the best of "moral sentiments" to wider and wider circles of humanity, beyond the restrictions of the inner groups, eventually encompassing the whole of humanity. ${ }^{5}$

One can imagine a hunter-gatherer society in which the evolutionary benefit accrued to those who narrowed their groups to bands or tribes that could care for themselves. Caring too much about others can become expensive. To early humans, expensive and life-threatening were the same thing. Even within this setting, however, cooperation was something that survival demanded. We evolved to work with and help others. ${ }^{6}$

Groupness exists and is a human tendency. It can have good or bad effects. But now, in our globalized, transnational world, it is becoming important for us to sometimes work against groupness. Our world requires more cooperation among groups and less exclusivity. Museums working for social justice combat negative forms of groupness by teaching us to think our way out of it. For Robert Janes, museums are founded on imagining ourselves in the shoes of others. At bottom, this is not only thinking, but also feeling. Museums must be smart guardians against groupness and teach visitors to be on their guard as well. This means setting the stage for intellectual and emotional experiences to intertwine in the gallery.

\section{The universe of obligation}

The concentric circles of caring, or ripples, that emanate from each of us form what Facing History and Ourselves, a non-profit that develops curricula and also supports teachers, called the "universe of obligation." Museums can help visitors bring people from the outside circles closer into their universe of obligation. Two organizational forces are at work in structuring our universes of obligation: our social commitments and emotional ties and are one, and geography is the other. Though it doesn't seem as if our physical proximity to others should necessarily play a role in how well we empathize with them, it does. ${ }^{7}$

In his studies of obedience and authority after World War II, Stanley Milgram found that people are more willing to harm others the further they are from them physically. ${ }^{8}$ Milgram's finding provides more support for the special place museums have in bringing people together. The ways of structuring public space and third spaces discussed in Chapter 4 may help to combat visitors' willingness to do wrong when they know better.

Museums' ability to turn "them" into "us" is part of what makes these institutions special. Letting us "walk a mile in another's shoes" isn't just a saying. When museums excel at helping visitors imagine the experience of another, visitors' own bodies ensure their empathetic responses. Empathy is a naturally arising outcome of the way the human brain functions. ${ }^{9}$ 
There are systems in the brain that enable us not only to imagine what someone else's experience was like, but also to actually feel the foreign experience physically and emotionally simply by watching that person. ${ }^{10}$ The phrase "monkey see, monkey do" represents a deep neurological truth: each thing we do activates its own pattern in the brain. When we watch someone else taking action, that activates the same pattern, as if we were taking the action ourselves. Everyday experience tells us that, to our brains, seeing is very like doing. If you cut your finger, you cringe. If you see someone cut his finger, you also cringe. Moreover, if you look at Caravaggio's painting Incredulità di San Tommaso (Figure 1.1), wherein Thomas plunges his hand deep into a wound on Christ's side, you cringe.

The especially cringe-inducing nature of this image is such that it is the subject of conversation in introductory art history classes everywhere in the Western world. Consider our viewing ability to empathize with the subjects of images across whole collections. Curatorial choices have profound implications for the empathetic feelings that will form in the gallery.

When people empathize, they can actually catch each other's emotions. We know that instinctively from being with someone whose poor mood poisons our own, or someone who "lights up a room," as the saying goes. When people do catch each other's emotions, they unknowingly and involuntarily coordinate their movements, including micro-expressions that flicker across the face too quickly for the conscious mind to register. ${ }^{11}$ Our eyes send the information directly to the brain. This happens in museums as well. John Falk and Lynn Dierking

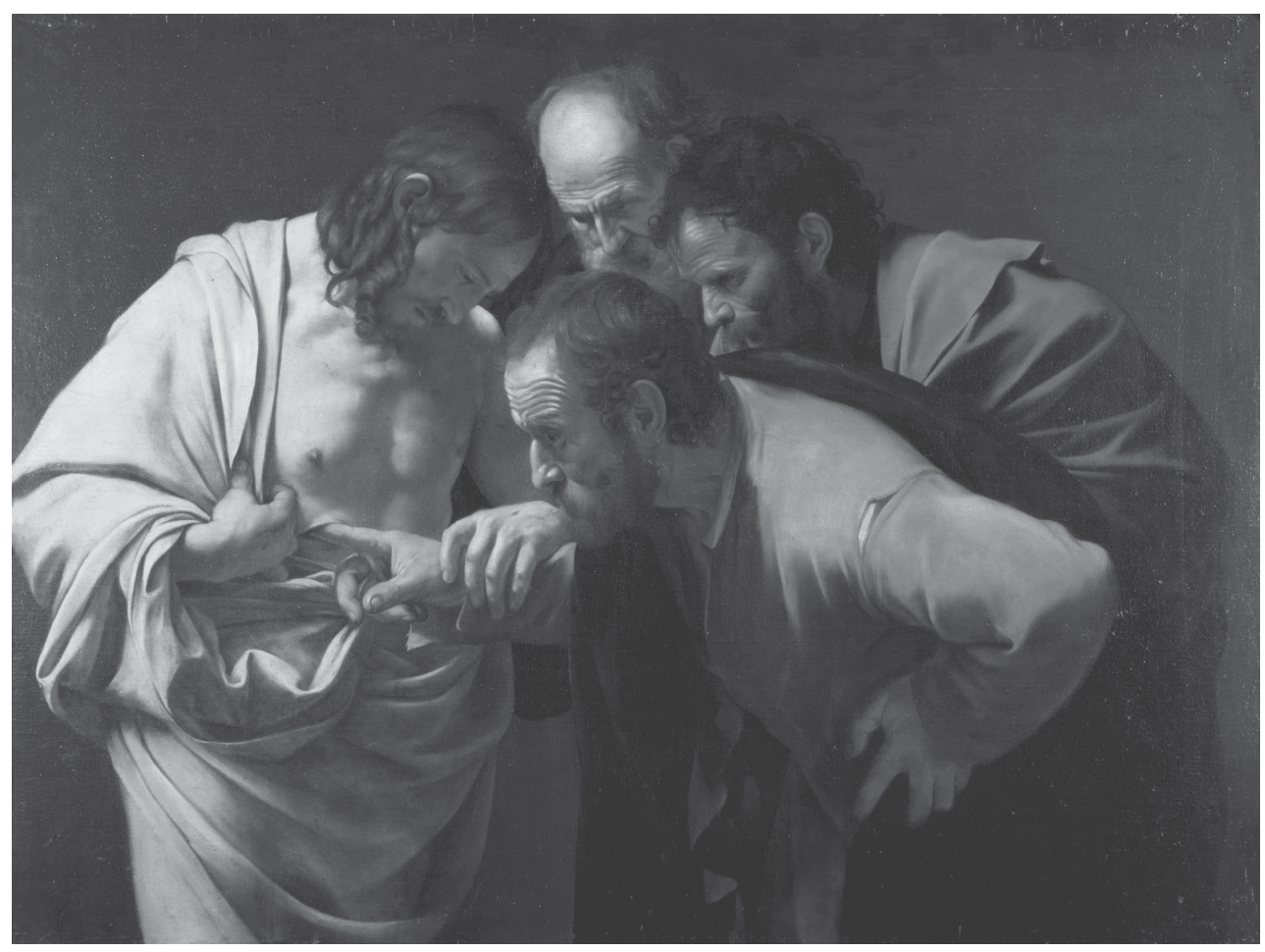

FIGURE 1.1 Incredulità di San Tommaso by Michelangelo Merisi da Caravaggio, 1601-1602, oil on canvas, 42" x 57". Courtesy of Stiftung Preußische Schlösser und Gärten Berlin-Brandenburg/ Photographer: Hans Bach. 
have thoroughly documented the social nature of many museum visits. ${ }^{12}$ Our experiences relate to those of our companions, but also to those of strangers, as James Elkins demonstrates in Pictures and Tears. ${ }^{13}$ One security guard at a Holocaust museum reported regularly seeing a single visitor cry or become angry in front of one particular exhibit and then seeing many other visitors, strangers to the first, following suit.

The ability to build empathy not only through interactions with other people but also through interactions with representations of people has tremendous implications for museums. According to Jeanne Nakamura, "responsibility for others can be learned through practicing it in a small world designed with that purpose in mind."14 Museums that are so motivated can be those worlds.

The kind of global change we need requires more than individuals taking responsibility for their actions, helping and feeling with others. Ultimately, we need groups allying with other groups, banding together, spanning the globe with resources to share, jobs to offer, ready to build on the assets of diverse cultures, countries, economies, and climates. This is where solidarity comes in. How are museums already becoming part of an international engine of sharing and helping? Though this is an internationally significant question, it can only be answered at the most local level. It begins with the roles and relationships museums have in their communities.

\section{Hospitality and empathy}

Museums that work for social justice through their exhibitions tend to have stances toward their visitors that break down into roughly two categories. One is strident. In this model, the museum hopes to teach the visitor humility and tolerance. In the second model, the museum is first and foremost a hospitable, comfortable place that welcomes the visitor. This may or may not extend all the way into creating a participatory culture or sharing authority, both discussed in Chapter 4. The model of hospitality offers more opportunities to museum professionals and a better experience to visitors. As scholars such as Simone Boda have noted, museums are third spaces, in Ray Oldenburg's sense of the term. Like libraries and parks, some museums are among the last great places away from home and work that visitors can enjoy free of charge. This is an essential starting point for drop-in visitors as well as for inclusion and civic engagement. Scholars and museum professionals have written a great deal about the different potential stances museums can have toward the visitor as well as the role of museums, which implies a particular stance toward the visitor. ${ }^{15}$

In our time, the urgency of fostering positive relationships in the public sphere is plain. Making hospitality the foundation of interactions with visitors can support better relationships between visitors and the museum and between visitors and others in their lives. Edith Doron, senior program manager for nexus projects at the Carnegie Museums of Pittsburgh, has inspired my thinking on the way museums relate to their visitors. ${ }^{16}$ Drawing on Kant, Doron discusses tolerance and hospitality as two sides of the same coin. Tolerating living in close proximity to others leads to a state of hospitality wherein others have the right to visit. Yet it is easy for us, as Doron puts it, to feel that we do not need guests. We only tolerate them. In fact, the ethos of hospitality is good for society in general because we do need guests. Ultimately, we need all of those who are different from ourselves. That is the recipe for keeping our shared project of humanity going. "We," however that notion is construed, do not survive (or thrive) if "they" don't. Our existence is contingent and shared. Just as healthy agriculture requires diversity, so do our human societies. 
Hospitality is an entry point into building empathy, which is, in turn, a prerequisite for social justice. When we host guests, we must empathize with them - imagine how we would feel in their position and anticipate their needs. In the museum setting, as staff empathize with visitors through demonstrations of hospitality, visitors will begin to empathize as well. The approach museums take to their visitors informs the relationships visitors will form with others in the gallery, such as the people who are subjects of the exhibitions. Nina Simon, Executive Director of the Santa Cruz Museum of Art \& History and author of the influential Museum 2.0, describes how this happens between tour guides and visitors to the Wing Luke Asian Museum in Seattle. ${ }^{17}$

When a tour guide, $\mathrm{Vi}$, took as few as three minutes to get to know visitors and learn their "entrance narratives," she was able to return time and again to engaging the group based on personal details. She connected visitors to the stories on view by asking them to compare the subjects' stories to those of the visitors' own relatives. Her initial investment in empathy with the visitors authorized her to ask visitors to empathize with the Chinese subjects of the exhibition. Thus, the relationship between the museum and the visitor foregrounds the visitor's tendency to empathize with the subjects of exhibitions and to begin to act with them in solidarity.

\section{Intentional welcoming}

Hospitality and solidarity are related. One way to think about this relationship is that solidarity is hospitality at the scale of groups. Another is that hospitality is the next step in a relationship. Empathy from person to person grows into solidarity from group to group. Hospitality means more than a mutually beneficial alliance. Hospitality means welcoming, a giving relationship of care between the host and the guest. The connection between hospitality and solidarity became clear to me in thinking about the preparations among the staff at the National Museum of Mexican Art (NMMA) for the opening of The African Presence.

The model of hospitality rather than tolerance is better suited to teaching us to step into another's shoes because we can be invited as guests to do so. This is especially true in culturally specific museums, which strengthen one group identity while seeking to decrease negative groupness, explained earlier in this chapter, in the form of prejudice.

The NMMA is a culturally specific first-voice museum dedicated to serving its local Mexican community. ${ }^{18}$ In this sense, it is a community museum. It is also a world-class art museum that exhibits and presents internationally and serves a diverse, international base of visitors. But it began quite humbly, in the early 1980s, when six Chicago Public School teachers quit their jobs and pooled $\$ 900$ of their own money to begin a project that would actually speak to their disillusioned Mexican high school students. After five years of holding exhibitions in small community spaces, the group opened the museum in the Harrison Park Boat Craft Shop in 1987. Now, the NMMA has a budget of $\$ 3.5$ million and roughly 200,000 visitors each year. ${ }^{19}$ This museum represents another possible relationship to social justice. The museum doesn't make social justice a primary purpose the way that Hull-House does. But the NMMA has always taken seriously the need for equity and the museum's potential to affect change. (Throughout my discussion of the NMMA, I will draw on over four years of experience working at the museum (2004-2008), both as Associate Director of Development and as Exhibition Curator for Who Are We Now?) 
The project, The African Presence in México, consisted of three exhibitions that opened in 2006 (The African Presence in México: From Yanga to the Present; Who Are We Now? Roots, Resistance, and Recognition; and Common Goals, Common Struggles, Common Ground), a series of public programs including a civic dialogue, a K-12 curriculum, a five-year international tour, and an eight-year tour of a panel exhibition. The African Presence in México armed visitors with the new knowledge of the history that Mexicans and Afro-Mexicans share south of the border. Who Are We Now?, my first curatorial effort, used art from the twentieth and twenty-first centuries to tell the history of connections between the two groups in the US and between African-Americans and Mexico. My project was principally about creating solidarity between Mexicans and African-Americans.

At an all-staff meeting shortly before the opening, Carlos Tortolero, the president and one of the founders of the museum, reiterated this particular goal of solidarity to the entire staff. He said that we were going to have a lot of new visitors in our museum home. If we did everything right, we would have a great number of African-American visitors in particular. He cautioned the staff that these visitors were to have the most welcoming and wonderful experience at the museum and that negativity of any kind would not be tolerated. He said that if any staff members felt prejudice toward our Black visitors or doubted the history we were presenting, if anyone didn't feel he could carry out our mission to explore and interpret this history respectfully with all our visitors, then they should look for another job now. Rather, he said, everyone in the museum, from the gallery attendants and custodians to himself and the directors, needed to embrace our visitors with the attitude that we have, as Mexicans, discovered African-Americans as long-lost family members. This history literally links these groups together, and he asked us to open the door of the museum with joy to these new members of our family. Cesáreo Moreno, Curator and Visual Arts Director of the NMMA, made the same points at his training of the tour guides:

African Americans have already embraced this exhibition. The problems will come from our own community. We have to be ambassadors of the history of the African presence. We will be baited to participate in discrediting the exhibition. DO NOT TAKE IT. ${ }^{20}$

Those messages stayed with me, in part, because of what had been happening already among the staff. As we put on what Moreno referred to as our "African Presence Goggles," we began to see the African presence in Mexico all around us. And this spread to those we talked to about the project.You don't un-see these connections. Staff members at the NMMA reported feeling a sense of familial kinship with African-Americans in a way they never had before.

The attitude Tortolero described was a crucial tactic in this project, coming as it did from a culturally specific museum. Furthermore, it was an attitude that can only emerge in a climate where staff and leaders are free from fear about the mission of the project. If the NMMA had been trying to conceal the goals of the project, or pretend that its goals were not political, our president would never have felt secure in being so open about prejudice with the staff. The openness paid off, too. Visitors felt the surprising connections that emerged as a result. One person from Chicago wrote: "Wonderful to see so many cousins - Gracias." Another visitor from Watsonville, CA, recognized the politics of the project outright: "The African Presence in Mexico exhibit was extremely well presented. It was both visually and intellectually stimulating. Thank you for your contribution to re-writing history." ${ }^{21}$ 
As Simon notes, encouraging others to feel empathy often begins with demonstrating to them that someone is feeling for them, listening to them, caring about them. ${ }^{22}$ It stands to reason, then, that making the visitor feel like a welcomed guest will be much more effective than putting her on her guard and making her feel defensive, as guilt and shame are likely to do. The museum's content need not change at all. One element of hospitality and a sign of empathy is the way in which the host addresses the guest: in this case, the way the museum addresses the visitor.

Forms of address create the publics they call upon. Museums have various ways of addressing their visitors. Many elements within the gallery send messages to visitors. Labels, didactic panels, and other texts telegraph highly specific messages about content and questions to the visitor. Museums have used labels and other forms of address to consolidate publics as if by magic. ${ }^{23}$ Lisa Lee, the former director of the Jane Addams Hull-House Museum, drew counterpublics - under- or misrepresented groups, marginalized groups, and generally counterhegemonic groups - from among the museum's visitors through the forms of address in the museum. All museums call publics into being through the use of specific forms of address. Therefore, it is worth using them mindfully. A look at some differences between the Verzetsmuseum (Dutch Resistance Museum) in Amsterdam and the Museum of Tolerance (MoT) in Los Angeles will illustrate how two different stances toward the visitor result in visitors having very different experiences of the content in the museum.

The Verzetsmuseum Amsterdam (Dutch Resistance Museum) tells the story of the various ways in which Dutch people responded to the Nazi occupation of the Netherlands during World War II. Former members of the Dutch resistance movement founded the museum in 1985 in response to rising right-wing political parties. The museum was initially housed in a former synagogue. It opened in its current site, the Planicus Building, in 1999. Since then, the museum has received around 50,000 visitors a year. ${ }^{24}$ Its annual budget is just under $€ 1$ million. ${ }^{25}$

The Verzetsmuseum Junior, the children's exhibition at the Verzetsmuseum and the MoT demonstrate two approaches to related material. The MoT prescribes all thinking for the visitor. At Verzetsmuseum Junior, by contrast, exploration and building empathy are the keys to the experience.

This exceptional exhibition is addressed to children by their peers, four real children caught up in the various Dutch experiences of World War II. Telling true stories of real individuals is very important for building empathy, as I discuss below, but making these stories into firstperson accounts is even more effective. Liesbeth van der Horst, the director of the museum, explained to me that finding the adults who had been these children and were willing to share their stories was the most challenging part of putting together the exhibition. ${ }^{26}$ The museum needed four specific individuals: a child in the Dutch SS; a Jewish child who hid, was discovered, and went to a concentration camp; a child whose family was with the resistance; and another child who was a bystander, unaffiliated with the different sides of the war. The exhibition opened in 2013 after three years of research.

Entering the exhibition, the visitor enters a Dutch neighborhood. In the center is an open plaza with a tree. Around the square are the homes of the four children. Each home is as big as a large play house, yet tall enough for adults to stand inside. A life-sized photograph of the child, cut out and mounted to stand alone, greets the visitor outside the home and gives the visitor a short story about his or her life (Figure 1.2). Many of the children's first-person stories are delivered via video or audio, some are text-only, on labels. Each of these front yards includes small seats for children to sit and listen to the stories as a group. 


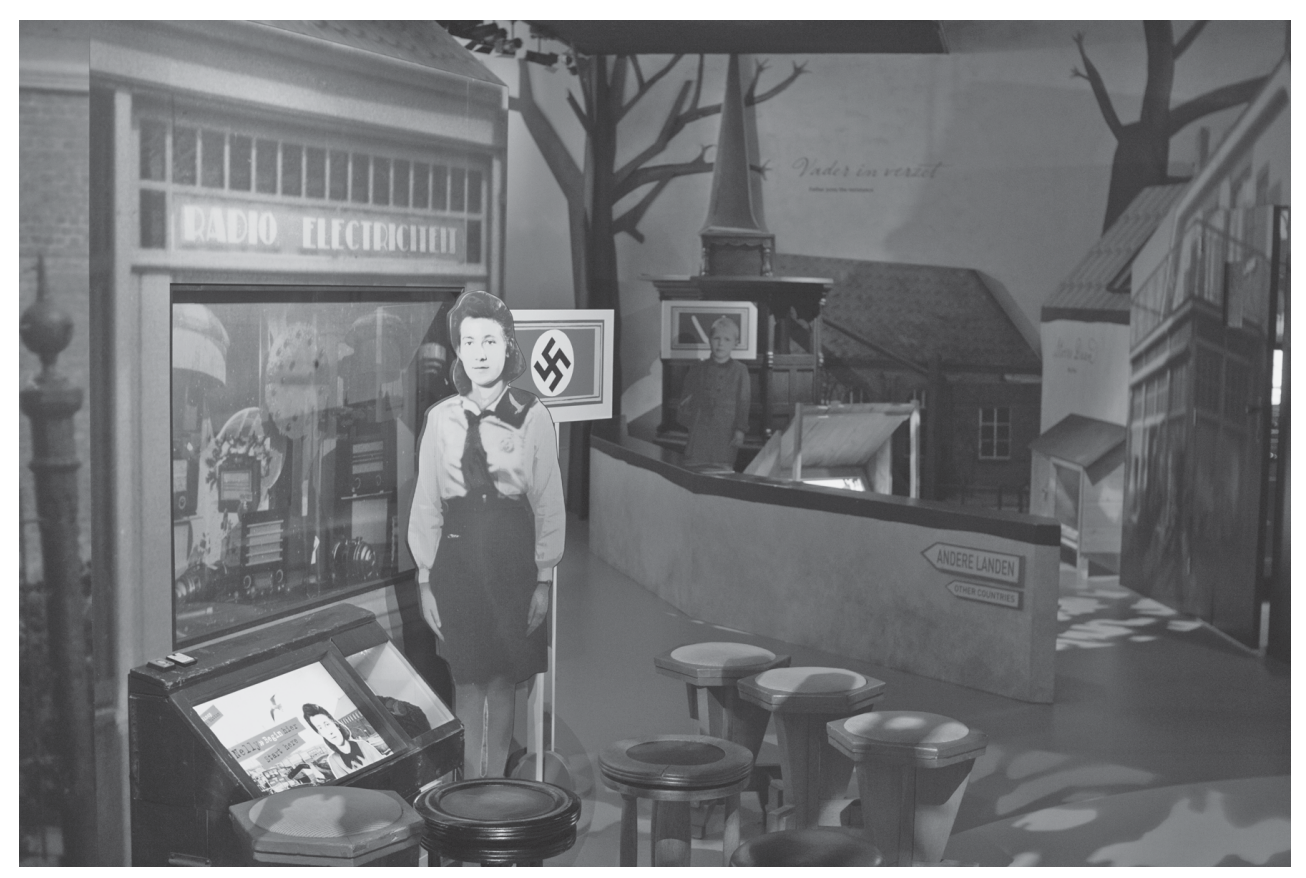

FIGURE 1.2 View of the plaza and Nelly's house in Verzetsmuseum Jr. at the Verzetsmuseum, photo by author (2017). Courtesy of Verzetsmuseum Amsterdam.

The collage-type aesthetic of the photo cut-out that introduces each child is also evident throughout the exhibition (Figure 1.3), in the videos, in the overall exhibit design, and on the website as well as in the book that accompanies the exhibition.

This aesthetic interposes and gathers photographic imagery in a narrative way that breaks with the original purposes of the historic documents. The strategy is both attractive and disarming. The cute, almost cartoonish design belies the seriousness of the subject matter and may make children feel more at ease in the space overall. It looks fun and is a very fun space to explore.

The environments are lush and complete. The visitor can then enter each home through a real door. She emerges into the family's living space, complete with dining table, perhaps a radio, musical instrument, coat rack, etc.

Many of these objects are authentic, and the wear-and-tear on them was a concern for the museum. But it hasn't materialized. According to van der Horst, the public has been very respectful of the objects in their museologically unusual surroundings.

The narratives are compelling. One reason is that they are real first-person narratives. Another is the details the children give. Jan, the boy whose family supported the Dutch resistance, talks about not trimming the hedges around his house because his family is hiding people inside. (Figure 1.4 shows his dining table.) Eva, who talked in her intro video about how excited she was to have a fast new bike, talks inside the house about pretending to ride her bike in bed while in hiding. It is so easy to imagine her lying on her back riding her imaginary bicycle in her tiny bunk beside a blacked-out window. Henk, the boy who is unaffiliated, collects shrapnel that falls into his gutters and around his yard and keeps it in 
a special box in his room. Nelly, the girl in the Dutch SS, tells the story of how her father became mayor of their town. The Dutch Nazi Party installed him in power as part of their takeover.

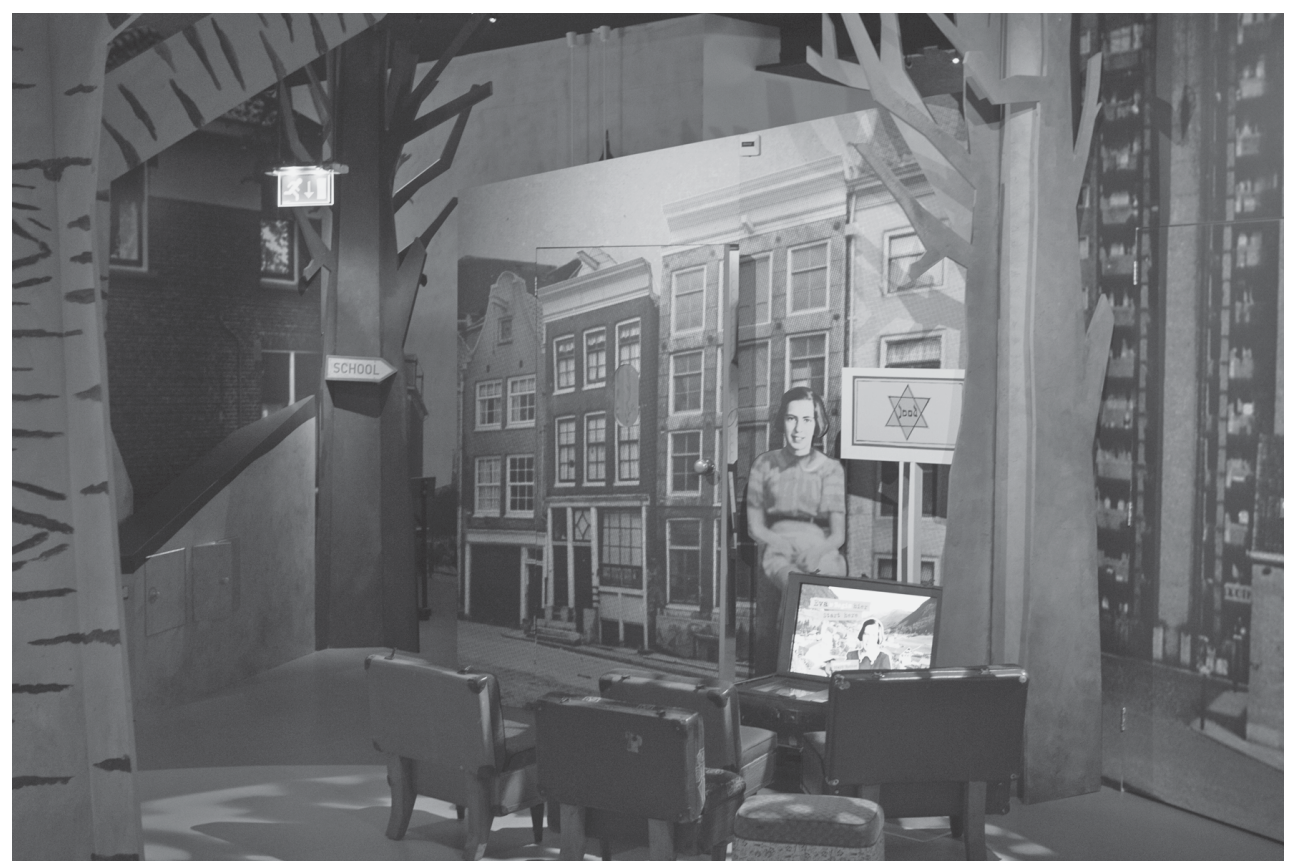

FIGURE 1.3 View of Eva's house in Verzetsmuseum Jr. at the Verzetsmuseum, photo by author (2017). Courtesy of Verzetsmuseum Amsterdam.

Eva's story, the story of the Jewish girl, takes the visitor from engagement and enjoyment of the narrative to the inevitable emotional overload of any story of the Holocaust. In Eva's house (Figure 1.3), we see the coatrack in the front hall. Each family member has a yellow star sewn onto his or her coat (Figure 1.5). At the dinner table, the family discusses the relative merits of hiding or of Heinz, Eva's brother, going to work in the camp as he has been drafted to do. There's a nice interactive in the table (digital plates) where visitors can weigh in on this conversation. Eventually, the father decides that the whole family will hide.Visitors can move into the next two rooms where we see and experience hiding through the bedroom where Eva pretended to ride her bike, where shadow puppets play on the ceiling, and the bathroom, where a section of the tile wall is a secret door that Eva and her mother can sneak through into their hiding place when police come. But the family is discovered, and another door takes us into Auschwitz.

At this point, it's hard to believe that the rest of the exhibition - the plaza and the neighborhood - lies just outside the walls of this section. The larger space of Eva's home, the hiding place, and the concentration camp is cleverly concealed in the gallery to look, from the outside, like blocks of apartment buildings.

The space of the concentration camp is dark so that we can watch the video of Eva's experience. The videos, like the whole aesthetic of this exhibition, is a collage of diverse - yet real - photography, sometimes with the figures outlined to give them a slightly cartoonish 


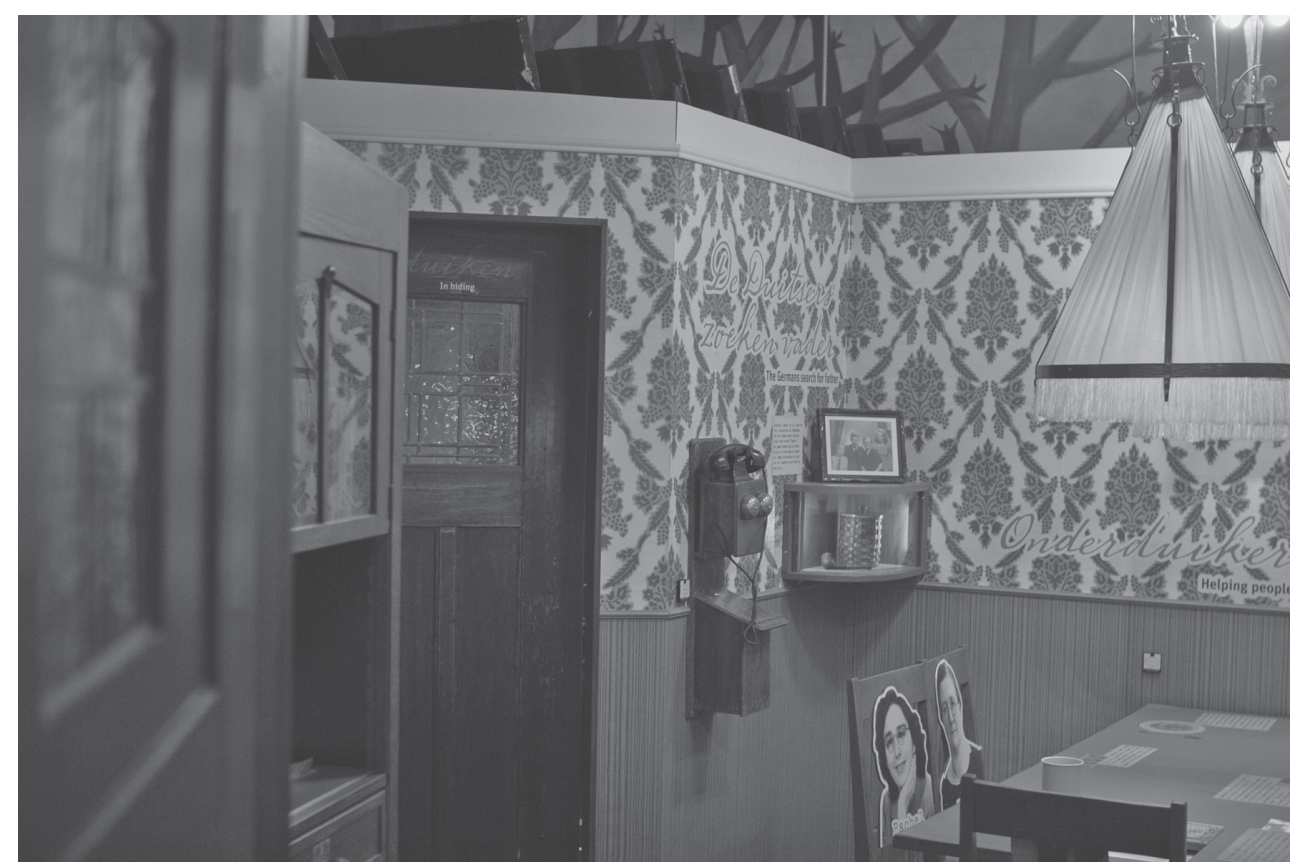

FIGURE 1.4 Interior of Jan's house in Verzetsmuseum Jr. at the Verzetsmuseum, photo by author (2017). Courtesy of Verzetsmuseum Amsterdam.

impression. Still photographs are animated into a kind of stop-motion collage that gives a slightly humorous visual effect to an otherwise deeply disturbing story. The video in this space tells how Eva's family travels by railcar to the camp. It tells how initially Eva and her mother are together in the camp, though they are suffering. When Eva's mother becomes sick and is taken away, Eva is sure that her mother has been killed. Eva's feet freeze, and she goes to the infirmary. There she finds her mother and crawls into bed to curl up against her skeletally thin, sick body. By this point, I was crying freely. Suddenly, Eva and her mother are freed. (The Germans had abandoned the camp, leaving only the sick prisoners behind. The Russians arrived and freed the remaining prisoners.) Eva's mother packs their few possessions into a knapsack, and they walk away. The emotional release was palpable. I fairly flew from the Auschwitz room out into the rest of the exhibition. After the intense emotional experience, I was disoriented, even in the small space. In the final space of the exhibition, the (still living) adults who had once been these four children weighed in on questions regarding wartime, international justice, the possibility of peace, and more.

This was the only area of the exhibition that I found lacking, though perhaps because the extreme emotions that preceded it made it hard to move back to an analytical frame of mind. The interaction with the videos of these individuals was structured through an activity on a podium where the oral histories came out in bits and pieces in response to how visitors answered certain questions. The strength of the rest of the exhibition had been these thick personal descriptions. If there had been the possibility of hearing the adults give longer-form responses more like the children had inside the exhibition, that could have been more effective for the creation of empathy, memory, and perhaps long-term engagement. 


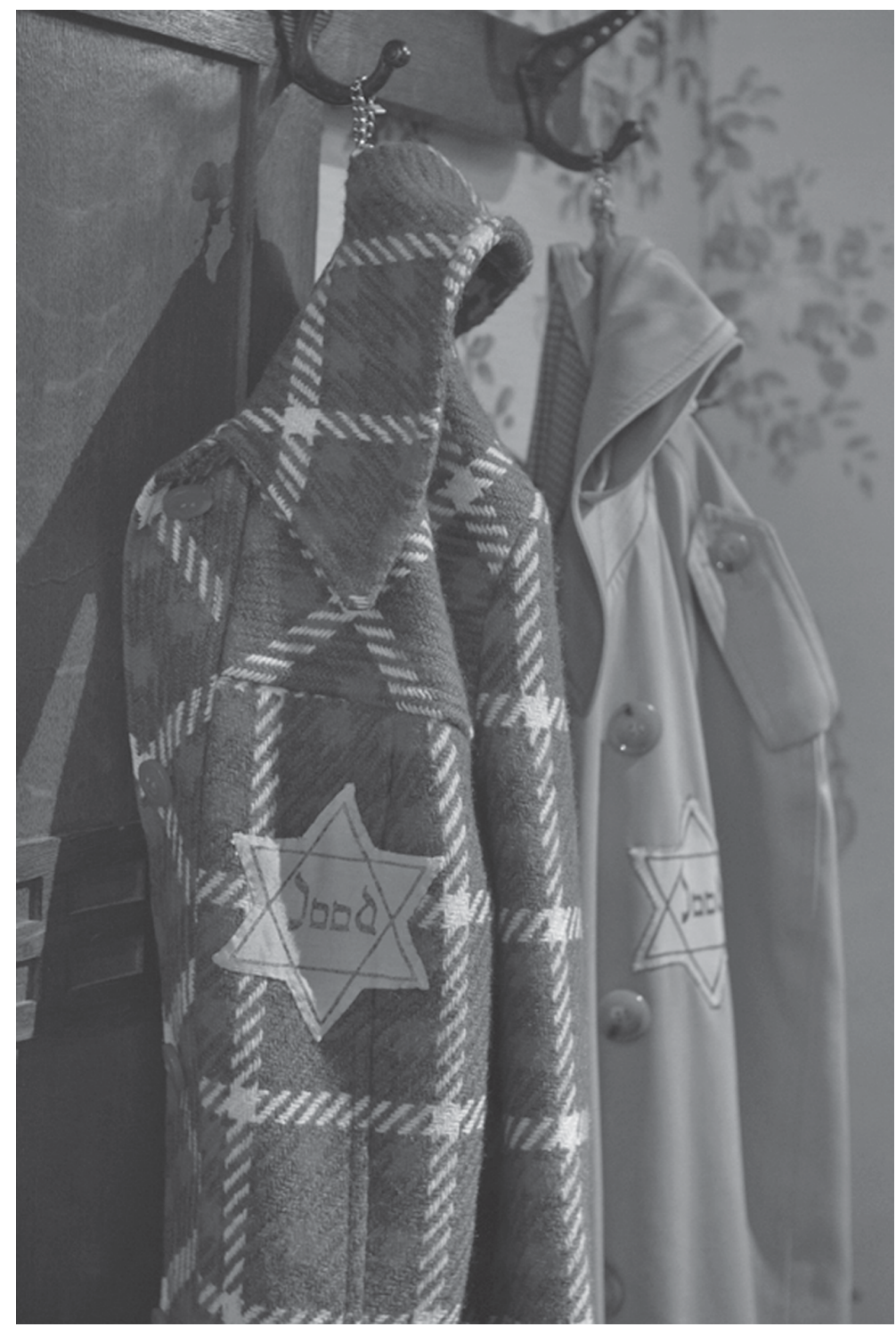

FIGURE 1.5 Interior of Eva's house with coatrack in Verzetsmuseum Jr. at the Verzetsmuseum, photo by author (2017). Courtesy of Verzetsmuseum Amsterdam.

The form of address in Verzetsmuseum Junior assumes that the visitor is a peer of the speakers, the children. They speak frankly and openly to the visitor, eager to share their excitement and anxiety, the highs and lows of their experiences. The exemplary immersive environment should aid children in accepting the children's invitation to listen even more than adults (because of children's size and the size of the exhibits). Only in a very special environment could a museum address the subject of concentration camps in an appropriate way for 9-yearolds. But Verzetsmuseum Junior has passed that test with flying colors. 
Whereas Verzetsmuseum Junior asks visitors to explore to their hearts' content, the MoT dictates. The pathway along which visitors are meant to think is brightly lit. The MoT is famous for the aggressive statement its entryway makes. The visitor must enter through one of two doorways. One, lit in green, is marked "unprejudiced." The other, lit in red, is marked "prejudiced." However, in case the visitor is considering entering through the unprejudiced door, the door bears the words "Think ... Now use other door." This is emblematic of the rest of the experience in the museum, according to Andrea Witcomb and Wendy Brown. ${ }^{27}$ As Witcomb demonstrates, the use of force, ideological or otherwise, does not breed tolerance, free thinking, or criticality of hegemonic norms. Simply put, the MoT does not model the kind of thinking and acting it supposedly wants to see in the public. It models the opposite. That begins with the name of the institution. I agree with Wendy Brown that tolerance is a troubling attitude, especially for an institution that purports to work for social justice. Tolerance creates a hierarchy wherein the one tolerating is superior to the tolerated one. Much more problematically, however, institutions from schools and museums, to corporations, and even the United Nations, promote tolerance as if it could be a broad social program. In fact, it is a personal value that only individuals can adopt. As a result, it frames the need for change as an individual problem, not one that requires changes in public systems that would result in greater social justice. The ethos of tolerance actually handicaps political social justice projects. ${ }^{28}$ Furthermore, when the onus is on individuals to be tolerant, the state is free to be intolerant in whatever ways most suit its needs, such as curtailing civil liberties and racial profiling. ${ }^{29}$

Victorian exhibitions provided a single order that was meant to convey a single true meaning to the visitor, such as a racial, ethnic, or gendered social hierarchy. Likewise, the MoT is structured to convey single meanings to the visitor, even though it provides the illusion of choice. ${ }^{30}$ In the Beit Hashoah section of the museum, dealing with the Holocaust, the MoT circumscribes the visitor's experience even more strictly than in the Tolerancenter, where the museum presents all other historical events. The Tolerancenter relies heavily on technology and only sketches out factual details and historical context. As Brown describes it, unlike the Tolerancenter, where presentations are anonymous and supposedly objective,

the organization and style of the Beit Hashoah makes clear that the Holocaust must have its whole story told, that it must be told authoritatively yet also entirely from the perspective of its Jewish victims. And it must be established as a single narrative, delivered at length without interruption, distraction, or choice on the part of the viewer, and without featuring debate or plural points of view. ${ }^{31}$

Crucially, make-believe characters and scenarios are not acceptable the way they are in the Tolerancenter. ${ }^{32}$ There's no make-believe in Verzetsmuseum Junior either, but the delivery of the content tells visitors that the experiences of these four children matter just as much as their own and vice versa. If Verzetsmuseum Junior does a better job than the MoT at cultivating empathy and building solidarity, perhaps it is because of the hospitality and empathy it shows its visitors.

Addressing the visitor directly and enlisting her in an exploration, an idea, or a social justice project is one mechanism for the museum to engage the visitor in thinking about contemporary relevance, a way to create a resonant moment for the visitor. Verzetsmuseum Junior aptly uses an age-appropriate visual vocabulary to engage children in the histories it presents 
and then move them toward thinking about our world today. The exhibition is an example of Tony Bennett's "civic seeing" for a young audience. "Civic seeing" is what Bennett calls the visitor's experience of the civic lessons embodied in the arrangements in an exhibition. These lessons are meant for visitors to see, understand, and perform in the world beyond the museum. ${ }^{33}$ Bennett suggests that museums are places where new realities are "constructed and then mobilized." ${ }^{34}$ Verzetsmuseum Junior promotes visitors' constructively imagining of a particular "new reality," a world without hate crime. It does so by directly approaching the visitor through the narrative and questioning at the end.

One way to see the importance of the form of address is to examine examples where there supposedly is no form of address, no institutional voice speaking to the visitor. The United States Holocaust Memorial Museum (USHMM) presents its interpretation not as interpretation, nor as a curatorial effort, but as fact. Cindy Miller, Project Director for the permanent exhibition at USHMM, reported that the council of planners for the exhibition decided to have no narrative voice in the permanent exhibition, the better to keep the exhibition "openended" and "engage [visitors] directly." Her goal was that visitors would not "think about the exhibition as a 'narrated interpretation' ... but will be satisfied that major interpretive dilemmas have been resolved." ${ }^{35}$ But, of course, this itself is an interpretive strategy.

The exhibit design reflects a parallel technique. Ralph Applebaum, the designer, said "we tried to bleach out the idea that a designer's style was important. We used basic abstract concepts of style - contrast, proportion, scale - within a modular matrix." ${ }^{66}$ This is a design strategy, just as the attempt to remove the narrator is a narrative and interpretive strategy. A design that looks stripped-down or un-designed doesn't simply spring into being. A designer creates it for a particular purpose. In an exhibition, the purpose is to create the experience that visitors have and the narrative that they perceive. In a subtle way, this intentional masking of design and narrative voice denies the visitor agency. Instead, the exhibition addresses the visitor, visually and verbally, as the receptor of information.

The Anne Frank House museum in Amsterdam has a traveling exhibition and debate program that demands agency of the visitor. Free2Choose was initially on view at the museum, but it closed in 2014. It became a traveling exhibition in 2006 and was eventually in use in more than twenty countries. It is still in use in ten countries outside the Netherlands.Visitors watch films that present conflicts between freedom of speech and freedom from discrimination. (Students in thirty countries are involved in the program, making new films to include in Free2Choose debates.) For example, if a hate group wishes to demonstrate at the funeral of a queer person who was murdered in a hate crime, whose rights should the law protect? ${ }^{37}$ Visitors must then vote on which right they think prevailed in each scenario. Leaving visitors to make their own decisions, come to their own conclusions, and use information as they will is de rigueur, but Free2Choose is different insofar as it actually asks visitors to reach a conclusion.

Whereas someone might not bother to consider an unasked question, many visitors who are asked questions directly within exhibitions do answer them. The way in which Free2Choose questions visitors is designed to produce a result. The gentlest nudge to think, to consider, to weigh options causes visitors to engage with the world around them, regardless of their opinions and the answers they do produce. Again, a positive practice that is effective for visitors leads back to the idea of hospitality. The curatorial practice of questioning that is present in Free2Choose is an institutional example of the natural exchange in a conversation. Speaking, listening, and asking after another person makes the visiting guest feel at home and enables 
her to feel the empathy of the host. So, too, the practice of questioning raises the stakes of the visit for the visitor herself and demonstrates to her that her answer matters to the questioner.

The notion that visitors will use resources in museums as they see fit is prevalent at many mainstream institutions and can absolve the museum of any need to be intentional about its goals for visitors. Visitors may ultimately not use the resources they found in the museum at all. But in Free2Choose, Anne Frank House and its partners take steps to ensure that visitors are engaging with contemporary concerns and carrying the dilemmas of Anne Frank's own day forward into our own. The exhibition/program does this through the strategy of questioning. Nina Simon proposes questioning visitors as one way of activating objects for social interaction. ${ }^{38}$ According to Richard Sandell, "a commitment to rights and social justice did not require museums to tell their visitors what to think." ${ }^{39}$ Especially in contentious topics that might fall under the rubric of exhibitions for social justice, learners may be more guarded and less ready to accept information that is relayed aggressively, as in the MoT. Indeed, the more a museum gives visitors the tools to think about contemporary concerns, the more effective its work will be.

\section{The hospitable nature of trust via touch}

Hospitality is not a new model for the museum. Rather, it is one that we've drifted away from since the museum became a public space in the late eighteenth and early nineteenth centuries. When museums opened to the public, classist and racist fears were prominent. Yet leaders inside and outside of museums envisioned them as places that could help socialize lower-class people and immigrants especially and assimilate them into the dominant national program. Together, prejudice and social engineering caused curators to envision a new form of engagement with guests.

In this new form, visitors would not touch the exhibits. Touch was an element of hospitality that would fall by the wayside. Investigating objects by touching them had been the norm in the museum of the early eighteenth century. Constance Classen described the model of the curator in the seventeenth and eighteenth centuries being that of the "gracious host." One of the ways the curator demonstrated this hospitality was through allowing visitors to touch the collections. ${ }^{40}$ As working-class people began to gain access to enter museums, gatekeepers began to fear public access and focus on the fear of working-class people touching the exhibits. In reality, objects in museums were under much greater stresses at that time because of environmental factors such as soot from lamps and pollution. ${ }^{41}$ As Fiona Candlin put it,

The estimation of touch had changed. Whereas the gentleman or lady's touch had been considered a viable, rational mode of learning about collections, and even their brutal treatment of exhibits had been tolerated, once the working class (whose touch had always been denigrated) gained admittance, touching became associated with damage, a lack of common sense and an absence of justice. ${ }^{42}$

Touch as a mode of exploration undoubtedly still has the effect of making visitors feel welcome. But it has not yet seen the full resurgence that future decades may bring demand for multisensory experiences in museums increases.

Nina Levent and Lynn McRainey say curators and artists are returning to a model of hospitality "as they step aside to allow space for the visitor to become part of the interpretive and creative process." ${ }^{43}$ To be sure, hospitality doesn't look like it did nearly three centuries ago, 
nor should it necessarily. Levent and McRainey signal to something I'll discuss in more depth in Chapter 4, the ways in which sharing authority and inviting participation have become a significant piece of the hospitality visitors do or do not feel in the museum.

\section{Enjoy!}

In 2014, Hull-House combined touch and another crucial feature of hospitality: comfort. What could be more hospitable than a cup of tea? During that winter, visitors to the museum could reserve a half-hour to read an alternative label (really a novella) for Jane Addams's traveling medicine kit (Figure 1.6) while drinking tea served to them by a staff member.

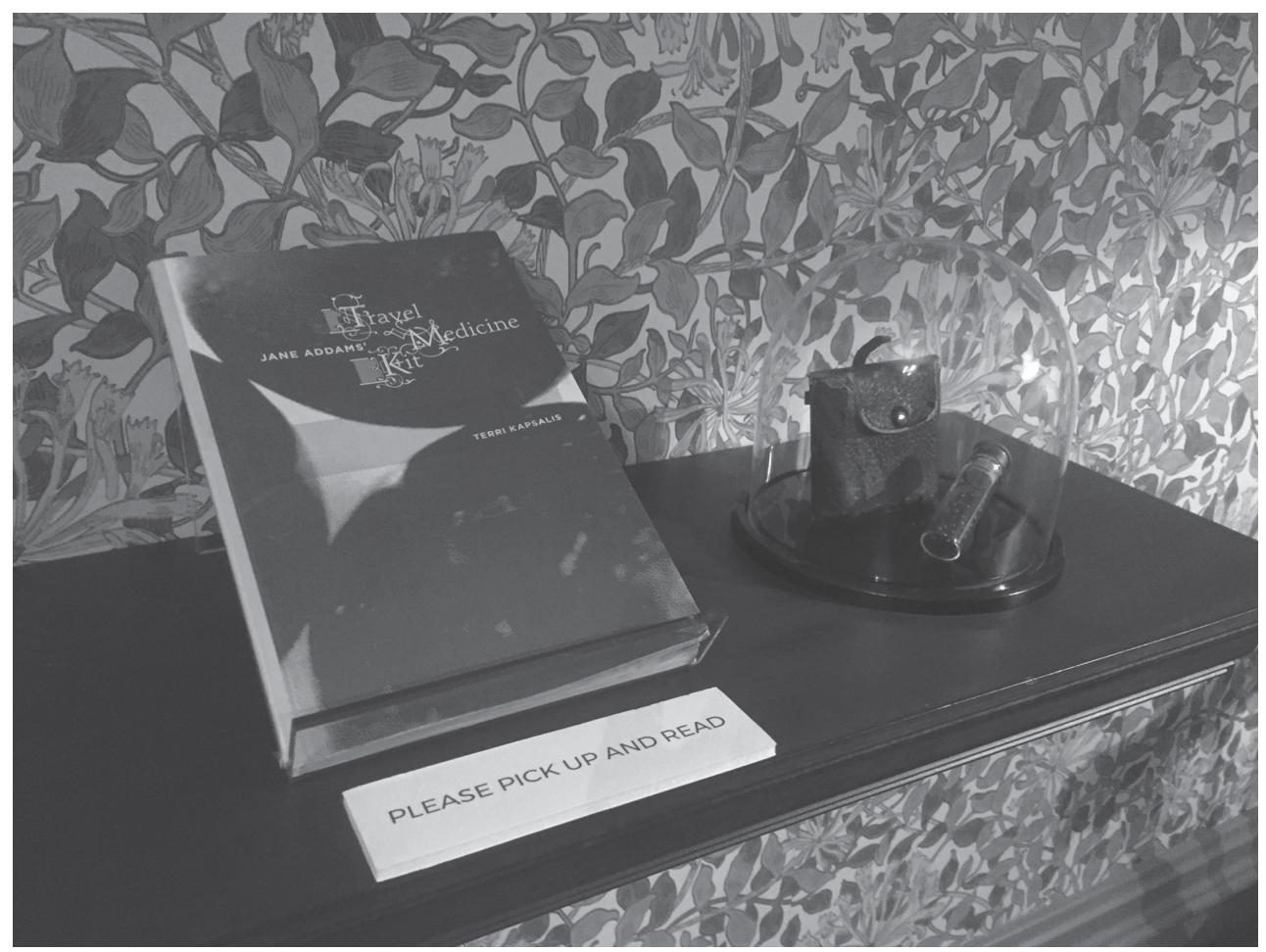

FIGURE 1.6 Jane Addams' traveling Medicine Kit and the alternative label by Terri Kapsalis. Photograph by Rachel Glass. Image courtesy of Jane Addams Hull-House Museum, University of Illinois at Chicago.

Hull-House is a small historic house museum with a big agenda. It's also part of the University of Illinois at Chicago. The site is all that remains of Chicago's Hull-House Settlement, an international pioneer in the Progressive movement. The museum started out as a sleepy historic site dedicated to the memory of Jane Addams, the Progressive reformer who founded the settlement along with Ellen Gates Starr. In 1963 the Hull-House Association decided to preserve two buildings from the Hull-House Settlement as a museum. It opened in 1967. In the twenty-first century it has become a Site of Conscience (joining in 2004) and has taken on the mantle of continuing the unfinished work of the Progressive reformers on topics as broad-ranging as labor rights, food justice, environmental justice, immigration reform, 
prison reform, and women's rights. The site is an evolving experiment in museological work for social justice. Its annual attendance is roughly 30,000 , and its budget is over $\$ 400,000 .{ }^{44}$

Hull-House excels at creating many different welcoming experiences. The environment at the museum is abuzz with happy, productive activity. One reason it is successful is that you enjoy visiting. Hospitality creates one kind of pleasure in the museum. That pleasure blends with experiences such as the tea drinking to compound enjoyment and comfort.

Pleasures - including the physical and emotional comforts of hospitality - are political for Hull-House, as they were for the Progressive reformers. After all, a settlement house is about inclusion and welcoming strangers. Claiming our right to leisure is part of enabling our practice of democracy. If a visitor feels that taking pleasure in her visit helps her fulfill her civic duty, she can be relieved of the Protestant guilt that can dog her through each hour of leisure time. The museum gives its visitors an intoxicating mandate to enjoy themselves. This is both a contextually appropriate lesson in history and, in its political content, a brilliant way of welcoming visitors.

\section{Telling individual stories}

Museums can build empathy in the visitor by providing the visitor with a hospitable environment and experience or through staff members' empathy for the visitor herself. Another way of building empathy appeals to humans' propensity to bond with other humans, one person at a time. In exhibitions, stories of real individuals function this way. Many things conspire to keep us from bringing people into our inner circles. One is compassion fatigue. ${ }^{45}$ Time and again, says Kelley Szany, Director of Educational Outreach and Genocide Initiatives at the Illinois Holocaust Museum, students say that they would feel a more intense obligation to others if they could better identify with them. She noted several instances of our compassion for strangers waxing when the stranger in question is one specific individual and waning with any more than one person. Well-done journalism about genocide always focuses on the individual rather than statistics. Szany attributes this to what Paul Slovic, the founding president of the Decision Research Institute at the University of Oregon, has called "The Psychic Numbing of Genocide." Szany is all too familiar with this effect through her students and also seeks to combat it through individual stories. As the saying goes, "One person is a tragedy; more than one is a statistic." Slovic's study demonstrated that the most effective way to build compassion is through focusing on one individual, without statistics.

The experience of staff members at Eastern State Penitentiary in Philadelphia illustrates a compelling exception to this rule. Eastern State Penitentiary in Philadelphia was founded in 1830. At the time, the idea of a penitentiary - where criminals would go to become repentant and be reformed - as opposed to a jail, which was just a holding area, was new. The model of solitary confinement and silence imposed at Eastern spread all over the US and Europe and competed with the so-called New York Model, wherein prisoners ate together and worked together, for predominance. The New York Model prevailed. The building was abandoned when the penitentiary closed in 1971. On the eve of the decision to sell the property, preservationists came together to stabilize the site and preserve it as a ruin. ${ }^{46}$ The site opened as a museum in 1994. Many visitors go to Eastern to see Al Capone's cell or to experience being inside what was once the most famous prison in the world. Eastern has transformed in recent years into a museum that is addressing the American crisis of mass incarceration directly. The combination of the public perception of Eastern as a mainstream tourist destination and the exciting curatorial work focused on contemporary concerns makes this site a truly 
unusual destination. Many sites involved in curatorial work for social justice have an audience that is self-selecting for its interest in social justice or related topics. Eastern, by contrast, is in the enviable position of being able to engage a more general public on these issues. The site's annual budget is $\$ 4$ million, and 240,000 people visit the site each year. ${ }^{47}$

In developing the interpretive strategy for Eastern, Sean Kelley, Director of Interpretation, actually tried to start with individual stories and move to statistics from there - and that strategy failed. He had much greater success when beginning with statistics, and then moving to individual stories.

It may be that Eastern State is successful at using statistics prior to individual stories because it presents the statistics in such a compelling way. A public infographic sculpture called The Big Graph clearly shows several problems: the US has the highest rate of incarceration in the world (Figure 1.7). By a huge margin. This despite the fact that the rate of violent crime in the US has remained the same for 40 years. ${ }^{48}$ In the US, the population of incarcerated people has grown 600 percent between 1970 and 2010. Black inmates are overrepresented in the prison population at a rate that is six times higher than White inmates. Black people have been overrepresented in prison populations since Eastern State was built in 1830, but the degree to which they are overrepresented has steadily grown since 1970 (Figure 1.8). ${ }^{49}$

Visitors encounter The Big Graph at the end of the guided tour, which all visitors take, whether on an audio guide or with a tour guide. From there, visitors usually continue to the adjacent exhibition, Prisons Today.

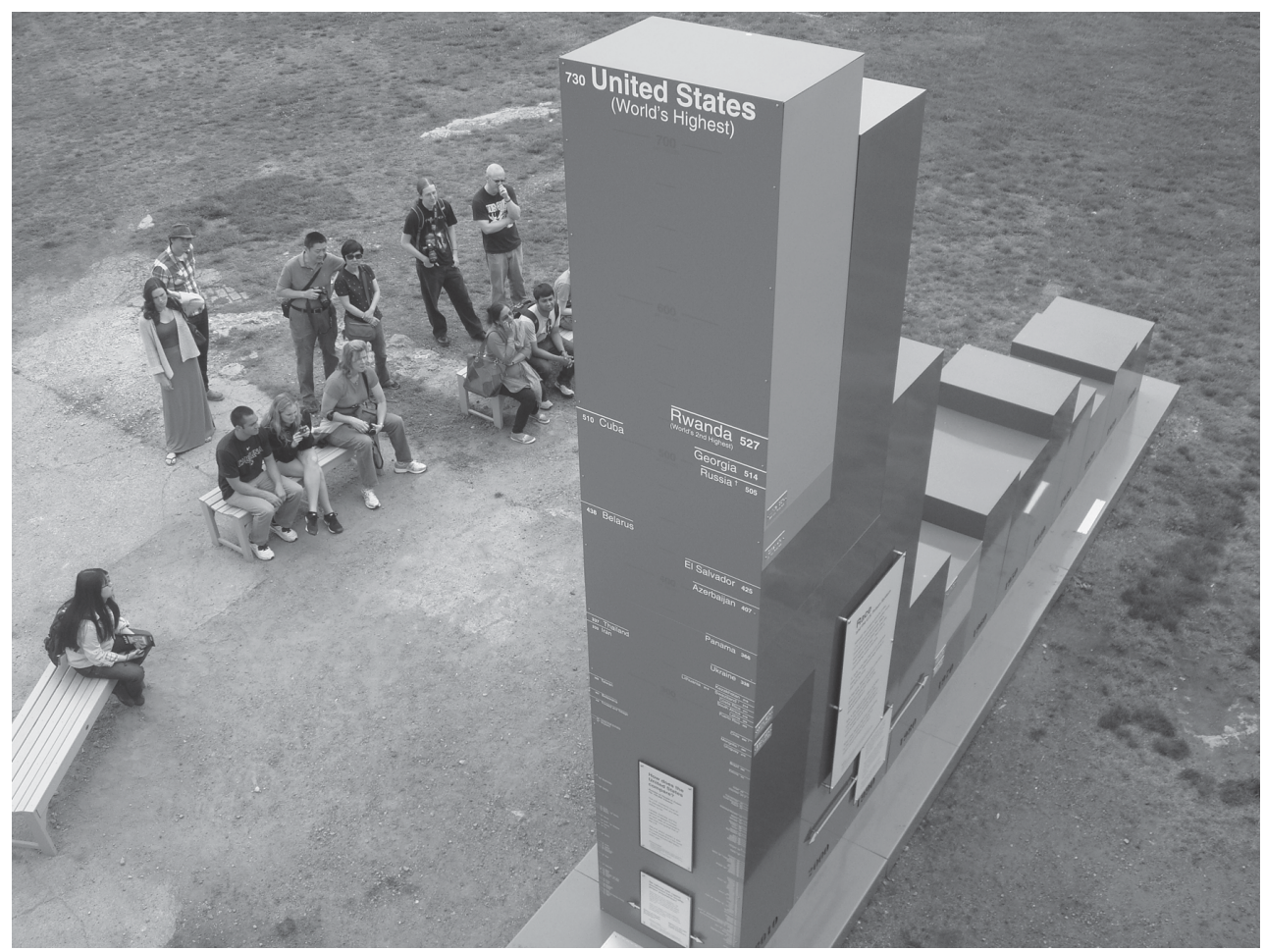

FIGURE 1.7 "The Big Graph" at Eastern State Penitentiary showing the US having the highest percapita rate of incarceration (2016). Courtesy of Eastern State Penitentiary Historic Site. 


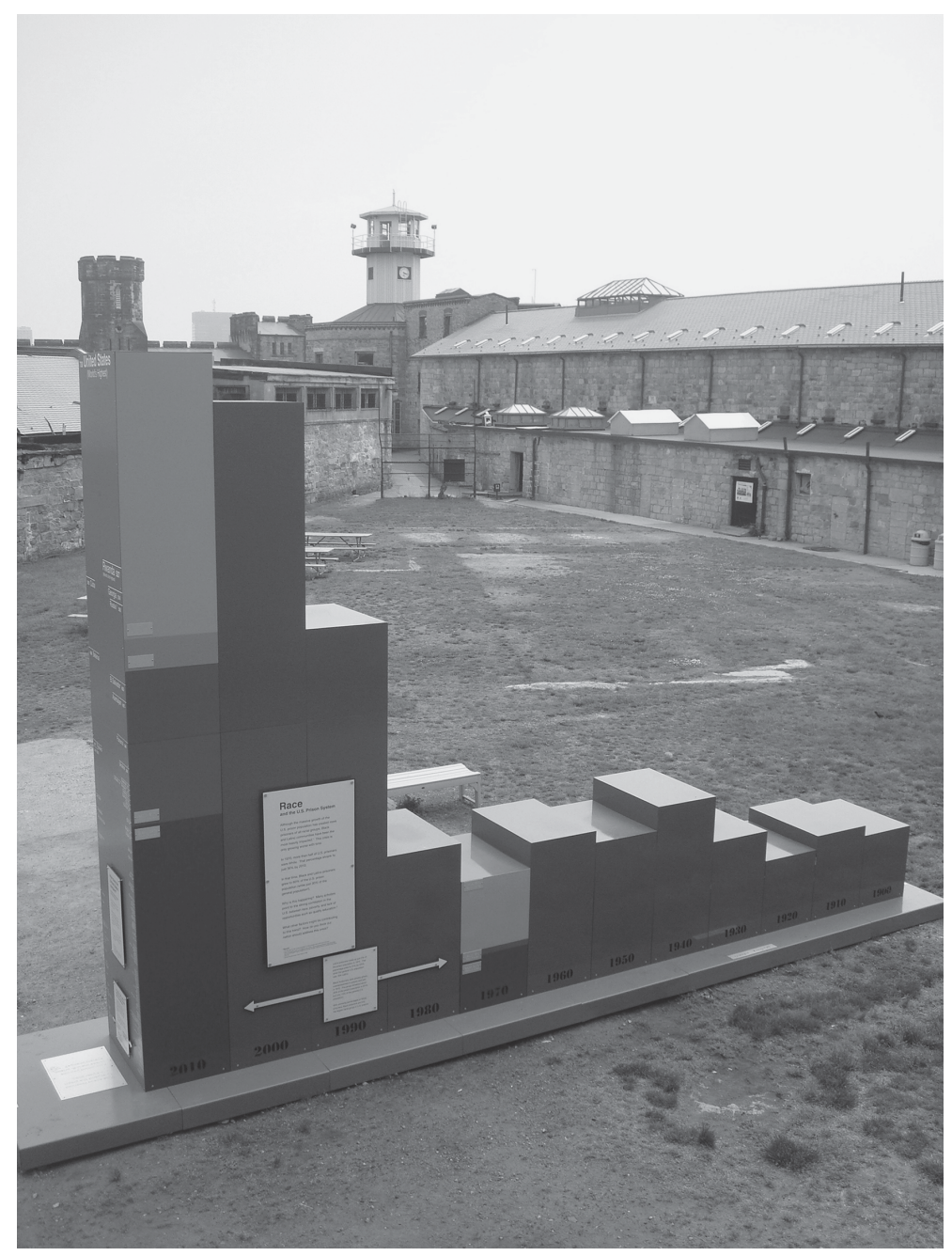

FIGURE 1.8 "The Big Graph" at Eastern State Penitentiary showing the spike in overrepresentation of non-White populations in jail beginning in the 1980s (2016). Courtesy of Eastern State Penitentiary Historic Site.

There, visitors are able to position themselves in the narrative and also to learn the stories of specific individuals. Figure 1.9 shows the entrance to Prisons Today.

In general, 70 percent of American adults admit to committing a crime that could have put them in prison. But most of them never go to prison. This exhibition explores some of the systemic reasons why, as well as what life is like for those who do go to prison and the families they leave behind. In the exhibition, the video assemblage "Six Voices" explores these stories, teaching, for example, that most inmates in Pennsylvania are parents. Their 81,000 children are victims as well. The goal here is for statistics to help visitors grapple with ideas that may not go with their existing mental pictures and then use individual stories to build empathy. It's still an uphill battle, however, where reporting and visitors' 


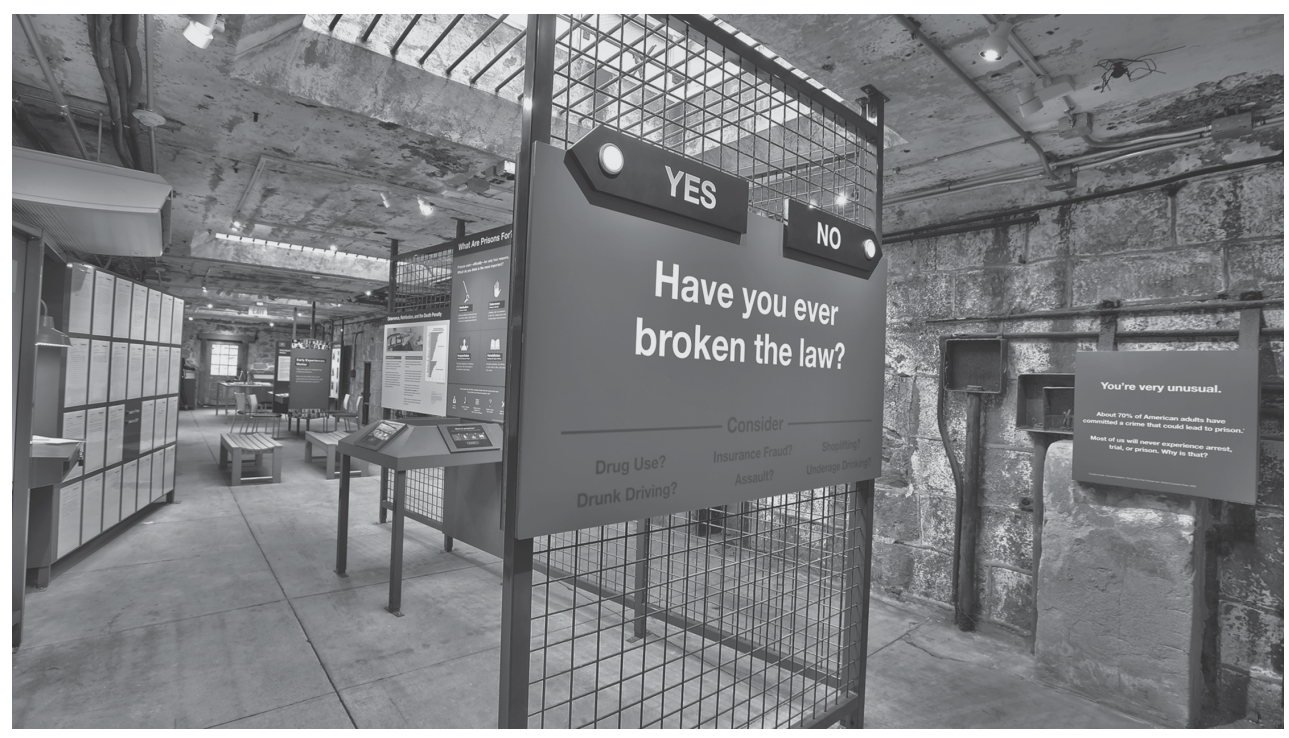

FIGURE 1.9 Inside Prisons Today at Eastern State Penitentiary (2016). Courtesy of Eastern State Penitentiary Historic Site.

experiences may not mesh. (Only 4 percent of visitors admitted to committing a crime when interviewed by staff.) Unfortunately, only 6 percent of visitors reported increased empathy for prisoners and their families as a result of viewing Prisons Today.${ }^{50}$ This seems low even when accounting for what is clearly a majority of incoming visitors viewing prisoners unsympathetically. But conversations with previously incarcerated tour guides can support the visit differently.

Eastern State has a program that employs previously incarcerated people as tour guides. And their presence can dramatically change the empathetic experience of visitors. Their past experience is not part of their tour unless they bring it up, and nothing else identifies them as previously incarcerated to visitors. However, these guides are regularly generous in sharing their experiences with visitors. One story demonstrates how significant this sharing can be in helping visitors build empathy. Cherie and Malayna, her 10-year-old daughter, live in Philadelphia and visit Eastern State a couple of times each year. Through Malayna's experience with one of the interactive elements in Prisons Today, she began a conversation with Sharmaine, a previously incarcerated tour guide. Sharmaine shared her story with Malayna and their interaction was so positive that it inspired Cherie to share a story with Malayna as well. Cherie's brother, Malayna's uncle, is in the middle of serving a ten-year prison sentence, and Cherie had not been able to tell Malayna the truth of where her uncle was until this experience helped reduce her fear of the subject.

Many creators of stories understand instinctively the importance of grappling the reader, viewer, or visitor to an individual protagonist early on, even if the focus of the story will then change. Whether you think of it as a hook to get your visitor involved or whether the individual's story is the point, individual stories involve humans in the bonding they do best rather than letting them move through the exhibition without connecting emotionally. 


\section{Using local stories}

One personal story was the ballast in the exhibition Without Sanctuary, at the Chicago History Museum, and it was all the more relevant for being local. The Chicago History Museum (CHM) is a large mainstream museum with its own long local history as the former Chicago Historical Society. Catherine Lewis's detailed study, The Changing Face of Public History: The Chicago Historical Society and the Transformation of an American Museum, reveals the museum to be representative of changes in the world of museums over the decades from the 1980s to the 2000s. ${ }^{51}$ The founders saw the museum as a way of shaping citizenship and ameliorating the problem of new immigrants. The museum has a history of working instrumentally for social change, yet not in ways contemporary visitors or museum professionals might qualify as "working for social justice." The museum's contemporary institutional line has strongly distanced the organization from that history. When I began this study, CHM was the only institution I was working with that purported, on an institutional level, not to work for social justice or social change. Yet, in the exhibitions I studied, the institutional line and the curatorial position differed in important instances. In 2017, however, in the wake of neo-Nazi terrorism in Charlottesville,VA, President of the museum Gary Johnson issued a letter to the staff and board outlining a plan for expanding and altering the museum's programming to combat hate, prejudice, and racism in particular. ${ }^{52}$ Following that, the museum created a statement on "Diversity, Innovation, and Social Justice." ${ }^{53}$ It is the most overt institutional support of social justice in the museum's long history. The museum sees 270,000 visitors a year, and has an annual budget of $\$ 8.6$ million. $^{54}$

Without Sanctuary was a touring exhibition about lynching in the US. Now the collection is permanently at the National Center for Civil and Human Rights in Atlanta. Every installation of Without Sanctuary was different because it was a collection that each site had to curate. ${ }^{55}$ By the time Without Sanctuary came to CHM, in 2005, the collection had been touring for five years with diverse results. ${ }^{56}$ When CHM planned to exhibit it, the museum had recently acquired the court drawings from the case of Emmett Till's murder. It was an opportunity to curate an exhibition that gave the local side of a national story. Joy Bivins, the curator of Without Sanctuary at CHM, used the museum's collection and the story of Till, who was from Chicago, to connect Chicago to the long history of racial violence in the US and to remind visitors that this violence affected African-Americans in the North as well as the South.

Some high school students did not believe that the atrocities in the exhibition were true. Bivins gave them a point of entry into the discussion of lynching through the story of Emmett Till, a boy of their own age. One visitor to the exhibition at CHM was struck by the individual stories, writing;

As I left the exhibition, I took a small card, which said, "I will remember William James, lynched 1909, Cairo, Illinois." Although the exhibition space was empty when I entered, when I left the room was full - full of ghosts. ${ }^{57}$

\section{Lighting the path toward systemic change}

First-person testimony has, so far, always been the most valuable currency of Holocaust remembrance. It has remained a constant at the Illinois Holocaust Museum ever since it was 
the Holocaust Memorial Foundation of Illinois (HMFI) (1984 to 2008). Holocaust survivors founded that storefront museum on Main St. in Skokie, Illinois, in response to the planned neo-Nazi march in Skokie in 1976. Skokie was once home to the largest community of Holocaust survivors outside of Israel. ${ }^{58}$ The Illinois Holocaust Museum is a hybrid institution; the founders also envisioned it as a new kind of Holocaust museum for the new century. They opened their new museum in 2009. Now the museum has a budget of $\$ 10$ million and roughly 104,000 visitors a year. ${ }^{59}$ Yet, it remains internally conflicted about how inclusive to make its narrative about the Holocaust as well as how to open the history of the Holocaust to be in conversation with other genocides. The leaders are a mix of Holocaust survivors and a new generation of educators and museum professionals. The tools they use and the choices they make in the gallery could have significant implications for memorial museums and sites of many kinds.

The testimony of local individual survivors - written, captured on film, or given to visitors first-hand - provides the most crucial emotional and narrative currency in the permanent exhibition at the Illinois Holocaust Museum. And the museum's feedback from teachers and students bears out the power of individual stories. Chris Foster, a teacher from Warsaw Community High School in Indiana, wrote that his students' more than 120 letters positively reviewing their visit to the museum

answer the critical questions that must be explored before expending resources on any unit of study ... "Does exposing students to the harsh realities of the Holocaust change their lives?" ... "Does this unit help students really question what kind of person they are and what kind of person they want to grow into?" My unqualified answer after working with this unit is still an unqualified "YES."

The students routinely refer to their conversations with specific survivors at the museum. In their letters, the students reflected on their own experiences of prejudice, marginalization, and violence and embrace the goal of being an "upstander," recognizing that they have, in the past, been bystanders at times.

Susan Sontag writes, in Regarding the Pain of Others, that it is the viewer's moral responsibility not to be desensitized by violent images. Instead, she argues, viewers should engage with images, allowing them to build viewers' capacity for compassion and translate it into action. ${ }^{61}$ Nevertheless, compassion fatigue is a real problem in both private experiences with violent imagery such as reading or watching the news and in public experiences as in Holocaust museums. Chapter 2 offers some strategies for avoiding it, in addition to the individual stories discussed here.

The challenge of using individual stories is that they privilege the power of the individual, the upstander, so much that we don't learn about creating institutional or systemic change. At the Illinois Holocaust Museum and other museums, the important lessons about individuals could be more well balanced with additional material that addresses systemic change.

The topic of working together for institutional change is dealt with very well in the final section of the Illinois Holocaust Museum's permanent exhibition. It addresses the fight against the proposed neo-Nazi march. This exhibit includes discussions of protest, legal battles, peaceful demonstrations, and the story of the creation of the HMFI and then the Illinois Holocaust Museum as mechanisms for sustained education and positive social change. One indication that the topic of systemic and institutional change deserves more attention throughout the 
exhibition is that some students and teachers are only taking home the message about individual choice. As one teacher put it, "Why don't people recognize the power of their individual decisions and the ability to make a difference in the world? How do we empower young people? You have provided us with inspiring stories of individual choice." ${ }^{2}$ The comment is both a tremendous compliment on the efficacy of the exhibition and a subtle warning that it may be worth complicating the exhibition's message. The Illinois Holocaust Museum is not alone. Small museums struggle with this especially, but some - such as the Harriet Beecher Stowe House in Connecticut - are bravely working to complicate their messages and make them more relevant.

Once individual visitors begin to empathize with individuals in an exhibition, the time is right to consider how to parlay that empathy into something more. Empathy with one other person can become a path that connects the visitor back to her many communities and affiliations as well as a path forward into solidarity through the broader world of the exhibition. The visitor can connect to other stories within the exhibitions, certainly. But she can also connect to larger groups that exist beyond the exhibition. As the exhibition appeals to her identities as a member of various groups, perhaps through forms of address, she might now bridge to feeling solidarity with other groups. In exhibitions for social justice, groups are almost always involved. Those groups may have been persecuted or marginalized on the basis of some feature of their identity. They may be working for a common cause or against a common enemy. Ultimately, empathy, walking a mile in the shoes of another, can blossom into solidarity as connections between or within groups become plain. That can be a foundation for action on the part of the visitor. Next, I will explore one way of building solidarity among generations.

\section{Building intergenerational communities of memory}

Communities of memory - or solidarity among generations - emerge around a shared experience of a historical event. ${ }^{63}$ For example, those who survived the Holocaust formed a specific community of memory. But this first generation was only one of these communities around this particular historical episode. Each subsequent generation has its own remembrance of and relationship to the events of the Holocaust. So, each is its own community of memory that is, nonetheless, connected to that first one.

When the Illinois Holocaust Museum set out to ensure that the story of the Holocaust would remain relevant to future generations, as well as to those whose families and cultures were not involved in the Holocaust, the leaders of the museum decided on an interesting tool: an exhibition of contemporary art. ${ }^{64}$ The exhibition was Legacy of Absence (2009), curated by Clifford Chanin. At this writing, Chanin is the Vice President for Education and Public Programs of the 9/11 Memorial. Chanin's technique of connecting communities across generations was nestled within this art exhibition. Chanin did not try to pursue the impossible goal of giving each new generation the same memory as the last. Rather, he wanted to ensure that new generations did not forget the Holocaust. Legacy is one possible way to connect past and present, Jewish and gentile. ${ }^{65}$

Chanin's vision of communities of memory relates to Alison Landsberg's concept of prosthetic memory, wherein popular culture can give people access to memories of events they did not actually experience. ${ }^{66}$ For Chanin, the goal of Legacy was to reflect on the common language of memory that artists use to explore violent events such as genocides. He argues that 
the artistic language around human rights abuses, genocides, and other mass violence "emerged from the way that the Holocaust had been represented in memory, whether by people who experienced it or not." Furthermore, according to Chanin, "the collective memory of the events becomes a public good, shared by people who've experienced it and those who haven't alike." ${ }^{67}$ These memories are prosthetic in all but the first and maybe second generation. Nonetheless, prosthetic memories still help to build intergenerational solidarity.

Another, perhaps even more significant, way of building intergenerational solidarity is to fully engage the relationship between the Holocaust and other, more contemporary, episodes of genocide and mass violence. For Chanin and the Illinois Holocaust Museum, the relationship between the Holocaust and other episodes of mass violence is but one reason for the ongoing relevance of the Holocaust. They also argue that the Holocaust is the root of our contemporary visual language for processing all mass violence. Chanin uses the example of collective memory around slavery in African-American communities to show that our society's way of remembering is "rooted in the Holocaust." ${ }^{68}$ Chanin rehung and reordered the exhibition in 2017 under a new title, The Act of Art, though much of the text and many of the ideas are the same as they were in Legacy of Absence. Just as humans bond to other individuals and communities of memory form intergenerationally, institutions form networks.

\section{Fostering solidarity among institutions}

Solidarity among institutions creates broader support for social justice work in museums and increases the likelihood that visitors will encounter curatorial work for social justice. In turn, social justice builds the relevance of museums and the sustainability of our societies. The International Coalition of Sites of Conscience (SoC) is the primary international network for museums working for social justice. Some of the sites are big players, high-profile institutions known internationally. Some are quite small and are building their international reputations from their membership in this coalition. In general, however, SoC has a powerful model that has important implications for the rest of the museum world, cultural sector, and beyond. The power of SoC is in its networks. It organizes its members into regional networks as well as networks by topic, so that members can work together across regions. For example, a new thematic network focuses on institutionalization, incarceration, and internment.

It is the coalition's role as a network that makes it most valuable to the constituent members. Employees of member institutions describe the connections they gained to other like-minded individuals at organizations around the world as the most important benefit of participation in SoC. A Global Networks team, directed by Linda Norris and comprised of regional liaisons, connects all 200 sites in sixty-seven countries with each other and the coalition. The liaisons are able to provide culturally appropriate personal attention to members and to harness the diversity of member sites for the coalition as a whole. Norris reports that the coalition is a mix of museums that have "come to social justice" and social justice organizations that have come to see museology as a useful tool for their work. ${ }^{69}$ As a result, these organizations are very supportive to one another. The established museums can help small or newer museums with museology and the established social justice organizations can help museums understand what they know of working with communities and turning "memory into action," as Norris put it. Through the networks, the coalition disseminates models for practice and assimilates innovations from around the world. 


\section{Strong regional networking}

Two regions of the world are notable for their networking, for building institutional solidarity: Europe and Latin America. But the reasons are quite different. Europe stands out as replete with networks of all kinds. This networking, however, looks quite different from the Latin American context. In particular, the networking in Europe is not about solidarity, as it is in Latin America. The European Union is the organizing feature of the European political and cultural policy system. European bureaus of culture fund museums and cultural sites and, in so doing, work to promote the connection of each European nation to the EU. While there are many individual museums in Europe that do important curatorial work for social justice, the European networking model does not require as much attention in this chapter as the Latin American one.

Latin America is home to many museums that address one specific niche within curatorial work for social justice. They reflect on histories of mass violence and human rights violations with the goal of encouraging respect and discouraging further violence. Norris and Cuéllar at SoC noticed that the Latin American/Caribbean network stood out as a model for other regional networks, just as I had found it to be a region where museums were exemplifying solidarity. One reason for both of our observations may be that Latin Americans are, as Cuéllar and Norris put it, "standing together to respond to a shared context of attempts to erase the past for political gain." 70 The nations share recent histories of violence and authoritarian political regimes. As Latin Americans seek justice and work to remember what has happened, international efforts, such as the Inter-American Court of Human Rights, help contribute to the sense that the quest for justice in Latin America is a shared project. Here are four Latin American examples of museums with innovative projects that can build empathy and solidarity.

\section{Museo de Antioquía, Medellín, Col ombia}

The Museo de Antioquía is an art museum. In 2018, it opened a new space called Sala Cundinamarca, a physical renovation to the museum that was part of the project Museo 360, which began in 2016. The purpose of Museo 360 is to positively affect the social life of Medellín and connect the museum to its local communities. Sala Cundinamarca was a way of opening the entire back of the historic building to foot traffic, thus making the boundary between the city and the museum permeable and demonstrating much more vividly to the public that the museum is their museum. The project poses great challenges to the institution in terms of security and conservation, but that makes Museo360 all the more brave. It's a powerful message.

The museum creates a range of exhibitions, from traditional art historical ones to contemporary ones such as Erika Diettes's Relicarios (curated by Ileana Diéguez). Relicarios is a meditation on locations where there has been violence or armed conflict. Diettes spent years traveling around Colombia collecting relics of people who were murdered. She displayed the relics with pictures of the deceased cast in resin where they float eerily. Each casting looks like a tombstone and the formation of all of them together turns the gallery into a graveyard. As in many Latin American countries, the histories of civil war, dictatorships, disappearances, and drug-related violence are common themes in Colombia. With Museo360, the museum is making a statement that it is committed to relevant work such as this. 


\section{El Museo de la Memoria y los Derechos Humanos, Santiago, Chile}

Museo de Antioquía offers a practical form of solidarity to its visitors with Museo360, and so does El Museo de la Memoria. This is a memorial about the state-sponsored violence in Chile from 1973 to 1990, with the goal of working for "never again." The museum makes an effort to connect Chile to the rest of the world through violent events, including those in Chile, and by mounting exhibitions about international solidarity with Chile. This approach stands in contrast to many Holocaust museums, for example, where the decision is often to separate the Holocaust from other genocides or mass violence. A portion of the permanent exhibition displays photographs of the 190 private memorials around the country mounted on picket signs. These memorials include everything from portions of cemeteries dedicated to the victims of the golpe del estado and the dictator Pinochet to sculptural memorials in front of public buildings and memorials in the desert. Many are sponsored by the city or state. The website of the museum provides excellent catalogs of them and of sites of torture and political prisons with maps and descriptions. It also replicates a tool available in the museum that allows people to search for their loved ones and find out what happened to them from the Comisiones de Verdad. Another interactive display allows the visitor to track the kinds of justice that were meted out in each instance of violence. An oral history project is capturing the memories of those who were in exile outside of Chile during the dictatorship.

Put together, the efforts of El Museo de la Memoria demonstrate that the whole lived experience of the dictatorship is valuable and that that experience is ongoing, decades later. Through the many tools the museum puts in the hands of visitors and virtual visitors, the museum honors the need for truth, justice, and closure. In doing so, it acts in solidarity with Chilenos and brings Chilenos around the world together.

\section{Casa Memoria José Domingo Cañas, Santiago, Chile}

This is the site of a former detention facility called Cuartel Ollagüe in Santiago. Neighbors, family members, and others with personal connections to those who were held and tortured there led the efforts to preserve it. Pablo Rochet, a business owner who owned the property next door, succeeded in demolishing Cuartel Ollagüe on the eve of its legal protection. Now the ground where the building stood is a historic site. Like El Museo de la Memoria, Casa Memoria reflects on state-sponsored violence of the twentieth century and the dictatorship of Pinochet. But it also connects the violent past in Chile to state-sponsored violence occurring in Chile today. The organization is documenting abuses of human rights that are ongoing during student protests. Casa Memoria is even training young people to collect documentation at protests. Through these activities, the museum is building solidarity with its visitors and all those who the dictatorship affected.

Perhaps one day, a much larger percentage of the world's museums will band together in an international network for social justice. Right now, SoC is the closest thing to this that exists. It's not yet clear whether one day SoC will be this mega network or whether it will be a node of this network, with science museums, children's museums, and mainstream museums banding together on other nodes.

New networks are emerging through social media and other platforms online. The Empathetic Museum is a small collective of museum professionals that developed out of a gathering at the American Alliance of Museums (AAM) annual meeting in $2014 .{ }^{71}$ The 
group has developed a useful list of steps to build empathetic practice in the museum as part of its set of resources. ${ }^{72}$ The Incluseum is a larger and longer-standing operation. ${ }^{73}$ Aletheia Wittman and Rose Paquet Kinsley founded the blog in 2012. It has become one of the most important voices today in the changing practice of museums and a crucial source for tools that help museums assess bias, acknowledge White privilege, and create inclusive practices. Their guides for conversation are appropriate for meetings, break rooms, and conversations by the water cooler. The Incluseum has many collaborators who are also producing useful tools. For example, Alyssa Machada published The Dreamspace Project: A Workbook and Toolkit for Critical Praxis in the American Art Museum on the Incluseum. Wittman and Paquet Kinsley have created a necessary resource for museum professionals interested in social justice as well as a virtual space for colleagues to connect and solve problems together. MASS Action (Museums as a Site for Social Action), an initiative of the Minneapolis Museum of Art, is another burgeoning digital resource, the hallmark of which has become its Toolkit and other resources for cultural workers. Though MASS Action is not a network, these resources are drawing together a network of museum professionals online.

The Social Justice Alliance of Museums (SJAM) is an initiative of National Museums Liverpool. Since its founding in 2013, eighty museums and museum networks and fifty allied organizations have joined SJAM. In some respects, its structure and membership looks like SoC did in its early days. Although SoC has more members across the Americas, SJAM is better represented in the UK and Europe. But it also has Asian and American members. The two organizations cross over in their work as well. Whereas the work of SoC has been more focused on historic sites using the past to work for justice in the present and future, SJAM is broader. SoC, by virtue of its focused approach, has developed many, highly specific resources for museums to use in their planning and programming. A member organization can, for example, download discussion guides for timely issues from the website and integrate them into public programming. SJAM is still in the early stages of building support for a movement. Is it the same movement as SoC? Are the two groups' focuses on human rights (SoC) and social justice (SJAM) different enough to separate them? Is SoC focused enough on historical sites to the exclusion of all else to separate them? SJAM feels like a more mainstream approach to committing museums to working for social justice, and its membership reflects that. Whereas a majority of sites of conscience are topically related to a social justice concern or marginalized population, members of SJAM tend to be mainstream museums, progressive though they are. This is a valuable asset, since mainstream museums - an institutional middle majority - are where there is most room for change. In time, SJAM could become a significant hub where museums band together internationally to work for social justice.

Meanwhile, collaborations between SoC and mainstream museums can also increase the relevance of mainstream museums and the reach of the coalition. Sites of conscience can help mainstream museums to gain relevance and resonance while mainstream museums can help the movement of sites of conscience gain traction with a much larger public. The coalition has been gaining more recognition among mainstream institutions. Recently requests have been sharply increasing for SoC to train museums outside the network of members in the coalition's signature method, "Essential Dialogue." The support the coalition offers these organizations is a fee-for-service training program that extends into institutional support. Interpreters or other staff members learn to guide visitors from identifying with a narrative they're seeing to understanding how history connects to them to going back to their communities and further engaging with that history or taking some kind of action. Then, SoC helps 
the client organization assess how best to support the work on dialogue within the organization, from revising the mission or strategic plan to educating board and staff members about the importance of tying their work to human rights.

In 2014, the coalition developed a department of Membership, Methodology, and Practice in response to the demand for training. The department had added several staff members by 2017 and still could not keep up with demand. In the first three years of the new department, SoC trained 3,000 museum professionals. The organizations seeking support from the coalition range from large, established mainstream institutions such as the Smithsonian and every region of the National Park Service to small historic sites and museums. These training programs provide an important revenue stream for SoC, but they also allow SoC to work toward building a movement wherein as many different organizations as possible are using their methodology and working for social justice. Crucially, the training program allows SoC to move beyond members and the kinds of organizations that become members to include other kinds of museums and institutions - science museums, children's museums, and mainstream museums, for example.

\section{Challenging and expanding personal identities}

Engaging visitors in individual stories, building communities of memory, and building networks of solidarity represent increasing challenges. But the most challenging way of inspiring empathy and solidarity is simultaneously intimate and community-oriented. Using a shared history to bring groups together is tricky and delicate, especially so when the history in question challenges visitors to reimagine, expand, or otherwise change their own personal identities. What more intimate position could a museum be in than asking a visitor to think differently about herself and her family? Yet museums do this all the time. When it works, illuminating a shared history can cultivate solidarity between groups in a lasting way, one that can even be passed down for generations.

The African Presence in México offered a profound example of this type of connection, as much for staff as for visitors. In the sections that follow, I will look at a range of curatorial techniques from this large project that went into helping visitors expand their own senses of identity. First, however, I will provide a brief history of the project and its significance.

This exhibition was about a forgotten chapter in Mexican history. Mexicans forgot the history of the African presence for political reasons. While on view at the NMMA, The African Presence drew 114,805 visitors, a close second for record attendance. ${ }^{74}$ The African heritage of Mexico threatened Mexican identity. Mexicanidad was forged in the Mexican Revolution. In particular, Mexicanidad refers to Mexican identity as Indigenous and Spanish - mestizo. What's more, acknowledging African heritage threatened to move Mexicanidad lower in the hierarchy of the casta system, the social hierarchy imposed on Mexico by the Spanish colonizers. In the casta system, each of sixteen different racial pairings has its own name and set of social expectations. Spanish + Indigenous $=$ mestizo. Spanish + African $=$ mulato, a lower category. After hundreds of years of Spanish colonization, the casta system became an entrenched way of thinking in Mexico.

Spaniards in Spain commissioned "casta paintings" to help them understand and control the subjects of their colony. ${ }^{75}$ Forms of these were common in all Latin American countries with race-based caste systems. Ilona Katzew, a curator of Latin American art, describes the paintings this way: 
Each image portrays a man and woman of different races with one or two of their children, and each is accompanied by an inscription that identifies the racial mix depicted. In addition to presenting a typology of human races, most casta paintings include samplings of local objects, food products, flora, and fauna of the New World. ${ }^{76}$

The casta paintings illustrated the social station of each category. "Español y Negro produce Mulato" (Figure 1.10) emphasizes how poor a choice this pairing is for the Spaniard by showing a scene of domestic violence, of a Black woman in power over a Spanish man, and of unattractive living conditions.

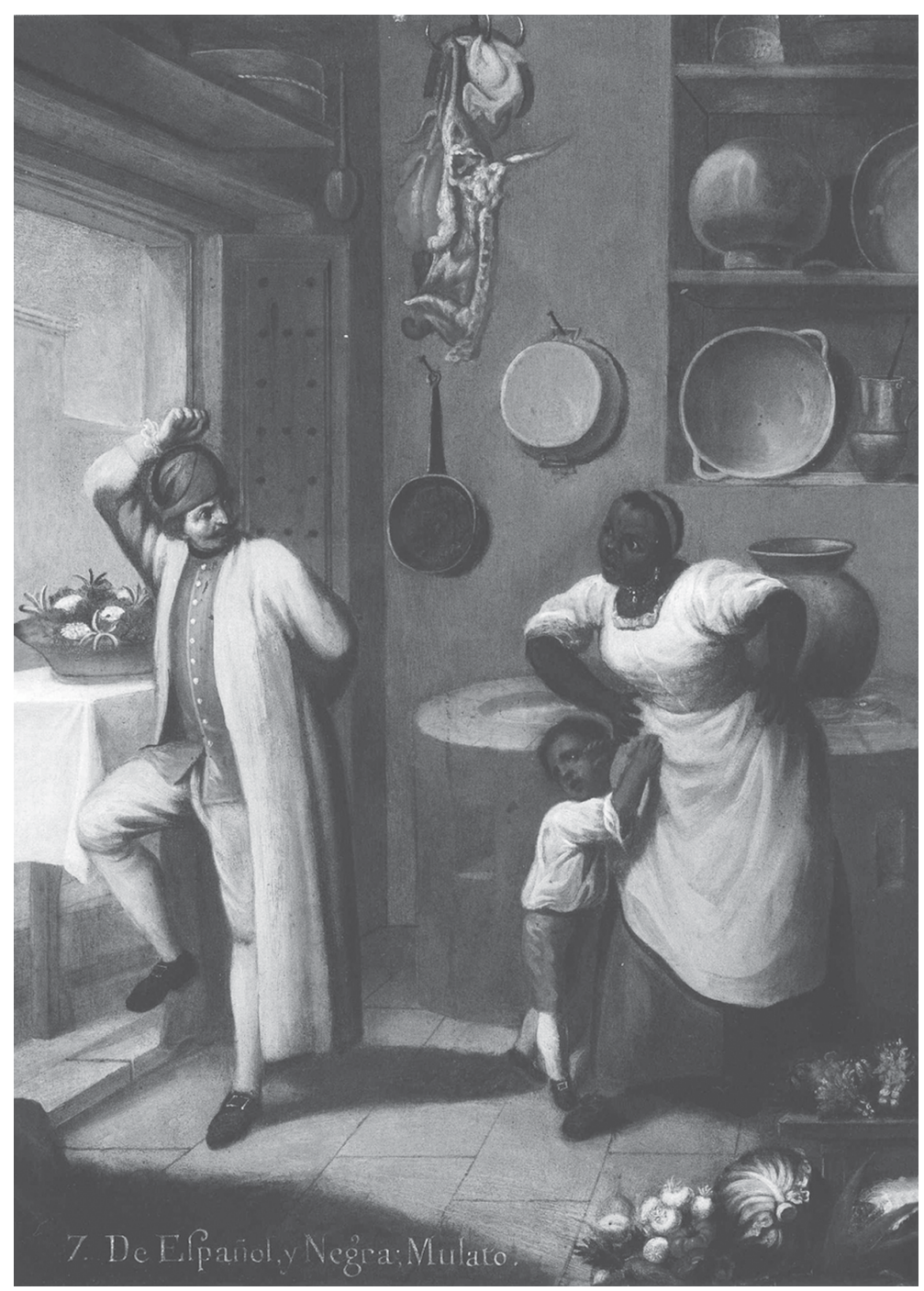

FIGURE 1.10 Anónimo novohispano, "De español y negra produce mulato," Segunda mitad del siglo XVIII, oleo sobre lámina de cobre, $43 \mathrm{~cm}$ x $32 \mathrm{~cm}$, Colección Museo Soumaya. Fundación Carlos Slim, Ciudad de México, México. Photo by Javier Hinojosa, courtesy of the National Museum of Mexican Art with kind permission from Museo Soumaya. 
Mexicans banded together to cast off Spanish rule during the Mexican War for Independence regardless of class, but the Mexican Revolution was different. Indigenous Mexicans and Mexicans of African descent fought a kind of class warfare against the criollos, an elite class of native Mexicans of full Spanish descent. In the wake of the Revolution the new Mexican government needed to heal a nation that was torn apart by ten years of civil war that killed 6 to 18 percent of the population. ${ }^{77}$ President Álvaro Obregón hired José Vasconcelos as the nation's first Minister of Education in the postwar period. His charge was precisely reunifying Mexico and educating Mexicans about their national identity.

Mexicanidad as we now know it was Vasconcelos's brilliant idea. It was succinct and it was readily illustrated and thereby was easily taught to the largely illiterate Mexican population. ${ }^{78}$ Vasconcelos hired muralists to paint his vision of Mexicanidad on the walls of the capital. (Diego Rivera is the most well-known.) Vasconcelos's vision, however, was specifically one in which the African presence in Mexican identity was ever-diminishing as the Mexican people "progressed" toward a "bronze race" that included only Indigenous and Spanish elements. Vasconcelos was racist. ${ }^{79} \mathrm{He}$ envisioned a day when Mexicans would form a superior "bronze race" or "raza cósmica," taking the best of the Spanish and Indigenous races and leaving the African behind. ${ }^{80}$ His notion of Mexicanidad as mestizaje, and of the Mexican as mestizo (in the sense of the word defined by the casta paintings), quickly took hold. It was also patently false. During colonial times, the population of enslaved Africans was 50 percent larger than the Spanish population. ${ }^{81}$ Thus the linguistic omission enabled Vasconcelos to erase more than 400 years of the African presence in Mexico at one fell swoop.

The museum's project, then, was explicitly an anti-racist one. The museum's goals for social justice were to support the bourgeoning Afro-Mexican movement for equitable access to Mexican identity, to educate Mexicans about a more ample and inclusive Mexicanidad, one in which many quintessentially Mexican things are recognized as being of Afro-Mexican origin, and to bring Mexicans and African-Americans together in the US to work for social change on the basis of shared history and a history of collaboration.

The museum's exploration of the topic happened in tandem with Afro-Mexican organizing. ${ }^{82}$ In 1992 Mexico officially recognized its African "third root," but did very little to educate Mexicans about it. In 1997, two separate Afro-Mexican groups organized gatherings to explore Afro-Mexican identity. ${ }^{83}$ Ever since, Afro-Mexican identity has been evolving and Afro-Mexicans have become more vocal. The museum supports the Afro-Mexican movement. The exhibitions' goal to set the historical record straight is part of the museum's effort to diminish prejudices among Mexicans and against certain Mexicans. But Mexico is still a pigmentocracy. ${ }^{84}$ One project at an institution in the US cannot undo the casta system, even with a five-year tour in Mexico. But it can help foster conversation about race in Mexico. ${ }^{85}$

Tortolero, President of the NMMA, lamented the worsening state of race relations in the US. The division between African-Americans and Mexicans seemed to be intensifying as Latinos became the largest group of color in the US (with Mexicans as the largest subset of that group). If the two groups worked together to demand their fair share of resources, they would have so much more than what either group had at the moment. Tortolero felt that educating these groups about their shared history could help. He hoped that The African Presence would bring the two groups together for precisely this kind of political work for positive social change. 


\section{Transferring trustworthiness with key objects}

As museums work to expand visitors' notions of their own identities, one technique is using significant objects. Objects that have both a strong cultural connection to visitors' existing senses of identity and clearly demonstrate the new facet of identity can be sources of revelation. One of the biggest hurdles Cesáreo Moreno, Visual Arts Director of the NMMA and co-curator of The African Presence, anticipated with the exhibition was getting Mexicans to accept the history of the African presence. A student could go all the way through college in Mexico and never know about it.Yet the deeply historical casta paintings plainly illustrated the presence of Afro-descendants in Mexico in a way that no one could deny. The comments from visitors support Moreno's assertion. One 57-year-old visitor from East Chicago, IN wrote "We came to view your 'Casta exhibit' - how enlightening. Yo siempre [he] sentido mucho orgullo ser Mexicana y entender nuestra cultura pero que bien aprender esta etapa de nuestro Mexico." 86 A number of comments came from Mexican visitors more than 50 years of age who were proud of this heritage, even when they sometimes suspected other Mexicans would not be.

Lest it seem like the use of the castas in this situation was simplistic, I'd like to share my favorite of Moreno's close readings from that exhibition. Showing the casta paintings engaged the Mexican visitor, but it also exposed the colonial Spanish agenda. As Moreno put it, casta paintings were a political campaign. ${ }^{87}$ Moreno was waging a new campaign. When he would take visitors through the exhibition, he would pause in front of one of the casta paintings (Figure 1.10) and point out the menudo and tripitas, classic Mexican foods made from offal, hanging in the kitchen of the Spaniard and mulata. "What could be more Mexican than menudo?" he'd ask. And then he'd tell the visitors how the Spanish colonizers kept the expensive cuts of red meat for themselves, while Indigenous Mexicans got a lot of their protein from insects. Africans, however, made many dishes, such as menudo, from offal. The story of menudo allowed Moreno to engage Mexican visitors in understanding that the Afro-Mexican history is their history and to demonstrate the pervasive nature of the African presence throughout Mexico. One strong image, replete with content about the Spanish and African origins of Mexican identity, could, through its unquestionable provenance and clear narrative nature, help visitors to reshape their own identities in an inclusive way.

I used this same technique in the sister exhibition of The African Presence, Who Are We Now?, which I curated. Though, in my case, the object was a map that the museum's graphic designer made to tell a story that grappled two groups together. Who Are We Now? was divided into three sections: Roots, Resistance, and Recognition. "Roots" investigated early connections between African-Americans and Mexicans. The story of Mexicans coming to the aid of enslaved African-Americans by connecting the Underground Railroad to Mexico was the most exciting. Thirty-six years passed between Mexico's abolition of slavery (1829) and abolition in the US (1865). During that time, a few thousand of those 100,000 people who sought freedom via the Underground Railroad made the journey down to Mexico. This was much shorter for some than traveling to the northern US or Canada. This story was my equivalent of the casta paintings.

If I could show collaboration between Mexicans and African-Americans through the story of the Underground Railroad, no one would doubt their potential to work together. I was able to do this thanks to the National Park Service's identification of a "stop" on the Underground Railroad in Mazamitla, Mexico. This story gave my exhibition and its goals legitimacy with visitors. It also gave me the opportunity to explain the differing social constructions of race 
in the two countries to help each group better understand the other. In the casta paintings Moreno found material that had such legitimacy with his audience that it gave credence to the subject matter as well. So it was with the Underground Railroad.

\section{Mobilizing shared vocabularies: verbal and visual}

Many anthropologists and linguists agree that when people share a vocabulary, they come together as a community, and conversely, when a community spends time together, it develops a shared vocabulary. As the linguistic anthropologist Bambi Schieffelin put it,"everyday speech activities are ... socializing activities, the basis for the transmission and reproduction of culture." 88 In the setting of a fifty to seventy-five-word label or a 100 to 250-word didactic panel, every word does count. Most curators work intensely on their texts, their ambassadors in the gallery. The NMMA strives for a voice that is colloquial and welcoming, especially in the Spanish. The texts at the NMMA use terms that give more power to the Mexican population. For example, "pre-Cuauhtémoc" replaces "pre-colonial" because it uses an Indigenous Mexican leader as the cultural referent. "Latino" replaces "Hispanic" as a refusal to call people by the name of their conquerors. "Culturally specific" avoids the belittling term "minority." This vocabulary is part of the mestizo museology of the NMMA. These terms appear in the mainstream lexicon. But the museum blends and changes their meaning both through the context in which it uses them and through more overt and intentional changes to terms' definitions. "Traditional" is another culture-crossing term. Whereas dominant Anglo culture often uses the term "traditional" to designate something primitive, akin to folk art, the museum uses it to designate longevity and cultural survival "in the face of domination." ${ }^{9}$

Cultures also share visual vocabularies. This is what makes internet memes funny, functional, and viral. Snippets of popular culture - visual cues that everyone in a certain nation, language group, or cultural background shares - get repurposed to humorous ends that resonate precisely because of the common currency they represent. With attention and a little luck, curators can use visual vocabularies to connect visitors to one another and to the museum inside the gallery as well. Moreno told me the story of his first tour of The African Presence for visitors. He was leading a group of African-American women. He feared that, coming from different communities, he and the visitors did not share a vocabulary, and that he would make some gaffe as a result. In fact, what he found in giving the tour was that the materials in the gallery gave him and the visitors a shared vocabulary and thus made them a kind of ephemeral community. One of the pieces that gave them a shared vocabulary was the triptych by Alfred Quiroz that the museum commissioned (Figure 2.9). The painting, La Raza Kózmika, spoke of stereotypes, hate crime, racial mixing, the casta system, and the shared histories of Mexicans and African-Americans. Moreno found that building this common vocabulary for visitors was so successful that he planned to use this technique again.

I used a visual form of this tool in Who Are We Now? I intended to demonstrate to visitors that the art forms Mexicans and African-Americans share constitute a shared vocabulary. Throughout the twentieth century, African-Americans found inspiration in the work of the Mexican muralists. As muralists, such as Diego Rivera, came to work on commissions in the US in the 1930s and '40s, and African-Americans traveled to Mexico to work with them, African-Americans began to incorporate murals into their culture-building and educational efforts. Ultimately, in the 1960s and '70s, a Black mural movement took place across the US. Printmaking, again something Mexican and African-American artists shared in Mexico, also featured prominently in Black initiatives in the US. The Black is Beautiful campaign and the 
Black Panthers, for example, are both well known for their prints, which allowed quick and inexpensive dissemination of information and arguments throughout Black communities. ${ }^{90}$ In both the Mexican and African-American cases, the printmaking also enabled the rapid dissemination of an iconography - a shared visual vocabulary - that further bound the group together and offered keys to members who wished to broadcast their identity. ${ }^{91}$

I investigated resistance to the dominant White culture in the US on the part of both the Mexican and African-American communities. Connecting the Mexican Revolution and the Harlem Renaissance brought the two groups together through something very dear to each. ${ }^{92}$ The denouement of the Mexican Revolution happened simultaneously to the Harlem Renaissance. ${ }^{93}$ Since Mexicans consider themselves to be mestizo, the fight for civil rights in Mexico has been largely about class and less about race. Numerous scholars, including Romare Beardon, Harry Henderson, Lizetta Le-Falle Collins, and Shifra Goldman, have documented this very focus on Indigenous Mexicans as an inspiring contemporary of the Harlem Renaissance. ${ }^{94}$

African-Americans were also significant participants in the exodus of artists to Mexico during McCarthyism of the 1950s. The Taller de Gráfico Popular (TGP), a printmaking workshop in Mexico, was an important venue for collaboration between Mexican artists and African-American artists such as Elizabeth Catlett, Charles White, and Margaret Burroughs. They worked together to combat injustice and to educate the Mexican public (only 37 percent of whom were literate by 1940)..$^{95}$ Cultural cross-pollination was important here too. Catlett illustrated the "Black is Beautiful" campaign from afar, and Burroughs returned from her time in Mexico to found the DuSable Museum of African American History in 1957 with a group of other Chicagoans.

Contemporary artists contributed powerfully to this tactic by demonstrating that the cultural cross-pollination and collaboration of the past has blossomed into solidarity in the present. I showcased artists who reached across Black/Brown lines in appeals to multiple groups, as with Favianna Rodríguez's "War Targets Poor People of Color" (Figure 1.11) or Carlos Cortéz's "Draftees of the World Unite!..." (c. 1960).

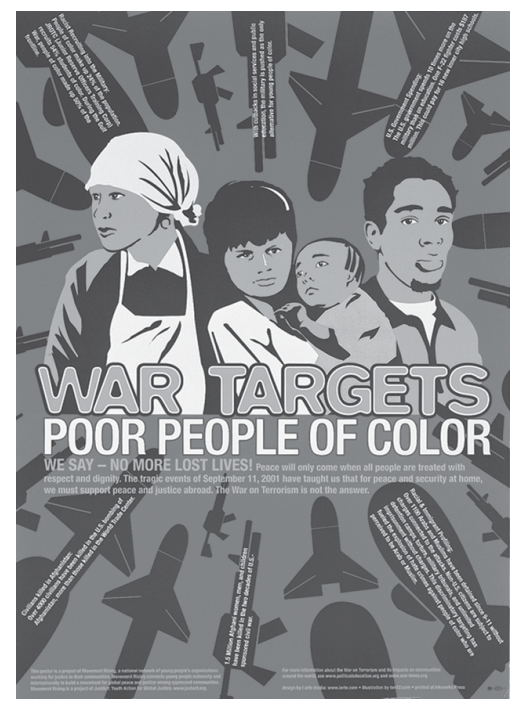

FIGURE 1.11 "War Targets Poor People of Color," by Favianna Rodríguez and Alfonso Jaramillo, i arte, 2002, offset poster, Permanent Collection of the NMMA 2003.327. Courtesy of Favianna Rodríguez, Alfonso Jaramillo, i arte, and the National Museum of Mexican Art. 
I also showed pieces by Mexican artists who hailed African-American or African champions across racial lines, as with Malaquías Montoya's Steven Biko and Malcolm X (1992), Chaz Boriquez's Malcolm as the Phoenix (1993) (Figure 1.12), and Carlos Cortéz's Ben Fletcher.

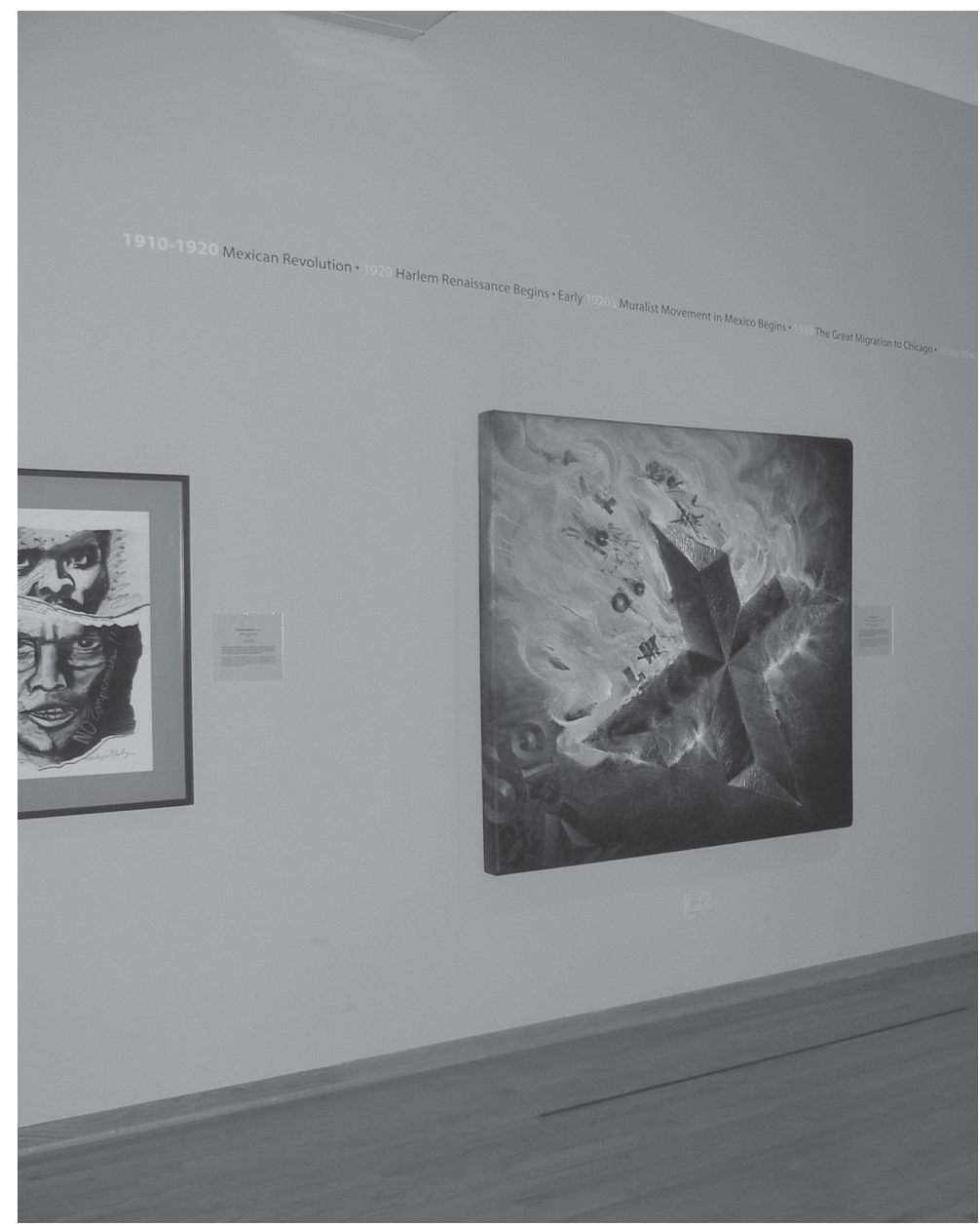

FIGURE 1.12 Gallery shot of Who Are We Now? showing (left to right) "Malcolm X \& Steven Biko" by Malaquias Montoya (1992) and "Malcolm as the Phoenix" by Chaz Bojorquez (1993). Image courtesy of National Museum of Mexican Art.

In the exhibitions at the NMMA and in my own mind, the idea of joining these two identities and histories through iconography came to life in the person and work of the African-American sculptor and printmaker Elizabeth Catlett. Catlett made her life in Mexico for many decades, married a Mexican artist, and raised three Mexican sons. But she remained connected to Black struggles in the US and viewed herself as a Revolutionary Black Artist. ${ }^{96}$ She was an important part of the Black Arts Movement and, by the early 1970s, was nationally accepted in the US as a significant Black Nationalist Artist. ${ }^{97}$ 
Near the end of her life, she visited the NMMA. We were opening The African Presence. We prepared for her visit for weeks, and an air of reverence pervaded as she toured the museum. Even in her nineties, Catlett lucidly and generously commented on our work. Our exhibition coincided with a solo show of her prints at the Art Institute of Chicago, an elite White institution. But on this night it was transformed. A delegation of staff from the NMMA attended the soiree. Gathering in the winter night to enter the museum, we were surrounded by Chicago's glittering Black elite. Swirling inside amidst snow and canapés, velvet, sequins, and glorious hats, the power of Catlett - this human touchstone - in both communities was undeniable.

\section{Conclusion}

The heart of this chapter is making outsiders matter like family. This could mean outsiders to a culturally specific museum, outsiders in a narrative, or simply those with whom visitors or staff do not yet identify. Many of the exhibitions in this chapter provide answers. Curators can identify materials that can build visitors' trust in the narrative of the exhibition even when it asks visitors to revise their own personal stories. This is what happened with the casta paintings in The African Presence and the Underground Railroad in Who Are We Now? Hull-House made visitors feel that they mattered like family by inviting them into intimate spaces and serving them tea. The Chicago History Museum made visitors feel at once like outsiders and insiders by creating a living room space in which to share individual stories that differed dramatically from those of some visitors. The Verzetsmuseum also built homes for visitors to explore, in which they could have intimate experiences such as participating in conversations around the dining room table, brushing past family members' coats in the entryway, and peering into cabinets and bedrooms. With The African Presence, the NMMA also found useful tools that apply to the creation of narrative rather than exhibit design:

- Learn why those who may seem like outsiders truly are like family to the visitor, the staff, or both.

- Practice this knowledge inside the organization and independently with friends and family. Try telling others the story.

- Know that your job depends on properly providing this welcome. Take the institutional commitment to the highest level.

There are many barriers to empathy. Growing disparities in resources, especially wealth, hinder feelings of empathy. It is difficult to feel empathy when you have more resources than others. A study from Psychological Science in 2016 shows that wealthier people are less likely to pay attention to other human beings, whether it be in passing on the street or even images of strangers' faces. Also in 2016, a study in The Journal of Cross Cultural Psychology by W.J. Chopik, E. O'Brien, and S.H. Konrath looked at empathy and the tendency to take the point of view of another in sixty-three countries. Of the top ten most empathetic nations in the study, only one was European (Denmark), and the US ranked seventh. ${ }^{98}$ Chopik et al. found, perhaps not surprisingly, that the most empathetic nations also "have higher levels of collectivism, agreeableness, conscientiousness, self-esteem, emotionality, subjective well-being, and prosocial behavior." It seems that improving empathy is almost a universally useful goal for a cultural institution. But for those who see themselves as working for 
social justice, cultivating empathy is essential. Solidarity enables work for social justice. But empathy enables solidarity. In curatorial work for social justice, helping individuals feel empathy is the first step.

\section{Notes}

1 Linda Norris and Julieta Cuéllar, interview with Global Networks Team, International Coalition of Sites of Conscience, phone, March 8, 2017.

2 Henri Tajfel. "Experiments in Intergroup Discrimination." Scientific American 223, November 1970: 96-102

3 Giulia Enders, Gut:The Inside Story of Our Body's Most Underrated Organ, trans. David Shaw, 1st edn (Vancouver: Greystone Books, 2015), 152

4 Philip Zimbardo, The Lucifer Effect: Understanding How Good People Turn Evil, 1st edn (New York: Random House, 2007).

5 Damasio, Looking for Spinoza, 163.

6 Damasio, 162.

7 Ira Chaleff and Philip Zimbardo, Intelligent Disobedience: Doing Right When What You're Told to Do Is Wrong, 1st edn. (Oakland, CA: Berrett-Koehler Publishers, 2015), 84.

8 Chaleff and Zimbardo, 84.

9 From a neurological standpoint, empathy is a natural part of the way the brain functions. Boris C. Bernhardt and Tania Singer, "The Neural Basis of Empathy," Annual Review of Neuroscience 35, no. 1 (2012): 1-23; Jean Decety and Claus Lamm, "Human Empathy through the Lens of Social Neuroscience," The Scientific World Journal 6 (September 20, 2006): 1146-1163.

10 Damasio, Looking for Spinoza, 115.

11 Elaine Hatfield, John T. Cacioppo, and Richard L. Rapson, Emotional Contagion (Cambridge; New York; Paris: Cambridge University Press; Editions de la Maison des Sciences de l'homme, 1994), 19, 38.

12 John Falk, Identity and the Museum Visitor Experience (Walnut Creek, CA: Left Coast Press, 2006); John H. Falk and Lynn D. Dierking, The Museum Experience, annotated edition (Washington, DC: Whalesback Books, 1992).

13 James Elkins, Pictures \& Tears: A History of People Who Have Cried in Front of Paintings (New York: Routledge, 2001).

14 Nakamura in Janet C. Marstine, The Routledge Companion to Museum Ethics: Redefining Ethics for the Twenty-First Century Museum, 1st edn (London: Routledge, 2011), 13.

15 Here is a range of approaches: Nina Simon, The Participatory Museum (Santa Cruz, CA: Museum 2.0, 2010); Sanford Sivitz Shaman, The Duty of Art: Museums and Social Consciousness, http://sirisbibliographies.si.edu/ipac20/ipac.jsp?uri=full=3100001 !1253 !104\&profile=biball; Lois $H$. Silverman, The Social Work of Museums (London; New York: Routledge, 2010); James Cuno et al., Whose Muse?: Art Museums and the Public Trust (Princeton, NJ: Princeton University Press, 2006); Diane Grams, Producing Local Color: Art Networks in Ethnic Chicago (Chicago; London: University of Chicago Press, 2010); Bill Adair, Benjamin Filene, and Laura Koloski, eds, Letting Go?: Sharing Historical Authority in a User-Generated World, 1 edn (Washington, DC: Pew Center for Arts \& Heritage, 2010); Bettina Messias Carbonell, Museum Studies: An Anthology of Contexts, 2 edition (Malden, MA: Wiley-Blackwell, 2012); Kylie Message, Museums and Social Activism: Engaged Protest (London; New York: Routledge, 2014); Robert R. Archibald, The New Town Square: Museums and Communities in Transition (American Association for State and Local History) (Walnut Creek, CA: AltaMira Press, 2004); Amy K. Levin, Defining Memory: Local Museums and the Construction of History in America's Changing Communities, 2007.

16 Edith Doron, "At Hospitality's Threshold: From Social Inclusion to Exilic Education," Curator: The Museum Journal 52, no. 2 (April 2009): 171, https://doi.org/10.1111/j.2151-6952.2009.tb00342.x. Marguerite La Caze suggests some limits to the model of hospitality. She writes about it in terms of refugees seeking asylum and immigration and more permanent arrangements of citizenship, writing 
that "Hospitality accounts for our initial response" to people, "but does not articulate the terms of a continuing interaction." Marguerite La Caze, Wonder and Generosity: Their Role in Ethics and Politics (Albany, NY: SUNY Press, 2013), 133.

17 Nina Simon and Jon Moscone, The Art of Relevance (Museum 2.0, 2016); Nina Simon, "Museum 2.0," http://museumtwo.blogspot.com/.

18 "First-voice" refers to culturally specific first-person stories, in this case, Mexicans telling Mexican stories.

19 "Guidestar Premium Report on the National Museum of Mexican Art," January 8, 2018, www. guidestar.org/ViewPdf.aspx?PdfSource=0\&ein $=36-3225519$.

20 "Training for Tour Guides on The African Presence in México with Cesáreo Moreno" (Mexican Fine Arts Center Museum, Chicago, February 10, 2006).

21 "Comments from the Guest Book during the Run of The African Presence in México" (National Museum of Mexican Art, Chicago, March 2006).

22 Simon and Moscone, The Art of Relevance, 108-109.

23 See Michael Warner, Publics and Counterpublics (New York: Zone Books, 2002). And Jennifer Barrett, Museums and the Public Sphere (Chichester:Wiley-Blackwell, 2011), 119.

24 van der Horst, Liesbeth, Het Verzetsmuseum Amsterdam: The Dutch Resistance Museum (Amsterdam: Verzetsmuseum Amsterdam, 2007), 185.

25 “Ondernemingsplan-2013-2016-Verzetsmuseum Amsterdam," Strategic Plan, Annual Report (Amsterdam: Verzetsmuseum, 2016), 9, www.verzetsmuseum.org/uploads/media_items/onder nemingsplan-2013-2016-verzetsmuseum-amsterdam.original.pdf.

26 Liesbeth van der Horst, interview with Liesbeth van der Horst, Directeur,Verzetsmuseum, personal, January 27, 2017.

27 Andrea Witcomb, Re-Imagining The Museum: Beyond the Mausoleum, 1st edn (London; New York: Routledge, 2003); Wendy Brown, Regulating Aversion: Tolerance in the Age of Identity and Empire (Princeton, NJ: Princeton University Press, 2006).

28 Brown, Regulating Aversion, 16.

29 Brown, 101.

30 Ibid, 114-115.

31 Ibid, 137.

32 Ibid, 139-141.

33 Tony Bennett in Sharon Macdonald, A Companion to Museum Studies (Chichester:Wiley-Blackwell, 2011), 263.

34 Tony Bennett, “Civic Laboratories," Cultural Studies 19, no. 5 (September 1, 2005): 525.

35 Edward T. Linenthal, Preserving Memory: The Struggle to Create America's Holocaust Museum (New York: Columbia University Press, 2001), 168.

36 Linenthal, 169.

37 I use the term "queer" to refer to anyone not specifically and exclusively heterosexual because I find it to be the most inclusive term. The common acronym LGBTQ strikes me as less inclusive because there are those who fall between its cracks. Likewise, I don't use "gay" as a general term because I feel that it excludes those who are queer but not homosexual.

38 Simon, The Participatory Museum, Chapter 4.

39 Sandell in Janet C. Marstine, The Routledge Companion to Museum Ethics: Redefining Ethics for the Twenty-First Century Museum, 1st edn (Routledge, 2011), 140.

40 Constance Classen in Levent and McRainey Nina Sobol Levent, Alvaro Pascual-Leone, and Simon Lacey, Multisensory Museum: Cross-Disciplinary Perspectives on Touch, Sound, Smell, Memory, and Space, 2014, 76, http://public.eblib.com/choice/publicfullrecord.aspx?p=1648843.

41 Fiona Candlin, Art, Museums and Touch (Manchester; New York: Manchester University Press; distributed in the United States by Palgrave Macmillan, 2010), 82-84.

42 Candlin, 85.

43 Levent and McRainey in Levent, Pascual-Leone, and Lacey, Multisensory Museum, 79. 
44 "Jane Addams Hull-House Museum at UIC to Reopen," ABC7 Chicago, http://abc7chicago. com/archive/7654372/; Lisa Lee, "National Endowment for the Humanities Interpreting America's Historic Places Implementation Grant \#20080827-BR" (Jane Addams Hull-House Museum, 2008), 8 .

45 The term "compassion fatigue" originated in the context of healthcare and domestic caregiving. In the 1950s, the phrase originally described nurses who burned out as a result of becoming too emotionally involved in the well-being of their patients. The term migrated from healthcare, where it is certainly still relevant, to journalism, where it came to mean the dwindling ability to feel compassion on the part of readers or viewers who become overwhelmed by distressing news. A study by Katherine Kinnick et al. suggests that widespread compassion fatigue in the general public is "a situational variable, rather than a personality trait." They attribute the rise in public compassion fatigue to "the nature of contemporary media coverage." Katherine N. Kinnick, Dean M. Krugman, and Glen T. Cameron, "Compassion Fatigue: Communication and Burnout toward Social Problems," Journalism \& Mass Communication Quarterly 73, no. 3 (September 1, 1996): 687-707. Since their article was published in 1996, it's only fair to say that the nature of media coverage has become even more overwhelming, constant, and difficult to digest and that compassion fatigue has probably been rising further since then.

46 Steve Buscemi, The Voices of Eastern State, Audio Tour (Philadelphia, PA, 2015).

47 "Guidestar Premium Report on Eastern State Penitentiary," Financial Report (Philadelphia, PA: Eastern State Penitentiary, 2018), 2, www.guidestar.org/ViewPdf.aspx?PdfSource=0\&ein=311627155. Sean Kelley, "Beyond Neutrality," AASLH History News: The Magazine for the Association of State and Local History 72, no. 2 (Spring 2017): 26.

48 The reason is that the US passed legislation to criminalize drug use in a new way, imposed mandatory sentencing, and created the "three strikes" rule, which keeps three-time repeat offenders in prison for life.

49 There are various reasons for this including the devastating effects of poverty in black communities, which has driven people to substance abuse and crimes of subsistence. The allocation of harsher penalties to the use and sale of crack cocaine than powdered cocaine was also an important factor. Since crack was much more prevalent in black communities in the 1980s and powdered cocaine was much more prevalent among White users, Black people bore harsher penalties for committing the same crime as White people.

50 Elizabeth Tinker, "Prisons Today: Questions in the Age of Mass Incarceration," Summative Report to Funder (Philadelphia, PA: Eastern State Penitentiary, September 21, 2016), 6-7.

51 Catherine Lewis, The Changing Face Of Public History: The Chicago Historical Society And The Transformation Of An American Museum, illustrated edition (DeKalb, IL: Northern Illinois University Press, 2005), 34.

52 Gary Johnson, "Letter from Museum President Gary Johnson to the CHM Trustees and Staff," letter, fall 2017.

53 Randy Adamsick, “CHM Diversity, Innovation, Social Justice” (Chicago History Museum, 2017).

54 Randy Adamsick, Development Director, CHM, “Letter," January 8, 2018.

55 Dora Apel, "On Looking: Lynching Photographs and Legacies of Lynching after 9/11," American Quarterly 55, no. 3 (September 1, 2003): 457-478; Carbonell, Museum Studies, 348-350.

56 A large body of literature critiques the book Without Sanctuary and the exhibition at its many venues. James Allen, ed., Without Sanctuary: Lynching Photography in America (Santa Fe, NM: Twin Palms, 2000); Bettina M. Carbonell, "The Afterlife of Lynching: Exhibitions and the Re-Composition of Human Suffering," The Mississippi Quarterly 61, no. 1-2 (2008): 197+; Apel, “On Looking”; Wendy Wolters, "Without Sanctuary: Bearing Witness, Bearing Whiteness," JAC 24, no. 2 (January 1, 2004): 399-425; Duane J. Corpis and Ian Christopher Fletcher, "Without Sanctuary," Radical History Review 2003, no. 85 (December 21, 2003): 282-286.

57 “Without Sanctuary," http://fnewsmagazine.com/2005/10/without-sanctuary/.

58 Arielle Weinenger, interview with curator, Illinois Holocaust Museum and Education Center, personal, July 18, 2011. 
59 Howard Reich, "Holocaust Museum, New 3-D Technology Bring Survivor Stories to Life," chicagotribune.com, www.chicagotribune.com/entertainment/museums/ct-illinois-holocaustmuseum-3d-survivor-stories-ent-0428-20160426-column.html; Lisa Bertagnoli, "Illinois Holocaust Museum Bets on Rock 'n' Roll,' Crain's Chicago Business, www.chicagobusiness.com/article/ 20170121/ISSUE01/170129968/illinois-holocaust-museum-bets-on-rock-n-roll.

60 Chris Foster, "Collection of Letters from Students from Warsaw Community High School, Warsaw, IN,” March 29, 2011, Illinois Holocaust Museum and Education Center.

61 Susan Sontag, Regarding the Pain of Others (New York: Picador, 2004).

62 "Teacher Feedback from Workshop Evaluations" (Illinois Holocaust Museum and Education Center, Skokie, IL, n.d.).

63 Clifford Chanin, interview with curator, Legacy of Absence, phone, October 11, 2011.

64 "Legacy of Absence Mission Statement" (Illinois Holocaust Museum and Education Center, Skokie, IL, January 23, 2008).

65 Legacy closed for renovations to the museum in 2016 and will reopen in 2018.

66 Alison Landsberg, Prosthetic Memory: The Transformation of American Remembrance in the Age of Mass Culture (New York: Columbia University Press, 2004).

67 Chanin, interview with curator, Legacy of Absence, October 11, 2011.

68 Clifford Chanin, interview with curator, Legacy of Absence, phone, June 17, 2013.

69 Linda Norris, Update on Global Networks Program at the Coalition of International Sites of Conscience, Phone, April 24, 2019.

70 Norris and Cuéllar.

71 "The Empathetic Museum,”'The Empathetic Museum, http://empatheticmuseum.weebly.com/.

72 “Steps for Building Empathetic Museums," http://empatheticmuseum.weebly.com/uploads/4/4/ 9/8/44983495/empatheticmuseum_steps_v01.pdf.

73 Aletheia Wittman and Rose Paquet Kinsley, "The Incluseum," the incluseum, July 2012, http:// incluseum.com/. Nearly 3,800 people follow@incluseum on Twitter; 1,100 people follow the blog.

74 Charles Storch,“'National' Status,” Chicago Tribune, December 5, 2006, http://articles.chicagotribune. com/2006-12-05/features/0612050232_1_latino-museum-museum-s-board-national-museum.

75 Ilona Katzew, Casta Painting: Images of Race in Eighteenth-Century Mexico / Ilona Katzew (New Haven, CT: Yale University Press, 2004), 1, 4. Early castas (1711-1760) are more celebratory about the criollismo or racial mixing of the colony, and later works are more focused on legitimizing racial hierarchy (1760-1790).

76 Ilona Katzew, 5.

77 The figure varies dramatically depending on whether you go with the official Mexican census figures, which were the worst in Mexican history directly following the Revolution, or whether you account for the population growth directly preceeding the Revolution. "Missing Millions: The Human Cost of the Mexican Revolution, 1910-1921, (c) Robert McCaa, 2001," www.hist.umn. edu/ rmccaa/missmill/.

78 "At the outset of the Mexican Revolution of 1910, only 15\% of the population was literate. After the revolution, literacy campaigns made it possible to increase literacy rates to 37\% [by] 1940." "Mexico Nonformal Education,” http://education.stateuniversity.com/pages/986/Mexico-NONFORMALEDUCATION.html; Enrique Krauze, Mexico: Biography of Power (New York: Harper Perennial, 1998), 391-392. Education was a significan focus during Álvaro Obregón's presidency and beyond.

79 Krauze, Mexico, 502. Vasconcelos was also a supporter of Hitler.

80 José Vasconcelos, La raza cosmica; misión de la raza iberoamericana (Madrid Aguilar, 1966). Originally published in 1925.

81 "Training for Tour Guides on The African Presence in México with Cesáreo Moreno." Damarys Ocaña, "Rediscovered Raíces," Latina Magazine, May 2006, print edition, sec. Arte.

82 Anani Dzidzienyo and Suzanne Oboler, Neither Enemies Nor Friends: Latinos, Blacks, Afro-Latinos (New York: Palgrave Macmillan, 2005), 127.

83 Dzidzienyo and Oboler, 128; Gina Sotelo, “África En México,” Universo, 1997, No. 134 edition. 
84 Together Aguirre Beltrán and Cruz-Carretero conducted an ethnographic study of the community of Mata Clara in Veracruz, a "community whose people have a clearly pronounced heritage of afro-genetic traits." Participants rejected the idea of marrying someone with a skin color "darker their own." Rather, they hoped for "refinement," or the lightening of the family's skin color over time through marriages with those of a lighter skin tone. This would result in a higher status for the couples' lighter-skinned children (Sagrario Cruz-Carretero in Mexican Fine Arts Center Museum, The African Presence in México: From Yanga to the Present, 1st edn (Chicago: Mexican Fine Arts Center Museum, 2006), 34).

85 Cruz-Carretero describes several projects occurring in Mexico directly prior to the opening of The African Presence there in 2007: an anti-racist academic project called "The Third Root: Presence of African Cultures in Mexico," the founding of the Consejo Nacional para Prevenir la Discriminación or CONAPRED (National Council for the Prevention of Discrimination) in 2001, Mexican participation at a UN roundtable on racism "in preparation for the World Conference against Racism, Xenophobia, Intolerance, and Discrimination in 2001," and an anti-discrimination campaign by CONAPRED in 2005. (Cruz-Carretero in Mexican Fine Arts Center Museum, 40-42.)

86 "Comments from the Guest Book during the Run of The African Presence in México" (National Museum of Mexican Art, Chicago, March 2006). Translation: "I have always been very proud to be Mexican and of my understanding of our culture, but how wonderful to learn about this phase of our Mexico." The word "etapa" has the connotation of an era, epoch, or phase, which makes me wonder if this visitor viewed the African presence as somehow being gone.

87 Cesáreo Moreno, interview with the Chief Curator and Director of Visual Arts at the National Museum of Mexican Art, personal, August 1, 2012.

88 Bambi B. Schieffelin, The Give And Take of Everyday Life: Language Socialization of Kaluli Children, 2nd edn (Tucson, AZ: Fenestra Books, 2005), 1.

89 Karen Mary Davalos, Exhibiting Mestizaje: Mexican (American) Museums in the Diaspora, 1st edn (Albuquerque, NM: University of New Mexico Press, 2001), 112-113.

90 Stokely Carmichael, one of the original Panthers, coined the phrase "Black is beautiful." "Black Is Beautiful" Celebration, Harlem, New York City, 1968, photograph, 1968, http://gateway.proquest. com/openurl?url_ver=Z39.88-2004\&res_dat $=$ xri:bsc:\&rft_dat $=$ xri:bsc:multimedia:lon4102, Black Studies Center.

91 Elizabeth Catlett, “The Role of the Black Artist," Black Scholar 6, no. 9 (June 1975): 10-14.

92 The artistic and political movements in Mexico and the US exchanged ideas, techniques, and even people, as when Langston Hughes, poet laureate of the Harlem Renaissance, traveled to Mexico to teach and write. (Faith Berry, Langston Hughes: Before and Beyond Harlem (Secaucus, NJ: Citadel, 2000), 4, 19; James A. Emanuel, Langston Hughes (New York:Twayne Publishers, 1967), 23, 69).

93 Lizetta Lefalle-Collins, Raquel Tibol, and Shifra M. Goldman, In the Spirit of Resistance: AfricanAmerican Modernists \& the Mexican Muralist School (New York: American Federation of Arts, 1996), 19-20.

94 Melanie Herzog, Elizabeth Catlett:An American Artist in Mexico (Seattle,WA: University of Washington Press, 2000), 52.

95 "Mexico - Nonformal Education."

96 Herzog, Elizabeth Catlett, 148.

97 Herzog, 151.

98 W.J. Chopik, E. OBrien, and S.H. Konrath, "Differences in Empathic Concern and Perspective Taking Across 63 Countries," Journal of Cross-Cultural Psychology, October 14, 2016, https://doi.org/ 10.1177/0022022116673910.

\section{Bibliography}

Allen, James, ed. Without Sanctuary: Lynching Photography in America. Santa Fe, NM:Twin Palms, 2000. Apel, Dora. "On Looking: Lynching Photographs and Legacies of Lynching after 9/11." American Quarterly 55, no. 3 (September 1, 2003): 457-478. 
Archibald, Robert R. The New Town Square: Museums and Communities in Transition (American Association for State and Local History). Walnut Creek, CA: AltaMira Press, 2004.

Bennett, Tony. "Civic Laboratories." Cultural Studies 19, no. 5 (September 1, 2005): 521-547.

Berry, Faith. Langston Hughes: Before and Beyond Harlem. Secaucus, NJ: Citadel, 2000.

Bill Adair, Benjamin Filene, and Laura Koloski, eds. Letting Go?: Sharing Historical Authority in a UserGenerated World, 1st edn. Washington, DC: Pew Center for Arts \& Heritage, 2010.

"Black Is Beautiful" Celebration, Harlem, New York City, 1968. 1968. Photograph. http://gateway.proquest. com/openurl?url_ver=Z39.88-2004\&res_dat=xri:bsc:\&rft_dat=xri:bsc:multimedia:lon4102. Black Studies Center.

Brown, Wendy. Regulating Aversion: Tolerance in the Age of Identity and Empire. Princeton, NJ: Princeton University Press, 2006.

Candlin, Fiona. Art, Museums and Touch. Manchester; New York: Manchester University Press; distributed in the United States by Palgrave Macmillan, 2010.

Carbonell, Bettina M. "The Afterlife of Lynching: Exhibitions and the Re-Composition of Human Suffering." Mississippi Quarterly 61, no. 1-2 (2008): 197-215.

Chanin, Clifford. Interview with curator, Legacy of Absence. Phone, October 11, 2011.

- Museum Studies:An Anthology of Contexts, 2nd edn. Malden, MA:Wiley-Blackwell, 2012.

. Interview with curator, Legacy of Absence. Phone, June 17, 2013.

Chopik, W.J., E. OBrien, and S.H. Konrath. "Differences in Empathic Concern and Perspective Taking Across 63 Countries.” Journal of Cross-Cultural Psychology, October 14, 2016. https://doi.org/10.1177/ 0022022116673910.

"Comments from the Guest Book during the Run of The African Presence in México." National Museum of Mexican Art, Chicago, March 2006.

Corpis, Duane J. and Ian Christopher Fletcher. "Without Sanctuary." Radical History Review 2003, no. 85 (December 21, 2003): 282-286.

Cuno, James, Philippe de Montebello, Glenn D. Lowry, Neil MacGregor, John Walsh Jr, and James N. Wood. Whose Muse?: Art Museums and the Public Trust. Princeton, NJ: Princeton University Press, 2006.

Dana, John Cotton. The New Museum. Woodstock,VT: Elm Tree Press, 1917.

Davalos, Karen Mary. Exhibiting Mestizaje: Mexican (American) Museums in the Diaspora, 1st edn. Albuquerque, NM: University of New Mexico Press, 2001.

Doron, Edith. "At Hospitality's Threshold: From Social Inclusion to Exilic Education." Curator 52, no. 2 (April 2009): 169-182.

Dzidzienyo, Anani and Suzanne Oboler. Neither Enemies Nor Friends: Latinos, Blacks, Afro-Latinos. New York: Palgrave Macmillan, 2005.

Elizabeth Catlett. “The Role of the Black Artist.” Black Scholar 6, no. 9 (June 1975): 10-14.

Emanuel, James A. Langston Hughes. New York: Twayne Publishers, 1967.

Foster, Chris. "Collection of Letters from Students from Warsaw Community High School, Warsaw, IN," March 29, 2011. Illinois Holocaust Museum and Education Center.

Grams, Diane. Producing Local Color: Art Networks in Ethnic Chicago. Chicago; London: University of Chicago Press, 2010.

Herzog, Melanie. Elizabeth Catlett: An American Artist in Mexico. Seattle, WA: University of Washington Press, 2000.

van der Horst, Liesbeth. Interview with Liesbeth van der Horst, Directeur, Verzetsmuseum. Personal, January 27, 2017.

Ilona Katzew. Casta Painting: Images of Race in Eighteenth-Century Mexico. New Haven, CT:Yale University Press, 2004.

Kinnick, Katherine N., Dean M. Krugman, and Glen T. Cameron. "Compassion Fatigue: Communication and Burnout toward Social Problems." Journalism and Mass Communication Quarterly 73, no. 3 (September 1, 1996): 687-707.

Krauze, Enrique. Mexico: Biography of Power. New York: Harper Perennial, 1998.

Landsberg, Alison. Prosthetic Memory: The Transformation of American Remembrance in the Age of Mass Culture. New York: Columbia University Press, 2004. 
Lefalle-Collins, Lizetta, Raquel Tibol, and Shifra M. Goldman. In the Spirit of Resistance:African-American Modernists \& the Mexican Muralist School. New York: American Federation of Arts, 1996.

"Legacy of Absence Mission Statement." Mission Statement. Illinois Holocaust Museum and Education Center, Skokie, IL, January 23, 2008.

Levent, Nina Sobol, Alvaro Pascual-Leone, and Simon Lacey. Multisensory Museum: Cross-Disciplinary Perspectives on Touch, Sound, Smell, Memory, and Space, 2014. http://public.eblib.com/choice/ publicfullrecord.aspx? $\mathrm{p}=1648843$.

Levin, Amy K. Defining Memory: Local Museums and the Construction of History in America's Changing Communities. Lanham, MD: Rowman \& Littlefield, 2007.

Linenthal, Edward T. Preserving Memory: The Struggle to Create America's Holocaust Museum. New York: Columbia University Press, 2001.

Macdonald, Sharon. A Companion to Museum Studies. Chichester:Wiley-Blackwell, 2011.

Marguerite La Caze. Wonder and Generosity: Their Role in Ethics and Politics. Albany, NY: Suny Press, 2013.

Marstine, Janet C. The Routledge Companion to Museum Ethics: Redefining Ethics for the Twenty-First Century Museum, 1st edn. New York: Routledge, 2011.

Message, Kylie. Museums and Social Activism: Engaged Protest. London; New York: Routledge, 2014.

Mexican Fine Arts Center Museum. The African Presence in México: From Yanga to the Present, 1st edn. Chicago: Mexican Fine Arts Center Museum, 2006.

“Mexico - Nonformal Education." http://education.stateuniversity.com/pages/986/MexicoNONFORMAL-EDUCATION.html.

"Missing Millions:The Human Cost of the Mexican Revolution, 1910-1921, (c) Robert McCaa, 2001." www.hist.umn.edu/ rmccaa/missmill/.

Moreno, Cesáreo. Interview with the Chief Curator and Director ofVisual Arts at the National Museum of Mexican Art. Personal, August 1, 2012.

Norris, Linda and Julieta Cuéllar. Interview with Global Networks Team, International Coalition of Sites of Conscience. Phone, March 8, 2017.

Ocaña, Damarys. "Rediscovered Raíces." Latina Magazine, May 2006, print edition, sec. Arte.

Schieffelin, Bambi B. The Give And Take of Everyday Life: Language Socialization of Kaluli Children, 2nd edn. Tucson, AZ: Fenestra Books, 2005.

Shaman, Sanford Sivitz. The Duty of Art: Museums and Social Consciousness. http://siris-bibliographies. si.edu/ipac20/ipac.jsp?uri=full=3100001 !1253 !104\&profile=biball.

Silverman, Lois H. The Social Work of Museums. London; New York: Routledge, 2010.

Simon, Nina. The Participatory Museum. Santa Cruz, CA: Museum 2.0, 2010.

Simon, Nina and Jon Moscone. The Art of Relevance. Santa Cruz, CA: Museum 2.0, 2016.

Simon, Nina. "Museum 2.0." http://museumtwo.blogspot.com/.

Sontag, Susan. Regarding the Pain of Others. New York: Picador, 2004.

Sotelo, Gina. “África En México." Universo, 1997, No. 134 edition.

"Steps for Building Empathetic Museums." http://empatheticmuseum.weebly.com/uploads/4/4/9/8/ 44983495/empatheticmuseum_steps_v01.pdf.

Storch, Charles. "'National' Status." Chicago Tribune, December 5, 2006. http://articles.chicagotribune. com/2006-12-05/features/0612050232_1_latino-museum-museum-s-board-national-museum.

“Teacher Feedback from Workshop Evaluations." Illinois Holocaust Museum and Education Center, Skokie, IL, n.d.

"The Empathetic Museum.”'The Empathetic Museum. http://empatheticmuseum.weebly.com/.

Tinker, Elizabeth. "Prisons Today: Questions in the Age of Mass Incarceration." Summative Report to Funder. Philadelphia, PA: Eastern State Penitentiary, September 21, 2016.

“Training for Tour Guides on The African Presence in México with Cesáreo Moreno." Notes. Mexican Fine Arts Center Museum, Chicago, February 10, 2006.

Vasconcelos, José. La raza cosmica; misión de la raza iberoamericana. Madrid: Aguilar, 1966.

Weinenger, Arielle. Interview with curator, Illinois Holocaust Museum and Education Center. Personal, July 18, 2011. 
Witcomb, Andrea. Re-Imagining The Museum: Beyond the Mausoleum, 1st edn. London; New York: Routledge, 2003.

"Without Sanctuary." http://fnewsmagazine.com/2005/10/without-sanctuary/.

Wittman, Aletheia and Rose Paquet Kinsley. "The Incluseum." the incluseum, July 2012. http:// incluseum.com/.

Wolters, Wendy. "Without Sanctuary: Bearing Witness, Bearing Whiteness." JAC 24, no. 2 (January 1, 2004): 399-425. 


\section{2}

\section{PHYSICAL EXPERIENCES}

\section{Building memories and empathy}

A combination of resonant content and physical experiences helps visitors make lasting memories of their visits to museums. From swinging on a swing to embodied emotions such as laughter or tears, physical experiences can enable empathy and solidarity to make a powerful platform from which visitors can act. There are many other kinds of physical experiences in exhibitions, including immersive environments, which offer special promises and challenges. Physical experiences offer opportunities to curators wishing to anchor and direct visitors' attention. Connecting content in the museum and visitors' own experiences is what makes content resonant. This often involves bringing in contemporary events. The possibilities for making content that resonates with visitors are as varied as the visitors themselves. I propose combining physical experiences, including emotional ones, and resonant experiences as a strategy for teaching content, building memories, building empathy, and, ultimately, inspiring action in the visitor. This chapter analyzes practices for creating physical experiences and resonant intellectual experiences and, finally, intentionally blending the two.

\section{Emotion}

Emotions are one kind of physical experience. And they can help visitors fix their memories of their experiences in museums and perhaps also the content. Neurologists such as Antonio Damasio demonstrate that all emotion is embodied and outward signs of emotion are simply examples of what can happen when a powerful emotion takes hold of a person. In the interest of simpler explanations, suggestions, and analysis later on in this book involving the terms "emotion" and "feelings," here is a brief summary of how Damasio describes emotions and feelings taking place in the body.

Emotions happen when we perceive certain things or when we remember perceiving them. ${ }^{1}$ All emotions are physical and result in numerous changes all over the body - miniscule and tremendous, perceptible and imperceptible to us and others. ${ }^{2}$ This can range from the presence and levels of chemicals that act on certain parts of the brain to changes in skin conductivity, from changes in temperature to changes in heart rate. ${ }^{3}$ In order to have emotions, 
the senses (internal or external) must perceive an "emotionally competent stimulus." 4 This is simply a trigger that begins an emotional process in the body. Such a trigger could be the sudden growl of a dog leaping against the fence as you pass by his yard or an unexpected meeting with a loved one on the street. Your heart leaps in both cases. The trigger can be negative or positive.

In the neurological literature, there is a difference between emotions and feelings. In essence, when we stop to think about an emotion, that's a feeling. Feelings come from emotions. Time and again, experiments have demonstrated that we do not consciously perceive or think about emotions (have feelings) until after the emotional response begins. ${ }^{5}$ Emotions developed evolutionarily to help creatures survive by giving them an edge in decision making. Feelings act as a quick reference guide to help us understand why we are doing or not doing things in given situations. ${ }^{6}$ You might feel anxious when you approach the yard with the barking dog, even though you know he is trapped behind the fence. Feelings are responses to triggers and also to the physical result of experiencing triggers. When we have feelings we are responding to the external or internal stimulus that started the emotional experience in addition to stimuli that are internal to our bodies. Since that second set of stimuli is inside the body, the body can act on it - respond to it or change the signals coming from it. Thus, as Damasio put it, "feelings are interactive perceptions." 7

It goes against our post-Enlightenment education to think of reason and emotion as connected rather than as opposites. But contemporary neurologists, such as Damasio and Joseph LeDoux, have demonstrated the fallacy of the notional split between reason and emotion. In fact, as Damasio puts it, emotion is part of making reason, and actually launches the process of rational thought. ${ }^{8}$ However, emotion and cognition are, as Robert Sapolsky, a neuroendocrinologist and professor of biology, neuroscience, and neurosurgery, put it, "shifting on a continuum." "9 Too much emotion makes it hard to think clearly. Too little emotion makes the experience bland and unmemorable. When emotion and cognition are in proper balance, there is a sweet spot that is beneficial for learning and making memories. ${ }^{10}$

\section{The role of emotion in learning}

As Damasio put it, "recall of new facts is enhanced by the presence of certain degrees of emotion during learning." ${ }^{11}$ But if the emotion is not coming from "visceral input to the brain" - sensations from the body - the emotion no longer assists learning. ${ }^{12}$ When people have intense emotional experiences, they can go back and replay them in their minds and, in doing so, physically relive the experiences in great detail. ${ }^{13}$ This might not happen on a grand enough scale during a museum visit for the visitor to have the same kind of recall as she would about a profoundly personal event such as her wedding or the birth of her child. However, my supposition is that the degree to which the visitor has an emotional response should correlate to the degree of recall she has about the experience in the museum up to a point. When a museum is interested in fostering action on the part of visitors, memory and empathy are both important.

Stephen Greenblatt's essay from 1990, "Resonance and Wonder," provides the foundation from which I argue that exhibitions for social justice are more effective when they combine resonance and emotion. For Greenblatt, wonder is "the power of the displayed object to stop the viewer in his or her tracks, to convey an arresting sense of uniqueness, to evoke an exalted attention." ${ }^{14} \mathrm{He}$ calls resonance: 
the power of the displayed object to reach out beyond its formal boundaries to a larger world, to evoke in the viewer the complex, dynamic cultural forces from which it has emerged and for which it may be taken by a viewer to stand. ${ }^{15}$

I borrow the ideas of resonance and wonder from this essay, but I use the term "emotion" instead of "wonder" because it enables me to more seamlessly address neurological ideas about emotion. I extend Greenblatt's work with the notion that physical experiences of wonder such as a shivers, tears, awe, and laughter tether and enhance our intellectual experiences of resonance. I argue that resonance and physical experiences such as emotion combine to strengthen curatorial work for social justice.

Allison Griffiths's Shivers Down Your Spine helps theorize the shift from emotion to resonance. Like a poem that blossoms in the mind of the reader, taking on form and substance beyond words on a page, an exhibition truly sings when it resonates with the visitor. Griffiths asked how ways of seeing spaces affect the way we think of other spaces and experiences. For example, arches can remind us of cathedrals and therefore signify sacredness. Griffiths concluded that emotion is necessary to draw viewers into understanding and resonance. Much like visitors to a cathedral feel their understanding of the space before they know it, so too in museums.Visitors experience an emotional landscape that informs the visit and the visitor's understanding of its importance. The experience of this emotional landscape informs the visitor, consciously and subconsciously, about the need to remember the visit.

\section{Mixing emotion and resonance in the gallery}

Emotion and resonance are useful for helping people build memories as well as empathy. Intentionally mixing emotion and resonance in the gallery supports these connected processes as inspiring visitors to act. When we consider how curatorial tools work on the brain, we can better understand how they might be combined to make exhibitions that are more effective for helping visitors learn, remember, and empathize. We can take advantage of tactics already in use in museums that dovetail with how our brains function. As emotional experiences work to build memories and the power of groupness (outlined in the Chapter 1) cements a sense of ownership and belonging, an exhibition can enthrall and engage the visitor.

Emotion launches the process of rational thought. Contemporary neurologists have shown that without emotion to pre-select choices - automatically and unconsciously through what we know as the gut reaction - we would wind up stuck in an endless loop of rational thought and never reach a decision. Damasio's work supports the idea that a visitor's embodied emotional response in a museum can anchor a moment of experience and thinking and turn it not only into a memory but into a "beacon of incentive" for continued engagement. ". "Somatic markers" are gut feelings that accompany each of the possible solutions to a given scenario. People experience emotions and, over time, begin to consciously reflect on them - noticing the changes in the body that emotions precipitate, monitoring them, and thinking about the causes of them. Damasio calls this having "feelings." ${ }^{17}$ Somatic markers accrue as people learn to connect specific emotions and feelings to their expected outcomes in certain situations. Thus, when we have a negative somatic marker or gut feeling, we seek to avoid going further down that particular path and vice versa. The positive somatic marker is what Damasio calls the "beacon of incentive" that can continue to draw a person down a certain path. In this 
way, through gut-level pushes and pulls, somatic markers can draw visitors around a museum as well as incline or disincline them to participate in activities and, perhaps, to follow up with other actions after the fact. It is up to the curator to examine the emotional incentives and disincentives that pull visitors through their galleries and invite visitors to linger or not. This involves everything from objects to wall color, lighting, and the placement and type of seating.

Though wondrous emotion is one of the special gifts museums have to offer, it is far from the exclusive province of museums. Natural wonders, houses of worship, and spectacles are some of the other places where we find this highly focused, overwhelming state of experience. However, because humans have, in many cultures, chosen to house and preserve unique and valuable objects, including art, in museum-like places, museums are an excellent place to seek wonder. And, for many, this is one goal of their visits.

Catherine Cameron and John Gatewood write that most visitors to museums and other historic sites are motivated by more than a quest for information or pleasure. They call visitors seeking a deeper experience or a personal connection to the past "numen-seeking." 18 The numinous connection between the visitor and an object involves an emotional response, but often relies on the visitor having some knowledge or idea about the object, while other emotional responses can occur without any prior knowledge. However, literature about numinous experiences is often applicable to other kinds of emotional experiences in museums, as well. In Kiersten Latham's article, "The Poetry of the Museum: A Holistic Model of Numinous Experiences" (2007), D.L. Perry described numinous experiences as promoting physical "visceral" - learning, which is characterized by gut feelings, the somatic markers discussed earlier. ${ }^{19}$ In both experiences, Perry associates profound understanding with experiences felt by the body, which we know to be consistent with neurological studies of learning and memory formation. Latham confirms, from the humanities rather than the brain sciences, that experiences of emotion build empathy. ${ }^{20}$ This is one of the core reasons that the strategy of combining emotionally compelling content with intellectually resonant content is useful to curatorial work for social justice.

Museums can teach empathy organically though exhibitions that use resonance and emotion. Wonder - embodied emotional experience - is one way of leading to resonance. We can build cross-cultural respect in the gallery by mobilizing physical experiences and embodied emotion. Your own space is a perfect laboratory to explore this process using the techniques that follow. Where are the emotionally freighted objects? What objects pull visitors into the space? Where are the intense emotional experiences? Where are the resting places? What other physical experiences are there for visitors?

\section{Making wonder: physical experiences in the museum}

Physical experiences in museums can take many forms. Visitors can take specific actions touching objects, doing activities, manipulating interactives, moving through immersive environments. Or visitors can have emotional responses - also physical experiences: gut-punching wonder that takes your breath away, the prickle of fear on the back of your neck, or stomachchurning revulsion. It follows that curators can foster these experiences either by inviting the visitor to engage physically with exhibits or by inspiring emotional responses. We can build on the affordances of the museum and use visitors' preexisting ideas about museums to help create these experiences. 


\section{Using inventive interactives}

In Re-Imagining the Museum, Andrea Witcomb described how the concept of what constitutes interactivity has narrowed since the 1980s. Whereas interactivity used to be about a visitor having a sensual experience, as of 2003 the definition was "a physical object which is added to the main display." The visitor's experience involves manipulating technology. ${ }^{21} \mathrm{Witcomb}$ demonstrates how interactivity can be conceptual as well and can be achieved without additional technologies. She establishes two types of interactivity that go beyond what she calls "technical interactives," things like lifting a flap, spinning a dial, or pushing a button. Spatial interactivity, in which the visitor has an active role in producing meaning in the museum, is one of these types of interactivity. ${ }^{22}$ The other is dialogic interactivity. As with certain examples below, such as the railcar and immersive art installations, the "spatial composition" of the gallery reveals its meanings as the visitor moves through it. ${ }^{23}$ These various ways of choreographing the multisensory experiences of visitors are useful - to paraphrase Peter Emmett, former Senior Curator of the Museum of Sydney - because they invite interactions that are diverse and offer real emotional payoff. ${ }^{24}$ The practices below encompass spatial and dialogic interactives as well as unusual versions of more technical interactives.

\section{Swing, dance, stomp, laugh: getting the visitor moving}

In May 2014, Heather Radke, then Exhibition Coordinator at Hull-House, opened an exhibition about free time and play. As she worked on The Right to Play, she meditated on the rallying cry from 1906 for the eight-hour work day: "eight hours for work, eight hours for rest, and eight hours for what you will." ${ }^{25}$ The structure of our labor organizing no longer rests on the same rhetorical foundation, Radke told me. We don't feel we have the right to time off and recreation. As Radke put it, "When you're working 15 hours a day you can't participate in democracy."26 That cuts the worker completely out of the goal of the Hull-House Settlement, leaving her no time to vote, protest, or even be informed. Hence the connection between play and social reform.

A swing hung in the center of The Right to Play (Figure 2.1), and visitors enjoyed it exuberantly or meditatively. The pleasurable experience of swinging didn't explicitly communicate the shifts in American workers' days, but the exhibition did and I propose that the combination of physical experience and intellectual experience is more likely to form a strong memory for visitors than texts alone.

Much like the swing in The Right to Play, the exhibition Unfinished Business: Arts Education featured interactives that physically involved visitors. Naomi Blumberg, then Exhibition Coordinator at Hull-House, curated the exhibition in 2011. Stomping and laughter sounded in the gallery as visitors taught themselves the "Tuttle Clog" from steps marked out on the floor (Figure 2.2).

This activity was based on the teachings of Mary Wood Hinman, one of the first professional folk dancers in the US. For Hinman, the cross-cultural education that folk dance enabled made dance a vehicle for social reform as well as a form of recreation. ${ }^{27}$ Ideally, these pleasurable physical experiences cement memories of content within the museum so that visitors can go out and use that content.

It may not matter how directly the experiences themselves relate to the content of exhibitions. Consider, for example, the case of "flashbulb memories." Roger Brown and James Kulik coined this term in 1977 to describe the unusually clear and long-lasting memories that 


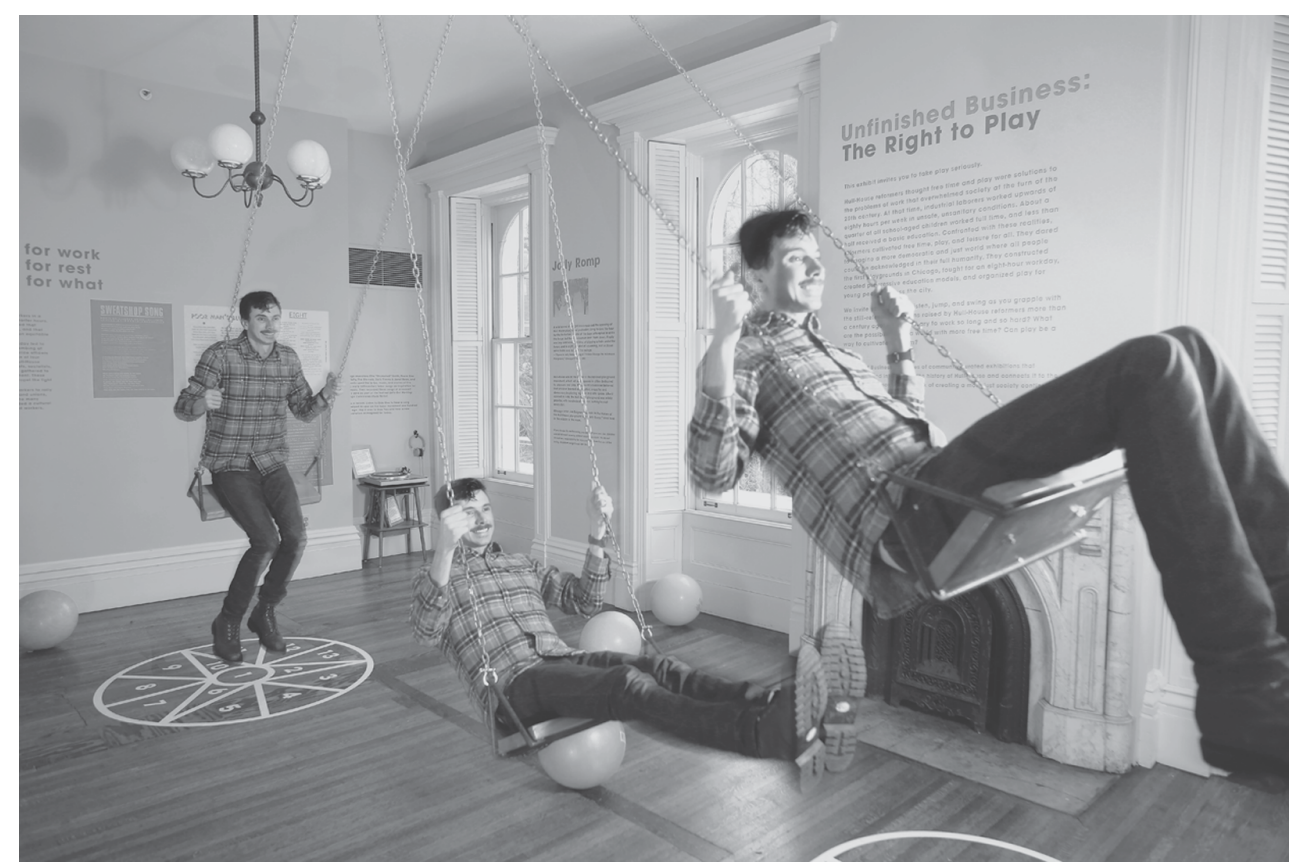

FIGURE 2.1 Gallery shot of Unfinished Business: The Right to Play at the Jane Addams Hull-House Museum (2014). Photograph by Simon Pyle. Courtesy of Simon Pyle.

accompany highly emotional events. For Americans in my generation, it easy to recall exactly what we were doing, who we were with, and where we were on September 11, 2001, when airplanes hit the World Trade Center. For our parents, the corollary might be the assassination of John F. Kennedy or Martin Luther King. Even those of us who were not involved in the events at all have enhanced memories of these times. What we were wearing, who we were with, etc., are unrelated to the details of the historical event in most cases. Likewise, though on a much smaller scale, I propose that our memories of experiences in museums can be anchored by physical experiences that are not directly related to the content we are learning. The Tuttle Clog doesn't contain any content itself about the problems with arts education today, though it was one of many dances Hinman used to bring people together across cultures. The simple physical activity of dancing, whether or not it contains information about cultural exchange (It very well may!), can help anchor visitors' memories of what they see, think, and learn in the exhibition. Physical experiences, of which emotional experiences are one type, enhance memories. This is one reason why they are important to curatorial work for social justice: without strong memories, visitors cannot act on their experiences in the museum long into the future, as discussed in Chapter 3.

\section{"Step Into Their Shoes": fueling the visitor's inner conversation}

One interactive at the Chicago History Museum was an embodied experiment in empathy - a physical experience for the visitor that could build memories and empathy at once. In 2011, Jill Austin and Jennifer Brier curated Out in Chicago at CHM.The exhibition was an interrelated urban history of queer Chicagoans and the city itself. The curators' goal was for visitors to step 


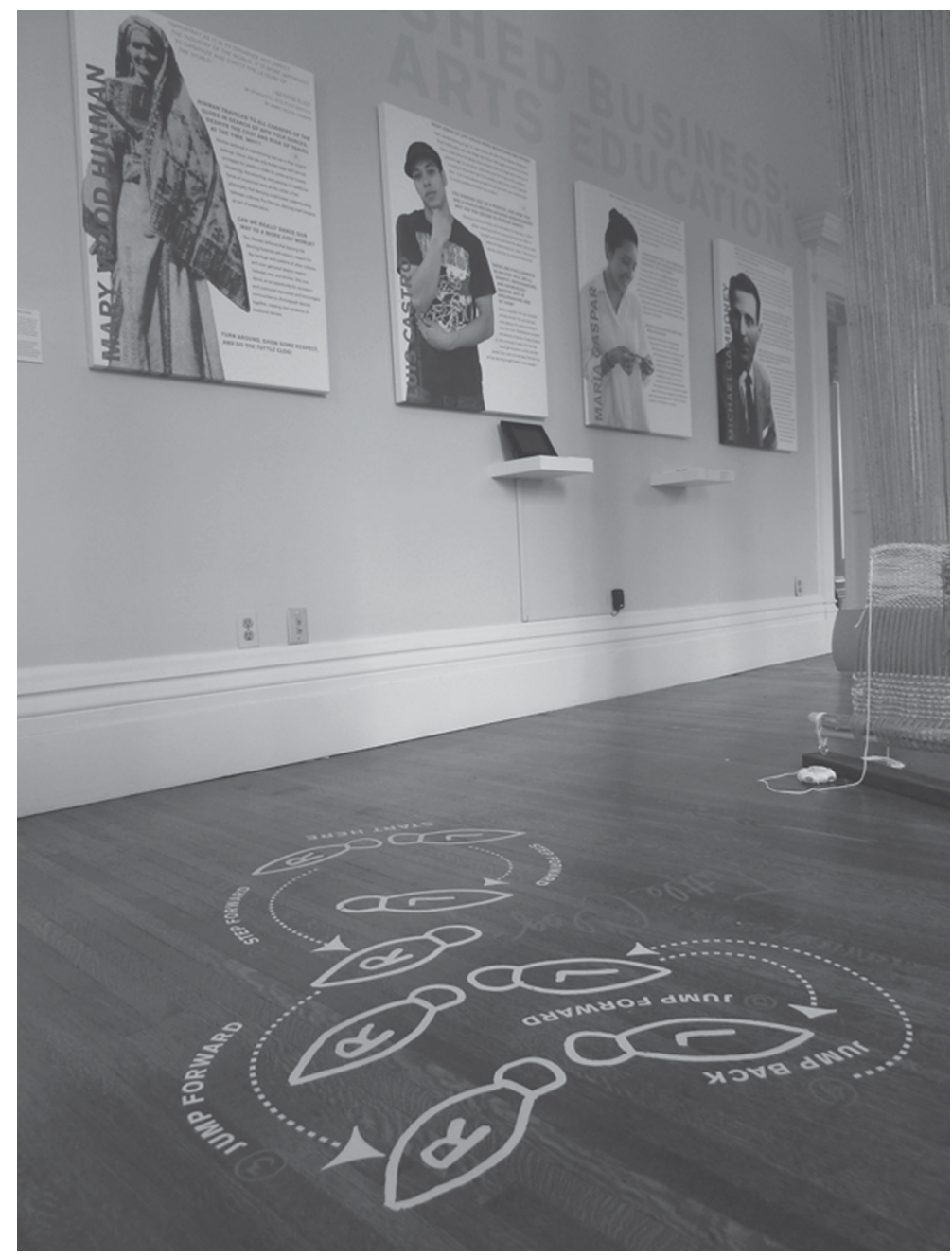

FIGURE 2.2 Gallery shot of the Tuttle Clog in Unfinished Business:Arts Education. Courtesy of Naomi Blumberg and the Jane Addams Hull-House Museum.

into other people's shoes and "imagine themselves as different." ${ }^{28}$ The interactive, "Step Into Their Shoes," was the exhibit in Out that most elicited an emotional response from visitors.

Three carnival cutouts comprised "Step Into Their Shoes."Visitors placed their faces in the cutouts and saw themselves as other people. Jane Heap (aka Richard), Albert Cashier, and liam Lair (sic) all made different choices about how to present themselves and their genders. Heap was a cross-dressing lesbian from the very early twentieth century. Cashier lived as a man and fought in the Civil War only to be discovered as female when he was injured and sent to a hospital. Lair is a contemporary transsexual.

The interactive was a visual pun that asserted that we all perform our identities, sexual and otherwise. It did so by deftly gesturing at the kinds of performance a general public might associate with queer people - cross-dressing and drag - while at the same time "exploiting 
freakishness, a point of debate within the community." ${ }^{29}$ The interactive worked to produce empathy, Brier says, by making people a tiny bit uncomfortable and thus introspective. The interactive also created a material example of what Michael Warner calls a queer moral alternative about sexuality. He writes

The rule is: Get over yourself. Put on a wig before you judge ... You stand to learn most from the people you think are beneath you. ${ }^{30}$

Witcomb wrote that the best interactives place the visitor into the narrative of the exhibition momentarily. ${ }^{31}$ This interactive achieved that goal clearly and succinctly.

\section{Enabling valuable tactile experiences}

Not every museum has the space or interest to create a large physical experience. (Space is one of the most significant resources expended in the Hull-House examples. The Tuttle Clog is an excellent example of a big experience that costs very little to produce.) Tactile interactives are a choice that can be more intimate, quieter, or simply smaller in scale. Haptic exploration benefits learning most when the visitor has a long time to touch the object, the object is three-dimensional, there is context and guidance about the object, and when senses other than touch are also engaged. ${ }^{32}$ The benefits of tactile experiences for blind or partially sighted visitors have been well studied. But touch can also improve the engagement of sighted visitors and help them form lasting and detailed memories. Educators, psychologists, and neurologists agree on this point, although the science of how touch informs the way we form memories is still in its nascent stages. ${ }^{33}$ The question then becomes how to craft memorable small-scale interactives freighted with emotion.

One important consideration is the way in which the experience of touch is distinct from other sensory experiences. Tactile experiences can be much more than a substitute for sight. Visitors can gain new kinds of expertise through touch while also having valuable physical experiences. Touching is also an opportunity for visitors to experience the validation of their existing knowledge. Students coming from disciplines in the arts, engineering, and design could have this experience touching textiles, ceramics, and furniture, for example. As Fiona Candlin put it in Art, Museums and Touch, touching art can change the way researchers and visitors interpret objects and therefore can also change art history itself. ${ }^{34}$ Sometimes handling the original object will be possible and sometimes not. Candlin illuminates the history of touch being all but eradicated from the museum after it was, in the seventeenth and eighteenth centuries, a staple form of engagement with objects. The evidence is overwhelming that, when possible, handling objects can be emotionally and sensuously powerful and memorable. When visitors are allowed to touch emotionally freighted objects, the golden combination of emotional thinking and haptic experience is most likely. Once again, this physical experience can enhance the visitors' memory of the visit and improve the chances of the visit affecting their lives and decision making into the future.

When the need to conserve the object or other considerations make it impossible to allow visitors tactile access to original objects, models or reproductions may be appropriate. The important thing is scaffolding the visitor's experience by providing context and guidance as well as considering the pleasure of touch and what objects people might want to touch. 


\section{Immersive environments}

One way to create an emotional response is to give the visitor the opportunity to do something physical - swing on a swing, dance, play games, or drink tea. Another way is to create an environment that makes the visitor feel a certain way. We have profound emotional sensations in response to spaces: the Sistine Chapel, the Grand Canyon, our own homes. Museums can do this as well. So-called immersive environments or immersive experiences have received a great deal of attention in recent years, even though they have been around for centuries, as Griffiths demonstrated. Today, immersive experiences in museums range from stepping into the jungle of pre-historic Chicago at the Garfield Park Conservatory to intimate conversation with a virtual representation of a Holocaust survivor at the Illinois Holocaust Museum. Examples of immersive environments from the Chicago History Museum's Out in Chicago and the Illinois Holocaust Museum's Karkomi Permanent Exhibition demonstrate how immersive environments cut across museological styles and subject matter. This section will contain examples from these two exhibitions in order to demonstrate some of the challenges and opportunities of immersive environments.

One environment in Out was a dramatic success, though it was not a comprehensively recreated environment. The team built a living room with an overstuffed sofa and a big TV. Originally, the plan had been to create a more fully developed environment that suggested a 1970s lesbian home. ${ }^{35}$ But it was always meant to be a living room, den, family room, or "really cool basement." It was extremely accessible and intimate, which was important to Austin. But it was also powerful as a nearly blank canvas that allowed visitors to overlay their own cozy experiences onto this space. The curators capitalized on the common experiences of comfort in living rooms generally and engaged those feelings in the hearts of visitors to make them comfortable in this otherwise foreign space filled with strangers. This experience of unexpected comfort is an example of curators perhaps unwittingly taking advantage of the brain's quick reference guide to feelings, somatic markers. For visitors of many different descriptions, the living room couch has happy associations, a gut-level feeling of comfort, and mobilizes positive somatic markers.

The space invited visitors to sit on the couch and watch TV together. The stories came from queer people from around the city: young, old, singles, couples, many professions, many languages, many skin colors. As I sat watching the videos, several teenage boys seemed afraid to encroach on my space on the couch. I invited them to join me and, to my surprise, they did. We watched the whole twenty-minute program together. No matter when you sat down, you had a hard time getting up before you had seen all of the interviews. These videos provided answers to an unspoken, and sometimes even unacknowledged, question from outside queer communities: what are queer people really like? Are they like me? The answer was a resounding yes. ${ }^{36}$ Brier and Austin wanted to involve visitors in the stories of queer Chicagoans. They also wanted to keep the scholarship of the exhibition informed by the lived realities of queer and straight Chicagoans. The home space achieved both of these goals.

Immersive experience is a hallmark of the Illinois Holocaust Museum's permanent exhibition, but in some cases the museum has been criticized for being overly immersive. The immersive nature of the permanent exhibition is a combination of the efforts of Stanley Tigerman, the architect of the museum, and David Layman, the exhibit designer. The immersive experience begins, as it does with many Holocaust museums, with the building. Sound, light, and altitude all play an intentional role in the experiential storytelling of the space. 
Michael Berenbaum, the curator of the United States Holocaust Memorial Museum (USHMM), and Yitzchak Mais, the curator of the Museum of Jewish Heritage in New York and former Head of Education at Yad Vashem, co-curated the Karkomi Permanent Exhibition. Berenbaum, Mais, and Rick Hirschhaut, Executive Director of the Illinois Holocaust Museum, all said that they were concerned about taking the immersive experience too far. But they did so anyway. The first and most obvious example of this is the exhibit on the mobile killing site of Babi Yar, the ravine in Kiev where the largest single massacre by the Nazis during the Holocaust occurred. ${ }^{37} \mathrm{~A}$ label warns the visitor that she is about to come upon very graphic historical footage from BabiYar, yet the visitor cannot bypass this exhibit. Historical footage of the massacre blends with the carpeting and the graphics on the walls. Both have been printed with a still from this footage to make it look as if the visitor is standing in the ravine observing the massacre in progress. Dim lighting enhances this effect. The space is all-encompassing.

This choice of design is inconsistent with the museum's own philosophy, a traditional one wherein "the void of the Holocaust is impenetrable. Only the survivors understand what occurred." ${ }^{38}$ So from the point of view of the museum, why try to penetrate the void of the Holocaust with the tools of the designer? This exhibit also takes unfair advantage of the visitor. Stacey Mann and Danny Cohen discuss the way in which designs such as the exhibit at the Illinois Holocaust Museum can trigger traumatic experiences in visitors in their essay, "When a Boxcar Isn't A Boxcar: Designing for Human Rights Learning." ${ }^{39}$ In particular, Mann and Cohen argue in favor of designs that offer safe spaces in which visitors can choose how and when to expose themselves to disturbing content so that they have some ability to modulate their emotional experiences. The railcar discussed below is one example of an experience that is structured in such a way.

The Babi Yar exhibit reneges on the museum's commitment to hospitality (discussed in Chapter 1) even as it succeeds in producing a profound embodied emotional response. But museums should not create physical experiences at any cost. One staff member described the exhibition as being "too experiential or environmental" overall. This person, who wished to remain anonymous, said, "I don't like the idea that when you're in the ghetto, there's a brick floor, and when you're in the concentration camp, there's barbed wire." And yet visitors often cry while watching the video on the camps. Is this because of the environment or in spite of it? Is this a sign of success? Producing emotional responses is a delicate business. When the museum incites tears, it's worth asking whether curators should give preference to certain kinds of materials in doing so, such as the testimony of survivors.

In The Holocaust in American Life, Peter Novick asked why Americans remember the Holocaust as we do, and what value it contains for us culturally and politically. Is Holocaust memory as we do it good for Jews? His political argument that Holocaust memory in the US serves to shield American identity from our own genocides has merit. He asks what the point is of seeing a movie such as Schindler's List and having a good cry about the Holocaust. ${ }^{40}$ The same question pertains to museums. It is not in the scope of this project to debate the merit of Holocaust museums as vehicles for social justice. However, in the context of my argument, there is a simple answer to Novick's question. In Holocaust museums, as in other kinds of museums, crying, and other embodied emotional responses, are useful. They're useful for building memory and empathy and perhaps also for inspiring action through that empathy.

Unlike the testimony of survivors, which so often elicits tears, the barbed wire and the cobblestone floor at the Illinois Holocaust Museum elicited a sense of disbelief in me. Rather than making me feel "just like" I was in these spaces, as Hirschhaut had said they would, the 
fake cobblestone underfoot encouraged me to envision what the real streets of the ghetto must have been like - uneven, filthy, etc. ${ }^{41}$ This technique worked in a backward way, because otherwise I might not have thought about the street at all. But it did not work as the museum intended.

The question of what makes an immersive environment effective is a difficult one. My quibbles with environments such as the ghetto are telling because of Layman's fine work and attention to detail. The document describing his scenic wall details features photos of the real places upon which the design is based..$^{42} \mathrm{He}$ even provides for a force-rusted finish on the prop padlock and chain on a gate in the section on liberation. Recreating environments may not be the most successful tool. Nevertheless, the museum routinely receives glowing letters from the students who are its intended audience.

Another immersive environment at the Illinois Holocaust Museum elicits emotion and remains consistent with the museum's philosophy. This environment does not violate the supposed impenetrability of the Holocaust because it is actually an object. The twentiethcentury German railcar is the museum's core artifact. It is of the kind that was used to transport Jews to their deaths in the camps.

The question of whether and how authenticity is important looms around the exhibit of the railcar. The railcar, though authentic to the period of the Holocaust, may or may not have carried Jews to the camps. The museum notes its uncertain provenance but does present it as a real object. It stands in metonymically for the experience many victims of the Holocaust had of traveling by cattle car to a concentration camp or death camp. Furthermore, this is one of the experiences that authors and educators such as curators most frequently leverage to try to place the visitor/reader in the shoes of a victim of the Holocaust. This may be because of the volume and variety of sensory information Holocaust survivors can provide about their journeys in the railcars.

Video testimonies of several survivors precede the railcar. Six monitors focus together on one person at a time. One monitor in each bank of three plays video of the survivor speaking. The other four monitors play historical footage that illustrates his or her story. No survivor stands out from the others as having a more poignant or affecting story. The survivors describe the sounds of illness, fear, desperation, and death aboard the cars. Likewise, they describe the stench of a car packed with terrified humans with no way to relieve themselves except an open bucket, the painful indignity of such travel. Their stories, distinct in their details but all equally disturbing, remained with me - people attempting to trade their most prized remaining possessions, their wedding bands, for scraps of food; people being trampled to death; the occasional glimpse of the outside world from between cracks in the boards of the windowless car; total disorientation and a timeless, hellish sojourn to an even worse place. At the Illinois Holocaust Museum, the combination of the presentation of the railcar as real and the context of the survivors' testimonies about their experiences on similar railcars serves to shape the visitor's experience of the car as irreproachably real and authentic. That is the way in which authenticity matters in this exhibit.

The survivors are individuals who settled in the Chicago area after the Holocaust, so there is a sense of a local connection with them. Though there is no known connection between the survivors in the videos and the railcar, surrounding the railcar with these video testimonies gives it more resonance and cements the emotion that the car is likely to elicit. The testimonies remind visitors that the stories of the Holocaust in general and of this object in particular are not abstract or distant. The survivors are our own neighbors. In this way, the 
survivors are indexical for empathy among neighbors and embody the contemporary topic with which the exhibit resonates. The choice of whether or not to enter the car, and thus make the object an environment, is left to the visitor. The railcar is an excellent example of the kind of interactivity Witcomb proposes. The visitor may momentarily become the subject of the narrative. In this way, the visitor's action produces the meaning in the exhibit. ${ }^{43}$

Immersive experience is valuable primarily to build the emotional responses of visitors. Immersion facilitates emotional responses by replicating the circumstances under which others felt a particular response. This can create empathy directly, as it likely does in the case of Holocaust museums and other memorial museums, and it can prime the visitor for learning and memory through paving the way for resonant content to stick.

Recreated environments are most useful in two scenarios. When children are the primary audience, immersion can be a very effective way to create lifelong memories. I remember excellent immersive environments from the museums of my childhood. Traveling the Pacific at the Field Museum of Natural History featured the Tahitian marketplace (Figure 2.3). The marketplace is a complete environment, furnished with stalls divided by a chain-link fence and positioned on a concrete floor. In the stalls, "vendors sell everything from breadfruit, ginger root, and carrots to woven baskets and fishing gear." 44

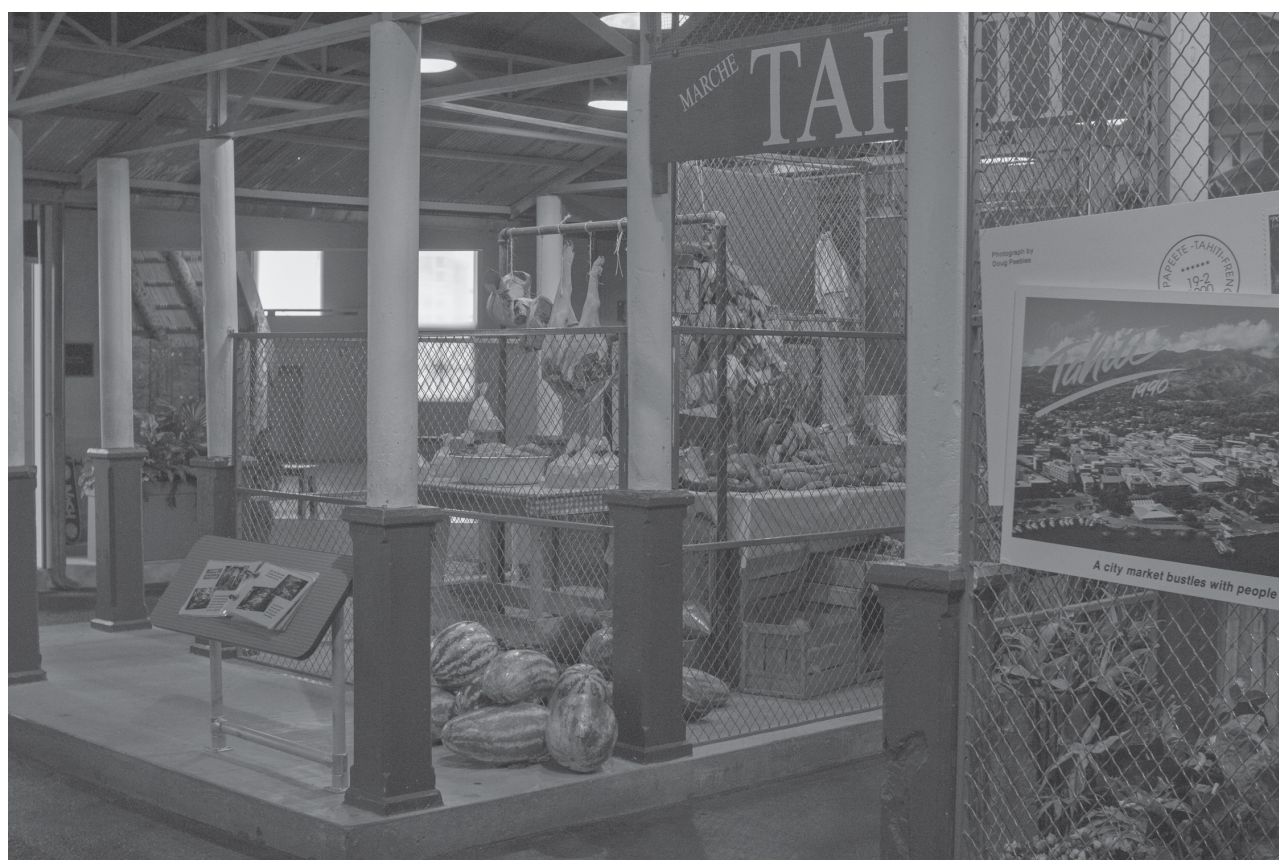

FIGURE 2.3 Tahitian Marketplace in Traveling the Pacific at the Field Museum; photo by author (2016). Courtesy of the Field Museum.

The marketplace contains some objects visitors can touch and others they cannot, but it feels and appears real. The stores contain some products we know, such as Orangina soda, and others we're less familiar with, such as hanging legs of ham and exotic produce. The same goes for Inside Ancient Egypt, also at the Field Museum, an exhibition that hasn't lost its magic for me yet, though its structure is becoming run-down. In this exhibition, the 
immersive environment is a tomb that sits in the museum almost like a large play structure that young visitors can meander through, encountering ancient artifacts along the way. In one area, paintings from the inside of a real tomb chamber grace the walls. At every turn, the visitor is reminded of Howard Carter's peering into King Tutankhamen's tomb for the first time and seeing "wonderful things." The space features several important physical activities, as well, notably the stone block like those that formed the pyramids. It is positioned on a sled so that children can try to move it. Strain as they might, singly or in groups, it is far too heavy (Figure 2.4).

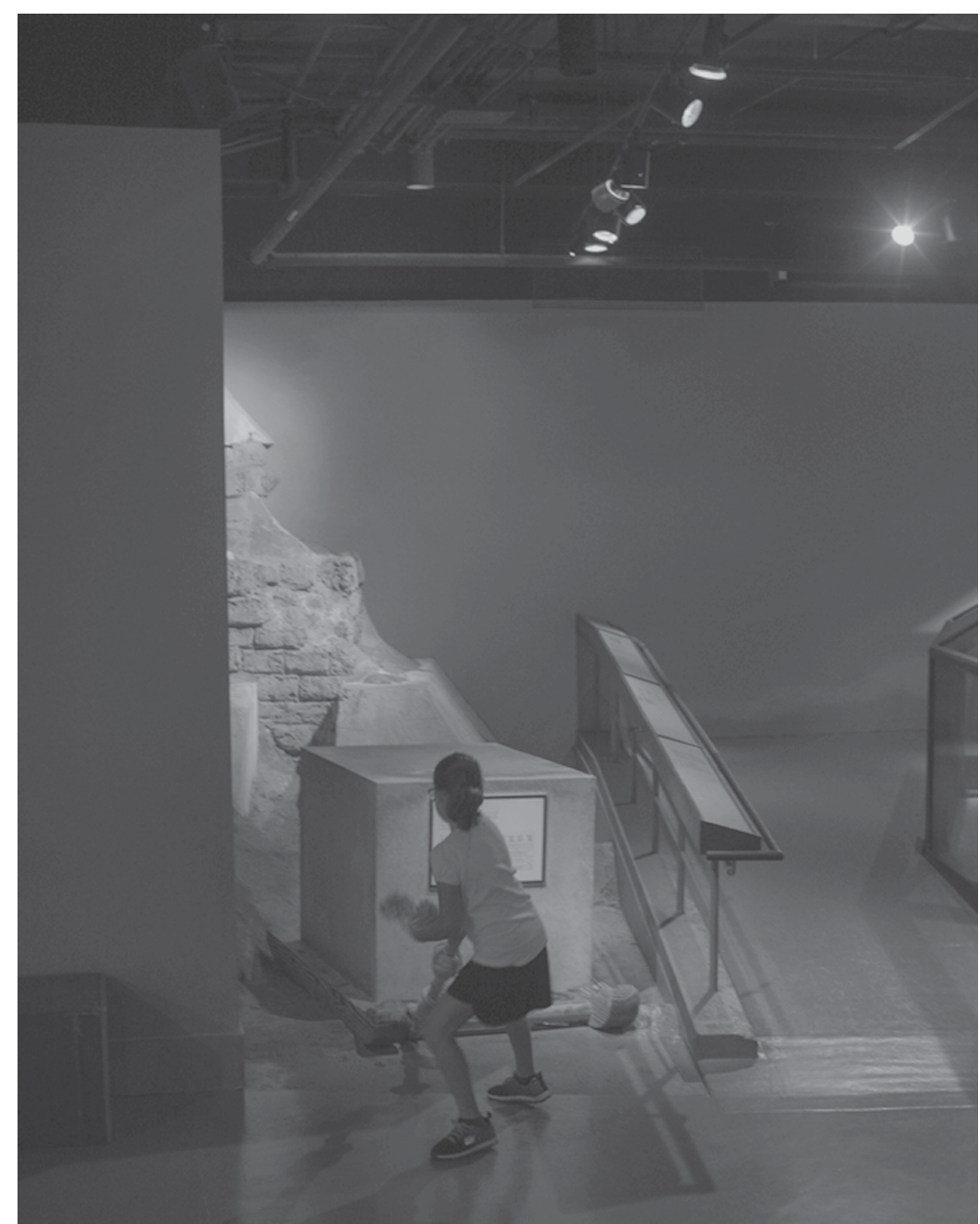

FIGURE 2.4 A visitor tries to move a stone block in Inside Ancient Egypt at the Field Museum; photo by author (2016). Courtesy of the Field Museum.

The second use of recreated environments is in the context of an art installation. In On the Object of the Museum and its Architecture (2004), Naomi Stead, a scholar of architectural history, theory, and design, describes the way in which history museums offer art as a way of engaging with difficult history. ${ }^{45}$ She notes the importance of installations the visitor can enter. Art installations that visitors can enter function as mini immersive environments. The act of 
entering the artwork is a physical experience and supports the development of memory and, depending on the content involved, empathy. In early 2017, the Denver Art Museum opened Mi Tierra: Contemporary Artists Explore Place. Thirteen Mexican-American artists produced new work about their bicultural identities for this exhibition. As Ray Mark Rinaldi put it in a review for The Know, "because the pieces are all big enough that you can walk through them, they are powerfully involving - seeing 'Mi Tierra' is like watching a movie and being in the movie at the same time." ${ }^{46}$

From 2015 to 2016, the Hull-House Museum hosted an art installation that the visitor could move through. Into Body Into Wall was a collaboration between the museum, The 96 Acres Project, and Maria Gaspar, an artist from the Mexican neighborhood of LittleVillage or La Villita in Chicago. Gaspar founded 96 Acres in 2012. The group organizes site-specific art projects in collaboration with the local community around the Cook County Jail in order to reflect on and potentially transform the jail and the criminal justice system in the US. Cook County Jail is one of the largest pre-detention jails in the US. The jail is located in a residential area, abutting Little Village and South Lawndale.

Into Body Into Wall consisted of a single diaphanous curtain that wound through a small gallery. The curtain hung a few inches above the floor and moved with the air in the room (Figure 2.5). The curtain was printed with a life-sized color photograph of the gray wall that surrounds Cook County Jail, including a roughly six-inch-tall band of green grass at the bottom and perhaps four inches of white sky (punctuated by the brick of what must be interior walls or guard towers) at the top. All of the flaws of the wall were apparent - flaking

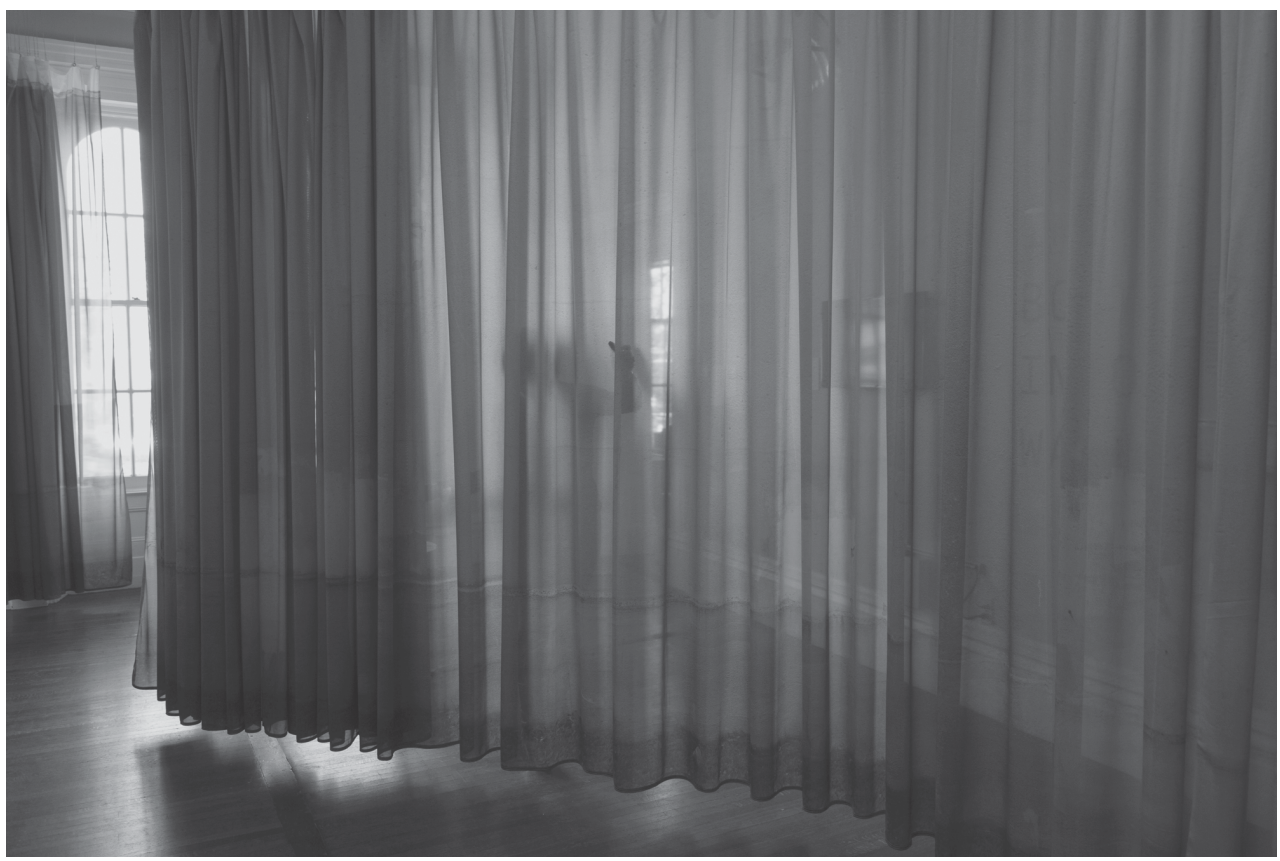

FIGURE 2.5 Photograph by Rachel Herman of Into Body Into Wall by Maria Gaspar at the Jane Addams Hull-House Museum (2015). Courtesy of Maria Gaspar. 
paint and sections that have been poorly painted over, badly patched concrete and holes in the concrete that expose the rebar beneath, peeling caulk, and cracks (Figure 2.6). Nevertheless, the curtain was sheer and the visitor could easily see the museum or street beyond it. The natural drape of the curtain caused it to hang softly.

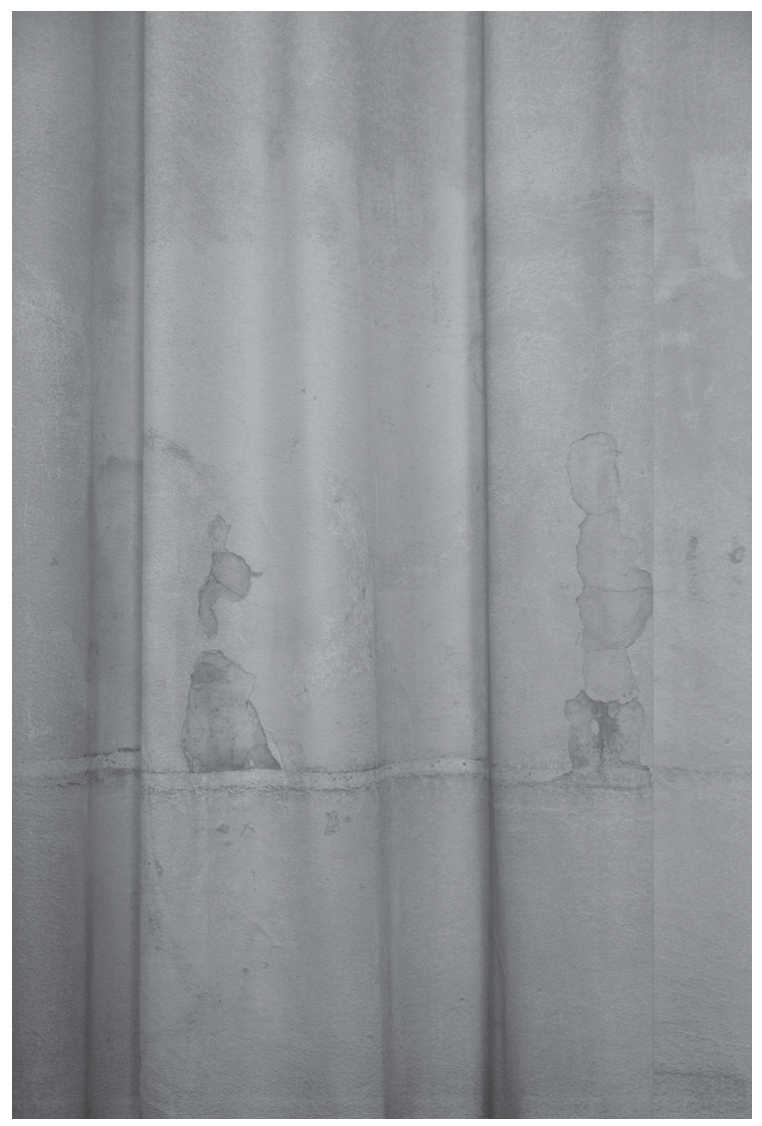

FIGURE 2.6 Photograph by Rachel Herman of Into Body Into Wall by Maria Gaspar at the Jane Addams Hull-House Museum (2015), detail of curtain. Courtesy of Maria Gaspar.

The curtain transformed the room into a maze of four communicating spaces. One area in the entry to the gallery featured a screen and audio dome. Six videos introduced diverse initiatives of the 96 Acres Project and other collaborators.

The curtain delineated a path through the gallery that skirted the exterior walls of the corner room. There the curtain sheathed the nearly floor-to-ceiling windows of the Italianate Hull-House. The largest single space the curtain described held a transparency projector and a screen, two chairs and a table, and two sets of headphones hanging from the ceiling.

The smallest space inside the gallery was a tiny circle of the room shielded in a whorl of curtain (Figure 2.5). Inside were two chairs and a tiny table, large enough to hold a phone and a card prompting visitors to share their own messages and stories about incarceration or Cook County Jail. 96 Acres is about representing "the actual size and scale of the jail" and about thinking of alternatives to the way incarceration functions in our society. One prompt 
on the card asked visitors to imagine what they would do with the 96 acres upon which the prison sits. This call to action is reiterated in the room with the transparencies, where visitors were encouraged to write their visions of transforming the 96 acres on the plastic sheets. A heavy stack of more than thirty completed cards sat beneath the projector. The headphones were for listening to seven audio pieces by former inmates, staff, legislators, and community members about the jail. The more time I spent within the curtain, the more I thought about what I have that those inside the real wall do not. The more time I spent within the curtain, the more solid it seemed.

Two more examples of immersive art installations come from Chicago's Museum of Contemporary Art (MCA). A large bay window punctuated the middle of the exhibition Kerry James Marshall: Mastry (2016). Marshall is well known for his grand portraits of Black figures as well as of quotidian Black life. His mission has been to bring Blackness and Black experience to the walls of museums that have long been the province of White artists and subjects. Mastry exhibited a great range of Marshall's ouvre, and moved from experimental self-portraits to life-sized scenes that are reminiscent of renaissance, baroque, and impressionist masterpieces. The installation "Baobab Ensemble" gave the visitor pause between views of bedrooms, barber shops, and beauty parlors and the next gallery, which featured monumental memorial paintings. At the figurative baobab tree, visitors were invited to share in Marshall's collection of images. Piles of clippings from art books, magazines, and newspapers lay in front of plastic-wrapped cushions on the floor. Examining the images revealed precisely the absences of Blackness in the art history canon that the artist is working against. This installation served at least a double function. It allowed visitors to see for themselves what Marshall himself has noticed, though many visitors needed no convincing on this front. It also gave visitors a break in the action of viewing his intense and monumental paintings. This was a moment for visitors to build the resonant meaning of their emotional experiences in the galleries.

The dilemmas Alfredo Jaar presented in his installation at MCA, aptly titled "The Sound of Silence," haunted me for the rest of the day. Silence is exactly what the visitor heard at the end of this experience. The installation stood apart from the other works in the exhibition Witness (2016) on the MCA's second floor, in a gallery down the hall. Inside the white space of the gallery was a large metal cube clad in long, vertical fluorescent lights. The lights were very bright. As the visitor entered the space and walked around the side of the cube, past the lights, she cast no shadow. At last, behind the cube, her eyes adjusted. A horizontal line of red LEDs: Do not enter. The lights changed to a vertical green line: Enter. Inside, the cube was dark like a theater.The minute-long wait for the film to begin allowed the visitor to notice the four tall flash lights on tripods that remained quiet and dark, for now. Simple white words on a black screen told the story of Kevin Carter, a man who led a difficult life, yet was honorable and helped others. He stumbled into photojournalism. Carter had been photographing starving people at the center of the Sudanese famine and stepped out into the bush, alone, perhaps for a break. There he came upon a very young girl struggling to make her way to a relief station. A vulture sat beside her, presumably waiting for her to become completely exhausted. Carter waited twenty minutes near the girl, trying to get the shot he wanted. He did not help her, and no one knows what happened to her. The lights flash, blinding the visitor temporarily, and she sees the photo then, at the most unsuspecting moment. Carter's photo won a Pulitzer Prize. He received great criticism for not helping the girl and he committed suicide. When the screen goes dark at last, the mind reels at the inhumanity of Carter's actions, even as it is clear that his previous experiences must have disabled him emotionally in some critical way. Jaar's 
intention was to "draw out the human implications and ethical concerns of taking a photo like this." In order to do so, Jaar avoided creating a display that could be viewed quickly. Instead, he created "an enclosed environment in which a narrative unfolds gradually." 47 I have questions about the work, such as whether it is more effective to leave the visitor deeply unsettled but without outlet or utility for that emotion or better to direct the visitor to action or decompression after viewing the installation. But I think Jaar's work is brilliant. It pairs an intellectual experience of storytelling and real contemporary events with an utterly memorable emotional experience with both the story and the physical environment of the installation. The museum collaborated in this by producing a second enclosure for the environment Jaar designed, the enclosure of the otherwise empty white gallery, without which the piece would have been less effective. Like the art installations, immersive environments need not recreate. Sometimes, absence can be most evocative. Just as the MCA supported Jaar's work by using the traditional environment of the museum, so museums can use one of their typical environmental strategies creating a narrative path - as a useful alternative to immersive environments.

\section{An alternative to immersion: the narrative path ${ }^{48}$}

Memorials and historic sites are particularly well suited to using a narrative path. ${ }^{49}$ In both, there is often a sense that visitors should walk a specific path, either as a way of remembering or as a way of stepping back in time. Like fingers handling a rosary, the visitor moves through space ritualistically, engraining a path in her memory as she traverses the physical path that others have also walked.

At the Illinois Holocaust Museum, the railcar sits upon tracks in a wedge-shaped "cleave," as the museum calls the split between the two wings of the building. Before the visitor confronts the railcar, she passes it, seeing it as if in a display case (Figure 2.7).

The railcar exemplifies the compound technique of the narrative path, wherein the exhibition intentionally reminds the visitor that she is in a museum while at the same time causing her to traverse a semi-immersive environment. The visitor has a choice with various implications. She might choose to enter the car. Perhaps she chooses to momentarily inhabit the narrative in a Witcomb-esque interactive, to try to put herself in the shoes of the people caught up in the Holocaust. Or perhaps she has a less overt focus on empathy and is simply curious. Perhaps she is just following the path the museum laid out. If she chooses not to enter the car, that implies a more conscious choice on her part. Avoiding the car involves straying from the path of least resistance in the gallery. She might choose to avoid the car because it is frightening or because she already has too much experience with this narrative, through her own history or the history of someone close to her. One of the marks of good museum work in this exhibit is that the railcar offers so many choices to visitors, all valid, each speaking to different visitors' needs.

Like the boat trip in the famous Disney ride, "It's a Small World," the environment of the museum includes a path that is itself a specialized space - like the canal - as well as separate spaces along and around that path, the exhibits. The narrative path pulls the visitor up next to the alternate reality of the exhibits while still preserving the original sense of place in the museum. The environment of the museum, which the visitor is constantly reminded of, aids her contemplation by providing a certain remove. Even while providing this space for contemplation, though, the narrative path does encourage a certain kind of thinking. 


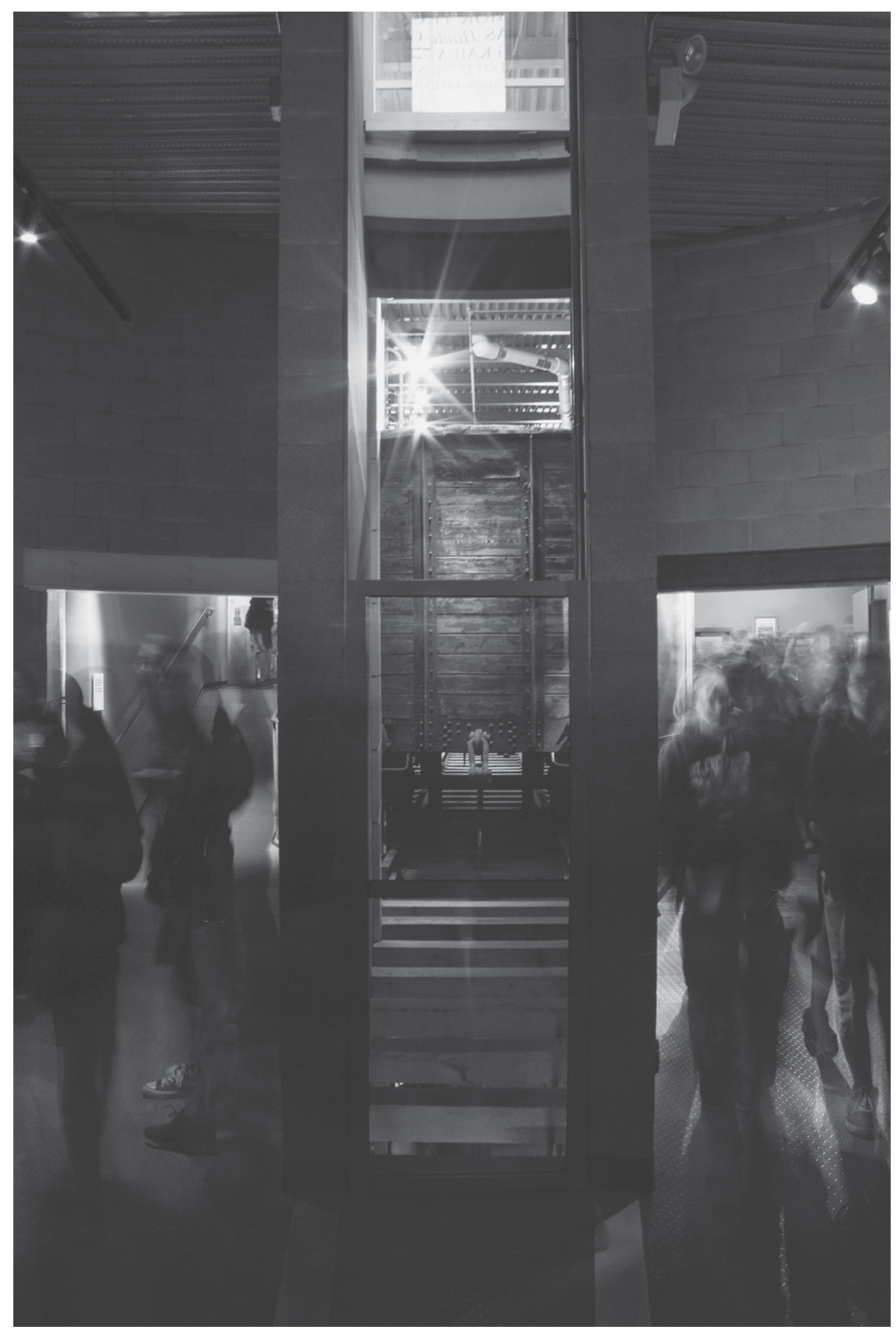

FIGURE 2.7 Railcar in the Cleave (2017). Courtesy of Illinois Holocaust Museum \& Education Center. Photography by Jesus Mejia.

The narrative path underscores the authenticity of what visitors see. Just as the moat around the lions at the zoo reinforces our understanding that the lions are real and dangerous, the path through the exhibits, and the remove it gives us, underscores the truth of the exhibits themselves while also assuaging our anxiety about that truth. The railcar is successful as an environment partly because the installation gives visitors the safety of remembering that they are in the museum space even though terrifying truths surround them. 
The experience of the United States Holocaust Memorial Museum (USHMM) relies in part on the narrative path.Visitors experience it as they walk past cases of hair, shoes, and personal belongings. During the planning of the museum, the commissioners returned home from their research pilgrimage to Europe certain that the new museum needed to create an experience for visitors that would send them on a similar trip. This was necessary in order for visitors to "confront the Holocaust viscerally." ${ }^{50}$ The council of planners hoped to send visitors on another journey, too. Ralph Applebaum, the designer of the exhibit, reported:

We realized that if we followed [eventual victims] under all that pressure as they moved from their normal lives into ghettos, out of ghettos onto trains, from trains to camps, within the pathways of the camps until finally to the end ... if visitors could take that same journey, they would understand the story because they will have experienced the story. ${ }^{51}$

The museum makes meaning through what visitors perceive, but also through the physical experience of the path they trace. These two ideas - walking in the eventual victims' shoes and tracing a specific path through the museum - became the basic building blocks of Holocaust museums. The Illinois Holocaust Museum, the Museum of Tolerance, and the Anne Frank House, for example, all feature them. Through these two frameworks, Holocaust museums often seek an impossible, and conflicted, goal. The goal of truly putting a visitor to a museum in the shoes of a person who experienced the Holocaust first-hand is literally not possible and, ultimately, not actually desirable. But it is important for museums to move visitors to as great an experience of empathy with these victims and survivors as possible. Many of these museums, however, are also working with an inner conflict. Elie Weisel and others feared that bringing the Holocaust into conversation with other events would bring about a "dilution" or "murder" of memory. ${ }^{52}$ According to Wiesel's narrative,

The Holocaust could never be understood, but, for the sake of humankind, had to be remembered. It was an event that transcended history, almost incapable of being represented except through survivor testimony ... The Holocaust was not only a transcendent event, it was unique, not to be compared to any other genocidal situation, and its victims were Jews. Any comparison of event or linkage to any other victim group could be, and often was perceived as, if not the murder of memory, at least its dilution. ${ }^{53}$

The inner conflict is represented by the essentialist point of view about the Holocaust on the one hand and the desire to bring others into understanding and sharing the narrative on the other. This dilemma crystalizes the twenty-first-century crisis of identity in which Holocaust museums find themselves. In order to remain relevant to future generations, they must open their discussions of the Holocaust in relation to other historical events and also their discussions of Gentile victims. These quandaries, the pushes and pulls of generational interests, cultural interests, and professional interests in the museum's narrative, inform the decisions of how to craft immersive environments in Holocaust museums and what the experiences of those environments are like.

The fully immersive environment and the narrative path rely on two different models for visitors' experience and involvement. To return to Andrea Witcomb, these practices insert the visitor into the text of the exhibition in different ways. In the immersive environment, the 
design invites the visitor to walk in the shoes of victims of the Holocaust through role play. ${ }^{54}$ Hirschhaut, Mais, and Berenbaum were correct that role play would be inappropriate in the context of the Holocaust, though they ultimately fostered it. The narrative path, on the other hand, does not offer a whole environment but rather signposts on a path, such as the video testimonies and the railcar. In this way, that tactic proposes the role of listener to the visitor, an active listener who can, in certain cases, inhabit spaces within the narrative.

In the narrative path, the museum circumvents the problem of having an artificial environment undermine emotion by deliberately drawing attention to the gallery. This environment carries resonant meanings of authority and authenticity from the museum. Great use of architectural space, objects, and installation can still achieve an excellent wondrous response. Rather than attempting to transform the museum into another kind of place and possibly falling short, the museum can simply be a museum and focus on its traditional tasks of presenting, displaying, and interpreting. Museum magic is sometimes most profound and pitch-perfect with a lighter touch.

\section{Taking ten: rest in the gallery}

Providing the right punctuation for histories of violence and cruelty can help avoid the common problems of overstimulation and compassion fatigue.Visitors may not form effective memories of their experiences, and, even more important, they may fail to feel empathy. Robert Sapolsky writes that "short-term stressors of mild to moderate severity enhance cognition, while major or prolonged stressors are disruptive." ${ }^{55}$ The stress that enhances memory and cognition is perhaps better termed "stimulation." 56 Stimulation helps the consolidation of memories and activates our "pleasure pathway" of dopamine receptors in the brain. ${ }^{57}$ This results in our seeking mild to moderate stressors that stimulate us. It is a rewarding activity that we are inclined to repeat. It is up to curators to keep exhibitions in the realm of stimulation and out of the realm of prolonged stress. This can be a challenge over the course of, say, a 300object exhibition on the Holocaust.

The more a curator can engage the visitor's sense of emotion without overwhelming her, the more the curator will be able to keep the visitor thinking. This is because rational thinking and emotion happen in direct proportion to one another up to a point. ${ }^{58}$ Some museum professionals know this from experience and try to build emotion for their visitors and themselves. As the staff was designing and planning the exhibits for USHMM, the Exhibition Department staged objects for colleagues to view and make selections. Planners "came to the storage facility to form sensory links with what many thought of as the 'real material' of the exhibition." ${ }^{59}$ Curators at the NMMA also visit special selections of material from the permanent collection in the vaults or off-site storage to see what emotional experiences they have in front of the works.

At museums with distressing narratives of violence, staff members often fear alienating visitors with too much dark or depressing content. Without comparing the importance of content that is historical, let alone memorial in nature, with that which is purely entertaining, Damasio's discussion of why films such as Alfred Hitchcock's are so popular offers a useful lesson.

These films and many others offer experiences of pain and suffering that the director then intermittently suspends. This temporarily gives the viewer feelings of well-being. ${ }^{60}$ In a way, it's almost the inverse of what happens with recreational drug use. The user feels good when high, but then feels worse than normal when the drug wears off. This leads the user to seek 
the high again. In the film example, the viewer is inclined to watch the film even though it is troubling because there are many tiny highs buried inside it every time there is a break in the negative content. It will certainly strike some as crass to consider the experiences of visitors to museums with disturbing historical content in this light. I am not suggesting that visitors take pleasure in the suffering of others. But I am suggesting that the same mechanism that works in film may work in the museum at the neurological level. Even though the content of museums can be deeply upsetting, visitors may return to museums with difficult history not only for conscious reasons but also because a properly punctuated experience of difficult histories can nonetheless be neurologically satisfying. The knowledge that this is a feature of visitors' experience, unconscious thought it may be, can help curators working in this type of site to structure the ebb and flow of difficult content.

Curators can care for visitors by giving them breaks while they are taking in challenging content. The best-known tool for protecting visitors from overstimulation is offering a space for decompression. Rather than dwelling on that practice, I will draw attention to underrecognized possibilities in the gallery. Controlling stimuli in the gallery, offering a change of topic, and creating "lines of sight" through the gallery are techniques that come from the Illinois Holocaust Museum and the Chicago History Museum, though variants of them can and should be found in many museums. I hope gathering them together in this manner will help other museums plan conscientiously for their portrayals of histories of violence.

Elements of the Karkomi Permanent Exhibition at the Illinois Holocaust Museum overwhelm the visitor aurally and visually. These issues may seem too obvious to write about. But not taking care to avoid them can undermine all of the hard work of the curatorial team and turn off the receptive visitor or drive her away. Aural overload happens throughout the permanent exhibition at the Illinois Holocaust Museum as a result of the regularly spaced, yet not aurally contained, videos. Audio domes would handily solve this problem. Visual overstimulation is a problem that could also be easily resolved. In a section called "World at War," for example, six monitors sometimes show part of the same picture and sometimes all show different images. They're disorienting and hard to read visually, since the footage is grainy and old. I think this exhibit was designed to be fast-paced and confusing in order to illustrate the Blitzkrieg and the fall of Poland, Denmark, Norway, the Netherlands, Belgium, Luxembourg, France, Yugoslavia, and Greece. But no other visitors ever joined me in viewing this set of videos. The confusion of the videos seemed to drive other visitors away.

I see the resting places and moments of normalcy in Holocaust museums as creating space for visitors' emotional systems to relax and for memories to take shape. The "Tower of Faces" at USHMM was originally conceived as just such a resting place from the most challenging parts of the narrative. ${ }^{61}$ The "Tower of Faces" is an assemblage of 1,000 photos from the Lithuanian town of Eiszyszki, whose 3,500 inhabitants were exterminated. It is a breathtakingly beautiful monumental exhibit that creates tension between old and new curatorial practices. While, in one sense, the exhibit is simply photos displayed on the wall, those photos are mounted on aluminum and laminated in plastic to create a uniform look and finish. Though the photographs are hung salon-style, they are not displayed two or three or even four photos tall, but stacked far overhead, more than twenty-five rows high. In the "Tower of Faces," the photos abut one another horizontally and vertically and cover all four walls of the tower. ${ }^{62}$ In that subtle flip of the expected, resonance reverberates between the visitor's location in the museum and the other time and place that the museum is evoking - Eszyszki (indeed, Europe) pre-1945. This resting time is necessary in any exhibition that deals with a particularly emotionally taxing history. 
At CHM, Joy Bivins described the design of her exhibition on lynching and racial violence. Bivins and her team designed Without Sanctuary to allow visitors to see the violence and have the space to engage with it, but also to have a "line of sight" to the responses and resistance to that violence. ${ }^{63}$ Though Bivins was referring to a literal viewpoint through the gallery, her phrase and purpose resonate with Matthew Guterl's concept of racial sightlines in Seeing Race in Modern America. For him, "A sightline is ... a persistent and prescribed reading of an image, or of images related to each other, sustained by the history of racism and race relations." $\mathrm{He}$ might see Bivins's lines of sight as working to disrupt the old racial sightlines that the lynching photographs cannot help but mobilize. The narrative of resisting violence helps avoid doubly victimizing people. It also draws visitors through the dark tunnel of the violent narrative.

Another way to punctuate and relieve difficult narratives lies at the opposite end of the emotional spectrum. Laughter engages us completely and often sticks with us after the fact. Cesáreo Moreno, co-curator of The African Presence and Director of Visual Arts at the NMMA, commissioned a work of art to address a particular concern in that exhibition. It was relatively late in the project, but Moreno felt that he was missing the piece that would display the dark side of the story, that would meditate on the circumstances of slavery under which Africans came to have a presence in Mexico in the first place, as well as on the ongoing racism in Mexico today.

Moreno commissioned a work by Alfred Quiroz, a professor of art at the University of Arizona and a Chicano artist of the Civil Rights Movement. His work has always been about stereotypes. His cartoonish style helps viewers to look at violent content from a bit of a distance even when they know the content is historical. It never occurred to Moreno that Quiroz would include the deeply controversial cartoon character Memín Pinguín, a depiction of an Afro-Mexican boy whose ape-like features read as clearly racist to anyone in the US but who remains popular in Mexico (Figure 2.8).

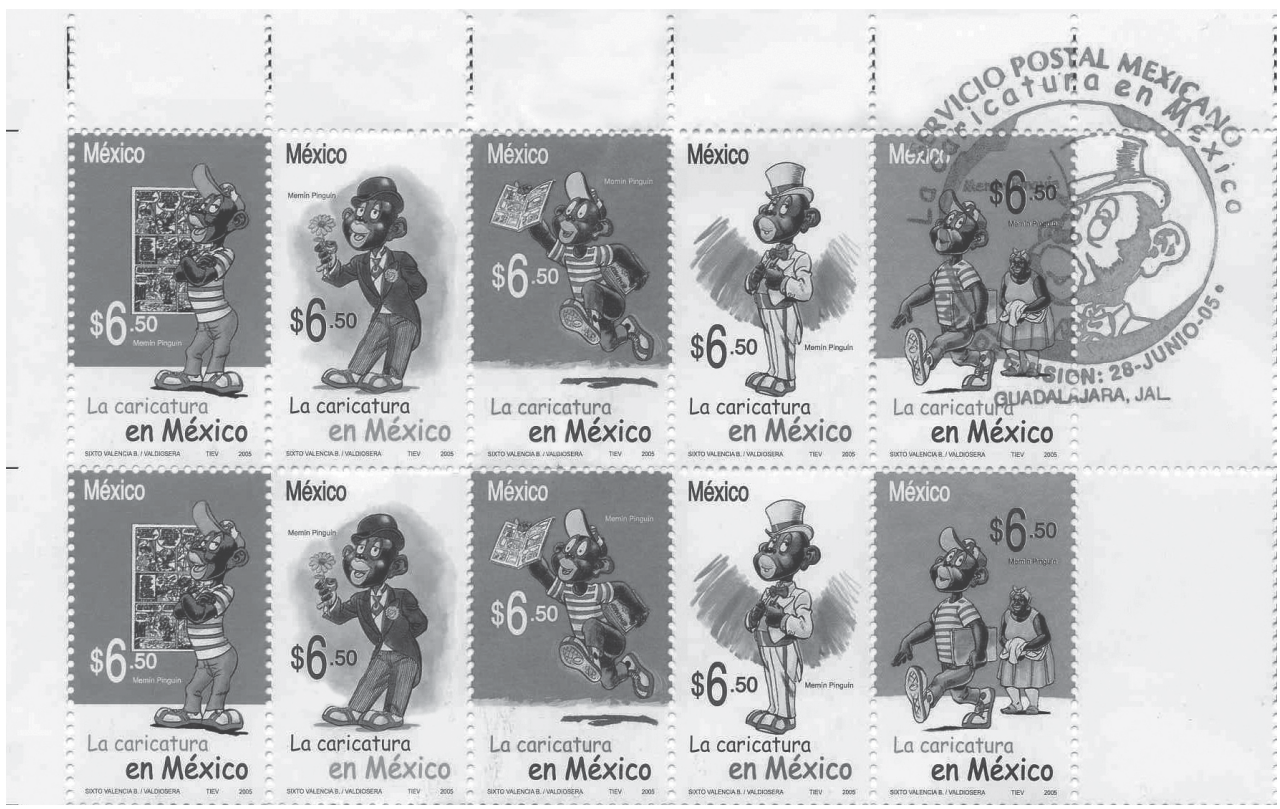

FIGURE 2.8 Fiftieth-anniversary commemorative postage stamps of Memín Pinguín (a character created by Yolanda Vargas in 1942) from Mexico (2005). Image courtesy of the National Museum of Mexican Art. 
It was too late to try to stop Quiroz from including Pinguín at that point because he was already the central figure in the 5' x 8' triptych, "La Raza Kózmika." (Figure 2.9)

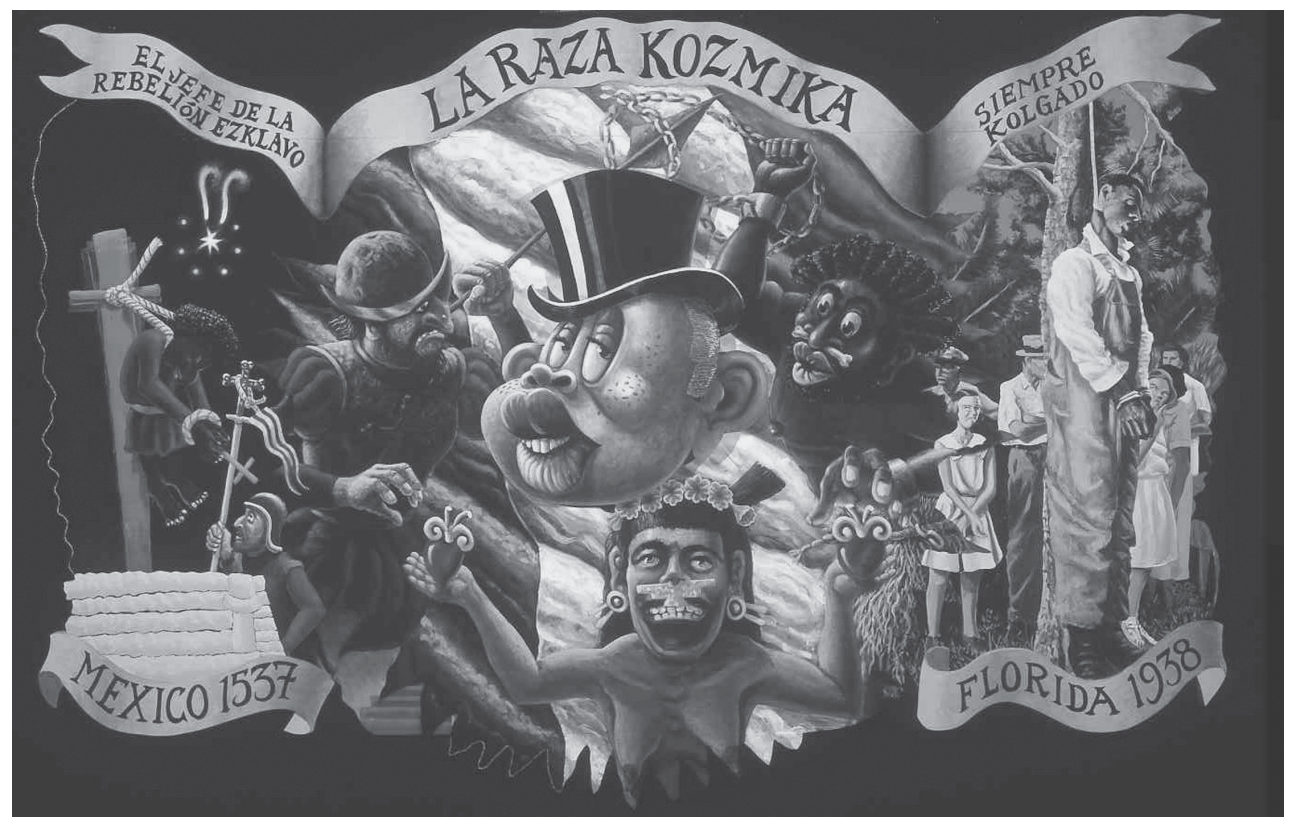

FIGURE 2.9 "La Raza Kózmika” by Alfred J. Quiroz (b. 1944), 2005, acrylic on wood panel, 64" × $95.5^{\prime \prime} \times 3.5^{\prime \prime}$, collection of the artist. Photo by Wilson P. Graham. Image courtesy of the National Museum of Mexican Art and Alfred Quiroz.

The title of Quiroz's piece reminds the viewer that he is making fun of the racist notion of improving the Mexican race by eliminating the African component. This idea came from Mexico's Minister of Education after the Mexican Revolution, José Vasconcelos. The triptych features a variety of offensive imagery. In the center, a whitened and lightened Memín Pinguín resembles a caricature from the Jim Crow South. Three other stereotypical figures surround him. A savage conquistador raises his spear at a savage African slave with a bone through his nose. They both reach down to snatch one of the human hearts the savage Indigenous woman holds in each of her hands. The backdrop of this central panel is the Mexican flag, tattered at the edges, and Memín Pinguín's head appears where the eagle atop the nopal traditionally does. The message is that Vasconcelos's magical mestizaje of the three stereotypical figures has resulted in the corrupt "bronze race" of Memín Pinguín, rather than the perfected one Vasconcelos sought. And that's just the center panel of the triptych. The side panels of the painting each feature a lynching. On the left, an African man hangs under the title "EL JEFE DE LA REBELIÓN EZKLAVO" (Head of the Slave Rebellion). Beneath his feet are the place and date: Mexico 1537. On the right, an African-American man hangs from a tree in a scene that is clearly copied from a postcard of a lynching. We know from the banner near the man's feet that it's Florida, 1938. Spectators stand around behind him, including men, women, and a little girl in the near middle ground. The banner over the man's head reads "SIEMPRE KOLGADO” (Always Hung). Quiroz undermines the legitimacy of the Spanish position at every turn in this piece, from his use of such a traditional colonial art form, the painted triptych on wood, to the bastardization of the castellano, where he changes "C"s to " $\mathrm{K}$ "s. ${ }^{64} \mathrm{By}$ 
doing this, and through his cartoony style, he asserts his Chicano identity and distances himself from the history at hand. But he also, as Moreno promised, takes shots at all of the characters in his piece. No one in the center panel is virtuous.

Moreno was terrified, as were the other staff members who saw the piece, that it would be unacceptable for presentation. But the members of the steering committee were enthusiastic about the work, saying that the exhibition is outside of most people's comfort zones anyway, and this piece allowed a discussion of that discomfort to begin right away. The committee helped to frame how the piece would be presented in the gallery by reviewing and editing the content of the label.Visitors seemed to respond to the piece in the same way as the steering committee. No one complained about the work. When groups toured the exhibition with a guide, they regularly discussed it at length.

\section{Creating ways for content to resonate with visitors}

Resonance is an important way for a visitor's engagement, piqued by emotional response, to take root. And it can arise from many different sources. They all stem from the groupness described in Chapter 1, which is to say that they all stem, in one way or another, from our many senses of identity. You may find resonance at a Holocaust museum because a relative of yours was personally involved, or because of the use of poison gas on innocent civilians in Syria.You may find resonance at the NMMA because you are Mexican or because you're visiting the Day of the Dead exhibition and a relative of yours passed away. Whatever the source of the resonance, once an installation in a museum triggers it, it strengthens your sense of groupness, in which you are an insider and define yourself as part of a group and distinct from outsiders to that group. This is one way to explain how museums help us step into one another's shoes. ${ }^{65}$ And it flips negative groupness on its head, using groupness as a tool to connect groups together through the intersectionality of individual visitors. ${ }^{66}$

Resonance is natural and flexible; however, curators must attend to the possibility that the way we shape narratives can exclude particular visitors as well. One example comes from the narratives that are prevalent in Holocaust museums. Placing the narrative of the Holocaust in conversation with other genocides has been controversial. Many Holocaust museums relegate this type of work to the periphery or even to programming, the website, or other areas that are not involved in the exhibitions at all. The closed narrative has a long history, dating back at least to the 1970s ${ }^{67}$ One result of separating the Holocaust from the rest of history and current events can be that the resonance and emotion the museum might hope to foster is impeded for those without a personal connection to the Holocaust. Another is that visitors who want to empathize with the subjects of the narrative because of their own experiences with genocide or other atrocities might feel isolated or disenfranchised. This is most unfortunate since they are uniquely positioned to carry these histories forward and maintain their relevance. Holocaust museums are debating whether they should be Jewish museums and to what degree they should also memorialize the non-Jewish victims of the Holocaust. ${ }^{68}$ For museums that choose to commemorate the diverse identities of Holocaust victims, several strategies are important to avoid further marginalizing other populations targeted by the Nazis. Curators can make many different visitors feel welcome and included in the museum through techniques such as these: creating nuanced portrayals of non-Jewish victims, involving the story of those people's lives before the Holocaust in a meaningful way, and not seeing their stories as only a way to bring more meaning to the Jewish story. Another crucially important element of creating relevance is involving members of the target community in interpretation. 
I discuss this further in Chapter 4. Quashing opportunities for resonance can disable the formation of empathy.

Resonance is also important for building memories. Daniel Schacter, Director of the Schacter Memory Lab at Harvard University, explains in The Seven Sins of Memory: if people can elaborate on incoming information and relate it to their own experiences, memories endure. ${ }^{69}$ Dierdre Wilson and Dan Sperber echo this idea, writing that from the point of view of cognitive sciences, relevance "yield[s] new conclusions that matter to you" while costing you as little effort as possible to take in the new information. ${ }^{70}$

Curators can use tools such as transparency of position, mobilization of data, and political appeals in combination as a way of offering diverse points of entry into the narrative, all the better to create resonance with many different visitors. These tools are straightforward and functional, and they can be accessible to all kinds of museums, regardless of size or budget.

\section{Taking a position}

There are various ways to go about taking a position and managing transparency. Here I will share examples from Hull-House and the NMMA about their processes.

Teresa Silva curated an exhibition called Unfinished Business: Juvenile Justice at Hull-House. She began laying out her curatorial position with a set of "curatorial questions" that she and the rest of the team needed to answer:

- What do we want our audience to know?

- What do we want our audience to feel?

- What do we want our audience to do? ${ }^{71}$

The curatorial questions enabled the group to agree on the content for the two main labels in addition to other content. The main labels introduced the concept of unfinished business - concerns that were pertinent to the Progressive reformers and also remain for us today. The labels let visitors know that the exhibition is about activism. ${ }^{72}$ They also introduced the curatorial partners, community groups involved in shaping the messages of the exhibition, and demonstrated that the museum was not alone in its call for reform of juvenile justice. But the curatorial questions were also bold, especially the final one. Many museums do not take the step of asking what they want visitors to do. But even if the museum has no plans to try to encourage a visitor to act, this is a useful question that demonstrates the human thinking behind the exhibition to those working on it together.

This kind of transparency extends an olive branch to the visitor and says "Yes! It is ok, even desirable, for you to make connections between this material, your life, and other contemporary phenomena because this material is situated in our contemporary lived political experience."When the museum invites the visitor to make sense of the content in the exhibition in the context of her own life and contemporary events, the museum helps the visitor build empathy. She may even become inspired to take action.

In the most controversial exhibitions at the NMMA, such as Declaration of Immigration and The African Presence, the decision to take a strong position came through the highest levels of the museum's leadership and the Exhibitions Committee. Carlos Tortolero, the president, engaged the Board of Trustees in supporting the vision for a project before the museum moved forward. Then it was up to curators, such as Moreno, to build a visual and textual statement in the form of an exhibition. But the museum doesn't fabricate these positions out 
of whole cloth. Especially for an exhibition of contemporary art such as Immigration, artists respond to the museum's call for proposals. The museum knows its position is on track when, as Moreno put it, a "critical mass" of artists supports the exhibition's thesis. In 2007, the Call for Proposals (CFP) for Declaration of Immigration stated the museum's goals plainly, yet in an open way that invited artists to coalesce around themes:

This exhibition will survey various attitudes and ideas regarding immigration ... One of the principal notions of the exhibition will be to display work that allows the general public to better understand the unique relationship between the US and its Latin American neighbors. Another aim is to somehow "put a human face" on immigration in order to more accurately show how this issue truly affects families in different ways ... Some of the issues that may be addressed include, but are not limited to ... : U.S. labor \& economics; Migration patterns; Immigrant dreams, struggles \& contributions; Cultural influences, assimilation \& identity; The rural and/or urban experience of the immigrant; Fears, stereotypes and misconceptions; The history of the US borders \& ports of entry; General concepts of borders (national, political, neighborhoods, neighboring communities ...). ${ }^{73}$

Though the collaborators and funders of the NMMA expect that museum to take a position, this, one of its strongest political stances, was very successful. The Warhol Foundation funded the exhibition. Many contemporary artists responded prolifically to the CFP, and those who participated in the exhibition had fun with the topic by producing playful works of art, such as the foosball table in Figures 2.10 and 2.11.

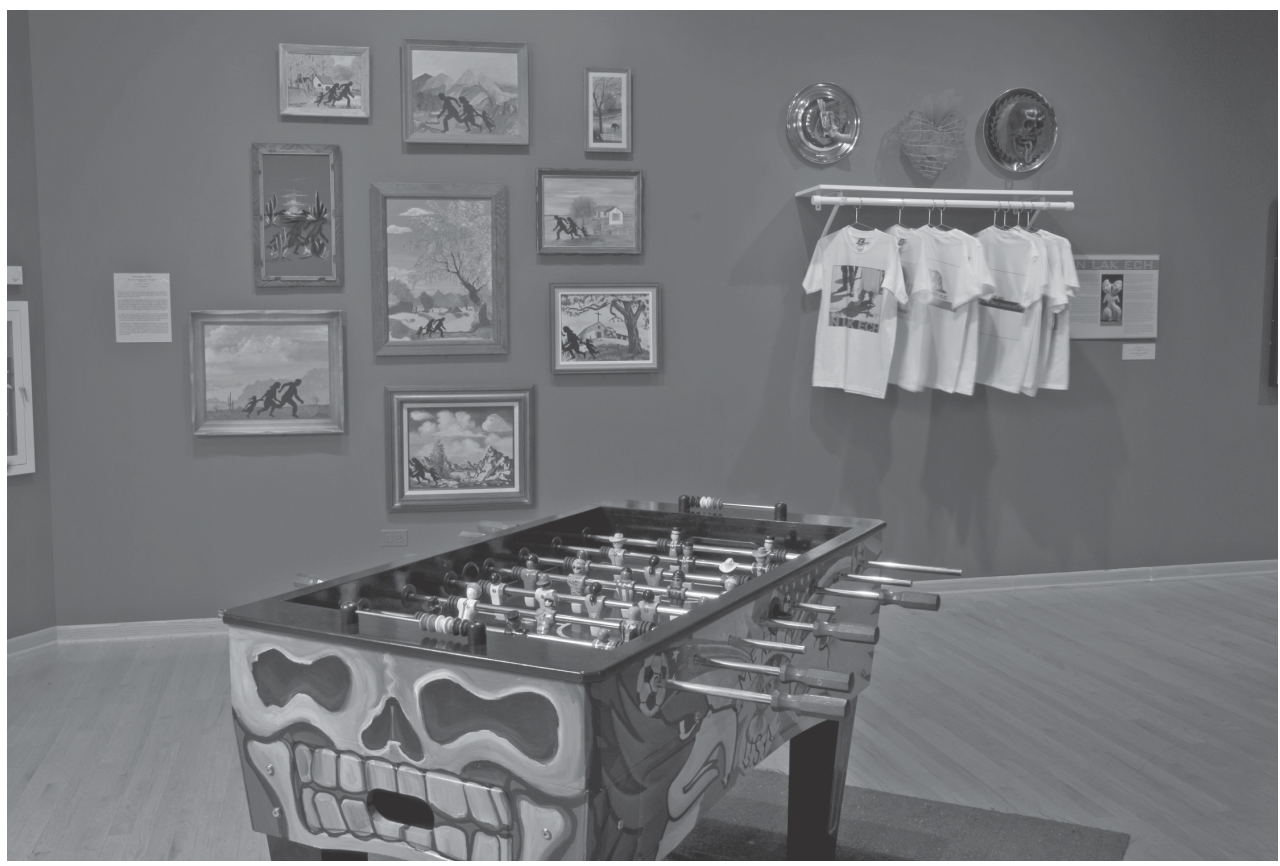

FIGURE 2.10 "Copa inmigración AKA Deport a Mex Foosball” by Juan and Ricardo Compean, 35" $\times 30^{\prime \prime} \times 56^{\prime \prime}, 2008$, mixed media with foosball table. Courtesy of Juan and Ricardo Compean and the National Museum of Mexican Art. 


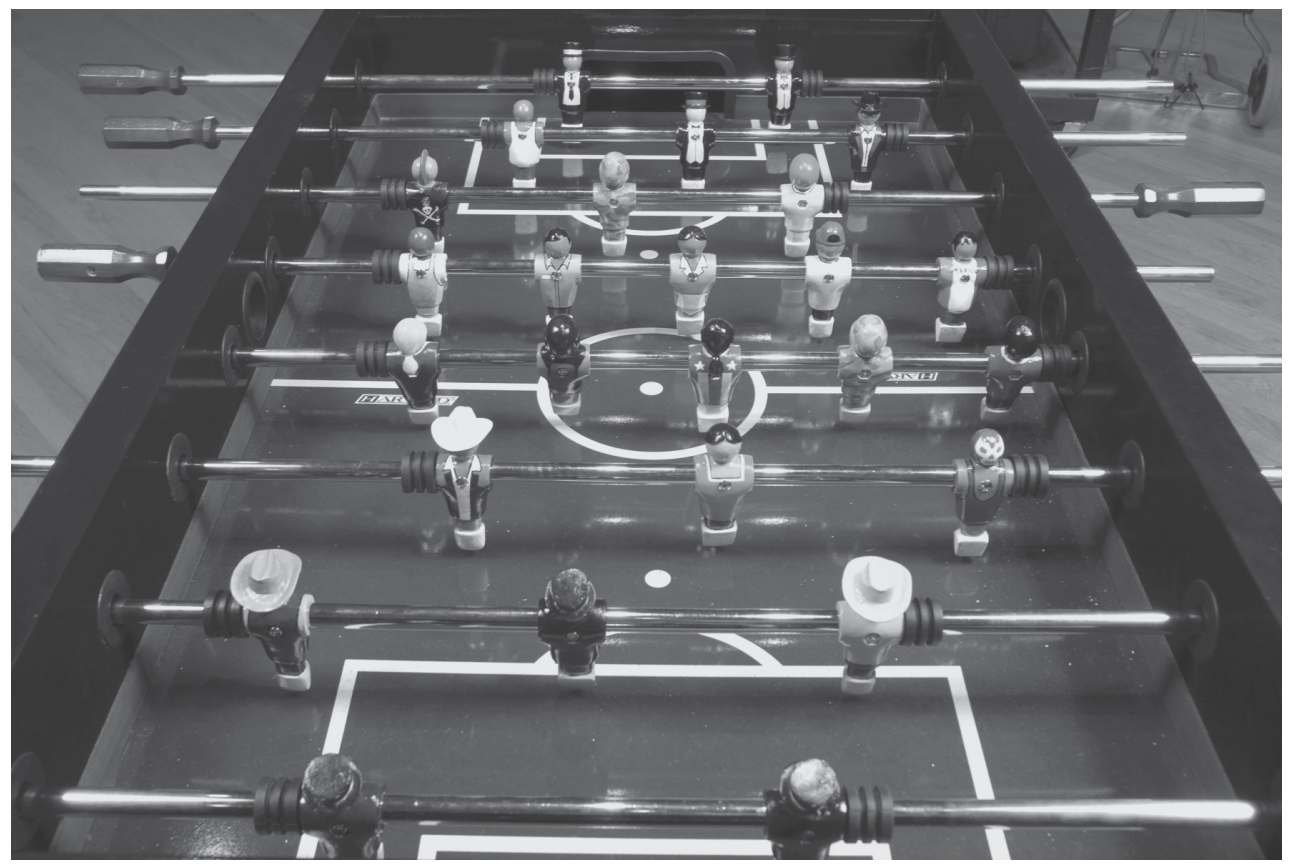

FIGURE 2.11 "Copa inmigración AKA Deport a Mex Foosball" detail by Juan and Ricardo Compean, $35^{\prime \prime} \times 30$ " $\times 56$ ", 2008 , mixed media with foosball table. Courtesy of Juan and Ricardo Compean and the National Museum of Mexican Art.

\section{Appealing to logic, using facts and figures}

As a politically motivated art museum, the NMMA regularly integrates a reasoned approach to the visitor with the presentation of artwork and other objects. But The African Presence offers a particularly strong example from that museum being, as it was, equally rich in information and art. The first of the three exhibitions, The African Presence in México: From Yanga to the Present, addressed the nearly 500 years of Afro-Mexican history that were unacknowledged in Mexico until 1992. Sagrario Cruz-Carretero was the co-curator. She had previously been the research assistant to Gonzalo Aguirre Beltrán, the Mexican anthropologist. When he published studies on Afro-Mexicans in 1953 and 1958, he was virtually alone in his field. As Cruz-Carretero put it, the elimination of race on the Mexican census after the Mexican War for Independence (1810-1821) created a legal situation in which the Afro-Mexican population was not an official entity. ${ }^{74}$ So, "Blacks in Mexico did not officially exist before this announcement [in 1992]."

The second exhibition, Who Are We Now? Roots, Resistance, and Recognition, covered the relationships between Mexicans and African-Americans in the US as well as between AfricanAmericans and the country of Mexico. The final section of Who Are We Now? "Recognition," explored the demographics of the 2000 census, the famous census in which, as many put it, Latinos surpassed African-Americans as the nation's largest minority. Though it is factually true, that statement pits the two groups against one another as if being the nation's largest minority were a status that a group should defend. It also frames as minorities two groups that become the majority in many cities when they come together. For example, when I curated 
this exhibition, the two groups made up 56 percent of the population in Chicago. ${ }^{75}$ Roughly 25 percent of the people in the Chicago area were Latino, and roughly 75 percent of the Latinos in the Chicago metro area were Mexican. ${ }^{76}$ These statistics were crucial to building a sense of political potential and to moving both groups away from the notion of being "minorities." To facilitate this, Angelina Villanueva, then designer at the NMMA, produced special maps that showed the distribution of the two populations around the country and where they converged (Figure 2.12).

I bookended the maps with stories of political collaboration. My curatorial narrative knitted together graphic, didactic elements, and objects in order to create resonance for visitors through an appeal to their engagement with current events. But the centerpiece of this strategy was the visual representation of data. This can be very compelling, especially around challenging or divisive topics.

\section{Making a political appeal}

I used a related technique in that same section of Who Are We Now? "Recognition" explored political collaborations between Mexicans and African-Americans in the US, such as the elections of Harold Washington and the mourning of his untimely death in 1987. The section featured Alderman Jesús “Chuy” García’s eulogy of Washington alongside photographs from Washington's mayoral campaign and wins (1983 and 1987). This was the emotional counterpart to the resonance of the statistics and maps, also in this section. Another collaboration resulted in Antonio Villaraigosa's successful campaign to become mayor of Los Angeles in 2005. Jennifer Jones had recently completed her master's degree when she first saw The African Presence and Who Are We Now? Now Jones is Assistant Professor in Notre Dame's Department of Sociology. I spoke to her in 2012, shortly after she completed her doctorate. She complained that stories of effective coalitions between Black and Brown people are always qualified with caveats. For her, seeing a Black/brown coalition in an unreservedly positive light was a refreshing place to end the exhibition. Several photos showed large marches and rallies that were clearly multiracial. African-Americans and Latinos stood together en masse at Harold Washington's election. For her, the photographs demonstrated, as I had hoped, that the two groups were sharing space and working together on a daily basis. ${ }^{77}$ One visitor's comment also indicated that this section was producing emotion and resonance. The 47-year-old visitor from Los Angeles wrote:

The two exhibits on Mexican-African heritage people are timely and wonderful. I was very moved at hearing Jesús García's eulogy for Harold Washington. I was at that funeral and at the acknowledgement of race politics in the election of my Mayor now, Antonio Villaraigosa. $^{78}$

Once again, the presentation of material that builds resonance through contemporary events is useful for visitors. In this case, the presentation focused not on data but rather on continuity of political work: the notion that people had come together to be involved in a project in the 1980s that had real effects and were once again doing so. I didn't make the suggestion outright in the texts, though I did in person when I guided visitors through the gallery, but my hope was that these ongoing stories of collaboration would inspire further contemporary collaboration in my own "majority minority" city. 


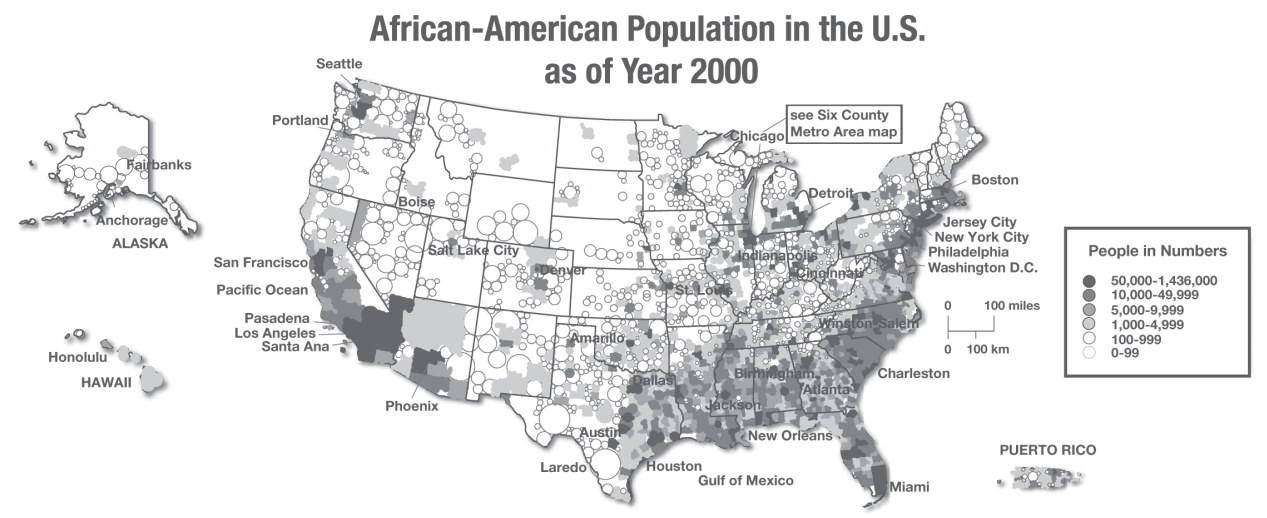

Population in the Six County Chicago Metro Area as of Year 2000

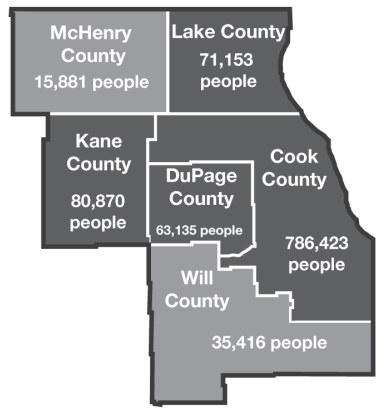

Mexican Population

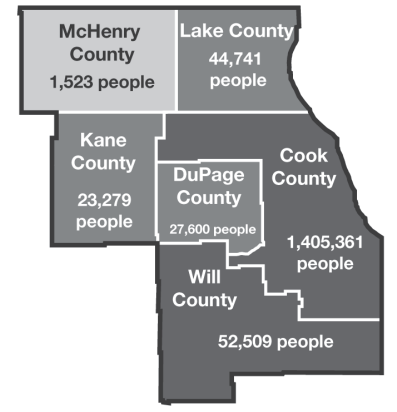

African-American Population

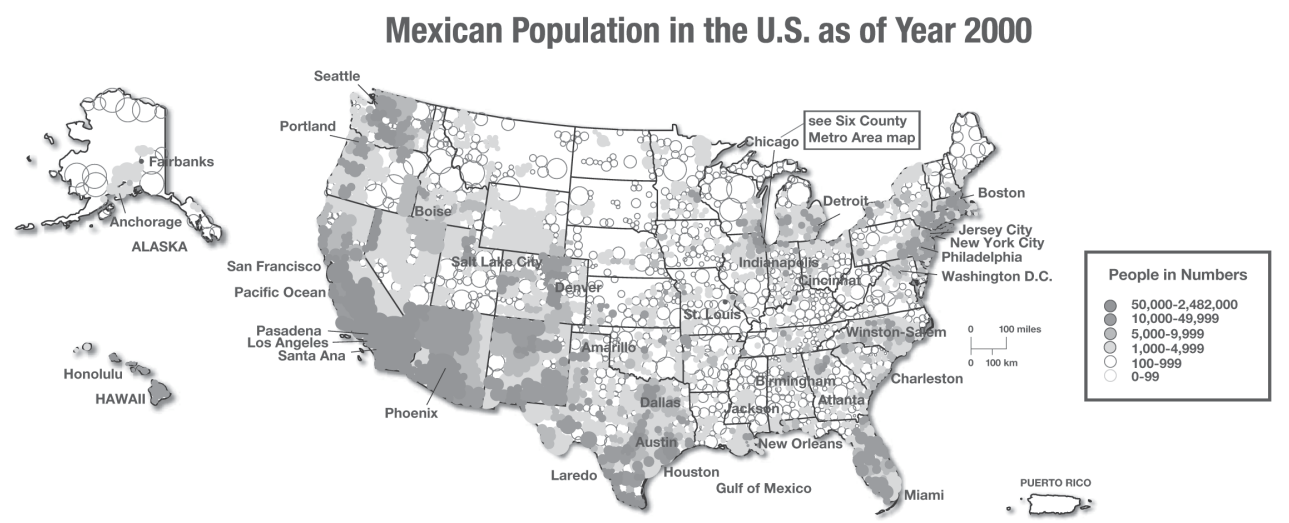

FIGURE 2.12 Census map didactic panel by Angelina Villanueva for Who Are We Now? Roots, Resistance, and Recognition, 2006. Courtesy of the National Museum of Mexican Art. 


\section{Using art to support wonder and resonance}

We know the power of art intuitively and physically from experiencing it in our own lives. There has been a resurgence of scientific interest in art and what draws us to the forms we love. From Ramachandran's self-proclaimed (yet untested) "rules" about what makes art attractive to the brain ${ }^{79}$ to Gallace and Spence's exploration of how the grouping principles of Gestalt psychology apply to tactile perception, ${ }^{80}$ it is clear that there are some universal elements of art that make sense to the human brain. Indeed, as Barbara Stafford put it, there are certain forms that never disappear from the visual record. She believes that this is because they are demonstrative of the way the brain and our consciousness works. ${ }^{81}$

Cesáreo Moreno, Curator andVisual Arts Director of the NMMA, sees visual art as one of the best challenges to preconceptions because it isn't based on language. Text invites immediate debate.Visitors can be drawn in to artworks before they realize they're dealing with a subject or position that makes them uncomfortable. As a result, art "can deliver a hidden bomb of an idea." 82 Clifford Chanin, SeniorVice President for Education and Public Programming at the 9/11 Memorial \& Museum, agrees. As he put it, art brings in other senses and experiences and connects to personal memory. This creates stronger memories. For Chanin, "art is approachable, a side door into charged material." ${ }^{83}$

When a museum wants to make art work for social justice, it needs to provide enough context to make the piece give the visitor as powerful an experience as possible. When I first saw the luminous paintings of the American West from the mid-nineteenth and early twentieth centuries, I wanted to lose myself in their majesty. But it wasn't until I learned about their role in creating and propagating the national idea of Manifest Destiny that I was able to experience their full force. I am still struck by their beauty, but now I also shiver at the darker significance of those light-filled pieces. John Berger, the visual studies scholar, argues that the way to place a work of art (in his case, a photograph) in the context of our experience is to make it powerful as an experience. This means the organization of artwork should mirror memory, which "works radially ... with an enormous number of associations all leading to the same event." ${ }^{84}$ Alternately, Berger writes, the presenter of the art can achieve the same effect by providing adequate context. Hull-House Museum works to provide the depth of context Berger requires with the politically relevant direction I described. The unconventional labels at the museum help with this, as does the way in which the temporary "Unfinished Business" exhibitions work "radially" with the permanent exhibition. The two exhibitions dance around one another, constantly referring to one another and redirecting the visitor to think backwards and forwards in time at once. My experience and Berger's scholarship both confirm, in a practical way, the mutual reinforcement that resonance and emotion provide for one another.

The African Presence demonstrates how art supports the co-production of resonance and emotion. Moreno's favorite section of The African Presence lay in the center of the exhibition. His plan for this room of contemporary photographs mirrored the museum's goals for the exhibition as a whole. Moreno wanted the visitors to recognize their family on the walls. Late in production, Moreno realized that these photos had much more power double-hung all together than if they were spread out throughout the exhibition. The photography room was small and contained. The twenty-three photographs inside had the effect of surrounding the visitor with Afro-Mexican faces of people harvesting cane, getting a haircut, going to a quinceañera, playing baseball, or just posing for the camera. Moreno saw his decision validated at each venue on the exhibition's tour as he saw the visitors have the same reaction each time. 
The early parts of the exhibition contained a lot of historical information. Emerging into this section, Mexican visitors saw Mexicans doing familiar things in familiar environments. Moreno could see both African-Americans and Mexicans relating to the Afro-Mexicans in the photographs, and that recognition was one of the purposes of the project all along. Moreno told me how he loved to stand in that section because you could see people whispering and pointing at the photos, and he knew they were discussing who the subjects of the photographs resembled in the visitors' own families. They'd say “There's Nacha in the kitchen! That's the way she dresses!" The resonant recognition and wondrous excitement mingled as visitors engaged with the photographs. As Moreno put it, "That's where a lot of the 'aha!' really happened." ${ }^{85}$ That "aha" moment is a feeling of both emotion and resonance. Art allowed this human connection and the leap of empathetic imagination that connected the visitors to the subjects and, perhaps, to each other.

In Exhibiting Mestizaje, Karen Mary Davalos describes the museum as using a subversive museology in which "emotions, not just aesthetics, are central to exhibition decisions." ${ }^{86}$ It is subversive, writes Davalos, because it gives primacy to everyday personal experience and shines the museological light of "serious study" on those areas, which are often ignored by art museums. She was writing about the museum's exhibition from 1991 El Jugete Popular Mexicano/Popular Toys of Mexico (1991), where the entire complex of objects and techniques for display encouraged long looking in the exhibition. This was also the case with previous exhibitions at the NMMA (then MFACM) for Day of the Dead. Wonder arrested the visitor long enough to open up the possibility of a resonant experience. That is precisely what happened in the room of photographs within The African Presence.

Not everyone has the same experience, however. Intentional use of resonance and emotion involves imagining and planning for this in the construction of an exhibition through the use of other diverse techniques. The curator must put herself in the shoes of the visitors, not only of herself as a hypothetical visitor, but of diverse kinds of visitors. Why have they visited the museum? Who are they with? What parts of their identities are most active today? Visitors whose own family histories do not lead them to connect with the photographs might not be having the same visceral experience in the photography room. Moreno tried to capture those other visitors in the net of resonance and emotion in other ways. He built a flow of sections after the photography room that casts, as he put it, a wide net. Exhibits on cooking, music, and film led into present-day organizing of Afro-Mexicans on the Costa Chica. For mainstream visitors, Moreno cited the Afro-Mexican history of "La Bamba," asking "who hasn't heard of 'La Bamba'?” For most Americans, the song is quintessentially Mexican, but the exhibition showed that it was actually Afro-Mexican. Likewise, learning that ubiquitous "Spanish" words such as chamba (work), fandango (a party with music), and pamba (beat) are actually African words is astonishing and personally meaningful to someone who has been using them her whole life in daily speech. As Moreno put it, "they're building blocks: [the African presence] is there, you've heard it, you've experienced it, you just didn't recognize it." 87

\section{Conclusion}

Though neurology can inform curatorial work, creating exhibitions is an art, not a science. I hope these practices can inspire that creative process while also making the curator's work for social justice more effective. I believe her work is more effective when visitors have experiences 
that are more memorable, when those memories are more detailed and long-lasting, and when visitors empathize with the subjects of the exhibition and even with others beyond the scope of the exhibition. For some curators, yet another sign of success will be when visitors take action within or beyond the gallery. That is the subject of the next chapter.

\section{Notes}

1 Antonio Damasio, The Feeling of What Happens: Body and Emotion in the Making of Consciousness, 1st edn (New York: Mariner Books, 2000), 56.

2 We may not ever know about some emotional signals. Antonio Damasio, Looking for Spinoza: Joy, Sorrow, and the Feeling Brain, 1st edn (Orlando, FL: Harvest, 2003), 148.

3 Damasio, 108-109.

4 Ibid., 57-58.

5 Ibid., 69, 101.

6 Ibid., 148, 165.

7 Ibid., 91-92.

8 Ibid., 71. Damasio, The Feeling of What Happens, 16.

9 Robert M. Sapolsky, Behave: The Biology of Humans at Our Best and Worst (New York: Penguin Press, 2017), 535.

10 Roman Duncko et al., "Acute Exposure to Stress Improves Performance in Trace Eyeblink Conditioning and Spatial Learning Tasks in Healthy Men," Learning \& Memory 14, no. 5 (May 1, 2007): 329-335; Bruce S. McEwen and Robert M. Sapolsky, "Stress and Cognitive Function," Current Opinion in Neurobiology 5, no. 2 (April 1, 1995): 205-216.

11 Damasio, The Feeling of What Happens, 294.

12 Damasio, 295.

13 Damasio, Looking for Spinoza, 98.

14 Greenblatt in Steven D. Lavine, Exhibiting Cultures: The Poetics and Politics of Museum Display (Washington, DC: Smithsonian Institution Scholarly Press, 1991), 42.

15 Greenblatt in ibid.

16 Antonio Damasio, Descartes' Error: Emotion, Reason, and the Human Brain (New York: Putnam, 1994), 174.

17 Ibid., 145.

18 Catherine Cameron and John Gatewood, "Seeking Numinous Experiences in the Unremembered Past," Ethnology. 42, no. 1 (2003): 55.

19 Perry in Kiersten F. Latham, "The Poetry of the Museum: A Holistic Model of Numinous Museum Experiences," Museum Management and Curatorship 22, no. 3 (2007): 251.

20 Ibid., 250.

21 Bonnie Pitman-Gelles in Andrea Witcomb, Re-Imagining The Museum: Beyond the Mausoleum, 1st edn (London; New York: Routledge, 2003), 130-131.

22 Andrea Witcomb, Re-Imagining The Museum: Beyond the Mausoleum, 1st edn (London; New York: Routledge, 2003), 143.

23 Peter Emmett, Senior Curator of the Museum of Sydney, in Witcomb, 156.

24 Emmett in Witcomb, 160.

25 American Federation of Labor, Proceedings of the American Federation of Labor (Bloomington, IL: Pantagraph Printing and Stationery Company, 1906), 43.

26 Heather Radke, interview with Exhibition Coordinator,Jane Addams Hull-House Museum; Curator of Unfinished Business: Home Economics; Unfinished Business: Rec Room, personal, August 29, 2013.

27 Blumberg, Naomi, “Teaching Artist: Mary Wood Hinman” (Exhibit Texts, Jane Addams Hull-House Museum, 2011).

28 Jill Austin, interview with Co-Curator, Out In Chicago, Chicago History Museum, personal, October 4, 2011. 
29 Jennifer Brier, interview with Co-Curator, Out In Chicago; Associate Professor of Gender and Women's Studies and History, University of Illinois at Chicago, personal, September 6, 2011.

30 Michael Warner, The Trouble with Normal: Sex, Politics, and the Ethics of Queer Life (Boston: Harvard University Press, 1999), 39.

31 Witcomb, Re-Imagining The Museum, 144.

32 Alberto Gallace and Charles Spence in Helen Chatterjee et al., Touch in Museums: Policy and Practice in Object Handling (Oxford; New York: Berg, 2008), 163-178.

33 Alberto Gallace and Charles Spence, In Touch with the Future: The Sense of Touch from Cognitive Neuroscience to Virtual Reality, 2014; Elizabeth Pye, The Power of Touch: Handling Objects in Museum and Heritage Contexts (Walnut Creek, CA: Left Coast Press, 2007), 20; Chatterjee et al., Touch in Museums; Helen Chatterjee and Guy Noble, Museums, Health and Well-Being, 2013, http://public. eblib.com/choice/publicfullrecord.aspx?p=1389003; Gaynor Kavanagh, Dream Spaces: Memory and the Museum (London; New York: Leicester University Press, 2000), http://public.eblib.com/choice/ publicfullrecord.aspx?p $=436628$.

34 Fiona Candlin, Art, Museums and Touch (Manchester; New York: Manchester University Press; distributed in the United States by Palgrave Macmillan, 2010), 112.

35 Austin, interview with Co-Curator, Out In Chicago, Chicago History Museum.

36 Portraying the answer as "yes" was a politically motivated decision that the curators undertook to involve heterosexual visitors in the narrative at this particular point in the exhibition. Other points in the exhibition make it clear that queer communities are quite distinct from hetero ones. Likewise, there is a division in queer scholarship between those who favor portraying queer people as like hetero ones and those who favor the opposite. There are political reasons for both positions. For more on this subject see Michael Warner, The Trouble with Normal: Sex, Politics, and the Ethics of Queer Life (Boston: Harvard University Press, 1999).

37 Nearly 34,000 people were shot (or simply thrown, alive) into open pits in the ravine at Babi Yar. Timothy Snyder, Bloodlands: Europe between Hitler and Stalin (New York: Basic Books, 2012).

38 "Board Meeting with Stanley Tigerman on 12 Dec. 2000 Regarding the Capital Campaign" (Minutes, Illinois Holocaust Museum and Education Center, Skokie, IL, December 18, 2000).

39 Danny Cohen and Stacey Mann, "When a Boxcar Isn't a Boxcar: Designing for Human Rights Learning," Exhibitionist, Fall 2011.

40 Peter Novick, The Holocaust in American Life (Boston: Houghton Mifflin, 1999), 214.

41 Lisa Skoinik, "Out of the Darkness," Northshore Magazine, April 2009.

42 Layman Design, "Scenic Wall Details," exhibit design, 04 Design Control, Permanent Exhibit (Illinois Holocaust Museum and Education Center, Skokie, IL, December 30, 2008).

43 Witcomb, Re-Imagining The Museum, 144.

44 "Traveling the Pacific," http://fieldmuseum.org/happening/exhibits/traveling-pacific.

45 Lehrer et al. provide an excellent definition of "difficult knowledge" that informs my idea of difficult history. Erica Lehrer, Cynthia E. Milton, and Monica Patterson, eds., Curating Difficult Knowledge: Violent Pasts in Public Places, 2011 edition (Houndmills; New York: Palgrave Macmillan, 2011), 7-8.

46 "Rinaldi: 'Mi Tierra' Is the Most Important Contemporary Art Exhibit DAM Has Produced in Years," The Know, March 4, 2017, http://theknow.denverpost.com/2017/03/04/mi-tierra-denverart-museum/138031/.

47 Label text by Karsten Lund for The Sound of Silence by Alfredo Jaar, The Sound of Silence, wood, metal, flourescent tubes, LED lights, video projection, flash lights and tripods, and software designed by Ravi Rajan, 2006, Museum of Contemporary Art Chicago.

48 Due respect here to Donald Preziosi, who wrote about walking the path in a museum, calling it "extraordinary interactive machinery ... designed to engage and be operated by its users, who literally (re)enact history and chronology choreographically." Preziosi in Sharon Macdonald, A Companion to Museum Studies (Chichester:Wiley-Blackwell, 2011), 50.

49 Paul Williams explored the interesting example of the descending path at the Terrorháza in Budapest in Paul Williams, Memorial Museums: The Global Rush to Commemorate Atrocities (Oxford; New York: Bloomsbury Academic, 2008), 99-100. 
50 Edward T. Linenthal, Preserving Memory: The Struggle to Create America's Holocaust Museum (New York: Columbia University Press, 2001), 35.

51 Ibid., 170.

52 I'm using these terms in reference to Linenthal's description of Elie Weisel's narrative of the Holocaust. Edward T. Linenthal, Preserving Memory: The Struggle to Create America's Holocaust Museum (New York: Columbia University Press, 2001), 3.

53 Linenthal, 4.

54 Skoinik, "Out of the Darkness."

55 Robert M. Sapolsky, Why Zebras Don't Get Ulcers, Third Edition, 3rd edn (New York: Holt Paperbacks, 2004), 204.

56 Ibid., 342.

57 Ibid., 341.

58 Damasio, Descartes' Error.

59 Jeshajahu Weinberg and Rina Elieli, The Holocaust Museum in Washington (New York: Rizzoli International Publications, 1995), 67.

60 Antonio Damasio, The Feeling of What Happens: Body and Emotion in the Making of Consciousness, 1st edn (New York: Mariner Books, 2000), 59.

61 Weinberg and Elieli, The Holocaust Museum in Washington, 27.

62 Ibid., 72.

63 Matthew Pratt Guterl, Seeing Race in Modern America (Chapel Hill, NC: The University of North Carolina Press, 2013), 3.

64 Using " $\mathrm{K}$ " instead of " $\mathrm{C}$ " in this way is an example of a phenomenon sometimes called "satiric misspelling." "Satiric Misspelling," Wikipedia, the Free Encyclopedia, August 24, 2014, http:// en.wikipedia.org/w/index.php?title=Satiric_misspelling\&oldid=622115053. It is prevalent, though poorly documented, in both English and Spanish. Examples such as Kattie Cumbo's poem, "I Too Hear Amerikkka...Sing" substantiate the conventional wisdom that these substitutions have their roots in anti-racist art and rhetoric. In the substitution of the "KKK" for "C," the author accuses the nation of harboring and abetting the hateful domestic terrorism of the KKK. Kattie M. Cumbo, "I Too Hear Amerikkka...Sing," Negro American Literature Forum 6, no. 1 (April 1, 1972): 18, doi:10.2307/3041183. The Oxford English Dictionary substantiates this meaning for the substitution, citing "Amerika," "AmeriKKKa," and "Amerikkka" as all alluding either to authoritarian and fascist German and Russian regimes or to an association of America with the KKK. The meaning is an "American society viewed as racist, fascist, or oppressive, especially by African-Americans." The first usage according to the OED is from 1969. "Amerika, N.," OED Online (Oxford University Press), www.oed.com/ view/Entry/6352. In Spanish, the substitution is sometimes called "ortografía hipercaracterizada." The substitution of "K" for "C" in Spanish has come to have "radical, anarchist, and ... nonconformist or antimilitary" connotations. Félix Rodríguez González, "Medios de Comunicación Y Contracultura Juvenil," Círculo de Linguistíca Aplicada a La Comunicación 25 (2006): 20.

65 Another way of discussing this special job of museums is "relevance." Nina Simon's The Art of Relevance delves deeply into this topic. The difference between relevance and resonance is subtle. Whereas relevance is about how the visitor perceives the museum's presentation, resonance is about content in the museum striking a chord in the visitor. As Simon put it, you can't tell someone that something is relevant, you can only "present [it] ... in relevant terms." Nina Simon and Jon Moscone, The Art of Relevance (Santa Cruz, CA: Museum 2.0, 2016), 52.

66 I use "intersectionality" as Kimberlé Crenshaw Williams defines it in "Mapping the Margins: Intersectionality, Identity Politics, and Violence Against Women of Color," to denote the various ways in which race, gender, and other facets of our individual identities interact to shape our experiences and the ways in which our experiences are represented in politics and other social structures. As William puts it, intersectionality is about "the need to account for multiple grounds of identity when considering how the social world is constructed" (358).

67 The first Holocaust museum was the Chamber of the Holocaust in Jerusalem, founded in 1948. Jean Arundale et al., Terrorism and War: Unconscious Dynamics of Political Violence (London: Karnac Books, 2002), 368 . 
68 See Novick for an exploration of the oft-mentioned "eleven million" victims of the Holocaust. Novick documents how Simon Wiesenthal made that number up, initially not intending to use it as a descriptor for the Holocaust but rather for "Nazi crimes." Novick, The Holocaust in American Life, 214-216. Eleven million is actually far too low an estimate for the total number of civilians murdered by the Nazis. Novick mentions this, but Timothy Snyder documents it comprehensively. According to Snyder, Hitler and Stalin murdered 14 million civilians in a premeditated fashion between 1932 and 1945. More than half of these people were intentionally starved. Many were shot into open pits or gassed. Most of them never went to concentration camps. Timothy Snyder, Bloodlands: Europe between Hitler and Stalin (New York: Basic Books, 2012), vii-viii, xviii.

69 Daniel L. Schacter, The Seven Sins of Memory: How the Mind Forgets and Remembers (Boston: Houghton Mifflin, 2001), 34.

70 Dierdre Wilson and Dan Sperber in Simon and Moscone, The Art of Relevance, 32.

71 Teresa Silva, "Unfinished Business: Juvenile Justice: Exhibit Layout” (Exhibit Layout, Jane Addams Hull-House Museum, n.d.).

72 Teresa Silva, interview with Curatorial Assistant (facilitator of "community-curated" Unfinished Business) at Jane Addams Hull-House Museum, personal, August 5, 2011.

73 Cesáreo Moreno, "Call for Proposals for Declaration of Immigration, an Exhibition at the National Museum of Mexican Art" (National Museum of Mexican Art, Chicago, 2007).

74 The African Presence in México: From Yanga to the Present, 1st edn (Chicago: Mexican Fine Arts Center Museum, 2006), 32-34; Sagrario Cruz-Carretero in Susan Fong, "The African Presence in Mexico: From Invisible to Visible," Streetwise, March 7, 2006.

75 Elena Gonzales, "Who Are We Now? Getting Connected » AREA Chicago," http://areachicago. org/who-are-we-now-getting-connected/.

76 US Census Bureau, "American FactFinder - Results," http://factfinder2.census.gov/faces/ tableservices/jsf/pages/productview.xhtml?pid=DEC_00_SF1_DP1.

77 Jennifer Jones, interview with SBS Diversity Post Doctoral Fellow at The Ohio State University, Sociology, and visitor to The African Presence, phone, September 6, 2012.

78 "Comments from the Guest Book during the Run of The African Presence in México" (National Museum of Mexican Art, Chicago, March 2006).

79 V.S. Ramachandran, The Tell-Tale Brain: A Neuroscientist's Quest for What Makes Us Human (New York: W.W. Norton \& Company, 2011), 200-244.

80 Gallace and Spence, In Touch with the Future, 36-58.

81 Stafford, Echo Objects, 106.

82 Cesáreo Moreno, Interview with the Chief Curator and Director of Visual Arts at the National Museum of Mexican Art, Personal, August 1, 2012.

83 Clifford Chanin, interview with Curator, Legacy of Absence, phone, October 11, 2011.

84 John Berger, About Looking, 1st American edn (New York: Pantheon Books, 1980), 60-63.

85 Moreno, interview with the Chief Curator and Director of Visual Arts at the National Museum of Mexican Art.

86 Karen Mary Davalos, Exhibiting Mestizaje: Mexican (American) Museums in the Diaspora, 1st edn (Albuquerque, NM: University of New Mexico Press, 2001), 136.

87 Moreno, interview with the Chief Curator and Director of Visual Arts at the National Museum of Mexican Art.

\section{Bibliography}

“Amerika, N." OED Online. Oxford University Press. www.oed.com/view/Entry/6352.

American Federation of Labor. Proceedings of the American Federation of Labor. Bloomington, IL: Pantagraph Printing and Stationery Company, 1906.

Arundale, Jean, Coline Covington, Jean Knox, and Paul Williams. Terrorism and War: Unconscious Dynamics of Political Violence. London: Karnac Books, 2002. 
Austin, Jill. Interview with Co-Curator, Out in Chicago, Chicago History Museum. Personal, August 10, 2011.

-. Interview with Co-Curator, Out in Chicago, Chicago History Museum. Personal, October 4, 2011. . Interview with Co-Curator, Out in Chicago, Chicago History Museum. Personal, November $2,2012$.

Berger, John. About Looking, 1st American edn. New York: Pantheon Books, 1980.

Blumberg, Naomi. "Teaching Artist: Mary Wood Hinman.” Exhibit Texts. Jane Addams Hull-House Museum, 2011.

"Board Meeting with Stanley Tigerman on 12 Dec. 2000 Regarding the Capital Campaign." Minutes. Illinois Holocaust Museum and Education Center, Skokie, IL, December 18, 2000.

Brier, Jennifer. Interview with Co-Curator, Out in Chicago; Associate Professor of Gender and Women's Studies and History, University of Illinois at Chicago. Personal, August 19, 2011.

- Interview with Co-Curator, Out in Chicago; Associate Professor of Gender and Women's Studies and History, University of Illinois at Chicago. Personal, September 6, 2011.

- Interview with Co-Curator, Out in Chicago; Associate Professor of Gender and Women's Studies and History, University of Illinois at Chicago. Phone, August 1, 2014.

Cameron, Catherine and John Gatewood. "Seeking Numinous Experiences in the Unremembered Past.” Ethnology. 42, no. 1 (2003): 55.

Candlin, Fiona. Art, Museums and Touch. Manchester; New York: Manchester University Press; distributed in the United States by Palgrave Macmillan, 2010.

Cesáreo Moreno. "Call for Proposals for Declaration of Immigration, an Exhibition at the National Museum of Mexican Art." National Museum of Mexican Art, Chicago, 2007.

Chanin, Clifford. Interview with Curator, Legacy of Absence. Phone, October 11, 2011.

- Interview with Curator, Legacy of Absence. Phone, June 17, 2013.

Chatterjee, Helen, Sally MacDonald, David Prytherch, and Guy Noble. Touch in Museums: Policy and Practice in Object Handling. Oxford; New York: Berg, 2008.

Chatterjee, Helen and Guy Noble. Museums, Health and Well-Being, 2013. http://public.eblib.com/ choice/publicfullrecord.aspx?p=1389003.

Cohen, Danny and Stacey Mann. "When a Boxcar Isn't a Boxcar: Designing for Human Rights Learning.” Exhibitionist, Fall 2011: 26-31.

"Comments from the Guest Book during the Run of The African Presence in México." National Museum of Mexican Art, Chicago, March 2006.

Crenshaw, Kimberle Williams. "Mapping the Margins.” Critical Race Theory: The Key Writings That Formed the Movement. New York: New Press, 1995.

Cumbo, Kattie M. "I Too Hear Amerikkka... Sing." Negro American Literature Forum 6, no. 1 (April 1, 1972): 18.

Damasio, Antonio. Descartes' Error: Emotion, Reason, and the Human Brain. New York: Putnam, 1994.

- The Feeling of What Happens: Body and Emotion in the Making of Consciousness, 1st edn. New York: Mariner Books, 2000.

Davalos, Karen Mary. Exhibiting Mestizaje: Mexican (American) Museums in the Diaspora, 1st edn. Albuquerque, NM: University of New Mexico Press, 2001.

Gonzales, Elena. "Who Are We Now? Getting Connected »AREA Chicago.” http://areachicago.org/ who-are-we-now-getting-connected/.

Guterl, Matthew Pratt. Seeing Race in Modern America. Chapel Hill, NC: University of North Carolina Press, 2013.

Jaar, Alfredo. The Sound of Silence. 2006. Wood, metal, flourescent tubes, LED lights, video projection, flash lights and tripods, and software designed by Ravi Rajan. Museum of Contemporary Art Chicago.

Jennifer Brier. Interview with Jennie Brier, Co-Curator, Out in Chicago, Chicago History Museum. Phone, August 7, 2014.

Jones, Jennifer. Interview with SBS Diversity Post Doctoral Fellow at The Ohio State University, Sociology, and visitor to The African Presence. Phone, September 6, 2012. 
Kavanagh, Gaynor. Dream Spaces Memory and the Museum. London; New York: Leicester University Press, 2000. http://public.eblib.com/choice/publicfullrecord.aspx?p=436628.

Latham, Kiersten F. "The Poetry of the Museum: A Holistic Model of Numinous Museum Experiences." Museum Management and Curatorship 22, no. 3 (2007): 247. https://doi.org/10.1080/ 09647770701628594.

Lavine, Steven D. and Ivan Karp. Exhibiting Cultures:The Poetics and Politics of Museum Display. Washington, DC: Smithsonian Institution Press, 1991.

Layman Design. "Scenic Wall Details." Exhibit design. 04 Design Control, Permanent Exhibit. Illinois Holocaust Museum and Education Center, Skokie, IL, December 30, 2008.

Lehrer, Erica, Cynthia E. Milton, and Monica Patterson, eds. Curating Difficult Knowledge:Violent Pasts in Public Places, 2011 edition. Houndmills, Basingstoke; New York: Palgrave Macmillan, 2011.

Linenthal, Edward T. Preserving Memory: The Struggle to Create America's Holocaust Museum. New York: Columbia University Press, 2001.

Macdonald, Sharon. A Companion to Museum Studies. Chichester:Wiley-Blackwell, 2011.

Mexican Fine Arts Center Museum. The African Presence in México: From Yanga to the Present, 1st edn. Chicago: Mexican Fine Arts Center Museum, 2006.

Moreno, Cesáreo. Interview with the Chief Curator and Director ofVisual Arts at the National Museum of Mexican Art. Personal, July 6, 2012.

- Interview with the Chief Curator and Director of Visual Arts at the National Museum of Mexican Art. Personal, July 27, 2012.

- Interview with the Chief Curator and Director of Visual Arts at the National Museum of Mexican Art. Personal, August 1, 2012.

- Interview with the Chief Curator and Director of Visual Arts at the National Museum of Mexican Art. Personal, February 14, 2013.

- Interview with the Chief Curator and Director of Visual Arts at the National Museum of Mexican Art. Personal, February 6, 2014.

Novick, Peter. The Holocaust in American Life. Boston: Houghton Mifflin, 1999.

"Proceedings: Chicago Historical Society." Progress Report. Chicago History Museum, Chicago, October 25, 1929. Subseries 1. Board of Trustees; Box 5: Minutes 1928-31; Bound volume: Proceedings, CHS, October 25, 1929. Chicago History Museum.

Pye, Elizabeth. The Power of Touch: Handling Objects in Museum and Heritage Contexts. Walnut Creek, CA: Left Coast Press, 2007.

Radke, Heather. Interview with Exhibition Coordinator, Jane Addams Hull-House Museum; Curator of Unfinished Business: Home Economics; Unfinished Business: Rec Room. Personal, August 29, 2013.

- Interview with Exhibition Coordinator, Jane Addams Hull-House Museum; Curator of Unfinished Business: Home Economics; Unfinished Business: Rec Room. Personal, September 19, 2013.

Ramachandran,V.S. The Tell-Tale Brain: A Neuroscientist's Quest for What Makes Us Human. New York: W. W. Norton, 2011.

"Rinaldi: 'Mi Tierra' Is the Most Important Contemporary Art Exhibit DAM Has Produced in Years." The Know, March 4, 2017. http://theknow.denverpost.com/2017/03/04/mi-tierra-denver-artmuseum/138031/.

Rodríguez González, Félix. "Medios de Comunicación y Contracultura Juvenil." Círculo de Linguistíca Aplicada a La Comunicación 25 (2006): 5-30.

Sapolsky, Robert M. Why Zebras Don't Get Ulcers, Third Edition. New York: Holt Paperbacks, 2004.

"Satiric Misspelling." Wikipedia, the Free Encyclopedia, August 24, 2014. http://en.wikipedia.org/w/ index.php?title=Satiric_misspelling\&oldid=622115053.

Schacter, Daniel L. The Seven Sins of Memory: How the Mind Forgets and Remembers. Boston, MA: Houghton Mifflin, 2001.

Silva, Teresa. Interview with Curatorial Assistant (facilitator of "community-curated" Unfinished Business) at Jane Addams Hull-House Museum. Personal, August 5, 2011. 
_ "Unfinished Business: Juvenile Justice: Exhibit Layout." Exhibit Layout. Jane Addams HullHouse Museum, ND.

Simon, Nina and Jon Moscone. The Art of Relevance. Santa Cruz, CA: Museum 2.0, 2016.

Skoinik, Lisa. "Out of the Darkness." Northshore Magazine, April 2009: 44-46.

Snyder, Timothy. Bloodlands: Europe between Hitler and Stalin. New York: Basic Books, 2012.

Stafford, Barbara Maria. Echo Objects: The Cognitive Work of Images. Chicago: University Of Chicago Press, 2009.

Tigerman McCurry Architects. "Holocaust Memorial Foundation of Illinois - Exhibit Concepts," July 2005. Illinois Holocaust Museum and Education Center.

"Traveling the Pacific." http://fieldmuseum.org/happening/exhibits/traveling-pacific.

US Census Bureau. “American FactFinder - Results.” http://factfinder2.census.gov/faces/tableservices/ jsf/pages/productview.xhtml?pid=DEC_00_SF1_DP1.

Warner, Michael. The Trouble with Normal: Sex, Politics, and the Ethics of Queer Life. Boston: Harvard University Press, 1999.

Weinberg,Jeshajahu and Rina Elieli. The Holocaust Museum in Washington. New York: Rizzoli International Publications, 1995.

Williams, Paul. Memorial Museums: The Global Rush to Commemorate Atrocities. Oxford; New York: Bloomsbury Academic, 2008

Witcomb, Andrea. Re-Imagining The Museum: Beyond the Mausoleum, 1st edn. London; New York: Routledge, 2003. 


\section{3}

\section{INSPIRING ACTION}

This chapter considers the actions of visitors during and after visits to museums around the world. It is neither scientific nor comprehensive, but it offers something true to the human experience. This is a collection of stories and observations that honors the complex factors at work when we make the decision to take action: our many - sometimes competing commitments, interests, and sources of information. Exhibitions at the NMMA - The African Presence and Who Are We Now? - inspired Jennifer Jones to continue her research into the AfroMexican component of Black/Brown relations. She is now Associate Professor of Sociology at the institute for Latino Studies at the University of Notre Dame. The musical producer and artist Rostam Batmanglij had a hit song in 2017 called "Bike Dream." Rostam explained how he has always been chasing the sound of "planetarium music" from a film strip at the National Air and Space Museum, which he visited as a child. He keeps trying to recreate it in his music, and the eerie rising chords that waver in pitch in "Bike Dream" are one example of this. ${ }^{1}$ These are two personal, idiosyncratic examples of actions that exhibitions have inspired. Lessons for curators emerge from the broad consideration of our informational environments and empathetic connections to others.

The question of whether or not museums should strive to inspire action on the part of their visitors is an open one. There is a long history of museums working for social change. ${ }^{2}$ Many curators and other museum professionals and many institutions have this as a goal; many do not. My purpose is not to advocate for museums to inspire action but rather to support an increasing number of cultural workers in this area and to engage researchers and students in this understudied area of museum work. As Erica Lehrer et al. put it in Curating Difficult Knowledge, "the goal of curatorial work is no longer simply to represent but to make things happen." ${ }^{3}$ Artists, too, are increasingly interested in inspiring action. Recent volumes, such as The Land We Are: Artists and Writers Unsettle the Politics of Reconciliation in Canada by Sophie Mccall and Gabrielle Hill and Strike Art by Yates McKee, demonstrate this. ${ }^{4}$ Other scholars and artists, such as Therese Quinn, Matthew Yasuoka, and Jose Luis Benavides, view "contemporary calls for museums to encourage participation, become relevant, and even offer services" as "necessary, but inadequate." Instead of promoting visitors to take single actions, 
these activist scholars would like to see museums helping visitors envision and enact changes in their lives that promote social justice - "more just ways of living."

I hope to provide a resource for those who do wish to inspire action as well as some answers for those who ask "do the techniques in this book really work?" I respect and share that question. It's complicated, and it begets more questions. What does it mean for the techniques to "work?" Maybe the techniques "work" if they inspire certain sorts of actions, whether in the museum during the visit, immediately after the visit, or long after the visit. However, this is not the kind of study that can answer that question quantitatively. There is much research still to be done on the ways in which visiting exhibitions influences visitors' decision making and actions.

However, many studies have been done on the memory of visitors. The question of the durability and ongoing utility of visitors' memories is pertinent to this chapter's overall question of inspiring action. If content is to become part of visitors' informational environments, it is helpful for them to remember it. John Falk and Lynn Dierking discuss them in The Museum Experience Revisited as they seek to help museums mesh their agendas with those of visitors. In the twenty-one years since Falk and Dierking's Museum Experience came out, studies of visitors' memories have gone from being few and preliminary to being numerous and conclusive. The evidence is now clear: "Museum-going appears to consistently result in indelible memories." Though memories change over time, some studies have shown the accuracy of these memories. $^{7}$ Memories of visits to museums are long-lasting because visitors' experiences involve: novelty, personal meaning, emotion, and rehearsal (talking about the visit before and after). ${ }^{8}$ As environments, museums are well-suited to building memories because they support these four elements of experience.

As we process and consolidate memories, we continue to learn. One result of this is that knowledge gained from experiences in museums is useful in different ways over time. Falk and Dierking reported that when visitors left museums, they viewed certain things they saw and did as being most salient. Four to eight months later, they saw a different set of things as most salient. ${ }^{9}$ Our construction of memories over time is often framed as a defect of memory, as if our memories were perfect on the day we made them and then entered a process of decline. On the contrary, the construction of memory over time can be an asset. In thinking about memories made in museums, the day the visitor makes the memory, she may still not totally understand all she has seen. As she goes on through other experiences and takes in other information outside of the museum, and as she discusses (rehearses) her experience in the museum with others, she may come to a better, more useful understanding that shapes her memory from the museum. As Falk and Dierking put it, "The constructive quality of memory enables humans to invent, theorize, and create, and that is exactly what users of museums do." ${ }^{10}$

The question about the quantitative effects of curatorial techniques can also distract from our understanding of human decision making. Human decision making is complex and cannot usually be reduced to single inputs and outputs. It may now be common for a visitor to sign a petition after having visited a museum where an exhibition treated a related topic. But the following hypothetical situation is probably much more common: Someone regularly engaged with a topic of contemporary relevance - say, healthcare. She was talking about it with friends, family, and colleagues, reading about it in the news, listening to podcasts, radio, and browsing the internet. Then, she visited an exhibition that discussed approaches to healthcare around the world and how it can be distributed equitably. She discussed the exhibition with those in 
her circle, rehearsing and cementing memories of it. A couple of years later, when Congress was trying to pass a new healthcare act, she remembered some of the ideas from the exhibition and looked to see if they were part of the new legislation. Upon finding that one of them was, and that her congressperson was planning to vote against it, the visitor called the congressperson and shared with her the evidence for why this provision worked and asked her to vote in favor of it.

The road is winding. Our informational environments are complex and open-ended. The most influential elements of these environments are the utterances of important people in our lives. Even the most trusted other sources of news are secondary.Visitors see museums as more trustworthy than other sources in that secondary layer. ${ }^{11}$ This makes museums a useful component of a visitor's informational environment that could affect someone's thinking or action now or in the future.

\section{The butterfly effect}

We know that experiences can lead to actions, and that even small actions can yield huge impacts. For example, museums often inspire visitors to take small actions such as taking a selfportrait. Nine hundred visitors to the Lincoln Park Zoo took "selfies" with a pro-conservation message in Wild Horizons (2017). The images that made it to social media would have had broad visibility. One thousand children visiting the same exhibition drew pictures with proconservation messages. Even medium-sized actions such as planning a project or event as the result of visiting an exhibition are common as well. As with the so-called butterfly effect, these actions can rapidly trigger much bigger sets of actions by whole communities of people.

Mark Kohan's life's work has become an example of the butterfly effect in action. Kohan is Assistant Clinical Professor in the Neag School of Education at the University of Connecticut. Kohan shared his story with me by phone in 2016. ${ }^{12}$ Kohan grew up in a biracial interfaith family in a crossover rural/urban setting in West Virginia. From a young age, he had access to museums, unlike most of his peers. He began to see museums as being part of places where "more seemed possible." When Kohan reached adulthood, his youthful experiences in museums remained memorable. Perhaps that is because these visits were special yet common enough that they became a part of how he has approached travel and professional development.

In 2009 Kohan moved from West Virginia to Cincinnati to begin his doctoral work. The city had changed from his childhood trips there because of a new museum, the National Underground Railroad Freedom Center. Kohan left feeling the need to amplify the offerings of the Freedom Center. As he grappled with his experience at the museum and how to better the understand legacy of slavery in Cincinnati, Kohan created partnerships between the Freedom Center and the University of Connecticut (UConn), where Kohan was working on his doctorate. He had the backing of the university and the Center for Holocaust and Humanity Education. Kohan was studying education in a local context of contentious battles about education. For two-and-a-half years, he worked on making change rather than "chasing punitive mandates." In 2011, he brought a group called the Freedom Writers and one of the original Freedom Riders together at the Freedom Center and five other locations that were significant in public memory.

Kohan joined a group of social studies teachers and others who were concerned about social justice to create a grassroots professional development network, the "Teaching for Hope and Justice Network." They focused on addressing racism, the history of race in Cincinnati, 
how institutional racism was occurring, what it looked like, and what they could do about it. The group helped museums connect new exhibitions to students and teachers. In 2013, the network became a formal entity within the Center for Hope and Justice Education at UConn.

The effects of Kohan's visit to the Freedom Center in 2009 ramified locally for years and then continued across the country through personal and professional experiences. The visit is still snowballing. It influenced Kohan's dissertation and a novel he wrote with input from his high school students in an effort to disrupt what counts toward tenure as research. Rich Cooper, then head of experiences at Freedom Center, introduced Kohan to the Mashantucket Pequot Museum and Research Center, also in Connecticut, which opened an exhibition on implicit bias, called Understanding Implicit Bias, in winter 2016. Through the collaborations between Kohan and the staff at Mashantucket Pequot, UConn became the next stop for the exhibition (spring 2017). As of spring 2019, the exhibition was on view at the National Underground Railroad Freedom Center in the museum's Open Your Mind learning lab.

Several UConn students sought Kohan's mentorship. He took them to visit Mashantucket Pequot Museum. At least two important sets of actions resulted. First, Kohan and a colleague from UConn organized a panel on Standing Rock at UConn. ${ }^{13}$ (Thousands of protesters camped out on the Standing Rock Reservation in resistance to the construction of the Dakota Access Pipeline, which threatened the area's clean water, from April 2016 to February 2017 until police forced them to leave. $)^{14}$

Then, the UConn students began working to convert Columbus Day to Indigenous People's Day on campus. The visits that students and staff members from UConn made to Mashantucket Pequot are also having effects in the realms of changing UConn's mascot and collaborating on the possibility of a tribal college on campus. As Kohan put it, "the initial visit [to Mashantucket Pequot Museum] was so powerful that it became a moment of finding time to institutionalize collaboration."

Understanding the full effects of Kohan's visit to the Freedom Center took more than a decade. To be sure, Kohan is an educated, interested, engaged museum visitor who was already sympathetic to and literate in museums at the time of his visit. But that should not diminish the value of the work that he has paid forward from all that the staff at the Freedom Center built and presented. The lesson here is that inspiring action can take time, but it certainly happens and it happens in ways both big and small. Personal connections with friends, family, and colleagues were the keys that turned Kohan's visit into multitudinous actions. From 2009 to the present he has collaborated with many people, shared his ideas, and inspired others to build on theirs.

Here is another look at the winding tendrils of influence that can emanate from a museum through one visitor's experience. My own father, Laurence Gonzales, has written professionally for almost fifty years and is a Miller Scholar at the Santa Fe Institute. In the 1990s, he was writing a series of travel articles for Men's Journal in which he set out to discover the secret heart of several American cities: Austin, Miami, Las Vegas, and Memphis. The articles were meant for the business traveler who found himself with an extra day in a strange city and who wanted to feel like an explorer and find himself on the inside, rather than simply scratching the touristy surface.

When Gonzales embarked on his trip to Memphis, he had imagined that the piece would be about the blues, about Beale Street, about the Mississippi Delta and the Peabody Hotel. And he wrote about all of those things. But when he found himself in a cotton classing house, he began to think of slavery and remembered that the Lorraine Motel, where Martin Luther 
King was murdered in 1968, was a museum. Gonzales decided to visit the National Civil Rights Museum. The article changed, and so did Gonzales.

Like all visitors, Gonzales brought his own extant informational environment and his own lifetime of experiences to the museum. He brought his goals (a good story) and his personal and sociocultural context. Gonzales had been active in the Civil Rights Movement, as were so many of his peers. From childhood, he had been given to understand that Mexicans like him shared a racialized fate of oppression in the US with Black Americans. He knew the stories of Mexicans being lynched and had experienced racial violence first-hand.

Laurence was 20 years old when King was shot. In 1976, he interviewed King's killer, James Earl Ray, for Playboy magazine (Figure 3.1). The interview took place three days after Ray had escaped from the Brushy Mountain State Penitentiary in Petros, Tennessee. When Gonzales interviewed him, Ray had many scratches from fleeing through the woods near the prison.

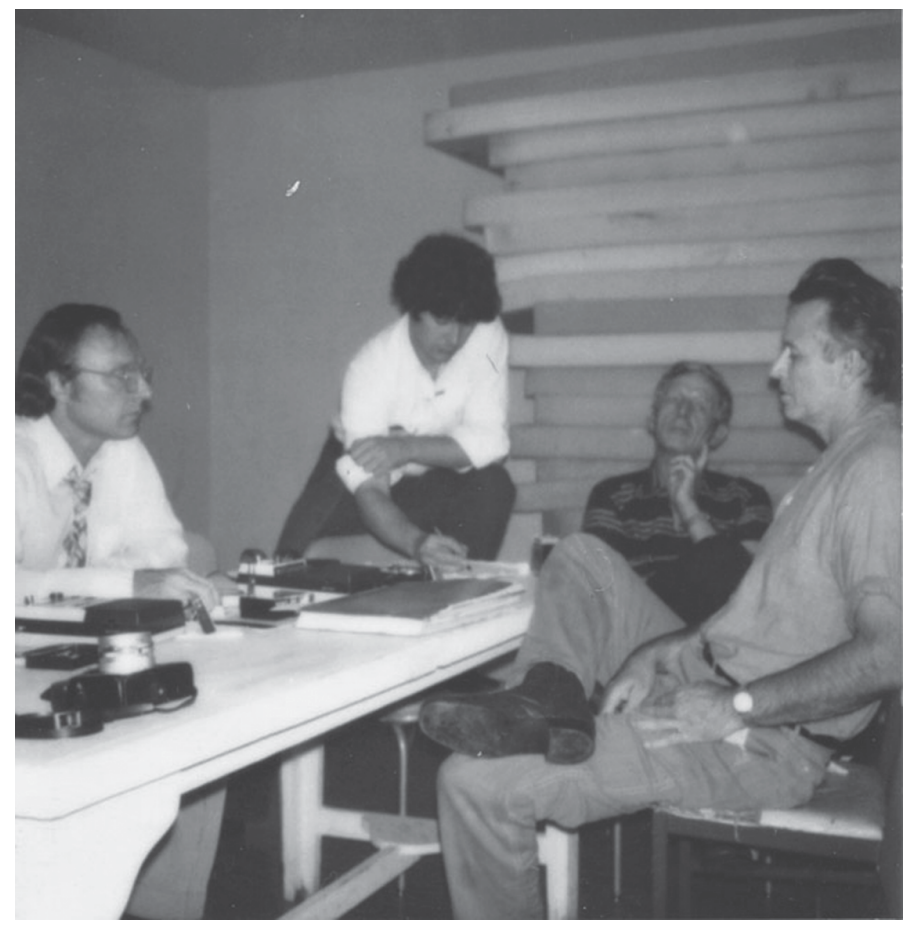

FIGURE 3.1 Playboy interview with James Earl Ray at Brushy Mountain Penitentiary, 1977. Left to right: Jim McKinley, lead author on the interview; Laurence Gonzales, collaborating author; Ray's attorney; James Earl Ray. Collection of the author.

Gonzales's memories of the interview remained detailed forty years later, down to the contents of Ray's lunch and the sounds in the prison. Gonzales called his visit to the Lorraine Motel "one of the most moving cultural experiences I've ever had." This from a man who has made a living for decades seeking out cultural experiences and telling the tales, who has played trumpet on stage with Johnny Winter, who Little Richard kissed on the mouth after a concert, and upon whom Hunter S. Thompson bestowed the gift of a leaky can of ether after accidentally setting fire to Gonzales at a party. It was clear to Gonzales, having arrived at the 
motel, that the dark side of Memphis, the underbelly for which he had been searching, was the death of Martin Luther King.

Twenty years after the visit, he doesn't remember a lot of details. But the impact, he said, wasn't in the details. The cultural force of the visit was in looking out of the motel and up to the balcony where King stood and across to the rooming house from whence Ray shot. This view was shocking to Gonzales because it demonstrated plainly how "stupidly simple" the assassination was. King stepped out onto the balcony the day after making a speech in which he said "I'm not fearing any man!" Ralph Abernathy and others in King's inner circle were constantly begging him to be more careful and not to put himself in positions like the very one he was in when he was killed. Ray was not special. Anyone could have killed King at any time. Ray's shot was not even difficult. Gonzales said, "you look out and see that window and it hits you like a ton of lead. It was very emotional. The shot blew [King] out of his shoes. It was a hunting rifle."

The impact of that experience became the climax of Gonzales's article, "Blue Memphis." Gonzales described his physical reaction in the museum this way:

I knew in my heart that Ray was a pathological liar, that nothing he had told me could be believed, and that he and he alone had killed King with a single shot from a deer rifle, because he believed in his hopelessly backward mind that people would make him a national hero for ridding them of the leader of that cursed integration movement. And when I saw the little motel where he did it, saw how simple it had been, how cruel and simple, in this unassuming place, I was suddenly overcome. I thought I was going to faint. I sat down on a low concrete wall outside the Lorraine Motel and wept. ${ }^{15}$

Gonzales's visit to the Lorraine Motel meshed with his lifetime of experience and his physical experience tethered the memory within him forever.

"Blue Memphis," from 1995, was newly collected in Gonzales's House of Pain in 2013. As he put it, anyone who encounters the article now is going to get "a cultural message of real significance." The Lorraine Motel motivated Gonzales to pay that much more attention to what Hannah Arendt called the banality of evil. To the realization of how simple evil is and how it grows out of ignorance and stupidity. We cannot know how "Blue Memphis" has motivated readers over the years, but it certainly may have snowballed into many actions and mindsets. In the mid-1990s, Men's Journal had roughly 375,000 readers (including 300,000 subscribers plus newsstand).

\section{Evaluation influences our thinking about action}

If the actions visitors take long after a visit can be so significant, then it behooves institutions that want to inspire action to study the impact of their exhibits on visitors. Though this chapter is not entirely about evaluation, it is my answer to a question about evaluation. To that end, I'm also going to briefly address the topic of outcomes-based evaluation (OBE) and its alternatives. Andrew Pekarik is a program analyst in the Office of Policy and Analysis at the Smithsonian. He offers "participant-based evaluation," a "qualitative inquiry into the experiences of those involved in a project" as an alternative to outcome-based evaluation. ${ }^{16}$ Pekarik's model is open-ended, and its goal is to arrive at a more complex understanding of the project, rather than to distill the understanding of the project. The process begins without 
goals or boundaries. By contrast, Pekarik and others feel outcome-based evaluation is too limiting because it overlooks unintended outcomes and preserves a notion that the museum controls the outcomes. ${ }^{17}$

This kind of evaluation would have dramatic implications for how we design exhibits. Pekarik says it would result in subsequent projects being "design experiments," wherein exhibitions are not designed and built as a whole entities. Rather an early "seed" set of exhibits would be built and then expanded upon as iterations of participant-based evaluation takes place. "Eventually, it is declared mature, it stops changing, and, after a decent interval, it begins to thin as new growth - new displays for instance - begin to take away some of its territory."18 Pekarik views this process as appropriate for permanent exhibitions and has never found an example of it in practice.

It is easy to read a museum's refusal to conform to contemporary standards of evaluation as an attempt to avoid accountability. The experience that Hull-House has had in trying to buck the trend can be liberating and instructive for administrators who are frustrated by expending resources on evaluation that seems meant for someone else. The problem for Hull-House, as Heather Radke, former Exhibitions Coordinator, put it, has been finding a protocol for evaluation that takes seriously matters of importance to the museum. Hull-House is a museum that cares about motivating visitors to take actions, both in the museum and beyond. The museum has long recognized that affect and embodied emotional responses are crucial to the museum's goal of inspiring visitors to action.

In 2011, Lisa Lee, Director (2006-2012), planned to begin measuring affect as part of her regular survey of visitors. The staff completed some early evaluation projects with the new models they were testing. These were for programs and interventions, rather than exhibitions. They were implemented at "Rethinking Soup" and the tea drinking project in Addams's bedroom as well as a symposium about historic preservation. The evaluations for affect focused on the idea that sometimes the experiences you have in a museum don't lend themselves to description. The evaluations offered multiple avenues for expression. Visitors could draw, sing, or express themselves in other ways. After one visitor related her experience in the museum to a passage she had read in Moby Dick, the museum began asking visitors if anything else outside the museum related to their experiences inside. There are many creative ways to use evaluation to benefit your institution, rather than simply to satisfy funding requirements.

For those who like to see the results of evaluation, this success story combines inspiring and evaluating action and capturing it with evaluation mechanisms to create an excellent model. In 2013, Hull-House rolled its interpretation and "community engagement" into a tour program for the exhibition Unfinished Business: 21st Century Home Economics. Domestic workers from the Chicago Coalition of Household Workers (CCHW) contributed to the exhibition and did curatorial work (discussed in Chapter 4). Next, the museum staff worked with the domestic workers to produce the Love and Labor tours, guided tours by domestic workers for visitors. The domestic workers were able to share their personal experiences and, in discussion at the end of the tour, allowed visitors to acknowledge someone in their lives who does domestic work.Visitors wrote thank-you notes to these individuals that were displayed in the museum. The tour guides engaged visitors in the history of domestic work as well as the contemporary efforts to advocate for protections for domestic workers. At the time, only five states in the country offered protections for domestic workers similar to those for other workers, and the CCHW was working to gain approval for a piece of legislation called the Domestic Workers' 
Bill of Rights in Illinois. Visitors on Love and Labor tours had the opportunity to speak out on this issue and support the campaign for the bill of rights.

The museum had stated goals for the Love and Labor tours and it measured the goals through surveys before and after the tours, conversations, and interviews. The museum made a presentation about its evaluation of this program; ${ }^{19} 350$ people participated in 35 tours. Most visitors were White students on their first visit to Hull-House. Half of the visitors rarely visited museums at all. Overall, the visitors had an excellent experience on the tours. Roughly 70 percent of visitors were at least somewhat interested in participating in the organizing efforts for the rights of domestic workers in Illinois and more than 20 percent were very interested. Of the 70 percent of visitors who were motivated to change their behavior, most planned to attempt to influence policy and/or build connections with the CCHW. Almost 40 percent planned to donate to the CCHW. In addition, visitors reported reflecting on their own personal situations: were they paying their own domestic workers enough? Were they kind enough to the domestic workers they encountered? They expressed a commitment to thank and be kind to the workers they encountered. When asked what the tour made them want to do, visitors reported wanting to promote legislative actions, chiefly supporting the Domestic Workers' Bill of Rights, and committing to change personal behavior.

The Domestic Workers' Bill of Rights took effect January 1, 2017 in Illinois. With it, domestic workers are entitled to minimum wage, a weekly day of rest, protection from sexual harassment, and overtime pay. These are real and tangible benefits for at least 35,000 people in the state..$^{20}$ To be sure, the museum's program is not solely or even mostly responsible for this success, but it doesn't need to be. It needs to be - and is - a part of society, working to improve conditions for those who are not treated equitably.

In recent decades, evaluation has become a necessary component of work in non-profits: necessary first because funders demand it. Where it was once common, say, in the 1980s and '90s, for funders to provide general operating support and receive an annual report on the organization, now funding is almost always meant to support a particular program or element of the organization's work. Museums and other cultural institutions accordingly began to do more evaluation: from demographic surveys to pre- and post-visit surveys. At the same time, as museums have shifted their orientation toward visitors' experiences and away from simply presenting whatever cultural leaders felt was best, they have been gathering more information to try to improve their offerings for visitors: to capture what visitors care about, what they learn and how, who they visit with and why, and what they remember.

A small but growing set of initiatives to evaluate how visits to museums inspire visitors to take action is at the confluence of these broad trends. We might expect that museums working for social justice would be pioneering this type of evaluation. In fact, this type of museum is only now starting to participate in the types of planning, evaluation, and analysis around visitors actions that museums such as zoos and aquariums have been involved in for years.

\section{The model of zoos and aquariums}

Zoos and aquariums are an untapped source of expertise on planning for action and then evaluating those initiatives. The long history these sister institutions have in the world of conservation - and activism against zoos and aquariums - has made them leaders in research, planning, and evaluation for action as compared with demographics and the visitor experience. 
They have been the focus of visitor studies in the humanities and arts. Museums without living collections can learn a great deal from those with them.

The Brookfield Zoo is one of the sites operated by the Chicago Zoological Society. It opened in 1934 on 216 acres in Brookfield, Illinois. The Zoo is gigantic compared to Chicago's urban Lincoln Park Zoo (49 acres) described below. Brookfield is home to 2,300 animals from 450 species. Two million people visit the Zoo each year and its annual budget is $\$ 69$ million. ${ }^{21}$ Fifteen years ago, the Zoo became a developer of conservation psychology, a framework for inspiring visitors to conservation while responding to visitors' individual circumstances. As Carol Saunders, one of the original scholars in this area, put it, "conservation psychology is the study of the reciprocal relationships between humans and the rest of nature with a particular focus how to encourage conservation of the natural world." ${ }^{22}$ Saunders hired Jerry Leubke at the Brookfield Zoo just as conservation psychology was taking off, and he is still using the framework there today. Now Leubke is Senior Manager of Audience Research in the Department of Education, Conservation, and Training at the Zoo. There is much that museums in the arts and humanities could learn from the work of Leubke's team at Brookfield.

At Brookfield Zoo, the executive management team decides what exhibitions the Zoo will mount or renovate based on funding, shifts in conservation status for animals, and the current priorities in the near-term plan for exhibitions. ${ }^{23}$ Curators and lead keepers decide what animals will be on view in the exhibitions, and Interpretive Programs Coordinator Jamie Zite-Stumbris has free rein to write the content for labels and didactic panels within the exhibitions. Her background in environmental politics, rhetoric, and public argument makes it clear that she is the mechanism through which Brookfield Zoo can make its calls to action for visitors. They come in three different styles.

Two of them involve calls to take action as a citizen scientist. Six signs around the park give instructions for doing "research in your own backyard." At two other locations in the park, signs invite the visitor to conduct "Mobile Scientific Inquiries." This is an activity wherein the visitor makes and records observations of animals in an exhibition using the Zoo's own equipment. The zoo can use the observations to supplement the keepers' own observations. For each exhibition, Zite-Stumbris identifies a goal of how many visitors will conduct the Mobile Scientific Inquiries. That goal ranges from around 200 to around 500 visitors.

However, the most pervasive call to action at Brookfield Zoo is a specially branded sign throughout the zoo that says "You Can Help." Most of the Zoo's annual 2 million visitors will encounter some of the 40 of these signs in the park. Each one is connected with a particular exhibit and takes advantage of a moment of visitors building empathy with animals to give them a tool for taking action. The You Can Help signs offer suggestions for meaningful actions relating to conservation or environmental health. For example, near the bison the sign addresses the importance of eating bison rather than beef because the bison's grazing is more gentle on the land. You Can Help in the Big Cat Walk talks about sustainable forestry and urges visitors to seek out wood and paper products labeled with the FSC logo in order to preserve the rainforest. Anywhere there are species that eat fish, the You Can Help initiative highlights the Monterrey Bay Aquarium's standards for sustainable seafood and the importance of using their card when shopping for fish.

You Can Help began around 2013 as a response to two things. First, the Zoo was trying to tackle too many issues and wanted to create a more focused approach to inspiring action in visitors. Second, You Can Help is an example of conservation psychology in action.Visitors must empathize with animals at the Zoo in order to be inspired to take action, so the staff 
have dedicated great resources to building empathy, whether through the incomparable Hamill Family Play Zoo exhibition or the special platforms that help visitors get eye-to-eye with a lion. But there is a gap between caring and taking action. Researchers such as Leubke and Manda Smith at the Lincoln Park Zoo describe it this way: the more certainty the visitor feels that her action is likely to make a difference, the more likely she is to take action. According to Leubke, a motivated visitor can elevate her confidence enough to take action when the Zoo provides clear ideas for how to do so. You Can Help puts specific tools directly in the hands of visitors at the moment of relevance and empathy. But the Zoo is developing stronger evaluation tools for exhibits in a collaborative project with the Shedd Aquarium and eighteen other institutions around the world.

The John G. Shedd Aquarium is another Midwestern leader in audience research. The Shedd is home to one of the largest and most diverse marine collections in the world. It opened in 1930 as one of the first inland aquariums. For its opening, twenty railroad cars made eight trips to Key West to fill the tanks of the aquarium with a million gallons of seawater. ${ }^{24}$ Now, the Shedd houses 32,000 animals. ${ }^{25}$ Chicago's architectural firm, Graham, Anderson, Probst \& White of Field Museum and Wrigley Building fame, designed the Shedd to be a temple to Neptune. Marine details surround the visitor, from the sea creatures fossilized in the limestone floor to the lamps, clocks, and skylights that feature the swirls, fins, and flippers of sea life in iron work; 1.9 million people visit the Shedd each year, and the aquarium's annual budget is $\$ 58.8$ million. ${ }^{26}$ In this study, the Shedd is of interest because of its collaboration, planning, and research about building empathy in visitors and inspiring them to take action for conservation.

In 2014, Lindsay Maldonado, Director of Research and Evaluation at the Shedd, began finding that visitors were feeling all of the appropriate feelings: awe, wonder, excitement, empathy, and curiosity, for example. But they did not know what actions they could take next. ${ }^{27}$ That's when Maldonado reached out to Leubke at Brookfield to begin building a survey instrument that Association of Zoos \& Aquariums (AZA)-accredited institutions could use to answer questions about what inspires visitors and how, what helps build empathy and trust, and why visitors do or do not take action. In 2015, the two institutions began to build a consortium of sites that could participate in gathering data, testing, and validating a new survey tool. The new tool is neither as bounded as traditional OBE, not is it as open-ended as Pekarik's concept of exhibit design discussed above.

The collaboration between Brookfield Zoo and the Shedd demonstrates why planning for visitors' actions is slow to spread across the museum world. By the time the project, called "Assessing Conservation Science Learning at Zoos and Aquarium: Questionnaire Development And Validation," is generalizable, the development and testing of the survey will have taken at least six years.

One part of trying to understand how exhibitions inspire action begins with gathering data from and about visitors. Lincoln Park Zoo (LPZ) in Chicago does this on a scale and with a depth I have not seen at other museums, particularly in relationship to the actions a museum hopes its visitors will take. Lincoln Park Zoo (LPZ) is a free zoo located on Lake Michigan on the north side of Chicago. The Zoo, founded in 1868, is one of the oldest in North America. The annual budget is $\$ 45.7$ million and the annual attendance is roughly 3 million visitors. ${ }^{28}$ The Zoo houses nearly 1,000 animals of 200 different species. LPZ is significant to this study because of its pioneering efforts in inspiring action in visitors, especially in planning for and evaluating on those efforts. 
In 2017, the Zoo's Action Team began an annual practice of selecting an issue it hopes visitors will act on, such as conservation of African penguins. The team works to encourage visitors to take related actions. The team is comprised of members from several different departments at the Zoo: Learning, Conservation Science, Graphics, Communications, Marketing, Operations, and Animal Care, together with other committees such as the Interpretive Task Force and the Guest Experience Committee. The Action Team comes up with ideas for inspiring action that align with the vision. They and the other committees and departments implement the ideas.

LPZ has two departments dedicated to research on visitors. They evaluate the success of the initiatives the Action Team puts into place. One department, Smith's Audience Research Department, gathers data on the visitor's experience. The other, Kathy Kiser's Learning and Research Department, gathers data on how children learn from being at the Zoo. Both departments were founded in 2015. Smith's team gathers data in several ways. They do preand post-testing, where the Zoo gathers data from a visitor before and after a particular experience. The Zoo also practices interview surveying (asking questions of passersby informally), observational and anecdotal surveys (eavesdropping and watching visitors to see how they behave and what they talk about), and flow tracking (watching an area as opposed to a group of visitors). Lastly, the Zoo gathers data through the "full target journey." The target of data gathering is the visitor's complete journey through the Zoo.

In the full target journey, the visitor answers some questions before entering the Zoo. She will answer them again at the end to see how and if her answers change. She understands that the Zoo is gathering data in a longitudinal study about the whole scope of the visit. She also knows she will receive an incentive at the end for participating. The Zoo does not attach demographic data to this study. Plainclothes employees follow the visitor unobserved through her visit until she reaches the exit interview. The Zoo's goals for the future are increasing efforts to inspire action on the part of visitors and beginning to track this action beyond the visit.

Although the Shedd is still in the early stages of planning for action, it is still constantly gathering data about the experiences of visitors and what they may mean about action. The suite of evaluation tools that the aquarium uses can be a model for institutions wishing to create a comprehensive protocol for summative evaluation, and is an excellent compliment to the LPZ. The aquarium conducts an exit survey, a timing and tracking survey, Dimensions of the Visitor Experience (DoVE - a checklist of fifteen characteristics of the visitor experience that visitors report on after the visit), ${ }^{29}$ and targeted random observations for troubleshooting/ logistics and/or comprehension. For example, if there is a concern that an interactive in a particular area is not working well, staff will observe visitors in that area to determine and solve the problem.

One of the hallmarks of a well-organized plan for visitors to take action is some kind of institutional cohesion. The Brookfield Zoo's You Can Help program is one example. It is a highly visible, uniformly branded initiative that visitors encounter throughout the Zoo. Lincoln Park Zoo's Action Team offers another example of a good strategy for cohesion. In 2017, the Shedd does not have a unified approach as Lincoln Park and Brookfield do. But it will create one based on a new strategic plan. The Shedd is working to implement what we can identify here as best practices: offering visitors clear action steps at the moment of empathy in an attractive and highly visible manner, using messages and a look for these calls to action that is consistent across the institution, planning for action, evaluating on action, and integrating the plans to gather data into the overall planning for exhibitions at the outset. 


\section{Using social media to inspire empathy and promote action}

Brookfield Zoo has been experimenting with extending its practice of using empathy to promote action within the zoo into social media. The Zoo's research demonstrated that people engaged more on social media with animal personae than with humans tweeting or blogging as naturalists. Thus, in 2015 the Zoo named an Orinoco crocodile in the Swamp exhibit "Carlita the Crocodile" and began introducing her to the world of social media. The goal was to see if she could spur conversations about conservation. Carlita has accounts on Twitter (over 1,000 followers) and Instagram (250 followers) as well as a blog. Her posts are a combination of silly and conservation-themed messages. She engages readers on the issues of sustainable seafood and healthy waterways. For example, she was the one to teach many staff members at the Zoo about how the plastic beads in exfoliating soaps threaten the environment.

There are many museums that wish to inspire action in visitors and many that sometimes or always feature calls to action, but very few that do institution-wide planning on the subject or keep records about it. These institutions deserve to be heralded for contributing tools to the field that foster the survivorship and efficacy of museums today. Zoos and aquariums aren't the only models.

\section{Evaluating for action}

Over nearly a decade, President Lincoln's Cottage at the Soldier's Home has gone from a newly opened historic home in need of preservation to one that puts the past into the service of the present and the future. The Cottage is the summer home where Abraham Lincoln first drafted the Emancipation Proclamation, which he had been struggling with at the White House. The house is northeast of the White House in the neighborhood of Petworth - a forty-five-minute commute in the 2010s and the 1860s alike.

Lincoln's experience and the explorations of staff members both suggest that something about the physical space of the Cottage itself improved President Lincoln's ability to reflect and take action. The staff's hope is that the place will do the same for visitors. Specifically, the museum is dedicated to advancing Lincoln's work to eradicate slavery by working against contemporary slavery. According to the strategic plan for 2018-2022, "President Lincoln's Cottage is a home for brave ideas ... Today, the site offers an intimate and never-before-seen view of Abraham Lincoln's presidency and private life through authentic experiences that inspire action." 30

The organization directly calls visitors to action and, unlike many institutions, is working on tracking and evaluating that action. Lincoln's Cottage's exhibition Can You Walk Away? Modern Slavery and Human Trafficking in the United States is a good example of that type of study in progress. The exhibition began with a twenty-minute video in which the visitor meets victims of sexual trafficking and other forms of modern-day slavery as well as activists working against slavery on college campuses and in organizations such as the Polaris Project, an abolitionist group and partner of Lincoln's Cottage. The film ended with the question: "Now that you know... can you walk away?" This first call to action challenged visitors to remain engaged with the issue of modern-day slavery, even though it is so disturbing.

When the video ended, visitors entered the darkened space of the gallery in which rays of light shone on three books that addressed the questions: What is modern slavery? Who is vulnerable? And how do we end modern slavery? Unlike the materials in many reading 
stations within exhibitions, these books weren't attached to anything.Visitors could and did walk around with them. People were able to discover and share surprising things. Frequently, staff members observed visitors showing the books to the people they came with. This action employs the intimacy and trust that already exists among families and friends who visit the Cottage together. It also demonstrates the ways in which exposing slavery today can be an intimate undertaking. It can mean having a conversation of a very sensitive nature with someone you know or building trust with an acquaintance to enable a successful conversation to happen. Or it can mean trusting someone else, perhaps someone in law enforcement or a social service organization.

The books also differed from contemporary news sources in galleries in another way. Often, when a curator wants to bring the news into the story in the gallery, she will provide a curated set of news articles for visitors to look at. While this can be useful, it is often unattractive and unappealing compared to other elements in the gallery. Reading the news is not an organic way of spending time in an exhibition and visitors might gloss over it with the idea that they'll look into it later, if at all. The books in Can You Walk Away? were an extension of the label hierarchy in the exhibition. They carried the same design as the rest of the exhibition, and the information in them was artfully displayed in a way that was easy to read and easy to understand. A two-page spread might include a big bold headline supported by a couple of quotes and a captioned photograph. Or it might include simply two short statistics, one on each page. Page 1: In the US, an estimated 1.5 MILLION kids run away from home each year. Page 2: The average time it takes a runaway to be approached by a trafficker is 48 HOURS. ${ }^{31}$ Simple maps overlaid with accessible information are another important piece. Perhaps most significantly, the design was clean and inviting, attractive, and immediately engaging. At no point did the visitor have to wonder what the point is either of the book generally or of its purpose within the exhibition.

More directed calls to action within the exhibition; all contained the challenge: "Can you walk away?" Postcard pads assembled to form a subtle black-on-black message that read: "Can you walk away?" (Figure 3.2). White text overlaid each postcard with a statistic about human trafficking: "The average age of entry into prostitution is 13 ." Or " 12.5 million people are enslaved worldwide - more than were held at the height of the trans-Atlantic slave trade." ${ }^{32}$ On the back, each postcard prepared the visitor for some kind of action: share the hotline number for the National Human Trafficking Resource Center or send the card to the Secretary of State, for example.

During the run of the exhibition, roughly 40,000 people visited Lincoln's Cottage. The Cottage went through 14,000 cards during the run of the exhibition. We cannot know whether visitors took the cards for souvenirs or with the idea of taking action in mind. Nor can we know if visitors acted as they intended to when they took the cards. But it is clear that 35 percent of the visitors ended their visit to the Cottage by being inspired enough to take the first action - taking the card. ${ }^{33}$

In summer 2017, the museum completed a year-long phenomenological study of visitors' experience at the Cottage. Erin Mast, Executive Director and CEO of President Lincoln's Cottage, decided to embark on the study because the museum was receiving such a volume of high-quality messages from visitors that stated that they had felt transformed by their visits and that their visits continued to affect them for weeks, months, or even years. ${ }^{34}$ Mast recalled two elderly visitors from 2013. There had been a frequent story in the news about Amanda Berry, Gina DeJesus, and Michelle Knight, three women who were held captive in the home 


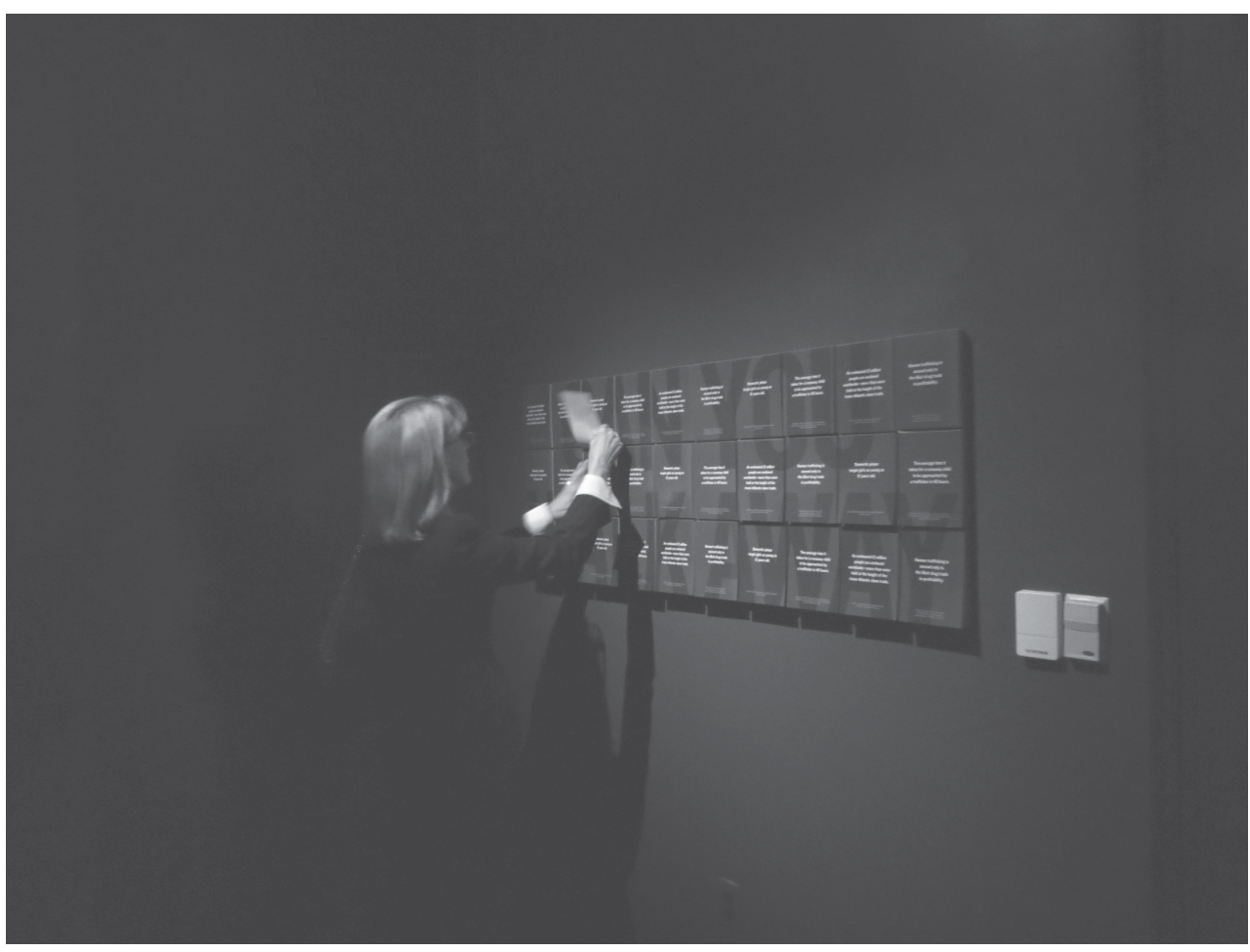

FIGURE 3.2 Gallery shot from Can You Walk Away? at Lincoln's Cottage, 2012. Take-away element: postcard installation. Courtesy of President Lincoln's Cottage.

of Ariel Castro in Cleveland for a decade before Berry broke out and freed them. The two visitors were also from Cleveland. They told Mast about how concerned they were that the kidnapping had happened in their own neighborhood. They felt they had previously not had any language with which to discuss such a thing. But, having visited the Cottage, they felt that they had gained a way of talking about what was going on in their own community. ${ }^{35}$ For visitors to go home from a visit to a museum and actually speak to others in their community about a problem such as human trafficking is a very powerful form of taking action indeed. Over the last few years, an increasing number of visitors have been reporting that they are on a return visit because the museum has fundamentally changed their situation in some way: their understanding of history or their teaching, for example. ${ }^{36}$

In looking for a way to capture these transformative experiences, Mast began a collaboration with Julio Bermudez, Director of the Cultural Studies and Sacred Spaces graduate program at the Catholic University of America (CUA) and member of the Academy of Neuroscience for Architecture. The project is a phenomenological visitor study. The goal of the study was using contemporary neuroscience to discover whether tours of Lincoln's Cottage can “open visitors' minds to new ideas and inspire action" as inhabiting the place did Lincoln and, if so, how that connection between space and state of mind works. ${ }^{37}$ The study examined the visitor experience in depth, asking questions such as how the visitor would "describe effects of darkness, light, weather, barriers in the rooms, and more. Did you feel inspired? Were you annoyed? Was the exhibition tiresome? Stimulating? Exciting?" ${ }^{38}$ In early 2018 the preliminary results 
from Mast's study show that the Cottage does inspire emotion and a desire to take action in a large majority of visitors $;{ }^{39} 83-84$ percent of visitors on the tour became aware of physical sensations such as smells, light, and textures in the Cottage. ${ }^{40}$ Mast wishes to expand the study to other sites using a combination of environmental psychology testing and portable brain-scanning technology. As with Assessing Conservation Science Learning, the project of the Shedd and Brookfield Zoo, Mast's study demonstrates the long time scale at play when museums use well-conceived and tested research to inform exhibitions.

\section{Types of action}

Action means different things to different museums.Visitors can write letters: to themselves, to a legislator, to a historical figure. Outside the museum, they can donate to causes, knit blankets, ally with groups, sign petitions, call lawmakers, vote, march, or defend someone. Visitors can contribute to artwork either before or after installation. To paraphrase David Garneau, art incrementally changes our minds - not only our opinions, but what we are even able to imagine and think. Though this is nearly impossible to measure, one effect of art is to create "new pictures of the world" in our imaginations. These pictures can influence our behavior. ${ }^{41}$

Roger Simon writes that curating difficult knowledge must be concerned with how to parlay the force of history into affecting our senses of responsibility for those who are unknown to us and engaging our capacities to act. ${ }^{42}$ This might mean giving blood during the Día de los Muertos exhibition at the National Museum of Mexican Art. It might mean speaking up about harassment or bullying. In their Harvey L. Miller Family Youth Exhibition Make a Difference!, the Illinois Holocaust Museum trains children to do this.

Lisa Lee described Re-Defining Democracy (2010), Hull-House Museum's then-new permanent exhibition, as "designed to cultivate emergence of a new political agent," the visitor. ${ }^{43}$ She referred to the museum trying to encourage individual visitors to go out and become activists. ${ }^{44}$ Political actions in museums have gotten much more interesting than signing a petition or contacting a congressperson. Those are still important actions, and it is wonderful when people can take them in the gallery while they're inspired to do so. But other actions that may have a less direct effect may be more memorable and therefore more valuable for maintaining visitors' engagement with an issue. Voting, confessing, sewing, and remembering are all political acts that museums can inspire. In turn, when the actions are interesting enough, they inspire stories that create opportunities for the content and the actions to snowball.

\section{When, where, and how do visitors take action?}

In this section - what remains of this chapter - I will offer examples from thirteen exhibitions. The stories demonstrate how visitors took action at diverse times relating to their visits (during, after, far beyond, and even before the visit).Visitors also took action in diverse ways, and these stories illuminate some practices that contributed to visitors' potential to act. From captioning photographs to co-creating artworks, from voting to returning stolen property, visitors to these museums acted in ways that will likely be memorable for them and may even inspire other actions in the future. 


\section{During the visit}

\section{Speaking to Memory: St. Michael's Indian Residential School}

My visit to the Museum of Anthropology (MOA) at the University of British Columbia in Vancouver began under the towering, slender pines of the Northwest coastal forest - red cedar, mountain hemlock, Douglas fir, and Sitka spruce. The museum is nestled in the forest, and its grounds contain a large reflecting pool surrounded by paths for walking. These are dotted with outdoor exhibits. Sculptures such as monumental poles and Haida house beams feature figures that could be spirits of this forest, both welcoming and guarding. The MOA is a destination in Vancouver, albeit a difficult one even for locals to access. Roughly 190,000 people make the pilgrimage each year, and the museum's budget is $\$ 5.2$ million. ${ }^{45}$ The museum was founded in 1947. It opened in its own dedicated building in 1976 under Michael Ames, whose writing and work at the MOA helped transform the curatorial field, changing it to be outward-facing and engaged with the public. ${ }^{46}$ The museum has been a pioneer in initiatives to involve the public in the institution, beginning with the institution of visible storage under Ames in the 1980s. The MOA continues to search for new and compelling ways to honor and collaborate with First Nations peoples on whose land UBC and the museum sits.

Pam Brown, a curator at the MOA in Vancouver, received a collection of photographs from her mother, Beverly Brown, who had attended St. Michael's Indian Residential School on northern Vancouver Island in Alert Bay as a girl. Canada and the US both had systems of boarding schools for native or Indigenous children that were meant to remove these children from their communities and assimilate them into the dominant White culture. Richard Henry Pratt, the founder and superintendent of the Carlisle Indian Industrial School in Pennsylvania, summed up the concept best when he said that the schools would "kill the Indian ... and save the man." In Canada, the system lasted from 1876 to 1996. Attendance at these schools was compulsory. Beverly's father gave her an automatic camera during the time she was at St. Michael's, and she used it to document her life there, photographing her friends and classmates. Mrs. Brown had never shared the photographs with her family before, but now - in 2012 - she chose to caption them by hand and donate them to the MOA archives. Digitally enlarged prints of the photographs covered one wall of an exhibition entitled Speaking to Memory: St. Michael's Indian Residential School.

Juanita Johnston produced the unusual presentation in the gallery. The gallery was nearly empty of objects. A centerpiece - the large dough mixer from the residential school's kitchen - eloquently summoned up the deeply institutional nature of the experience of residential school. The walls were covered with "reams of text," as Karen Duffek, Curator of Contemporary Visual Arts \& Pacific Northwest, put it. Specifically, one wall was covered with the apologies the government had issued about placing native children in residential schools. Another wall was covered with the complete text of interviews Vancouverites had given about their experiences at St. Michael's. These were intended for visual effect, but visitors read both of these walls of primary-source documents in great depth. This exhibition took place just as many people were learning about the residential school system through the process of the Truth and Reconciliation Commission.

The wall of photographs was set up so that visitors could add to the captions, and thus to the information in the archive. They participated heartily in this endeavor, frequently recognizing family members in the photographs. Looking at one of Beverly Brown's captioned 


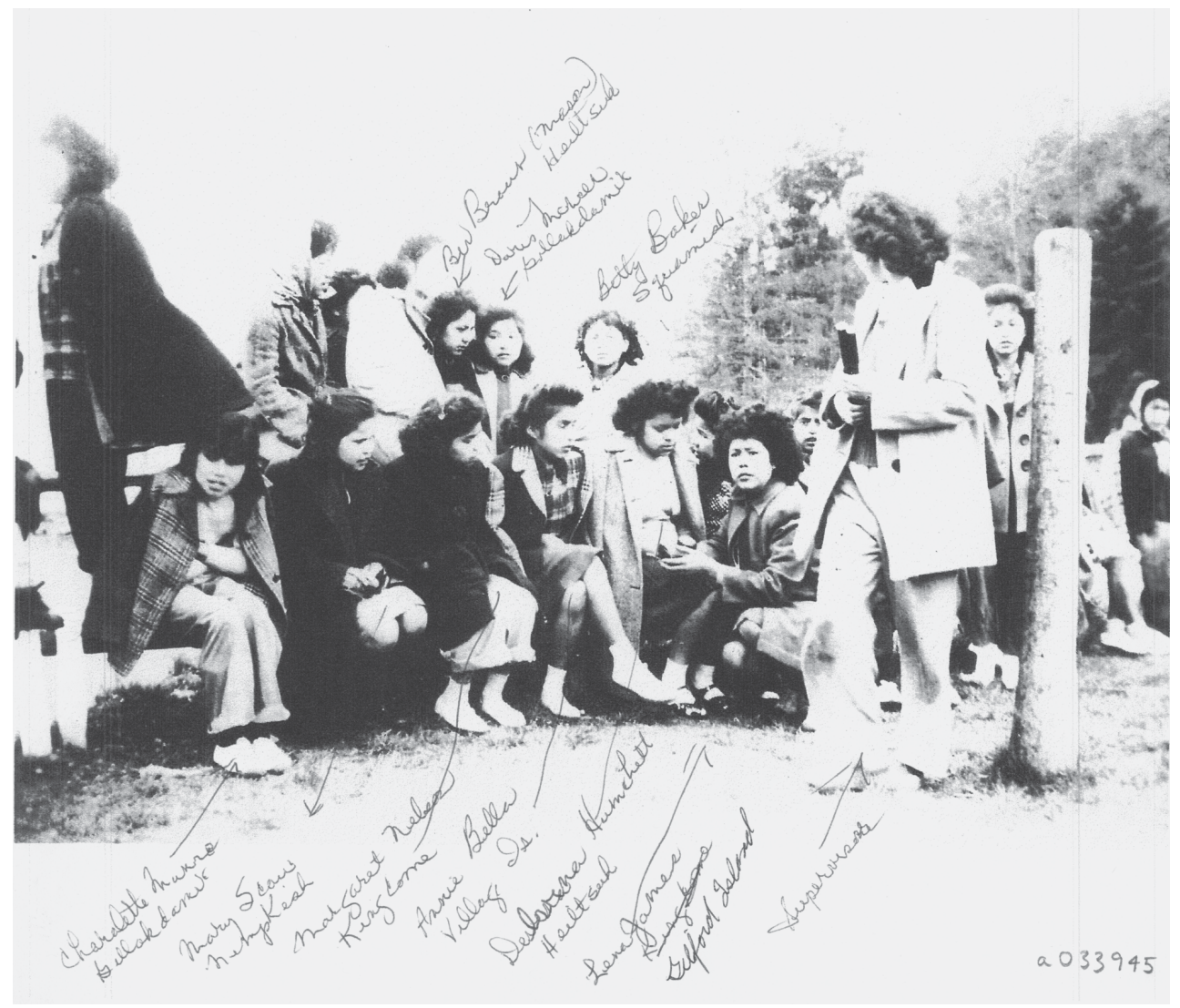

FIGURE 3.3 “Children at St. Michael's Residential School." Photo by Beverly Brown fonds (19371945), exhibited in Speaking to Memory: St. Michael's Indian Residential School, 2013-2014, Audrey and Harry Hawthorn Library \& Archives, UBC Museum of Anthropology. Courtesy of UBC Museum of Anthropology, Vancouver, Canada. Beverley Brown fonds. a033945.

photographs (Figure 3.3), it's easy to imagine both how visitors might want to read so much text and how they might be so interested in captioning the photos themselves.

Her handwriting transforms the image. In the photograph, we see the concerned faces of children and adults. The children are chilly, huddled together, dealing with uncertainty. Beverly's handwriting breathes life into each girl. We learn their names. We see Beverly, a friend, remembering her classmates. The captions remind us of all the relationships that connected these girls to their social fabric. The incongruence between the captioning, which we might imagine accompanying a posed group picture of smiling faces, and the visible tension in this candid photo only highlights the work of the captions. The exhibition inspired visitors to participate in captioning the photographs for several reasons. The exhibition was timely and built on existing community. It was visually and emotionally captivating, and it rewarded long looking as visitors discovered connections to their own pasts. It also offered opportunities beyond the scope of the visit because the experience prompted rehearsal on the part of visitors. 


\section{Unfinished Business: Arts Education}

Around the same time that the MOA was organizing Speaking to Memory, Hull-House was organizing Unfinished Business: Arts Education (2011). When I began my research at HullHouse Museum in 2011, the museum organized a different temporary exhibition each year that dealt with the "unfinished business" of the Progressive reformers. Inside these exhibitions, the museum would call visitors to take specific actions at "action stations" in the gallery. In Unfinished Business: Juvenile Justice, visitors were able to send postcards to inmates at the Tamms Supermax Prison. In Unfinished Business: Home Economics, visitors could think about use and reuse while learning to make an old T-shirt into a tote bag at Frau Fiber's action station.

Viola Spolin was a drama teacher, director, and actress who began working at HullHouse Settlement in 1924. There she met and studied with Neva Boyd, who founded the Recreational Training School at Hull-House Settlement. Boyd's program was a "one-year educational program in group games, gymnastics, dancing, dramatic arts, play theory, and social problems." ${ }^{47}$ Out of her work with Boyd, Spolin developed a set of exercises for actors to help them learn to improvise realistically. She called these "theater games," and became famous for them. According to Hull-House, Spolin "invented theater games as a way to facilitate training in a way that crossed ethnic and cultural barriers." ${ }^{48}$ Nick Rabkin, a powerful administrator and consultant on the arts in Chicago, was one of the advisors to Arts Education. Rabkin entered the cultural stage in Chicago as director of a theater company. He was enthusiastic about including Spolin in the project, writing that her games were "not just about making better theater - but better people and a better society." ${ }^{49}$

In recent years, the idea of games as constructive venues for making the world a better place has experienced a renaissance. In Arts Education, visitors could play some of Spolin's theater games together. In one of the games, Mirror Speech, two participants take turns leading and following. They choose a subject of conversation and then the initiator begins speaking while the reflector tries to mimic the words of the initiator exactly, speaking them at the very same time. Then they attempt to change roles with no pause in conversation. This experience created both empathy, as the partners mirrored one another, and hilarity as their attempts broke down. This game and others were designed to dismantle hierarchy in the theater setting and involve actors in the roles of directing as well. In Difficulty With Small Objects, a single player becomes "involved with a small object or article of clothing which presents some problem. Some examples include opening a tightly sealed jar, dealing with a caught zipper, a jammed drawer, tight boots.'The partner guesses the problem. In these activities, the combination of physicality, emotion (probably humor), and mirroring can produce empathy and the embodied emotional response that will drive the visitor's connection to resonant content.

\section{Official Unofficial Voting Station: Voting for All Who Legally Can't}

Jennifer Scott, who became the director of Hull-House in 2015, has developed and expanded the idea of the action station to encompass, in some cases, whole exhibitions. In 2016, Scott curated Official Unofficial Voting Station:Voting for All Who Legally Can't (Figure 3.4), an art and action installation by the artist Aram Han Sifuentes. (Figure 3.5 shows decorations that highlight the categories of people in the US who cannot legally vote.) "VOX POP: The Disco Party," which Han Sifuentes designed with Lise Haller Baggesen, occupied the second-floor 


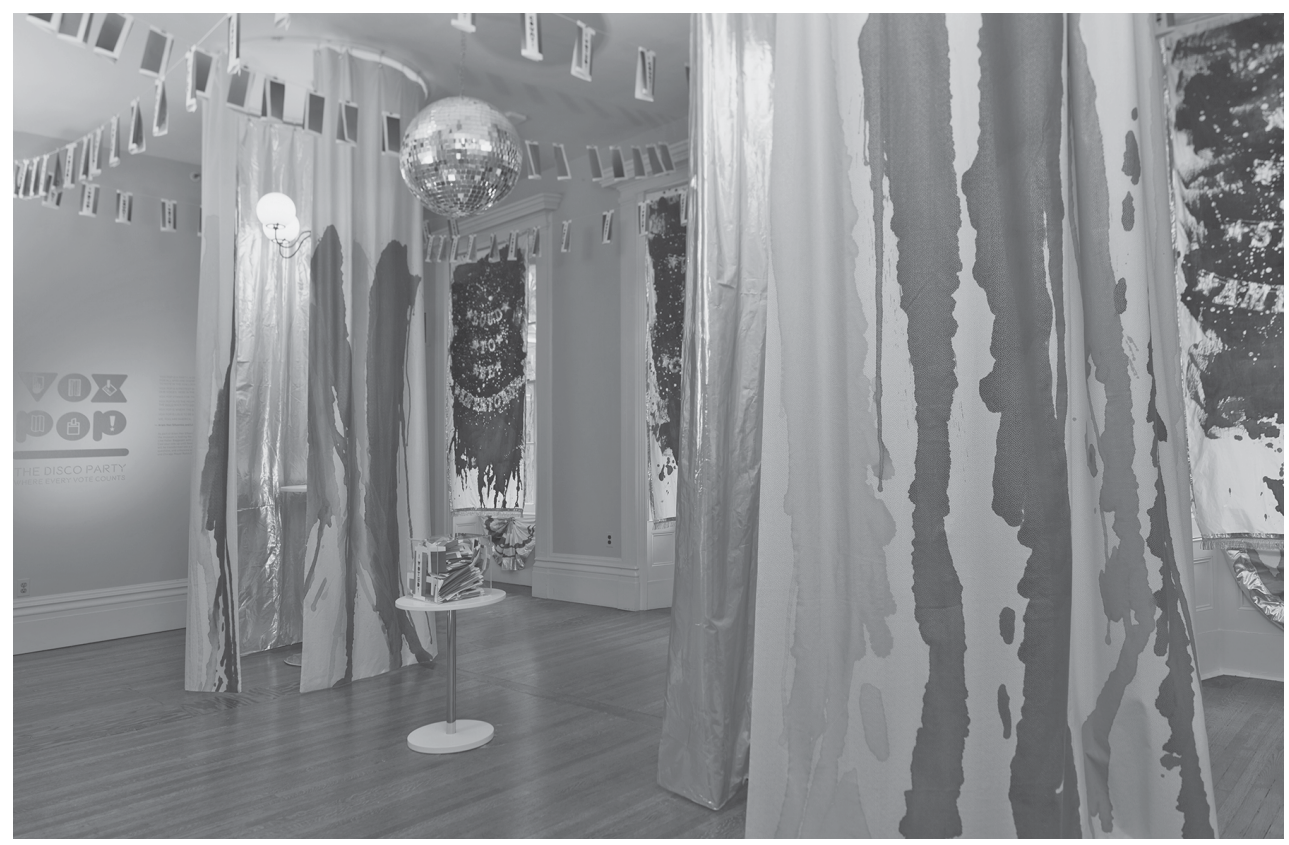

FIGURE 3.4 Unofficial Voting Station:Voting for All Who Legally Can't at the Jane Addams Hull-House Museum featuring "Vox Pop: The Disco Party" by Aram Han Sifuentes (2016). Photo by Sara Pooley. Courtesy of Aram Han Sifuentes.

gallery of Hull-House, where Unfinished Business was typically housed. A disco ball hung from the ceiling. Festive curtains of gold lamé designated voting booths where visitors could place their ballots (Figure 3.4). Tie-died bunting festooned the windows. Garlands of ballots hung from the ceiling, and the ballot box quickly filled with the pink, purple, and teal sheets that visitors completed.

Party music contributed to the sense that this space of civic activity and engagement was joyful, playful, fun, and hip. Bold graphics highlighted the voting process for those who could not read English (Figure 3.6); 2,182 people voted in total..$^{50}$ The exhibition inspired visitors to vote because it was timely, providing an outlet for visitors' existing feelings about the election. Amongst the visitors to the museum, the exhibition-cum-event did help to build community and the hip atmosphere also fostered participation.

\section{US Citizenship Test Samplers}

The museum also exhibited Han Sifuentes's work in US Citizenship Test Samplers. The exhibition offered opportunities to take several types of action. First of all, it was a crowd-sourced exhibition in which visitors who participated in Han Sifuentes's project were able to show their work as well. Han Sifuentes and other non-citizens stitched samplers that addressed questions on the test for citizenship to the US (Figures 3.7 and 3.9). (Han Sifuentes's sampler answered them all; Figure 3.8.)

Each sampler was on sale for $\$ 680$, the cost of the naturalization application.Visitors could take the action of buying the samplers, thus endorsing the value of the non-citizens to the 


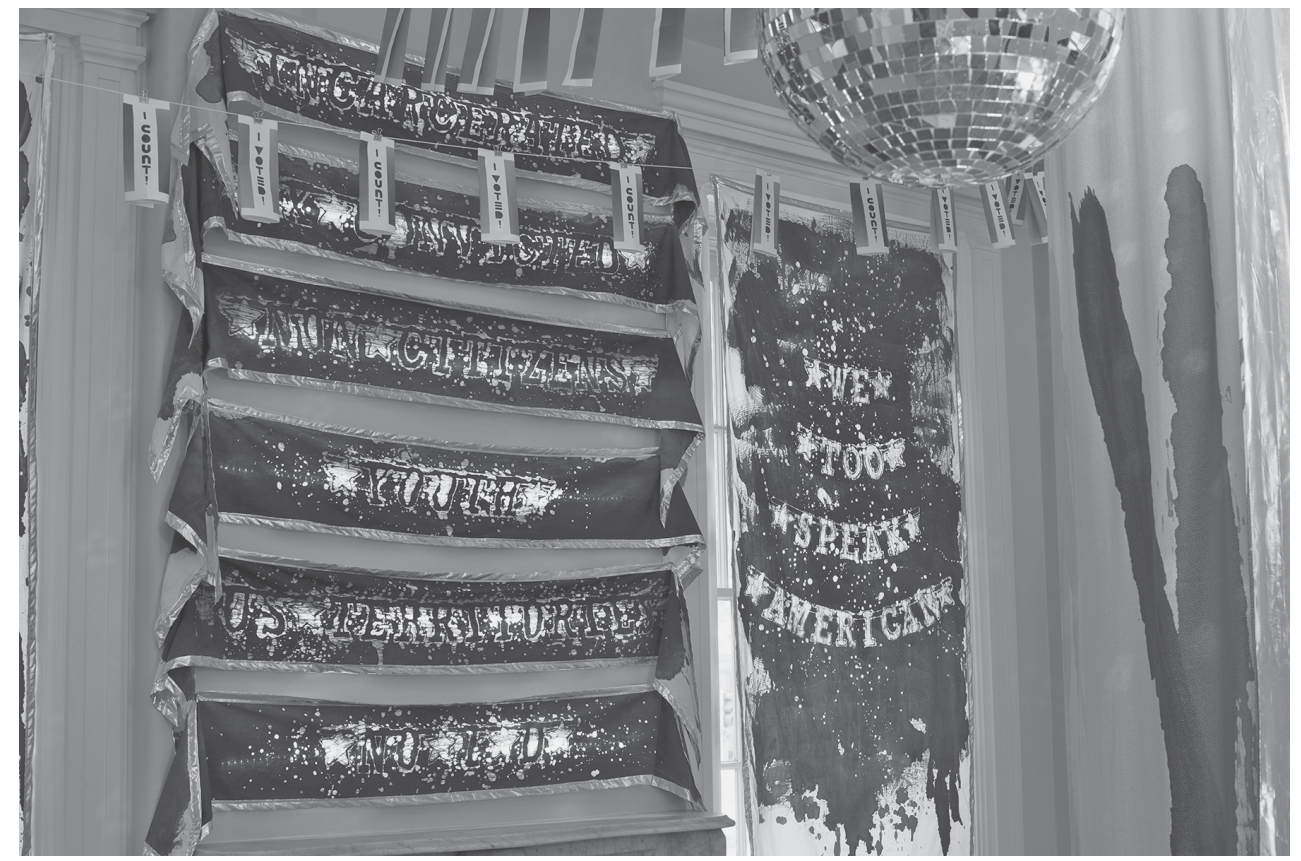

FIGURE 3.5 Unofficial Voting Station: Voting for All Who Legally Can't at the Jane Addams HullHouse Museum featuring "Vox Pop: The Disco Party" by Aram Han Sifuentes (2016). Banners read: "Incarcerated, Ex-Convicted, Non-Citizens, Youth, US Territories, No ID; We Too Speak American.” Photo by Sara Pooley. Courtesy of Aram Han Sifuentes.

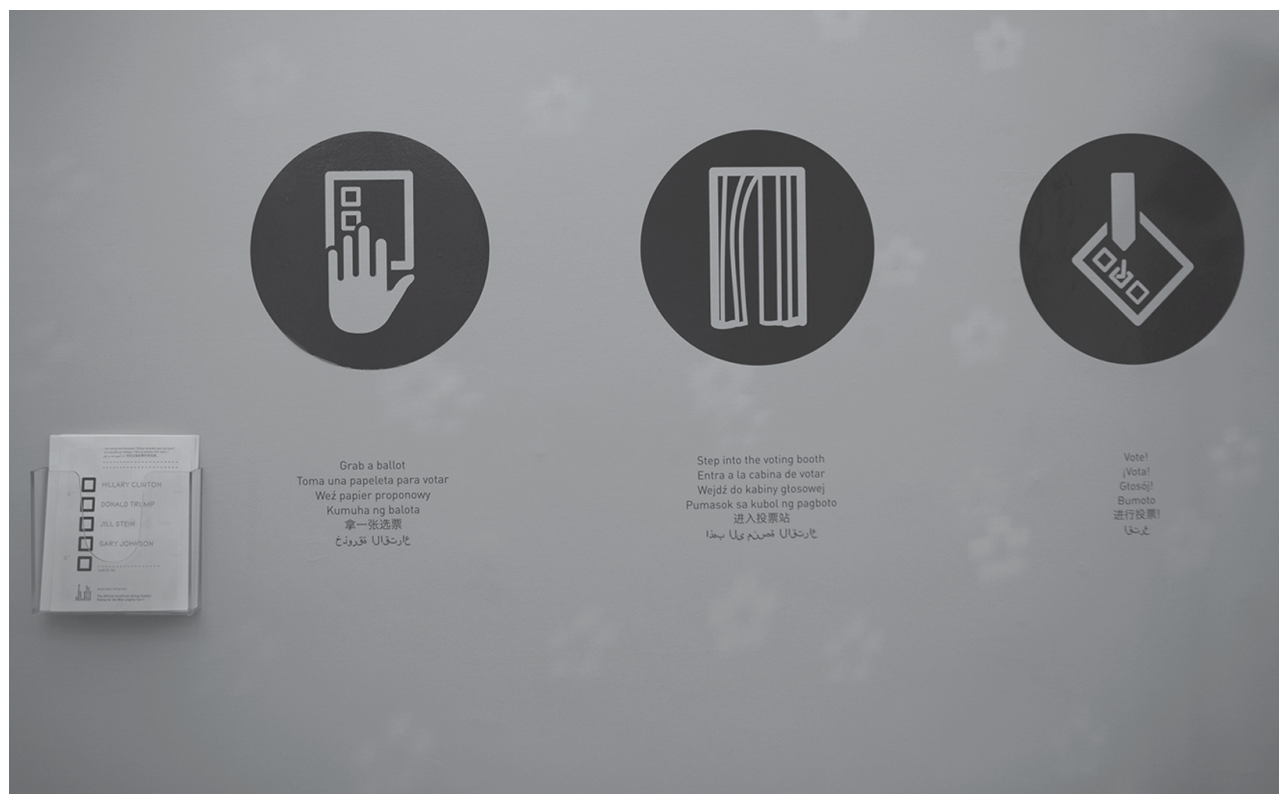

FIGURE 3.6 Unofficial Voting Station:Voting for All Who Legally Can't at the Jane Addams Hull-House Museum featuring "Vox Pop: The Disco Party" by Aram Han Sifuentes (2016). Photo by Sara Pooley. Courtesy of Aram Han Sifuentes. 


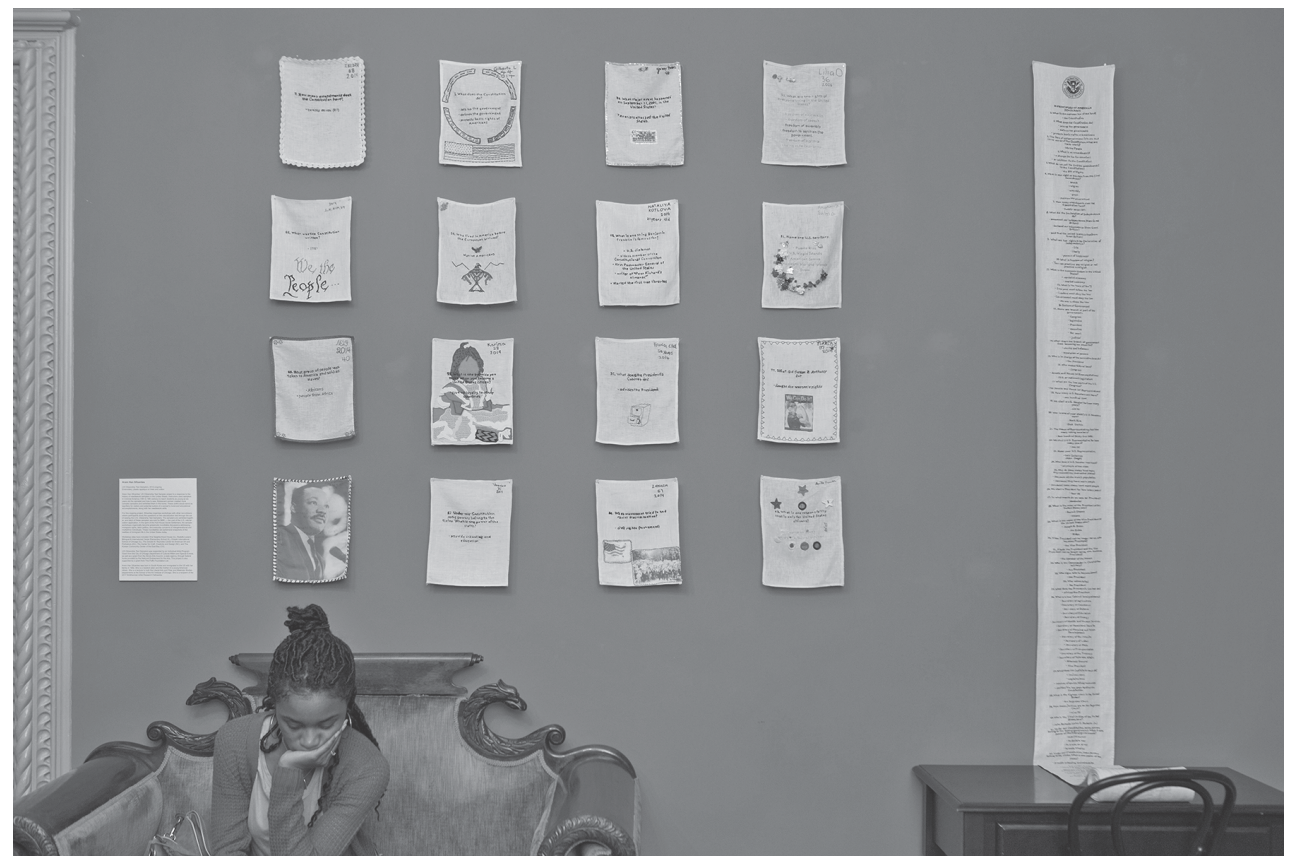

FIGURE 3.7 US Citizenship Test Samplers installed in the library of the Jane Addams Hull-House Museum, 2016. The long sampler on the right is by Han Sifuentes and the smaller ones are by participants in her project. Photo by Sara Pooley. Courtesy of Aram Han Sifuentes.

social fabric. One hundred and five participants made samplers and twenty had sold as of spring 2018. ${ }^{51}$ In addition to fostering community and being timely, this exhibition drew attention to a contemporary problem, raised awareness, and materially affected the ability of individuals to overcome the challenge of an expensive and, in some regards, irrelevant citizenship test.

Participatory art is another avenue by which visitors might take action in the gallery. In this example, the participation in the work of art is a bit more direct than it is in a social installation such as VOX POP or an exhibition such as US Citizenship Test, where participants make work in advance that is later exhibited. Exhibitions such as If You'll Remember, I'll Remember (2017) at the Mary and Leigh Block Museum of Art at Northwestern University in Evanston, Illinois and Women Hold Up Half the Sky (2012-2015), a traveling exhibition organized by the Skirball Cultural Center in Los Angeles enable visitors to alter one or more works of art in the gallery during the run of the show.

\section{If You'll Remember, I'll Remember}

The Mary and Leigh Block Museum of Art is a university museum at Northwestern University in Evanston, Illinois, just north of Chicago. The Block was the first museum I ever worked at, over the summers during college as an assistant preparator in the print room. The museum is a teaching institution where students curate some of the exhibitions. It was founded in 1980 and sees roughly 45,000 visitors each year. The museum’s annual budget is $\$ 3.6$ million. Over 


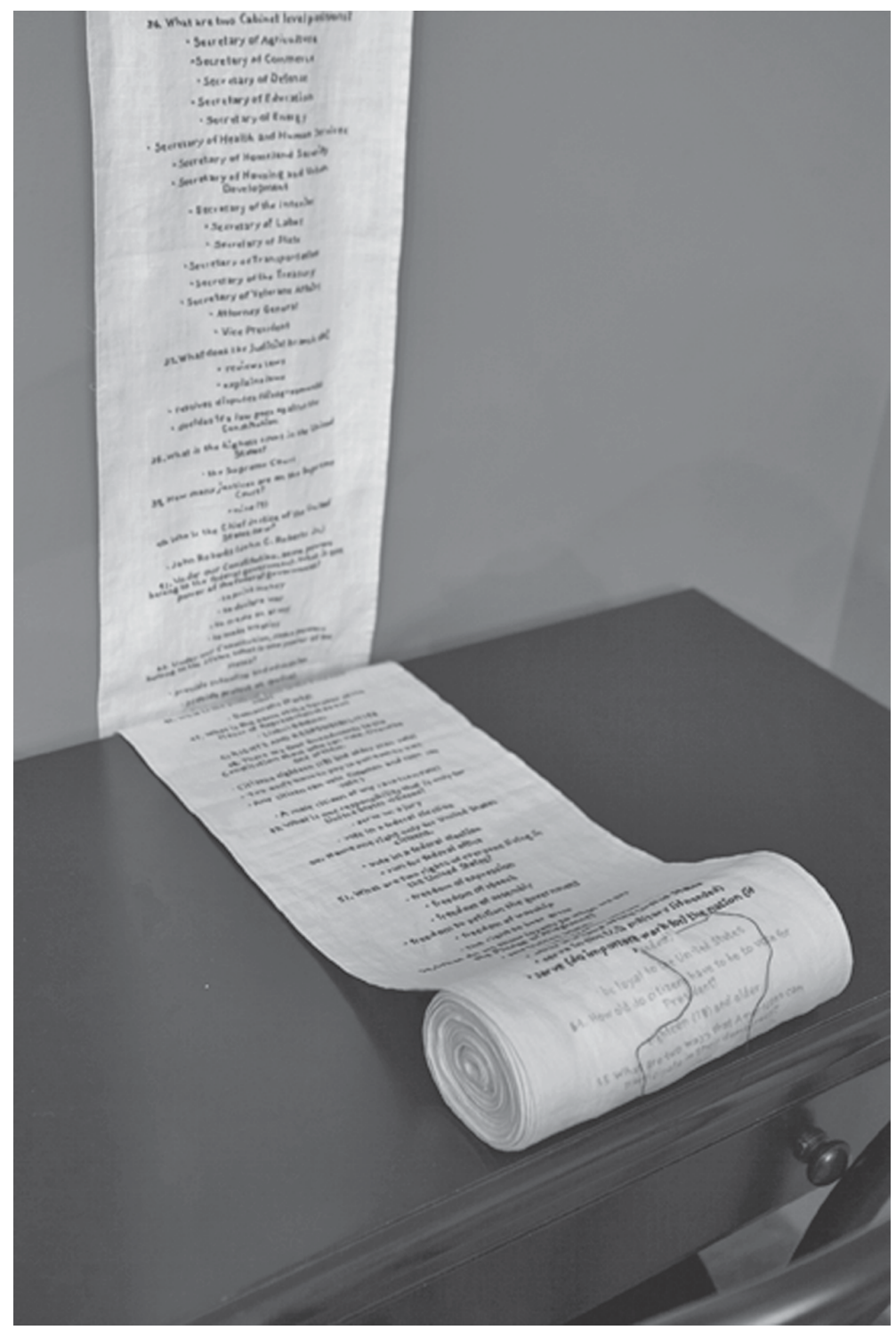

FIGURE 3.8 US Citizenship Test Samplers installed in the library of the Jane Addams Hull-House Museum, 2016. Detail of sampler by Han Sifuentes. Photo by Sara Pooley. Courtesy of Aram Han Sifuentes.

the last few years, the museum has changed, gaining a new director in 2012, Lisa Corrin, and Associate Director of Engagement Susannah Bielak in 2013. Corrin was the curator at Baltimore's the Contemporary when the museum invited the artist Fred Wilson to install the landmark exhibition Mining the Museum at the Maryland Historical Society. ${ }^{52}$ The practices of auto-critique that that exhibition has inspired in institutions across the US are crucial to the advancement of curatorial work for social justice. Though Corrin doesn't use the term "social justice" to describe her work at the Block, she is aware of the history of elitism and exclusion 


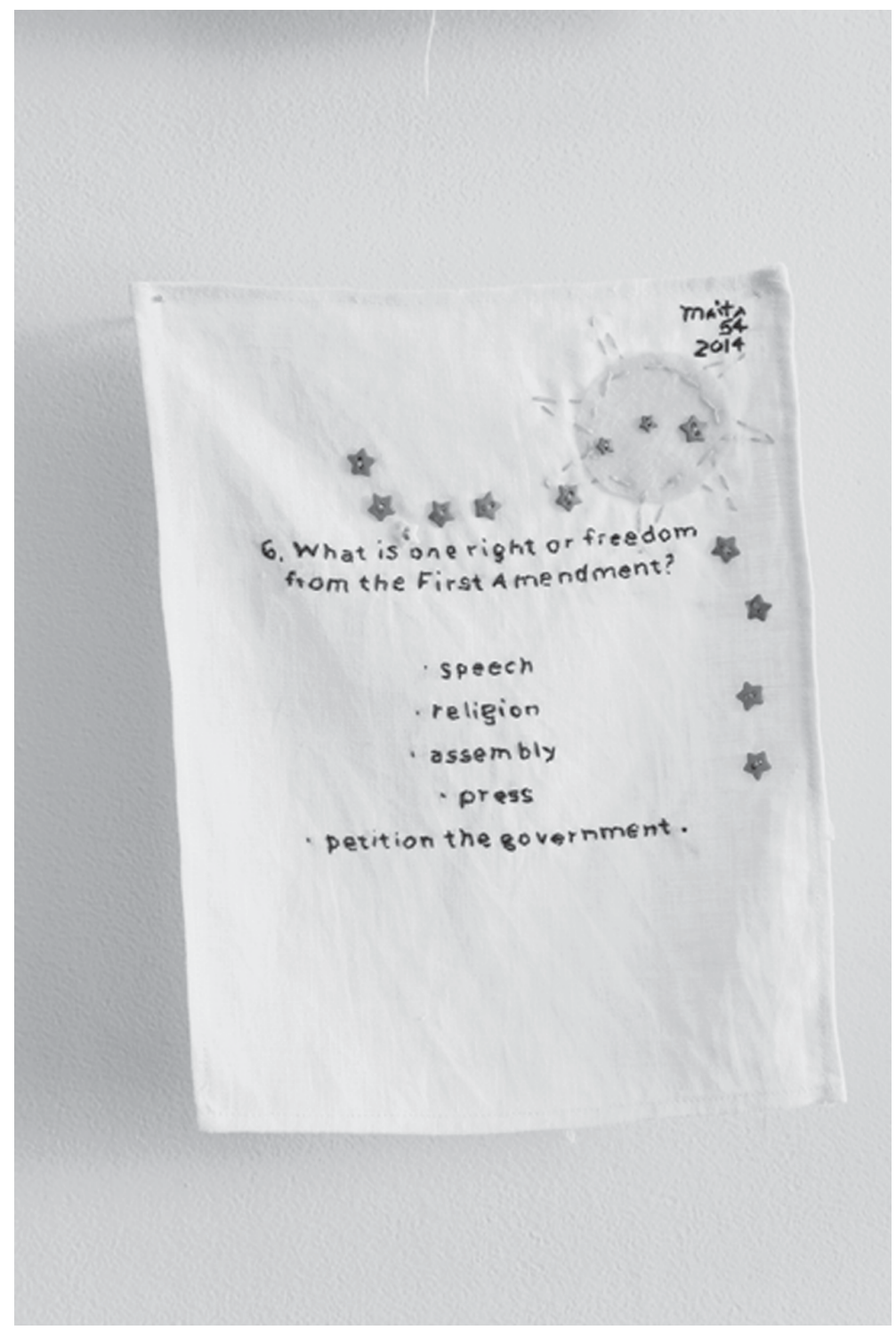

FIGURE 3.9 US Citizenship Test Samplers installed in upstairs hallway of the Jane Addams HullHouse Museum, 2016. "Question Number: 6. Name: Maita. Age: 54. From: Columbia. Moved to the U.S. in 2003." By Maita. Embroidery on linen or cotton with plastic beads. Size roughly 8" x $10 "$. Photo by Sara Pooley. Courtesy of Aram Han Sifuentes.

that museums have perpetrated and benefited from and is aware that museums help to shape people's values. To that end, Corrin is committed to building a diverse program at the Block and helping visitors question assumptions about the world around them and critique our society by raising awareness about important problems. ${ }^{53}$ As Corrin put it, the Block is not so different from the Biotech Department at the university. Both are searching for "creative solutions to problems that have been around for a long time." 


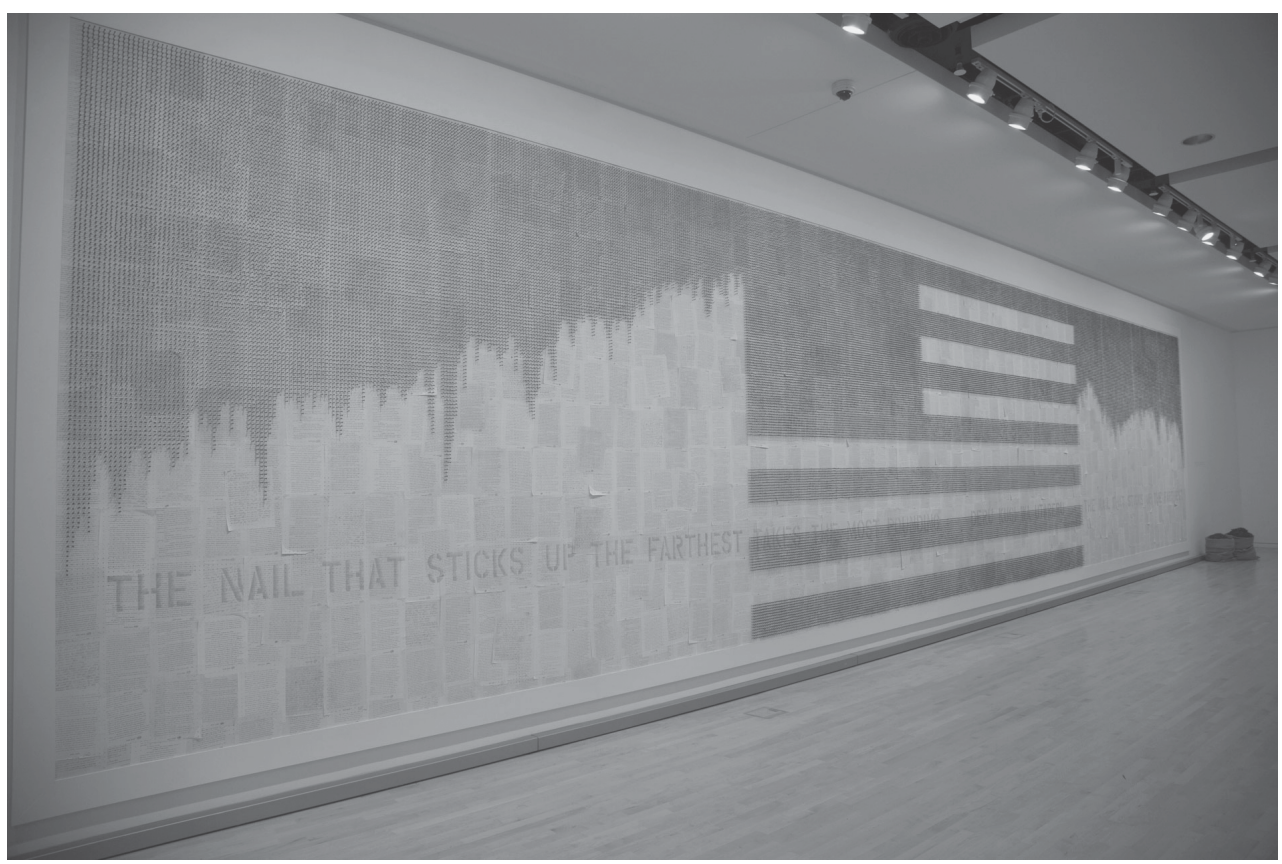

FIGURE 3.10 Kristine Aono, "The Nail that Sticks of the Farthest...," 2017, installation view, If You Remember, I'll Remember, February-June 2017, Mary and Leigh Block Museum of Art, Northwestern University, IL. Photo by Caroline Alice Claflin. Courtesy of Kristine Aono.

In If You'll Remember, artists commented on historical connections to the present on the seventy-fifth anniversary of Japanese internment. The exhibition was full of many unfamiliar juxtapositions of historical episodes and much food for thought. In Kristine's piece, “The Nail That Sticks Up The Farthest...", the walls were papered with letters from Aono's grandfather, who was interned. The Japanese saying, "The nail that sticks up the farthest takes the most pounding," was printed across the wall-length installation. Aono drove nails partway into the central area of the wall in the shape of an American flag (Figure 3.10) and invited visitors to drive additional nails into the wall. They did so, completing the piece as it remained on view (Figure 3.11). In this way, visitors took action that was visible to others and provided an opportunity for thinking about the resonance between Japanese internment and current events such as the separation of families attempting to enter the US and the refugee crisis. Contributing to the exhibition built the community around Northwestern University and attracted attention to a chapter of history that is frighteningly relevant today. The changing visual display invited repeat visits and therefore invited visitors to rehearse their visits.

Women Hold Up Half the Sky tells the story of injustice against women through the subjects of maternal health, trafficking, and gender-based violence. ${ }^{54}$ The exhibition includes a wall graphic that commemorates the estimated 60 million women and girls who are "'missing' because of infanticide, abuse, neglect, and other lethal forms of discrimination." 55 Twenty thousand empty circles represent the lives of these people on the gallery wall, and visitors are invited to fill the circles in with colored pencils. By the end of the exhibition's run, the statistic 


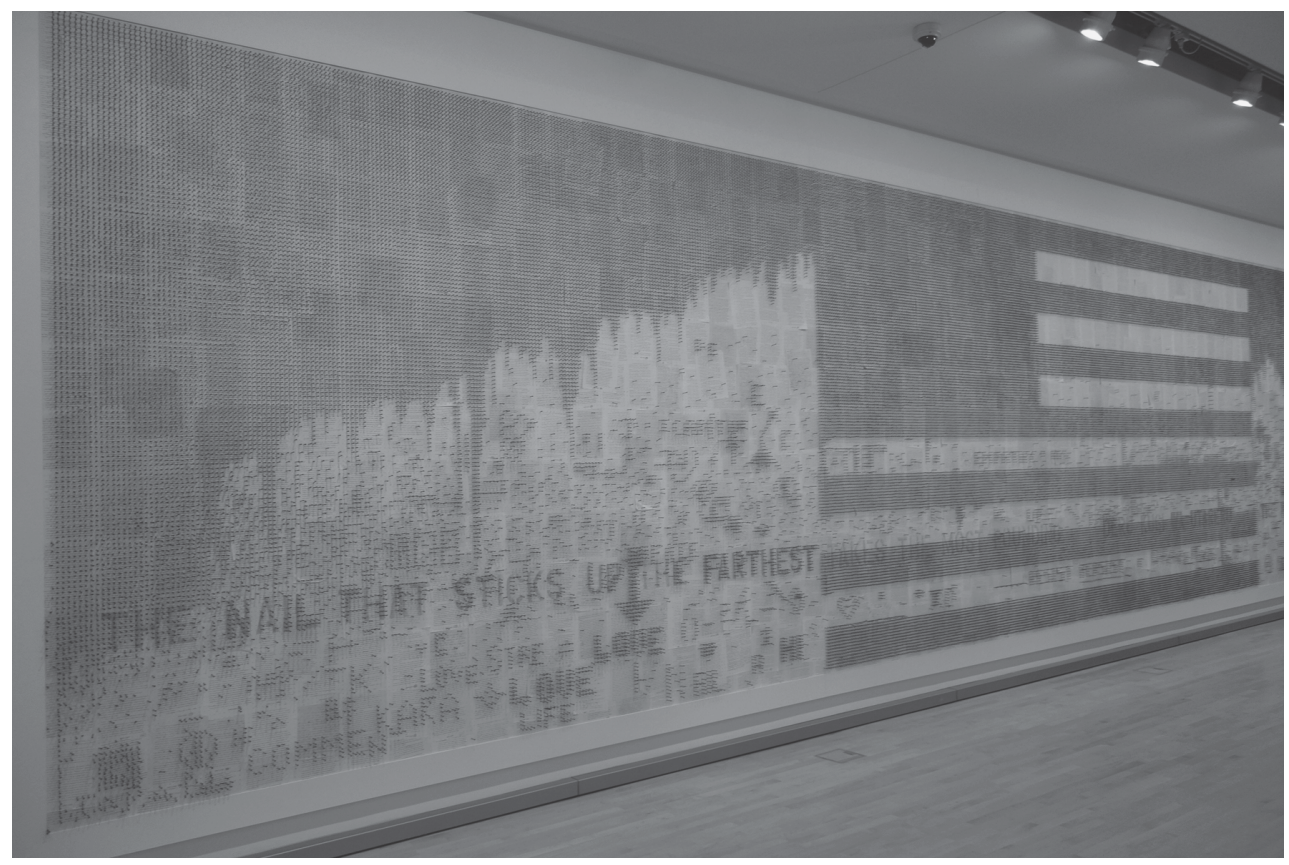

FIGURE 3.11 Kristine Aono, "The Nail that Sticks of the Farthest...," 2017, installation view, If You Remember, I'll Remember, February-June 2017, Mary and Leigh Block Museum of Art, Northwestern University, IL. Photo by Caroline Alice Claflin. Courtesy of Kristine Aono.

and the visitors' active acknowledgement of it, in the form of coloring in circles, combine to produce a visual display.

Displays such as the dot wall and Aono's installation also record and illustrate the number of visitors who have engaged with a particular issue, which may, during the run of the show, inspire the action of additional visitors. Just as children passing a fountain where others have tossed pennies want to toss one themselves, so we tend to participate in these participatory installations, the more popular they become. More is more. Action begets action.

Invitations to take action in the gallery build on the willingness of visitors to respond to an issue by getting them to do so right away. Following Steven Tepper and Yang Gao's philosophy of "do more, do more," that seed of acting in the museum may be enough to inspire further action outside of the museum. ${ }^{56}$

\section{At the end of the visit}

Some museums wisely acknowledge that the aftermath of the visit actually begins while the visit is still in progress, as people begin to process what they've seen and prepare to remember it. These museums provide opportunities to take actions that involve to reflecting and rehearsing (going through the experience mentally or verbally) while visitors are still in the museum. These opportunities range from sending postcards to the visitor herself or to others, or even to homework assignments. 
At Eastern State Penitentiary in Philadelphia, the visitor goes on a forty-five-minute audio tour of the site and then has the option to enter the exhibition Prisons Today. That exhibition examines the roots of mass incarceration in the US and the injustices of the criminal justice system (such as how the war on drugs disproportionately affects low-income people of color), and provides food for thought about how policymakers might change this broken system. At the end of the exhibition, visitors can prepare electronic postcards to themselves. The postcards arrive two months, one year, and three years after the visit. The visitor doesn't simply write a message for each of the three cards. Rather, once she selects her "cards," she is prompted to answer a series of questions: what did the exhibit make you think or feel?; Who do you think you'll talk to about your experience? What will you say? And why did you choose this person?; How do you hope the American criminal justice system will change in the next three years? The visitor also answers multiple-choice questions about what the exhibition sparked her interest in and what she plans to do in the next three years as a result. (The choices are vote more, advocate more, volunteer more, donate more, learn more, and listen more.) Roughly 54 percent of the visitors who do this activity open their postcards. Over 9,100 visitors have completed the postcard activity, resulting in 27,300 postcards, many of which have not yet been sent. As of winter 2017, visitors have opened 8,400 postcards.

In Unfinished Business: Juvenile Justice (2010), Hull-House offered a homework assignment (without referring to it as such) that promoted ongoing conversation (rehearsal) and reflection. Zines are cheap, fun, homemade mini-magazines intended for hand-to-hand redistribution. The presence of this takeaway cultural form in the gallery incites a chain of actions. The first action the visitor takes is to pick up and read the zine. The second is taking the zine home. The third is handing off the zine to another person and discussing the contemporary state of juvenile justice.

Whether conversations after the visit are about promoting the content from the exhibition or not, these rehearsals definitely help log and preserve visitors' memories of the visit. Falk suggests that this is one reason people have a tendency to remember their visits to museums so well many years after the fact.Visits to museums often contain novel experiences and content and so we are more likely to rehearse them with friends and family afterward. For those who do wish to promote content from the visit, however, contacting the visitor after the visit with specific steps for action is effective, as is creating other opportunities for rehearsal. ${ }^{57}$

\section{Far beyond the visit}

\section{Memory Jar}

When a visitor takes action after attending an exhibition, it can happen right away or it can take years. Readers familiar with Nina Simon's The Participatory Museum and The Art of Relevance will not be surprised to find that visitors to the Museum of Art and History (MAH) in Santa Cruz, California, where Simon is the executive director, take action in a variety of ways, inside the museum as well as after the visit. The next example of action is idiosyncratic but telling.

Sangye Hawke wanted to volunteer at Evergreen Cemetery, which the MAH owns. She was in the museum in 2011 waiting to become a member when she came upon an exhibition called Memory Jar. This was a participatory exhibition in which visitors could put a memory in a 
jar and put the jar on a shelf. Glass jars filled with memories lined the walls of the gallery. Labels on the jars said "Clare's Memory Jar" or "Antonio and Jeremy's Memory Jar." The prompt on the tag said simply "I remember..." and the reminiscing visitor filled in the rest. Hawke placed her memory in a jar and began meditating on the idea of putting memories into jars.

Her experience in the exhibition inspired the research project that would carry her through the next several years. ${ }^{58}$ The memories in the jars made Hawke think of lost things and injustices, and her experience inspired her to want to tell the stories of people whose stories were lost or forgotten. Hawke's work at the cemetery was to check data on each grave while restoring it. She came to look at her new research subject through the lens of her experience in the exhibition.

Popular history about local figures buried in the cemetery did not always match the archival research Hawke was conducting. Hawke was increasingly disturbed by her conviction that some of the local histories that had been promoted over the years were fictions designed to protect and maintain the prominence of wealthy White residents of Santa Cruz. Furthermore, Hawke met with staunch resistance from the governance committee of the cemetery in her efforts to tell the stories of people of color in the cemetery. With the help of other allies, such as Sibley Simon, who became chair of the committee, and George Ow, a prominent member of the Chinese community in Santa Cruz, the committee began to change, and support for Hawke's increasing research into cross-cultural stories in the cemetery began to grow.

Hawke decided to write a novel about one of the people she had researched in the cemetery - Andrew Jackson Sloan - and, in it, to tell as much of the true history of the local families as possible, including previously untold stories of cultural crossings and histories of color. She began working on the book Ghosts in the Gulch in 2013 and self-published it in $2015 .{ }^{59} \mathrm{~A}$ handful of copies sell each year in the local bookshop, which continues to feature it. In 2017, she was working on a sequel. Whatever the influence of Hawke's book on the management and telling of local history, her tremendous effort to produce the book demonstrates the catalytic power exhibitions.

\section{Casnaram, The City Before the City}

An exhibition at the MOA produced participation that was almost equally unlikely. From 2014 to 2017, three venues in Vancouver collaborated on an exhibition called 'cosna?วm, The City Before the City.$^{60}$ The MOA, the Museum of Vancouver, and the Musqueam Cultural Centre Gallery each hosted its own distinct installation of the exhibition simultaneously. ${ }^{61}$ The exhibitions told the story of a site that is familiar to many Vancouverites, who knew it as the Marpole Midden, a place to spend the day picnicking and playing archaeologist. Families took pride in "teaching their children about history" by digging up First Nation Peoples' belongings and taking them home. ${ }^{62}$ (UBC also organized digs there in the 1950s.) They unearthed belongings such as stone tools, bone and antler points, jewelry, and even human remains. What Vancouverites did not know was that the site was actually cəsna?əm, a 5,000-year-old Musqueam city that long predated Vancouver itself.

Nearly fifty distinct peoples comprise the Coast Salish group, and the Musqueam are one of those peoples. The metropolitan area of Vancouver sits on unceded Coast Salish native lands, meaning there was never a treaty in which the Coast Salish have given those lands over to the United Kingdom nor has any later treaty ceded them to Canada. To the Musqueam and other First Nations people in the area,Vancouver is squatting on their land. Nevertheless, those 
non-native people who went digging for history under the Arthur Laing Bridge did not view themselves as stealing the belongings of Musqueam ancestors or violating the sanctity of a significant ancient cemetery. They were simply hunting for treasure.

A plan to build condominiums on the site of cəsna?əm catalyzed the local Musqueam to protest desecration of the site. Museuqeam people held a vigil for almost a year, in 2012, and eventually the city agreed to stop the development. Susan Rowley, Curator of Public Archaeology at the MOA, and Jordan Wilson, a Musqueam master's student at UBC, cocurated the installation for the MOA. The exhibition was unusual. It was the story of an archaeological site, but did not feature any archaeological objects. ${ }^{63}$ Audio and video testimonies about the identity of the Musqueam took the place of exhibiting Musqueam belongings.

As awareness of First Nations people grew among Euro-Canadians and as times changed, people who had objects from cəasna?əm and other Indigenous sites in their possession became aware of the problems this presented. They wondered what they could do with these possessions. Some people threw them away out of guilt and anxiety or hid them. Inside of the exhibition, the MOA made a request to visitors that anyone who had previously taken Musqueam belongings from çsna?əm return them to the Musqueam. Several visitors did just that. They sent or brought objects to the MOA, which then transferred them to the Laboratory of Archaeology at UBC, which is the steward of objects for the Musqueam Cultural Centre. Visitors also contacted the museum about objects that they had collected from other Indigenous sites. Rowley assisted these visitors in finding the correct contact for repatriation based on the location of the material collected and, when necessary, also made introductions for visitors to the correct native authorities. It is incredible that these belongings should find their way home after so many decades.

\section{Digital visitors}

Digital tools allow people to visit and take action online, perhaps even before they ever visit the brick-and-mortar institution. In some cases, their digital visits encourage them to visit the physical museum. What does this mean for museums that want to inspire action? This section looks at the various ways digital tools can play a role in grappling visitors and potential visitors closer to the museum while also encouraging them to take action.

\section{Action Library}

The imposing building of the National Underground Railroad Freedom Center combines sweeping stone curves that are reminiscent of the National Museum of the American Indian (NMAI) with dark metal finishes and wings connected by bridges - the architectural vocabulary of a Holocaust museum. The museum opened in 2004. Now it sees 180,000 visitors a year, and its budget is $\$ 5.3$ million. ${ }^{64}$ In the entryway of the museum, a video underscores the museum's commitment to "social justice" and to raising "freedom fighters" of the future and "another generation of concerned citizens." The museum is in a multi-year-long plan to renovate permanent exhibitions such as Invisible: Slavery Today and Slavery to Freedom. But the staff are not content to put contemporary abolitionism on hold until its completion. The group is eager to work with any tools available to continue taking strides against contemporary slavery. The Freedom Center is unusual for the forethought and tracking it applies to fostering abolitionism in its visitors. 
The Freedom Center in Cincinnati runs a website called End Slavery Now, which features a digital "Action Library." In the Action Library, visitors can find over 150 specific actions they can take to work against contemporary slavery, such as contributing to the "Refugee Phrasebook," a multilingual crowdsourced guide to the most useful words for refugees in a new land. ${ }^{65}$ If the visitor has any knowledge of German, Arabic, Syrian, or Farsi, she can translate English words into those languages. In 2016, the museum formed a team to address modern-day slavery, and began tracking the actions of visitors.

Twenty percent of roughly 4,500 subscribers to the Slavery Now e-newsletter click through to the Slavery Now website. This is average for a non-profit. Of those 900 people per month, roughly 250-300 take action in the Action Library each month. These include the usual suspects of signing petitions and putting up flyers, as well as much more interesting actions. For example, visitors can volunteer online with Slavery from Space to scan satellite photographs of South Asia to look for brick kilns, which are commonly staffed by enslaved adults and children. As the volunteers scan the photos, they train a computer to recognize the varieties of kilns. The volunteers' identification of kilns teaches the computer's algorithm to find the kilns. Then, the computer can scan many more photos than humans. The results provide clues to groups working against slavery in South Asia about where to look for the kilns. ${ }^{66}$ They also provide information to lawmakers about the scope of the problem. Though we cannot know how many of the participants find their way to Slavery from Space through the Freedom Center, we do know that thirty-one people participated in the first round of volunteers scanning photographs. ${ }^{67}$

When a visitor to the Action Library takes action, the Slavery Now website will prompt her to report on her action. A message asks "Will you complete this action?" and the visitor can click yes or no. Though so-called "self-reporting" is never perfect, the Action Library encourages people who will feel proud of taking actions and recording them, much like applications such as "5 Calls."

5 Calls and other apps that track political action present the user with a range of issues that require attention. They let the user know which individuals she can call about the issue and provide phone numbers and scripts for the phone calls. Then, the caller can log the results of each phone call. The application acknowledges the user's completion of each issue, and the caller's total number of calls is always available. A similar system for Slavery Now would use visitors' personal pride in action to foster more action.

\section{Project Hyena Diorama}

One of the most successful models for museums inspiring action is one in which the museum's call for action touches those who have never visited the museum. They act. Then they visit. Simultaneously, existing visitors act and visit again. This is a model in which museums, visitors, and others reap the benefits of our increasingly digital, socially networked world in an authentic way. The reciprocal loop of actions and visits can occur naturally through the way people already tend to engage with museums and each other on social media. Examples from the Field Museum in Chicago and the Smart Museum of Art in Chicago will demonstrate the success that is possible with this process.

The Field Museum is a tremendous natural history museum on the shore of Lake Michigan in Chicago. Its building is 350,000 square feet, and its collection holds 25 million objects. ${ }^{68}$ Annual attendance is 1.65 million visitors, and the budget is $\$ 15.9$ million a year. ${ }^{69}$ The museum 
was originally founded as part of the World's Columbian Exposition in 1893. It was called the Columbian Museum of Chicago and was housed in the building that is now the Museum of Science and Industry. Edward Ayer, who would become the museum's first president, convinced Marshall Field of department store fame to fund the new institution with an inaugural gift of $\$ 1$ million, the equivalent of over $\$ 23$ million today. No museum had ever before received such a large single gift. ${ }^{70}$ This and other gifts that followed supported the purchase of collections that went on display at the World's Fair. The museum changed its name in 1905 and moved to the current building in $1921 .{ }^{71}$ Though the museum is a formidable player in the world of conservation and the sciences, its relationship to the human side of natural history - the peoples of the world - has been more fraught. Staff members have struggled mightily to shift the behemoth institution toward a more multi-vocal, less elitist interpretation over the decades, but it has been slow and thankless work indeed, always shunted aside, concealed, or downplayed at an institutional level. Only in recent years have visible changes begun to appear.

The work of Chief Curiosity Officer at the Field Museum and self-proclaimed Nerd Queen Emily Graslie lies at the nexus of myriad important issues for museums today. STEM vs. STEAM. Women in science. And, for the purposes of my work here, questions of how museums' outreach eventually finds its way back into the museum. How do museums find and bring in new audiences? What tips a visitor's interest into action? What kinds of actions do inspired visitors take, and over what timeline?

Graslie's experience with Project Hyena Diorama tidily demonstrates the complex potential of meeting visitors outside the museum in the digital world and of digital visitors in the museum. Shortly after Graslie joined the Field Museum in mid-2013, she became aware of the large empty space in the Mammals of Asia. This hall is just off the Great Hall (Stanley Field Hall). Anyone who has entered the museum and decided to wander around might easily stumble upon it. The hall now contains twenty dioramas with full-scale habitats. In 2013, one case had been empty, covered over by a map for sixty to eighty years. The museum had moved away from doing full-scale habitats and had turned its attentions to birds, Africa, and other initiatives. When Graslie learned of the empty space, she decided to see if she could use the digital community of The Brain Scoop, her popular YouTube show, to "make something happen" at the museum. The question of how to make the digital community's support of natural history museums tangible had been on her mind, and this seemed like the right the opportunity to test the possibilities.

The striped hyenas that now inhabit the diorama came from Mammals of Africa. They were installed in a corner, where they were neither terribly accessible nor interestingly featured and the specimens were in need of conservation. Their case, consistent with the others in that hall, contained minimal habitat elements and no "decoration," no murals or other backdrops. These specimens were far more significant to the history of the Field Museum than was apparent and they embodied a fascinating ecological story that was not being told. The hyenas came to the Field from Somalia, where Carl Akeley, the Field's first taxidermist, collected them on his first mission to Africa for the museum in 1896. This was the same trip that brought the museum the elephants that, along with Sue the Tyrannosaurus Rex, have been the anchors of the Great Hall. ${ }^{72}$ When Akeley collected the hyenas, their habitat was not confined to Africa; they lived in Asia as well.

Here was an opportunity for Graslie to conserve them, move them to a much richer environment, tell two important stories, and finish the hall of Mammals of Asia. Graslie seized on the opportunity to test out her digital community in this arena and launched an Indiegogo 
(crowd-funded) campaign to pay for the new diorama. In doing so, Graslie discovered that over 1,800 people from around the world would contribute to the Field Museum's first crowdsourced project, Project Hyena Diorama. Based on the relationships between subscribers to The Brain Scoop and visitors to the museum, described below, I estimate that at least 400 of these donors had never been to the Field Museum; 150 of the donors traveled to the museum in a blizzard in January to attend the opening event. In fact, one man had been on a bus on his way to the airport when his bus was stopped by snow. He actually got out and walked the rest of the way rather than miss his flight to Chicago. This kind of behavior is complicated and seems even inconceivable. Why go to all the trouble? In the end, I think people crave contact with the group. But what is the group? Graslie has turned The Brain Scoop, digital proxy for the Field Museum, into a group of over 400,000 highly motivated, interested, smart, excited people. It turns out, as Graslie's experiment with Project Hyena Diorama demonstrated, these people - far-flung as they are - actually have a relationship with the museum.

The doubters will say that this was just one isolated event. But consider this: In a sample of 1,820 visitors exiting the museum in 2016,12.9 percent follow one of the museum's channels on YouTube, though not exclusively The Brain Scoop. ${ }^{73}$ The Field Museum's own channel had 2,828 subscribers in 2019 while The Brain Scoop had 500,405 subscribers. Graslie estimated that 11 percent of audience members follow The Brain Scoop. Of the audience members surveyed in the exit survey, 5.7 percent made the journey to the museum because of The Brain Scoop. When we're talking about an annual attendance of 1.65 million visitors (2016), that 5.7 percent adds up to 94,050 people.

In the world of social media, it has become much easier for museums to act as conveners. Likewise, social media allows museums to find their people more easily. This may be one reason for the increasing number of actions on the part of visitors that actually precede the visit. Visitors take action once they realize that the museum is "their people" and then they want to see the results of their action in real life and connect further in the bargain.

The story of Project Hyena Diorama illustrates the non-linear way visitors' actions relate to museums. When I learned of the project, I had been searching for stories of visitors taking action. In this instance, what I found is even better.Visitors actually became visitors through an interaction with the museum that began before the visit. Then, too, action begot action. People watched The Brain Scoop. They donated to the Indiegogo campaign and came to care about the project and also the museum. In some cases, they visited the museum immediately afterwards. In others, they visited the museum later. Some people had already been to the museum. Perhaps that was how some viewers found The Brain Scoop. Some viewers and donors may never get to visit. There are multiple points of entry and multiple pathways for action.

\section{Welcome Blanket}

The same is true of Welcome Blanket (2017), an exhibition and project at the Smart Museum of Art in collaboration with the artist Jayna Zweiman. The Smart Museum of Art is part of the University of Chicago. It has an annual budget of $\$ 3.1$ million and over 70,000 visitors a year. ${ }^{74}$ The Smart Museum opened in the neighborhood of Hyde Park in Chicago in $1974 .{ }^{75}$ It is a teaching museum that, like the Block, is increasingly focusing on relating to and engaging visitors - making its work outward-facing. Also like the Block, a new director is helping the institution along this path. Alison Gass, a star of contemporary curatorial work at museums such as the San Francisco Museum of Modern Art (SFMOMA) and the Cantor Art Center at 
Stanford, joined the Smart as Director in 2017. The museum's innovative new practices, such as developing a crowd-sourced exhibition on the fly during its run, are contributing to its goal of being a place where visitors can grapple with and discuss important contemporary issues. According to Michael Christiano, Deputy Director for Audience Engagement and Public Practice, artwork can help us better understand our place in the contemporary moment. Welcome Blanket demonstrates how vivid this can be.

Zweiman became famous in 2017 for her "Pussyhat," which formed the visual centerpiece of the protest to Donald Trump's inauguration called the Women's March. (Figure 3.12 shows the results of the pussyhat pattern in action.)

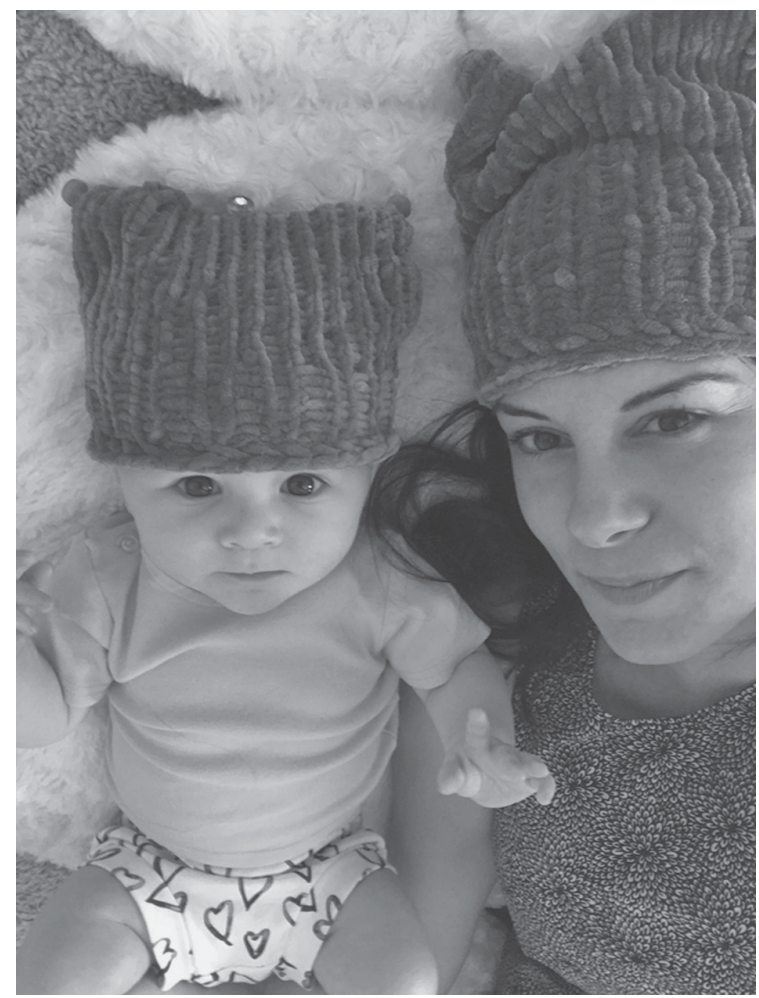

FIGURE 3.12 Kitten and Pussyhat, knitted by Rachel Leibowitz. Photo by Tanya Findlay, 2018. Courtesy of Arran and Tanya Findlay.

Likewise, Welcome Blanket was also both a protest and a moment of coordinated effort to create and to work for good in the present, not only through naysaying but also through positive action - as Zweiman put it, "taking our country by warmth, kindness, and inclusion." 76 Welcome Blanket protested Trump's efforts to build a wall along the 2,000-mile-long border the US shares with Mexico. It did so by engaging knitters - experienced and novice - as well as other crafters in making blankets to welcome new immigrants to the US. Zweiman's goal for the project was to collect 3,200 lap blankets to represent the 2,000 miles of the border with yards of yarn. She also hoped to spark a conversation between the makers of blankets and newly resettled refugees who received them, a commentary on how we make the fabric of our society, literally and figuratively. ${ }^{77}$ 
Welcome Blanket was a crowd-sourced project in which Zweiman and the Smart Museum provided the infrastructure and logistics, but the blankets were all made by individuals who were interested in responding to the project's call to action. The call to action went out through Zweiman's networks as well as the museum's. These included social media such as Facebook and Instagram, the digital knitting and crocheting community Ravelry (7.2 million members), and the museum's traditional media outlets. Arguably, the community on Ravelry has been the most significant source of blankets. Zweiman wrote this on the website: "Let's take the length of the proposed US/Mexico border wall and make it a length of inclusion by using 2,000 miles of yarn to make individual blankets for new refugees and other immigrants coming to the United States!" 78 Seven hundred and eighteen of the Ravelry members became members of the Welcome Blanket group, and they cheered each other on with the production of their blankets.

As with the Pussyhat Project, knitters had access to patterns, tutorials, and other instructions. A knitter named Kat Coyle circulated her pattern for a particular lap blanket that fit the yardage Zweiman had in mind for each blanket. Zweiman invited makers to package each blanket with a "welcome note" to a new immigrant. She provided templates for these notes as well, inviting makers to share their own immigration stories and to include words of welcome and advice for living in the US along with care instructions for the blanket and contact information, if they wished. ${ }^{79}$

Welcome Blanket, as a project and an exhibition, was a significant departure from the Smart Museum's earlier work. Typically, an exhibition would be planned three years in advance and the accompanying public programming would be planned one year in advance. Not so with Welcome Blanket, which opened with an empty gallery. (Figure 3.13 shows an early day in the exhibition's run.) Michael Christiano, Interim Senior Director of Museum Programs, was cocurator of Welcome Blanket along with Alison Gass, the museum's director. Christiano explained that Welcome Blanket represented a model that the museum hoped to follow more in the future. In this model, the work in the gallery and public engagement cannot be disconnected as with models, where public programming is ancillary. ${ }^{80}$

In Welcome Blanket, not only was the entire process of creating the exhibition part of the exhibition itself but the programming was also co-developed with the artist during the ongoing installation. For example, the museum hosted a weekly "knit-in." It was open to the public, though it began through the interest of the museum's own head of security. The museum also hosted a public weekly "unpacking party.'The Smart received twenty to forty blankets per day during the run of the exhibition. Staff members and members of the public typically unpacked around seventy blankets and moved them to the freezers where they needed to spend the week debugging to be safe for display. The blankets that had been frozen the previous week were now ready to become part of Zweiman's installation.Visitors could also knit and even re-learn how to knit in the gallery, which was stocked with supplies and patterns. Ultimately, visitors and volunteers would also become involved in the process of shipping the blankets to immigrant aid organizations that would then pass them on to specific families.

It's telling that two of the staff people at the Smart in charge of the project - Christiano and Harness - were not curators. The atypical team made the integration of exhibition and programming (or blurring the lines between the two) easier and more natural. Blurring these lines is also part of what the Smart Museum is working toward. The Smart Museum began looking at ways to expand its notion of interpretation in 2012 with the exhibition/program Feast: Radical Hospitality in Contemporary Art. During this project, the Curatorial Department 


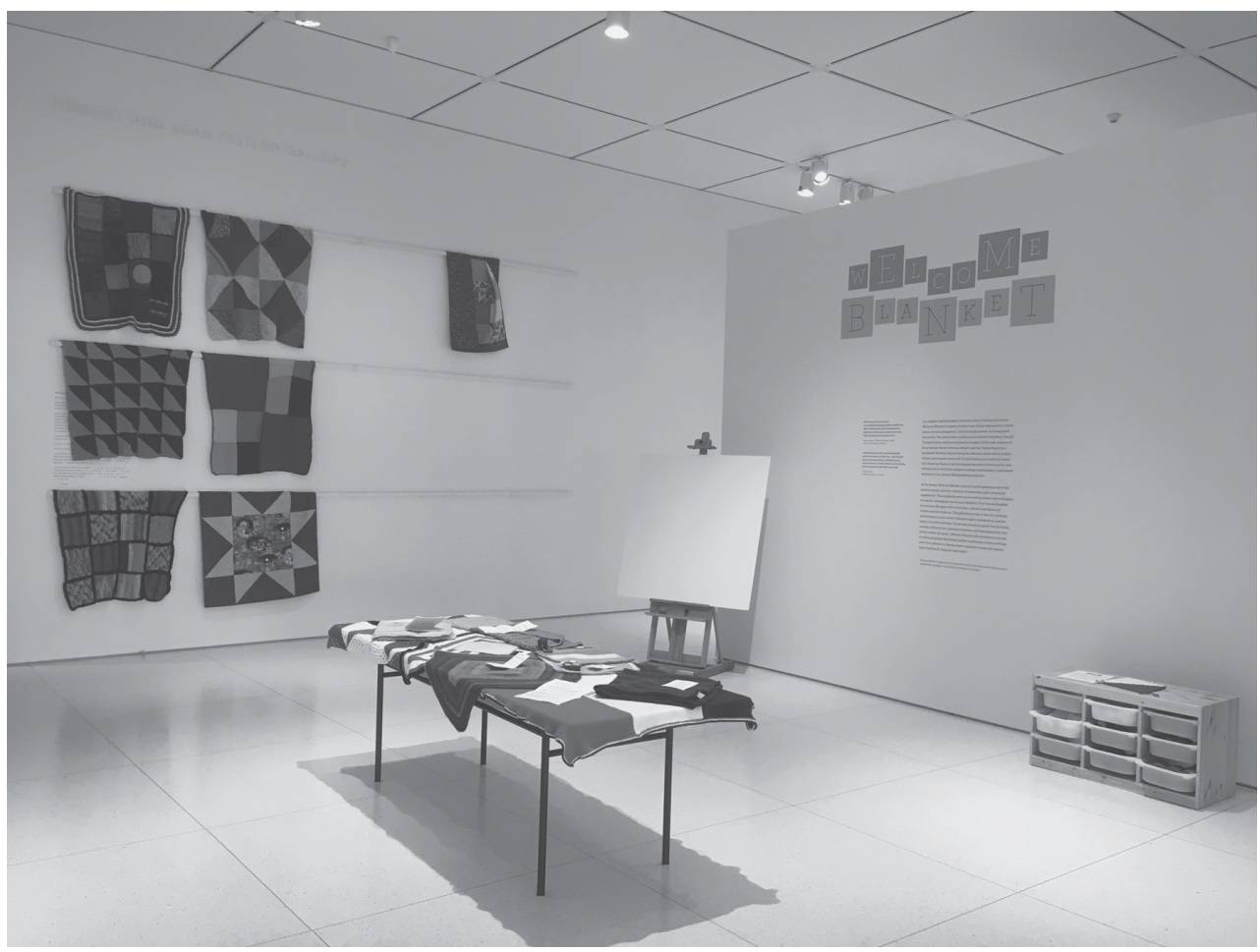

FIGURE 3.13 Welcome Blanket view from July 2017, shortly after the opening of the exhibition. Photo by Michael Tropea. Courtesy of the Smart Museum of Art.

and Education Department began to work more closely together. ${ }^{81}$ The change in interpretive work at the Smart Museum began with inviting creative individuals (artists, educators, and organizers, for example) to work in residency at the museum for a year. The museum also has a Programs Council that allows staff to "think across departments" such as Education, Curatorial, and Collections. ${ }^{82}$ Welcome Blanket is the programmatic successor of Feast.

It's no coincidence that a focus on hospitality in Feast paved the way for the calls to action in Welcome Blanket. Indeed, everything about Welcome Blanket, from its title on, embodies a philosophy of hospitality to the eventual recipients of the blankets as well as to the visitors to the Smart Museum. Just as a visitor to your home might feel all the more welcome when she is allowed to help out setting the table or preparing a dish, so too the visitors to the Smart Museum may feel all the more welcome at that museum for being allowed to contribute to and help set up an exhibition.

When I first visited Welcome Blanket, six weeks into its five-month run, the walls of the gallery were covered with blankets in a riot of colors and styles (Figures 3.14 and 3.15). Blankets lay stacked on a shelf.

The freezers were full of blankets. Down in the basement of the museum, the as-yet-unopened packages of blankets were stacked in two mountains that reached far overhead. The total number of blankets reached nearly 1,000. By the end of the installation, huge drifts of blankets covered every surface in the gallery, including the tops of shelves and cases (Figures 3.16 to 3.18). 


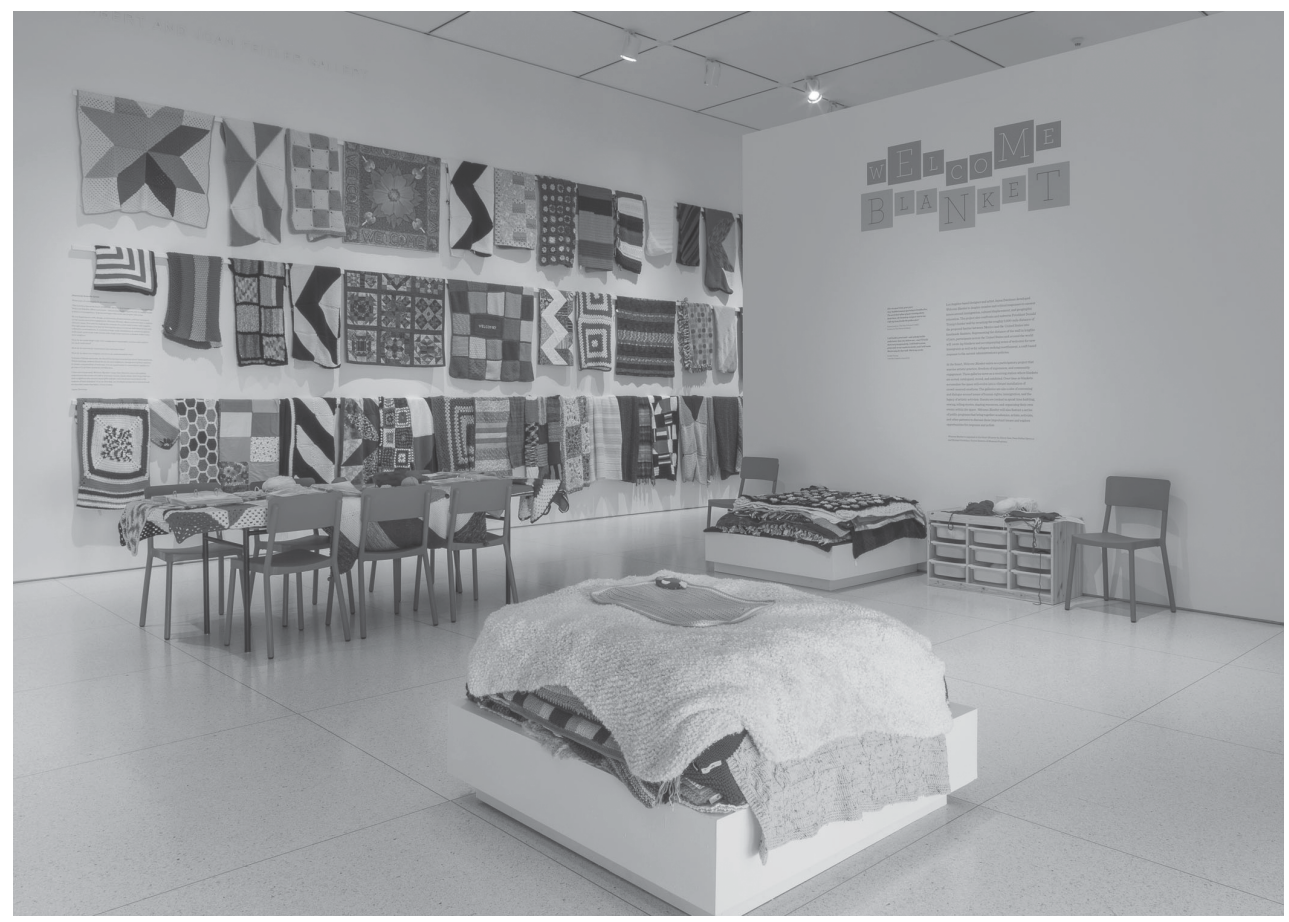

FIGURE 3.14 Welcome Blanket view from September 2017. Photo by Michael Tropea. Courtesy of the Smart Museum of Art.

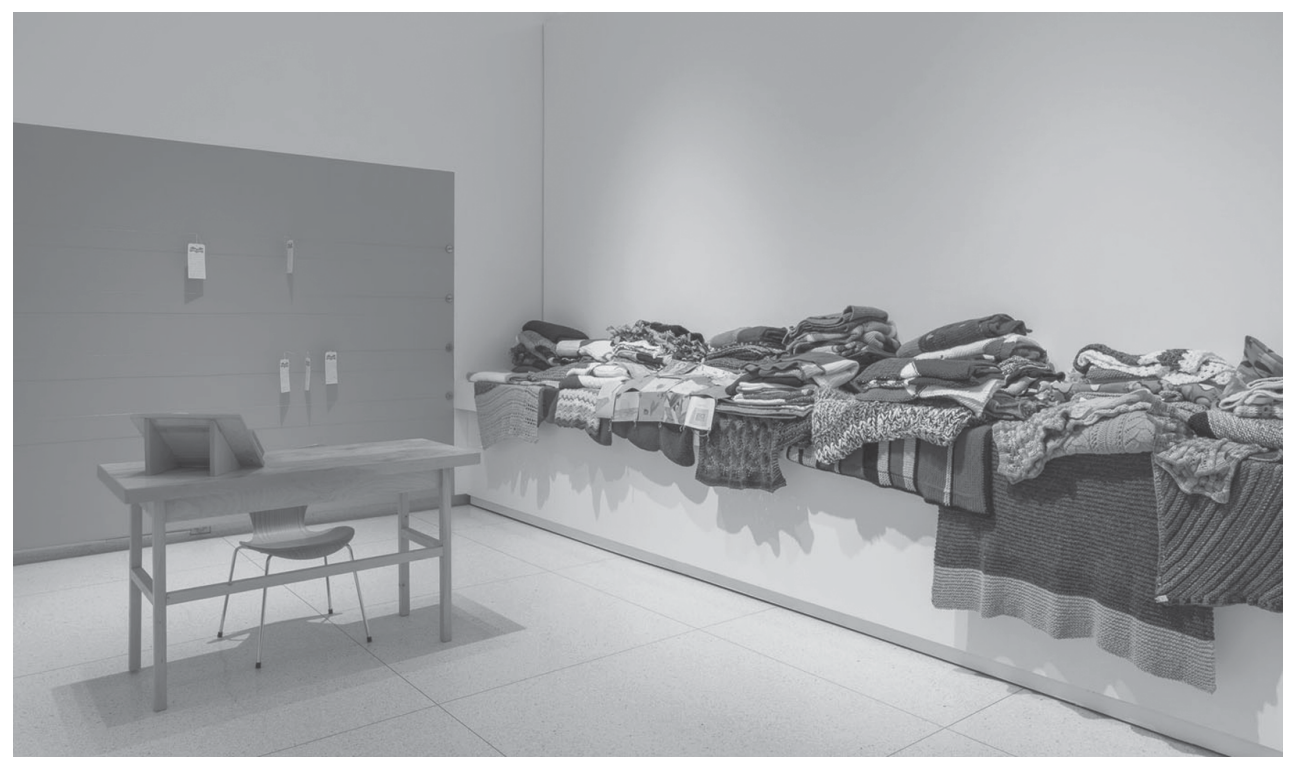

FIGURE 3.15 Welcome Blanket view from September 2017 showing an area where visitors could write welcoming messages to new immigrants to accompany blankets. Photo by Michael Tropea. Courtesy of the Smart Museum of Art. 


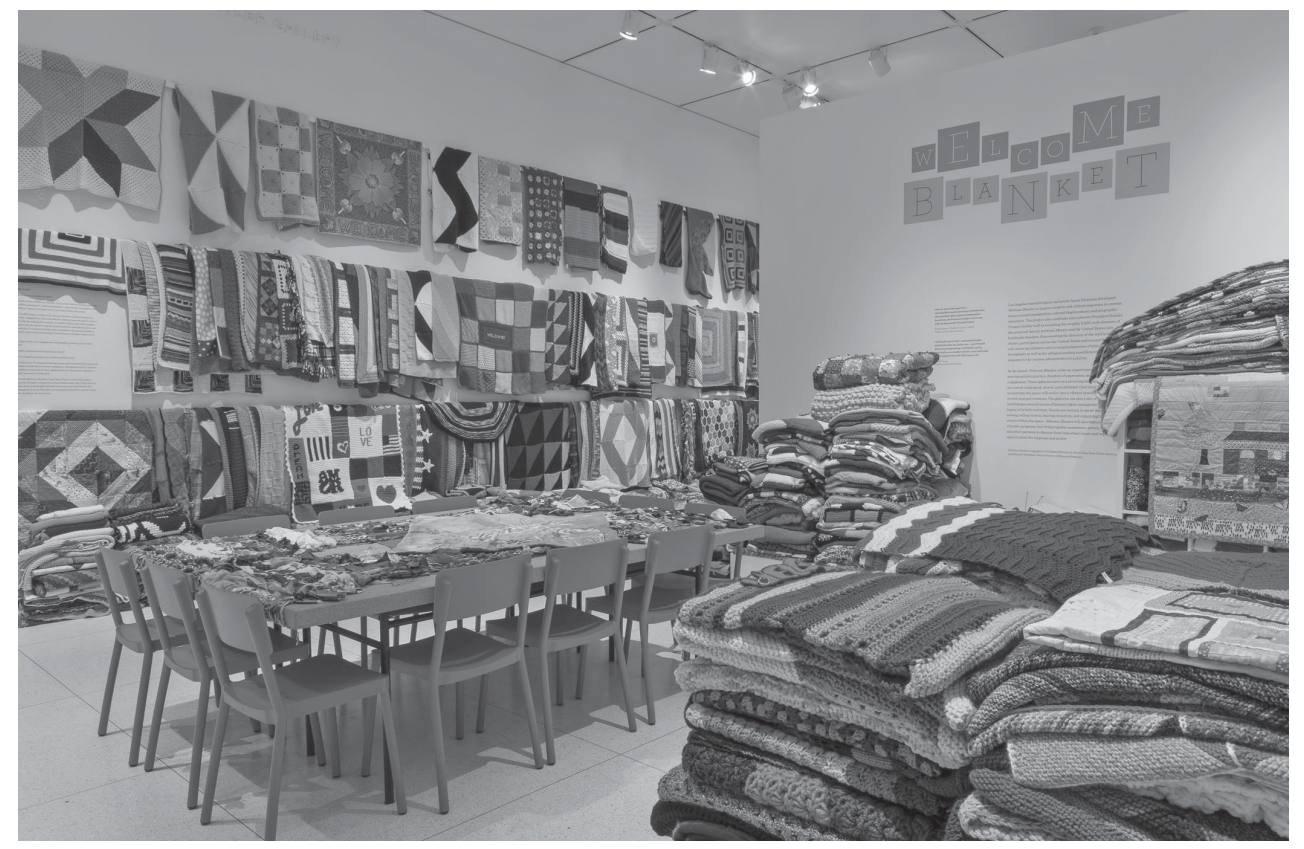

FIGURE 3.16 Welcome Blanket view from December 2017, close to the closing of the exhibition. Photo by Michael Tropea. Courtesy of the Smart Museum of Art.

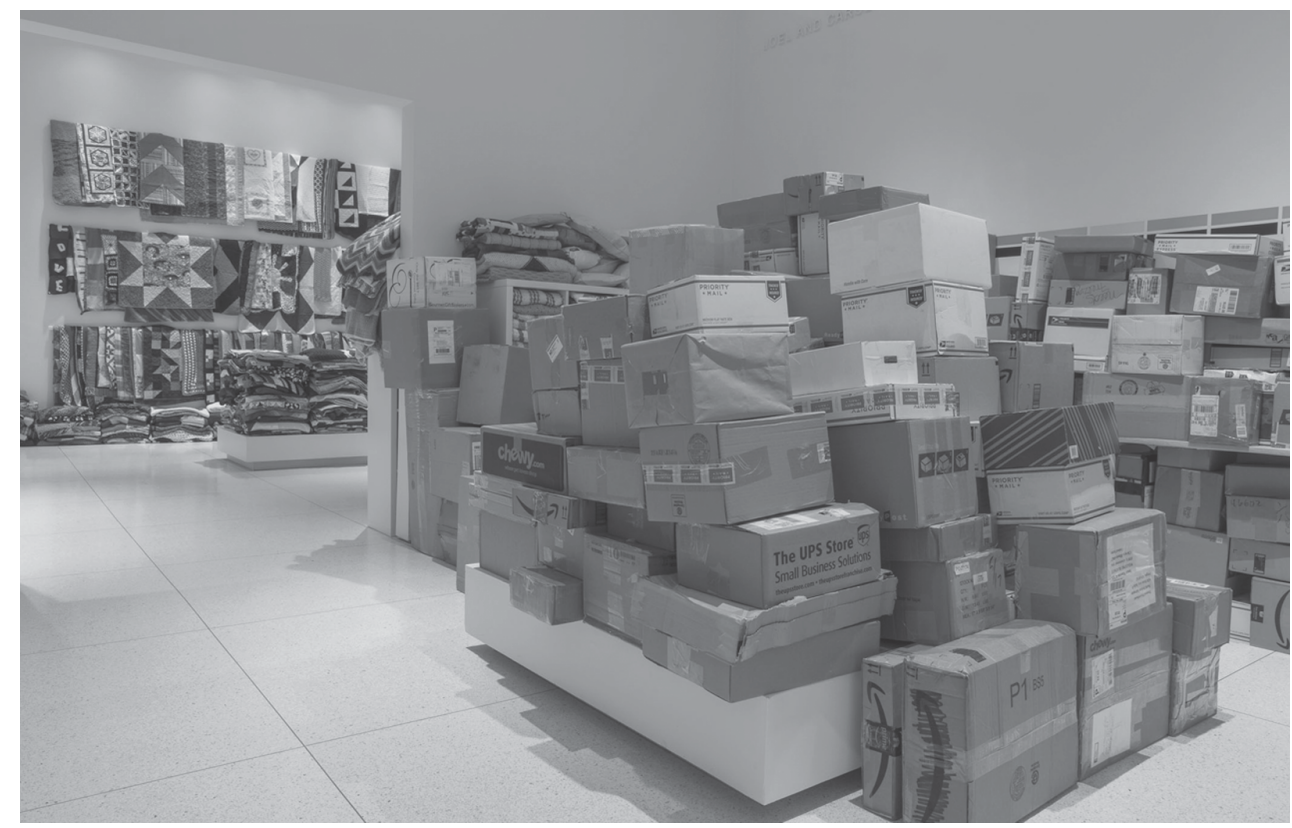

FIGURE 3.17 Welcome Blanket view from December 2017, showing part of the remaining mountain of blankets yet to be opened. Photo by Michael Tropea. Courtesy of the Smart Museum of Art. 


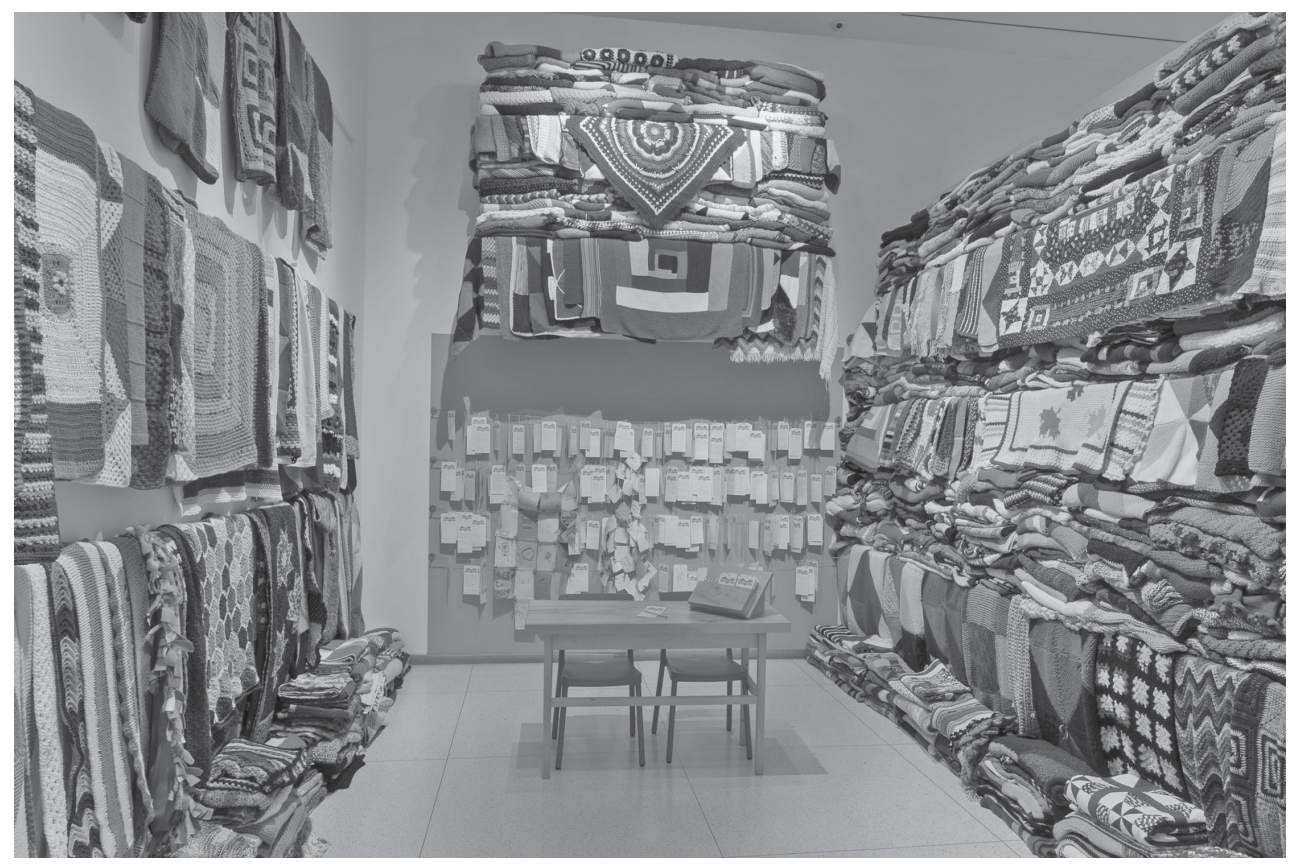

FIGURE 3.18 Welcome Blanket view from December 2017 showing an area where visitors could write welcoming messages to new immigrants to accompany blankets. Photo by Michael Tropea. Courtesy of the Smart Museum of Art.

The call to action inspired action. And the actors - the crafters making the blankets began to visit the museum. In many cases, these participants were new to the Smart Museum. Some of them traveled across the country to see their work on view and to participate in the multitude of other actions that visitors could take on site. Harness told the story of four friends from New York who made the unpacking party on Saturday the centerpiece of their trip together. ${ }^{83}$

\section{Conclusion}

Recall Oliver Sacks's exaltation of museums as places where he could be active in learning as a child. Later in his memoire, he described a transformative experience in a museum that influenced his actions over the course of years and, in so doing, influenced the development of science over the following several decades. At the age of twelve, Sacks first encountered the periodic table of the elements in the Science Museum of South Kensington. The table consisted of a huge cabinet, occupying "a whole wall at the head of the stairs." ${ }^{84}$ Each element was contained in a drawer of this cabinet. Upon studying the table, young Sacks understood its implications about how the universe is ordered. He "could scarcely sleep for excitement the night after seeing the periodic table," and he was inspired to visit it again and again, to memorize it. From there, he became obsessed with comparing the elements in various ways until at last his experiments led him to be able to predict what elements that were missing from the table in 1945 would look and behave like. His prediction of a second series of rare-earth 
elements in the table was confirmed by grown-up scientists after the end of World War II. Probably, nothing could have stopped young Sacks's passion for chemistry, even before his first fateful sight of the periodic table. But just as certainly, his experiences with the table as a boy influenced his illustrious career as a neurologist, professor, and writer.

This chapter has mapped the landscape of museums inspiring action. Though it is by no means a catalog of such museums, the chapter brings together stories and strategies that demonstrate the range of possibilities and the utility of continuing to try. I have also tried to highlight the ways in which institutions plan for, promote, and evaluate this extremely elusive topic. When museum professionals embrace the goals we have for our exhibitions and programs and work toward those, including working to inspire visitors to act, the actions do happen. Whether they happen quickly or in the way we imagine is another matter entirely. Becoming overly concerned with quantifying visitors' actions, however, can divert precious museological resources from the creativity needed to do great work. This chapter barely scratches the surface of an understudied topic that is, nevertheless, germane to the work of a quickly growing group of museum professionals. A longitudinal study would give us much more data about how visitors act on their visits in the short, medium, and long term after the visit. One that also observed the curatorial strategies at play in each exhibition the visitors visited would enable us to discover the relative merits of curatorial practices that do inspire action by providing a rubric for comparison across institutions and time.

\section{Notes}

1 Rostam in Hrishikesh Hirway, “Episode 117: Rostam," Song Exploder, September 14, 2017, http:// songexploder.net/rostam.

2 See Tony Bennett, “Civic Laboratories," Cultural Studies 19, no. 5 (September 1, 2005): 521-547; Patricia Johnston, Seeing High and Low: Representing Social Conflict in American Visual Culture, 1st edn (Oakland, CA: University of California Press, 2006); Paul Williams, Memorial Museums: The Global Rush to Commemorate Atrocities (Oxford; New York: Bloomsbury Academic, 2008).

3 Erica Lehrer, Cynthia E. Milton, and Monica Patterson, eds, Curating Difficult Knowledge:Violent Pasts in Public Places, 2011 edn (New York: Palgrave Macmillan, 2011), 6. Emphasis in original.

4 Sophie Mccall, The Land We Are: Artists and Writers Unsettle the Politics of Reconciliation in Canada, ed. Gabrielle Hill, 1st edn (Winnipeg, MB: Arbeiter Ring Publishing, 2015).

5 The Incluseum, "Anti-Prison Organizing and Museums: The Politics of Remembering and Forgetting," The Incluseum (blog), January 26, 2018, https://incluseum.com/2018/01/26/antiprison-organizing-and-museums-the-politics-of-remembering-and-forgetting/.

6 John H. Falk and Lynn D. Dierking, The Museum Experience Revisited, 1 edition (Walnut Creek, CA: Routledge, 2012), 201, 221.

7 Falk and Dierking, 202.

8 Ibid., 204-205.

9 Ibid., 201, 205.

10 Ibid.

11 This fact has been cited for decades, beginning with Roy Rosenzweig, The Presence of the Past: Popular Uses of History in American Life (New York: Columbia University Press, 1998). Here is a discussion of controversy on whether or not the public's trust of museums is well-informed about the work museums do: "Center for the Future of Museums: Trust Me, I'm a Museum," Center for the Future of Museums (blog), February 3, 2015, http://futureofmuseums.blogspot.com/2015/02/trustme-im-museum_3.html.

12 Mark Kohan, interview with Mark Kohan, Assistant Clinical Professor, Neag School of Education, University of Connecticut, phone, November 1, 2016. 
13 Glenn Mitoma, "11.2.15 Native Solidarity, Indigenous Rights, and Social Justice | Thomas J. Dodd Research Center," http://thedoddcenter.uconn.edu/2016/10/24/11-2-15-native-solidarityindigenous-rights-and-social-justice/.

14 Julia Carrie Wong, "Police Remove Last Standing Rock Protesters in Military-Style Takeover," Guardian, February 23, 2017, sec. US news, www.theguardian.com/us-news/2017/feb/23/dakotaaccess-pipeline-camp-cleared-standing-rock.

15 Laurence Gonzales, House of Pain: New and Selected Essays (Fayetteville, AR: University of Arkansas Press, 2013), 80-81.

16 Andrew Pekarik in Gail Anderson, Reinventing the Museum: Historical and Contemporary Perspectives on the Paradigm Shift (Walnut Creek, CA: AltaMira Press, 2004), 407.

17 Pekarik in ibid., 404.

18 Pekarik in ibid., 409-410.

19 Irina Zadov, “Love and Labor'Tours: Final Evaluation Presentation” (Chicago, March 14, 2014).

20 "Rauner Signs Law Extending Labor Protections to Domestic Workers," Chicago Tribune, www. chicagotribune.com/business/ct-rauner-signs-domestic-workers-bill-0816-biz-20160815-story. html.

21 “Chicago Zoological Society - GuideStar Profile," www.guidestar.org/profile/36-2167016.

22 Carol D. Saunders, "The Emerging Field of Conservation Psychology," Human Ecology Review 10, no. 2 (2003): 137-149, 138.

23 The discussion of Brookfield Zoo in this chapter is based on the following interviews: Jamie Zite-Stumbris, interview with Jamie Zite-Strumbris, Interpretive Programs Coordinator, Chicago Zoological Society at Brookfield Zoo, personal, November 16, 2017; Jerry Leubke and Jennifer Matiasek, interview with Jerry Leubke, Senior Manager of Audience Research, and Jennifer Matiasek, Audience Research, in the Department of Conservation, Education, and Training, Chicago Zoological Society at Brookfield Zoo, personal, November 16, 2017.

24 "History \& Architecture | Shedd Aquarium," Shedd Aquarium, www.sheddaquarium.org/AboutUs/History--Architecture/.

25 "Animals \& Care | Shedd Aquarium," Shedd Aquarium, www.sheddaquarium.org/Animals--Care/.

26 "Shedd Aquarium 2016 Annual Report: COMMUNITY," Shedd Aquarium, www.shedd aquarium.org/2016AnnualReport/community.html; Plate Moran, "Shedd Aquarium Society December 31, 2016 and 2015 Financial Statements," audit (Chicago: John G. Shedd Aquarium, 2017), 21, www.sheddaquarium.org/2016AnnualReport/assets/2016afssheddaquariumsociety_ financials.pdf.

27 The discussion of the Shedd Aquarium in this chapter is based on my interview: Lindsay Maldonado, interview with Lindsay Maldonado, Director of Research and Evaluation, John G. Shedd Aquarium, personal, November 27, 2017.

28 "Guidestar Premium Report on the Lincoln Park Zoo," financial report (Chicago: Lincoln Park Zoo, 2018), 2, www.guidestar.org/ViewPdf.aspx?PdfSource=0\&ein=36-2512404; Sharon Dewar, "Lincoln Park Zoo Overview," Lincoln Park Zoo, www.lpzoo.org/sites/default/files/Lincoln_ Park_Zoo_OVERVIEW.pdf.

29 Packer, Ballantyne, and Bond in Kris Nesbitt and Lindsay Maldonado, "Language as Process: Using Words to Shape Exhibition Design," Exhibition, spring 2016: 67.

30 "A Home for Brave Ideas: Strategic Plan: Investing in Our Future 2018-2022” (President Abraham Lincoln's Cottage at the Soldier's Home, 2017).

31 “Book 1:Who Is Vulnerable?" (President Abraham Lincoln's Cottage at the Soldier's Home, 2012).

32 President Abraham Lincoln's Cottage at the Soldier's Home, “Take Home Element: Can You Walk Away?” (President Abraham Lincoln's Cottage at the Soldier's Home, 2012).

33 Callie Hawkins, “Thank You! And More," August 7, 2017.

34 Erin Mast and Callie Hawkins, interview with Erin Mast, ED and CEO of Lincoln Cottage, and Callie Hawkins, Director of Programs at Lincoln Cottage, phone, August 1, 2017; "Statement of Purpose - Phenomenological Study of Visitor Experience August 2016 - August 2017” (President Abraham Lincoln's Cottage at the Soldier's Home, 2016), 1. 
35 Mast and Hawkins, interview with Erin Mast, ED and CEO of Lincoln Cottage, and Callie Hawkins, Director of Programs at Lincoln Cottage.

36 Mast in Mast and Hawkins.

37 "Statement of Purpose - Phenomenological Study of Visitor Experience August 2016 - August $2017, " 2$.

38 Hawkins in Mast and Hawkins, interview with Erin Mast, ED and CEO of Lincoln Cottage, and Callie Hawkins, Director of Programs at Lincoln Cottage.

39 Erin Mast, “The Experience of President Lincoln’s Cottage Study and Report,"Visitor Impact Study Report (Washington, DC: President Lincoln's Cottage at the Soldiers' Home, 2018), 8, 15; 72.5 percent of visitors found the experience of the visit to be "emotional/intense"; 56 percent of visitors felt inspired to take action.

40 Mast, Erin, 7.

41 David Garneau in Mccall, The Land We Are, IX.

42 Lehrer, Milton, and Patterson, Curating Difficult Knowledge, 208.

43 Plenary session, Dimitra Christidou, “'Sustaining a Community of Learners:' Visitor Studies Association (VSA) 24th Annual Conference, July 24-27 2011 in Chicago," Journal of Conservation and Museum Studies, www.jcms-journal.com/article/view/jcms.91101/24.

44 Lisa Yun Lee, interview with Director, Jane Addams Hull-House Museum, personal, July 7, 2011.

45 "Museum of Anthropology at the University of British Columbia Annual Report," Annual Report (Vancouver, BC: Museum of Anthropology, 2017), 25-26, http://moa.ubc.ca/wp-content/uploads/ MOA_Annual_Report_2016_17.pdf.

46 Michael M. Ames, Cannibal Tours and Glass Boxes:The Anthropology of Museums, 2nd edn (Seattle,WA: University of Washington Press, 1993); Michael M. Ames, Museums, the Public, and Anthropology: A Study in the Anthropology of Anthropology (Vancouver, BC: University of British Columbia Press, 1986).

47 "Neva Boyd," Wikipedia, the Free Encyclopedia, August 16, 2013, http://en.wikipedia.org/w/index. php?title=Neva_Boyd\&oldid=566763504.

48 Naomi Blumberg, "Hull-House Teaching Artists" (Jane Addams Hull-House Museum, 2011).

49 Nick Rabkin, "Moving Forward with Curating the HH Story," April 22, 2011.

50 Aram Han Sifuentes, "Vox Pop and Samplers," December 23, 2017.

51 Aram Han Sifuentes.

52 Fred Wilson and Howard Halle, "Mining the Museum," Grand Street, no. 44 (January 1, 1993): 152.

53 Lisa Grazoise Corrin, interview with Lisa Graziose Corrin, The Ellen Philips Katz Director of the Mary and Leigh Block Museum of Art at Northwestern University, personal, February 27, 2014.

54 Skirball Cultural Center, "Women Hold Up Half the Sky - Prospectus" (Skirball Cultural Center, 2012), 2.

55 Skirball Cultural Center, 5.

56 Bill Ivey and Stephen Tepper, Engaging Art: The Next Great Transformation of America's Cultural Life, 1st edn (London: Routledge, 2007), 17-48. They argue that "participating in political, religious and cultural life is part and parcel of a broader phenomenon of social engagement." One of the tools they used to determine, for example, that those who do more do more, is the General Social Survey that the National Opinion Research Center at University of Chicago has been conducting since 1972. Gao and Tepper used it to analyze the participation of people in activities such as "attending church, joining civic associations, voting, attending sporting events, going to see a movie, camping, attending museums, and attending performing arts events."'They found that "there was a strong positive relationship among all of these items ... so ... people who go to museums are also more likely to volunteer, read the newspaper, go camping, watch movies, and go to church."

57 Karen Hughes, Jan Packer, and Roy Ballantyne, "Using Post-Visit Action Resources to Support Family Conservation Learning Following a Wildlife Tourism Experience," Environmental Education Research 17, no. 3 (n.d.): 307-328.

58 The MAH published a short video on its YouTube channel of Hawke telling her story. santacruzmahtube, When Museum Participation Sparked a Historical Fiction Novel, 2016, www.youtube. $\mathrm{com} /$ watch? $=8$ pygN9KTeAE. 
59 S.L. Hawke, Ghosts in the Gulch: An Evergreen Cemetery Mystery No. 1 (CreateSpace Independent Publishing Platform, 2015).

60 "'crsnaใəm" is the Musqueam spelling. When Anglicized, the name of the city is typically spelled "Cesnam."

61 In Canada, art museums are called galleries.

62 Susan Rowley, interview with Susan Rowley, Curator of Public Archaeology, Circumpolar, Pacific Northwest at the Museum of Anthropology, Vancouver, Canada, personal, August 31, 2017.

63 The other exhibitions at Musqueam Cultural Centre and Museum of Vancouver did feature objects. The MOV, for example, was using the exhibition as a way to discuss its own collecting history.

64 "Guidestar Premium Report for the National Underground Railroad Freedom Center," Financial Report (Cincinnati, OH: National Underground Railroad Freedom Center, 2018), 2, www.guidestar. org/ViewPdf.aspx?PdfSource=0\&ein=31-1436217; "National Underground Railroad Freedom Center,"Wikipedia, September 23, 2017, https://en.wikipedia.org/w/index.php?title=National_ Underground_Railroad_Freedom_Center\&oldid $=802034030$.

65 "Basic Conversation," Refugee Phrasebook (blog), www.refugeephrasebook.de/basic-conversation/.

66 Grace Ballenger and Grace Ballenger, “A.I. Could Help Combat Modern Slavery, If Humans Don't Mess It Up,” Slate, June 30, 2017, www.slate.com/blogs/future_tense/2017/06/30/how_artificial_ intelligence_may_help_combat_modern_slavery.html.

67 "Slavery from Space: Statistics," www.zooniverse.org/projects/ezzjcw/slavery-from-space.

68 Steve Johnson, "Field Museum: Packing in Science and Much, Much More," chicagotribune.com, www.chicagotribune.com/entertainment/museums/ct-ent-0807-museum-101-field-museum20140806-column.html.

69 Grant Thornton, "Field Museum Financial Statements and Report of Independent Certified Public Accountant," Audit (Chicago: Field Museum of Natural History, 2016), 10, www.fieldmuseum.org/ sites/default/files/2016_field_museum_financial_statements.pdf.

70 admin, "Field Museum History," text, The Field Museum, February 23, 2011, www.fieldmuseum. org/about/history.

71 The Field Museum Library, "Moving the Field Museum (1920)," text, flickr, February 23, 2011, www.flickr.com/photos/field_museum_library/sets/72157614806438040/.

72 In summer 2018 Sue was reinstalled upstairs in Evolving Planet and a titanosaur called Máximo took her place.

73 Ashlan Falletta-Cowden, "Field Museum 2016 Attendance Tracking Study" (Chicago: Field Museum, 2016).

74 Lisa Bertagnoli, "Second-String Institutions Fight for Their Share of the Donor Pie," Crain's Chicago Business, www.chicagobusiness.com/article/20140329/ISSUE03/303299992/second-stringinstitutions-fight-for-their-share-of-the-donor-pie.

75 "History | Smart Museum of Art," Smart Museum of Art, https://smartmuseum.uchicago.edu/ about/history/.

76 “Blog," Welcome Blanket, www.welcomeblanket.org/blog/.

77 Jayna Zweiman, "Artists's Statement in Welcome Blanket at the Smart Museum of Art" (Smart Museum of Art, July 17, 2017).

78 "Ravelry: Welcome Blanket," www.ravelry.com/groups/welcome-blanket.

79 "Welcome Note," Welcome Blanket, www.welcomeblanket.org/welcome-note/.

80 Janya Zweiman, Michael Christiano, and John Harness, interview about Welcome Blanket at the Smart Museum, personal, phone, Skype, August 30, 2017.

81 Michael Christiano, follow-up with Michael Christiano, phone, September 7, 2017.

82 Christiano.

83 Zweiman, Christiano, and Harness, interview about Welcome Blanket at the Smart Museum.

84 Oliver Sacks, Uncle Tungsten: Memories of a Chemical Boyhood, 1st edn (New York: Knopf, 2001), 187. 


\section{Bibliography}

“A Home for Brave Ideas: Strategic Plan: Investing in Our Future 2018-2022.” President Abraham Lincoln's Cottage at the Soldier's Home, 2017.

Anderson, Gail. Reinventing the Museum: Historical and Contemporary Perspectives on the Paradigm Shift. Walnut Creek, CA: AltaMira Press, 2004.

Aram Han Sifuentes. "Vox Pop and Samplers," December 23, 2017.

Ballenger, Grace and Grace Ballenger. "A.I. Could Help Combat Modern Slavery, If Humans Don't Mess It Up.” Slate, June 30, 2017. www.slate.com/blogs/future_tense/2017/06/30/how_artificial_ intelligence_may_help_combat_modern_slavery.html.

"Basic Conversation.” Refugee Phrasebook (blog). www.refugeephrasebook.de/basic-conversation/.

Bennett, Tony. “Civic Laboratories.” Cultural Studies 19, no. 5 (September 1, 2005): 521-547. https://doi. org/10.1080/09502380500365416.

"Blog." Welcome Blanket. www.welcomeblanket.org/blog/.

Blumberg, Naomi. “Hull-House Teaching Artists.”Jane Addams Hull-House Museum, 2011.

“Book 1: Who Is Vulnerable?” President Abraham Lincoln's Cottage at the Soldier's Home, 2012.

"Center for the Future of Museums: Trust Me, I'm a Museum." Center for the Future of Museums (blog), February 3, 2015. http://futureofmuseums.blogspot.com/2015/02/trust-me-im-museum_3.html.

Christiano, Michael. Follow-up with Michael Christiano. Phone, September 7, 2017.

Christidou, Dimitra. “'Sustaining a Community of Learners:' Visitor Studies Association (VSA) 24th Annual Conference, July 24-27 2011 in Chicago." Journal of Conservation and Museum Studies. www. jcms-journal.com/article/view/jcms.91101/24.

Falk, John H. and Lynn D. Dierking. The Museum Experience Revisited, 1st edn. Walnut Creek, CA: Routledge, 2012.

Falletta-Cowden, Ashlan. "Field Museum 2016 Attendance Tracking Study." Chicago: Field Museum, 2016.

Gonzales, Laurence. House of Pain: New and Selected Essays. Fayetteville, AR: University of Arkansas Press, 2013.

Hawke, S.L. Ghosts in the Gulch:An Evergreen Cemetery Mystery No. 1. CreateSpace Independent Publishing Platform, 2015.

Hawke, Sangye. Interview with Sangye Hawke, author of Ghosts in the Gulch; volunteer for the Museum of Art and History in Santa Cruz at Evergreen Cemetery; Minister in Formation, Unitarian Church; first-year student, master's in Divinity, Star King School for the Ministry, Berkeley, CA. Phone, September 28, 2017.

Hawkins, Callie. "Thank You! And More.” Personal correspondence, August 7, 2017.

Hirway, Hrishikesh. "Episode 117: Rostam.” Song Exploder (blog), September 14, 2017. http:// songexploder.net/rostam.

Hughes, Karen, Jan Packer, and Roy Ballantyne. "Using Post-Visit Action Resources to Support Family Conservation Learning Following a Wildlife Tourism Experience." Environmental Education Research 17 , no. 3 (n.d.): $307-328$.

Ivey, Bill and Stephen Tepper. Engaging Art:The Next Great Transformation of America's Cultural Life, 1st edn. London: Routledge, 2007.

Johnston, Patricia. Seeing High and Low: Representing Social Conflict in American Visual Culture, 1st edn. Oakland, CA: University of California Press, 2006.

Kohan, Mark. Interview with Mark Kohan, Assistant Clinical Professor, Neag School of Education, University of Connecticut. Phone, November 1,2016.

Kris Nesbitt and Lindsay Maldonado. "Language as Process: Using Words to Shape Exhibition Design." Exhibition, Spring 2016: 64-69.

Lee, Lisa Yun. Interview with Director, Jane Addams Hull-House Museum. Personal, July 7, 2011.

Lehrer, Erica, Cynthia E. Milton, and Monica Patterson, eds. Curating Difficult Knowledge:Violent Pasts in Public Places, 2011 edn. New York: Palgrave Macmillan, 2011. 
Leubke, Jerry and Jennifer Matiasek. Interview with Jerry Leubke, Senior Manager of Audience Research and Jennifer Matiasek, Audience Research, in the Department of Conservation, Education, and Training, Chicago Zoological Society at Brookfield Zoo. Personal, November 16, 2017.

Maldonado, Lindsay. Interview with Lindsay Maldonado, Director of Research and Evaluation, John G. Shedd Aquarium. Personal, November 27, 2017.

Mast, Erin. "The Experience of President Lincoln's Cottage Study and Report."Visitor Impact Study Report. Washington, DC: President Lincoln's Cottage at the Soldiers' Home, 2018.

Mast, Erin and Callie Hawkins. Interview with Erin Mast, Executive Director and CEO of Lincoln Cottage, and Callie Hawkins, Director of Programs at Lincoln Cottage. Phone, August 1, 2017.

Mccall, Sophie. The Land We Are: Artists and Writers Unsettle the Politics of Reconciliation in Canada, ed. Gabrielle Hill, 1st edn. Winnipeg, MB: Arbeiter Ring Publishing, 2015.

Mitoma, Glenn. "11.2.15 Native Solidarity, Indigenous Rights, and Social Justice | Thomas J. Dodd Research Center." http://thedoddcenter.uconn.edu/2016/10/24/11-2-15-native-solidarityindigenous-rights-and-social-justice/.

“Neva Boyd." Wikipedia, the Free Encyclopedia, August 16, 2013. http://en.wikipedia.org/w/index. php?title=Neva_Boyd\&oldid $=566763504$.

President Abraham Lincoln's Cottage at the Soldier's Home. "Take Home Element: Can You Walk Away?” President Abraham Lincoln's Cottage at the Soldier's Home, 2012.

Rabkin, Nick. "Moving Forward with Curating the HH Story." Personal correspondence, April 22, 2011.

"Rauner Signs Law Extending Labor Protections to Domestic Workers." Chicago Tribune. www. chicagotribune.com/business/ct-rauner-signs-domestic-workers-bill-0816-biz-20160815-story. html.

"Ravelry:Welcome Blanket." www.ravelry.com/groups/welcome-blanket.

Rosenzweig, Roy. The Presence of the Past: Popular Uses of History in American Life. New York: Columbia University Press, 1998.

Rowley, Susan. Interview with Susan Rowley, Curator of Public Archaeology, Circumpolar, Pacific Northwest at the Museum of Anthropology, Vancouver, Canada. Personal, August 31, 2017.

Sacks, Oliver. Uncle Tungsten: Memories of a Chemical Boyhood, 1st edn. New York: Knopf, 2001.

santacruzmahtube. When Museum Participation Sparked a Historical Fiction Novel, 2016. www.youtube. $\mathrm{com} /$ watch? $\mathrm{v}=8$ pygN9KTeAE.

Skirball Cultural Center. "Women Hold Up Half the Sky - Prospectus." Skirball Cultural Center, 2012.

"Slavery from Space: Statistics." www.zooniverse.org/projects/ezzjcw/slavery-from-space.

"Statement of Purpose - Phenomenological Study of Visitor Experience August 2016 - August 2017." President Abraham Lincoln's Cottage at the Soldier's Home, 2016.

The Incluseum. "Anti-Prison Organizing and Museums:The Politics of Remembering and Forgetting." The Incluseum (blog), January 26, 2018. https://incluseum.com/2018/01/26/anti-prison-organizingand-museums-the-politics-of-remembering-and-forgetting/.

"Welcome Note." Welcome Blanket. www.welcomeblanket.org/welcome-note/.

Williams, Paul. Memorial Museums: The Global Rush to Commemorate Atrocities. Oxford; New York: Bloomsbury Academic, 2008.

Wong, Julia Carrie. "Police Remove Last Standing Rock Protesters in Military-Style Takeover." Guardian, February 23, 2017, sec. US news. www.theguardian.com/us-news/2017/feb/23/ dakota-access-pipeline-camp-cleared-standing-rock.

Zadov, Irina. "'Love and Labor' Tours: Final Evaluation Presentation.” Presentation, Chicago, March 14, 2014.

Zite-Stumbris, Jamie. Interview with Jamie Zite-Strumbris, Interpretive Programs Coordinator, Chicago Zoological Society at Brookfield Zoo. Personal, November 16, 2017.

Zweiman, Janya, Michael Christiano, and John Harness. Interview about Welcome Blanket at the Smart Museum. Personal, phone, Skype, August 30, 2017.

Zweiman, Jayna. "Artists's Statement in Welcome Blanket at the Smart Museum of Art." The Smart Museum of Art, July 17, 2017. 


\section{4}

\section{WELCOME, INCLUSION, AND SHARING AUTHORITY}

Sharing authority begins not with giving outsiders access to decision making inside a museum, but with welcoming and including people, first at the museum in general and then into processes that pertain to specific projects or the museum as a whole. The first points of contact when someone visits a museum, passes one on the street, or sees information about one in the media will begin to determine whether or not that person feels welcomed by the museum. What language(s) does the museum use? Whose faces greet the visitor? How is the visitor treated? As a potential threat to be regulated, or a guest whose visit is eagerly awaited? As a customer? As a student?

The history of mainstream and universal museums in the US and beyond demonstrates how these kinds of institutions can easily fall short of making all visitors feel welcome and included. Nina Simon explores this topic in depth in The Art of Relevance. ${ }^{1}$ As an introduction to contemporary ideas of sharing authority, I will review six different models of museums as places that bring diverse groups of people together.

These models of spaces enable different forms of thinking about museums and communities. The last model, the decolonizing museum, is the most radical. I spend more time exploring it as contemporary context for the other models and as a frame for the curatorial practices that follow. I discuss three ways to share authority: with visitors, with members of specific communities, and with both. This last can be an important way to bring people together to work for a cause. I explore many practices that can support the work of museums in these areas. The first three are elements of all exhibitions that have important effects on the processes of sharing authority, building community, and connecting diverse communities within and beyond the museum. ${ }^{2}$ The following four are larger institutional initiatives.

\section{Model 1: congregant spaces}

Elaine Heumann Gurian, a leading scholar of museums and consultant to museums around the world, invented the terms "congregant behavior" and "congregant spaces." Congregant behavior is our human tendency to want to spend some of our time in the peaceful company of others, whether we know them or not, whether we interact with them or not. ${ }^{3}$ Gurian 
cites the places she calls "institutions of memory" libraries, archives, schools, courts, religious organizations, museums, and others, as congregant spaces. ${ }^{4}$ Without these kinds of spaces, Gurian argues, our social cohesion erodes. ${ }^{5}$ According to Gurian, institutions of memory must embrace their potential to become congregant spaces in order for our societies to remain civil. ${ }^{6}$ Museums, in particular, should view it as their responsibility to serve as gathering places. ${ }^{7}$ Barriers to public access of museums are a common subject, as is the price of admission. But since access is a prerequisite for both welcoming and sharing authority, another of Gurian's points bears repeating here. One of the best steps toward becoming a congregant space is making admission free. ${ }^{8}$ How can people congregate, gather, etc. spontaneously and without explicit purpose if they need to pay admission?

\section{Model 2: cosmopolitan canopies}

Congregant spaces and cosmopolitan canopies are examples of how hospitality provides an entry point into sharing authority. In many ways, the two models are similar. Elijah Anderson, the sociologist who coined the term "cosmopolitan canopy," and Gurian share concerns about the decline of civility. But Anderson's concept differs in important ways. While Gurian envisions a good congregant space as being almost like an extension of the street, ${ }^{9}$ Anderson views cosmopolitan canopies as public places that function as escapes from the street. For Anderson, cosmopolitan canopies are a vital antidote to social isolation that occurs not as a result of our human condition, as Gurian suggests, but through a situation that is partly of our own making. As urban public places have become increasingly diverse, Anderson explains, strangers have become more "tense" and "wary" around those different from themselves. Anderson describes the defensive and complex "eye-work" many pedestrians use to create a falsely private zone for themselves on the street and to distance themselves from unknown passerby. But looking around, over, under, and "through" others is dehumanizing. ${ }^{10}$ It cuts others out of a social moment, something we have evolved to value highly. In turn, this continues to damage the social fabric and further isolates individuals, implying that people's needs are not commonly shared. As Anderson sees it, the cosmopolitan canopy is a place where people can experience relief from the isolation of the street.

Anderson envisions a specific use to which visitors to the cosmopolitan canopy put their experience - "folk ethnography." 11 As strangers talk to one another, they find evidence that supports their preexisting notions about others and imagine new "folk theories." 12 Folk ethnography involves "testing or substantiating stereotypes and prejudices or, rarely, acknowledging something fundamentally new about the other." ${ }^{13}$ Strangers share authority as participants in this process over the folk theories each one forms and elaborates. Though experiences in the cosmopolitan canopy may tend to be positive, they may engrain beliefs that actually do not support the health of society. The curiosity of strangers about one another runs in multiple directions along lines of color, class, gender presentation, sexuality, etc. and is not limited to curiosity of those in a normative or hegemonic category over others. It runs the other way as well. Anderson qualifies the shared experience of the cosmopolitan canopy as an environment of "symmetrical relationships,"14 unlike the contact zone, described below, where the relationships are known to be asymmetrical.

Finally, a cosmopolitan canopy is undefended against strangers. On the contrary, hospitality toward strangers is part of the ethos of this space. Anderson notes that in culturally specific neighborhoods, "keen notice of strangers is the first line of defense." 15 One reason 
for this is that cosmopolitan canopies are supposedly shared spaces that do not belong to any one group. ${ }^{16}$ It's odd, then, that culturally specific museums, such as the National Museum of Mexican Art (NMMA), have been specifically cited as being cosmopolitan canopies, ${ }^{17}$ since they are spaces that one group does expressly own. For the designation of "cosmopolitan canopy" to ring true, the culturally specific institution in question must commit to welcoming those outside the group. The NMMA did so early on, effectively subverting, as the Chicano and Latino Studies scholar Karen Mary Davalos put it, the myth that "differences result in conflict." 18 Over decades, this stance has contributed to others' recognition of the museum's work.

\section{Model 3: dialogic museum}

Jack (John Kuo Wei) Tchen's model of the dialogic museum is another foundation for museum work that has been vital to practices of sharing authority. Tchen is a historian, curator, Professor at New York University, and co-founder of the Museum of Chinese in America. His model moves past congregant spaces and cosmopolitan canopies. In those spaces, co-presence and chance encounter are the dynamic experiences. Tchen envisions dialogue, a more active experience, as the sine qua non. He defines this model as "engaging with ... audiences in mutually exploring ... memory and meaning," and stresses the importance of using it to inflect institutional practices across the board. Tchen and others at the Chinatown History Museum pioneered this model of museum work in the exhibition Memories of New York Chinatown. Through the work on this exhibition and, later, transforming the institution into a dialogue-driven one, Tchen explored a variety of strategies that are useful for sharing authority, and actually co-creating authority, with stakeholders and visitors. ${ }^{19}$ These all come under the banner of dialogic museum work along with Tchen's interventions of collaborative development, evaluation, and retesting of components for exhibition; ${ }^{20}$ collecting memories; collecting experiences of those outside the source community; and training interested stakeholders and visitors to participate in the process of documentation and interpretation. ${ }^{21}$ For Tchen, the hallmark of a dialogue-driven exhibition is that any visitor can "choose to collaborate ... in documenting and discussing his or her memories and reflections." 22 Dialogue continues from planning through the experience of the exhibition. The final component of dialogue as Tchen envisions it is listening. He planned for staff to take part in both active and passive listening (conversation and observation) in and around Memories of New York Chinatown. ${ }^{23}$

Liz Ševčenko, founding director of the Coalition of International Sites of Conscience (SoC), used Tchen's dialogic model in the formative stages of SoC. She said there are at least three different ways we can conceive of a dialogic museum:

- "one that promotes public discussion of a truth that has been forgotten or deliberately suppressed ...

- one in which the dialogue is between "academic historians and people with lived experience"

- $\quad$ and one founded on direct conversation among visitors

Here sharing authority is about serving as a forum for open discussion of the implications of the past for the present, as opposed to imposing a single conclusion or moral. ${ }^{24}$ 
For Tchen, dialogue and sharing authority are about interrogating the validity of historians' sources and making sure those sources are not rooted in prejudice or the marginalization of others. ${ }^{25}$

\section{Model 4: first-voice ${ }^{26}$}

Dialogic and first-voice museum work are models that help curators to shape the narrative in a museum through the voices of stakeholders. First-voice institutions achieve their social justice missions in part simply by existing. "First-voice" is the institutional equivalent of "firstperson." It refers to a narrative point of view in which a culturally specific group tells its own stories. Likewise, a first-voice museum is one that employs members of its own community to tell its community's stories. However, first-voice museums need not speak exclusively to their own group. Nor do they need to be the only source of knowledge about the group. One goal can be creating a rounded picture of the group along with other institutions.

Part of the equitable distribution of risks and rewards in society, part of social justice, is creating equitable access to cultural patrimony and to being a custodian of that patrimony. Groups should also have the right to equitable representation in the shared cultural landscape. Thus, when we take a bird's-eye view of the museum world, culturally specific museums such as the NMMA constitute one form of sharing authority with a cultural community. That doesn't imply anything about the ability of that museum to share authority. Rather, the institution itself is a break in what is still a largely hegemonic structure within the museum world.

Like first-voice, community museums are those created by, about, and for a community. There are two main understandings of community museums in the US. In one, they are the museum equivalent of community centers - small, hyper-local places that are primarily relevant to their own neighborhoods. In the other understanding, "community" stands for "culturally specific." "Culturally specific" can stand in for non-White or refer to White cultural groups as in museums such as the Swedish American Museum and the Irish American Heritage Center. Culturally specific museums can be large, even national, museums or much smaller endeavors. Different scholars have used the terms "ethnically specific museum," "culturally specific museum," and "community museum" to describe the same kinds of institutions. ${ }^{27}$ For the sake of clarity, I will use the term "culturally specific museum."

Culturally specific museums offer a particular opportunity to examine what it looks like to make hospitality a goal from the founding of the museum. Culturally specific museums strengthen one group identity while also seeking to decrease negative groupness, discussed in Chapter 1, in the form of prejudice. The cultural landscape in Chicago, and the NMMA in particular, exemplify how culturally specific museums intentionally share authority. Working for social justice is historically important for the neighborhood of Pilsen, where the NMMA is located, as well as in other culturally specific organizations in Chicago. In the 1960s and '70s, culturally specific groups around Chicago such as African-Americans, Mexicans, and Asians, were engaged in a civil rights project of building equitable representation in the city as well as equitable access to services. The creation of culturally specific institutions such as the Ebony Museum in 1961 (which became DuSable in 1973) and the MFACM in 1986 (which became the National Museum of Mexican Art in 2006) was part of this strategy. ${ }^{28}$

The NMMA combats the invisibility and marginalization of Mexican people and their culture in the American social and cultural landscape and stakes a claim to a place in the cultural sphere and to a meaningful history. This is the oldest function of culturally specific museums. 
Christina Kreps, the museum anthropologist, frames the museum's existence as more equitably distributing the human right to be custodian of your own culture. ${ }^{29}$ Furthermore, culturally specific museums have a specific cultural patrimony bound up in Indigenous curatorial practices, as I'll discuss in the context of decolonizing museums, and specifically the work of Amy Lonetree, below.

\section{Model 5: contact zones}

Contact zones privilege the voices of stakeholders alongside the newly created points of view that arise from the interaction of people in historically unequal power relations. In Imperial Eyes: Travel Writing and Transculturation, Mary Louise Pratt, a linguist and professor of Spanish and Portuguese, defines a "contact zone" as

the space of colonial encounters, the space in which peoples geographically and historically separated come into contact with each other and establish ongoing relations, usually involving conditions of coercion, radical inequality, and intractable conflict. ${ }^{30}$

James Clifford, the interdisciplinary historian, adapted Pratt's definition to the setting of museums in Routes:Travel and Translation in the Late 20th Century. At first blush, Pratt's description might sound like an extreme one for a museum. The most salient part of her definition for me is her assertion that this model presupposes a reciprocal relationship in which colonizer and colonized interact and affect one another's "understandings and practices" even while in a relationship with a pronounced asymmetry of power. ${ }^{31}$

The reciprocity is crucial for Clifford as well. He postulates that, when museums take collections as their raison d'être, the collections set up a situation wherein the cultural power of the objects in the collection confers power on the museum as well. The communities that are culturally tied to the objects then must enter the museum in order to gain access to cultural meaning that is rightfully theirs. Cultural owners of materials in the museum may transform the power of the museum by requesting certain kinds of stewardship and assistance from the museum as part of its relationship with the objects in the collection. The collection itself creates an opening for new relationships to develop between the museum and those whose heritage it contains. ${ }^{32}$

Bernadette Lynch, a scholar and museum professional, argues that we should embrace the notion of museums as contact zones. Contact zones, she writes, are uncomfortable by nature, but they also produce relationships that acknowledge asymmetries in power and relationships that are not colonial in nature. Contrary to the liberal model of a museum, which never cedes control completely but does hold back antagonism, Lynch envisions a museum that embraces antagonism through the notion of "friendly adversaries." ${ }_{33}$ In fact, for Lynch as for Lisa Lee, conflict is a vital part of the democratic process, and museums must enable respectful conflict in order to maintain their view of visitors as participants rather than consumers. ${ }^{34}$ Here, Lynch builds on the work of Pratt and Clifford.

Taking Clifford's work together with Lynch's, we can use this framework to imagine a point of departure for curatorial work wherein even unequal power relations involve agency on both sides. In these relationships among stakeholders and museums, each stands to gain when negotiations and cultural exchanges can include frank expressions about unequal relationships and vested interests. 


\section{Model 6: decolonizing museums $\mathrm{s}^{35}$}

Whereas models such as dialogic and first-voice museum work focus on sharing authority over narratives, this model is about reshaping the authority of the museum as a whole. In the twenty-first century, museums have been making efforts to "decolonize" themselves, to change their models so that they are no longer agents of colonialism. This is a radical way of thinking about equity and inclusion in the museum. Museums acknowledge that their colonial heritage still inflects the way they function, and then make changes.

Native scholars such as Amy Lonetree view decolonization as a stance that pertains specifically to the relationship between museums and American Indian nations and other first peoples (sovereign nations). In her book, Decolonizing Museums, Lonetree lays out the elements of a decolonizing practice focused on respecting the sovereign rights of First Nations. First, museums must help communities grieve atrocities and otherwise manage histories of "unresolved grief." Museums must use powerful and precise language that avoids euphemism and the use of the passive voice. Lonetree urges us to call genocide and atrocities what they are - mass murder - and to name the perpetrators, from Custer to so-called settlers, who killed off the inhabitants of the land so that they could steal it. This is one step toward breaking the silence that has legitimized colonialism. For Lonetree and other native scholars such as Maria Yellow Horse Brave Heart and Lemyra DeBruyn, naming the causes of "historical unresolved grief" in native communities will lead to a new kind of understanding. The hope is that non-native people will come to understand the intense trials of native peoples and the near-miracle of their contemporary survival in the face of genocide, forced acculturation, extreme marginalization, and the many ills that follow from crushing poverty. Breaking the silence means that the native understanding of the sources of the myriad social problems that are ongoing in native communities can now be shared with the non-native people. ${ }^{36}$ When both groups understand this history of genocide and marginalization, they can work to change the contemporary circumstances of native communities.

While "decolonizing" the museum began as an effort of Indigenous, First Nations, and native peoples, it has become far more ample. Chandra Frank, a Dutch/South African scholar and curator, extends the discussion of decolonizing the museum to European colonial relationships. Projects such as that of the Rijksmuseum, discussed below, fall into this category. For Frank, incorporating non-Western ways of making meaning is central to decolonial curatorial practice. ${ }^{37}$ The curatorial tasks associated with this kind of practice include:

- embracing decolonial aesthetics, supporting artists whose work does not hew to European standards for art and beauty,

- choosing forms of memory making in display and programming that involve stakeholding communities and that differ from European models,

- revising the vocabulary used to refer to stakeholding communities away from anthropological terms such as "source communities" and "target communities,"

- evaluating who benefits when museums include the memories of marginalized groups,

- producing nuanced representations of marginalized communities,

- seeking institutional collaborators that are active in decolonizing museums and recognizing decolonial aesthetics,

- $\quad$ and "repudiat[ing] the aim to serve a Western audience." 38 
Still other scholars, such Aletheia Wittman and Rose Paquet Kinsley of the blog The Incluseum, extend decolonization to relationships that have been colonial in nature if not in fact. ${ }^{39}$ The relationship between the White establishment and African-American communities in the US is one example of this. Thus decolonial practices become tools for undoing historical injustices such as racial oppression, classism, and patriarchy. Museums have not only been party to these practices. Their work has buttressed, excused, and made normal these systems of violence.

Colonial museums, perhaps more than any others, are guilty of this work. However, they also may have the most to contribute or gain by decolonizing. The Rijksmuseum, the Museum of the Netherlands in Amsterdam, is a monumental, labyrinthine testimony to the power of the Dutch in the colonial era. It was founded in 1800. The collection contains 1.2 million objects. The eighty galleries of the museum are spread across a vast building that - characteristically for Amsterdam - spans a broad bike path where cyclists zip beneath vaulted arches. Inside, the visual testimony to Dutch dominion is compelling - tile work, frescoes, glorious natural light all speak to the visitor in a vocabulary of royalty. The museum was founded in 1800 as the National Gallery of Art. At that time, it was located in The Hague. It moved to Amsterdam in 1808 and moved into the current building in $1885 .{ }^{40}$ The museum's attendance is 2.3 million visitors a year. ${ }^{41}$ Today curators are attempting to retool its messages for the present day - to decolonize it.

The Rijksmuseum is - in my observation - the first European museum to create a formal process for changing the terminology of its own collection to decolonize the museum. Scholars and journalists have picked up on the museum's "Adjustment of Colonial Terminology." ${ }^{42}$ In January 2017, I met with two curators at the Rijksmuseum about the project, Eveline Sint Nicolaas and Stephanie Archangel. ${ }^{43}$ The "Adjustment of Colonial Terminology" project was originally something the curators of history at the Rijksmuseum saw as "just doing their jobs." They received responses on social media to labels with offensive language that had been written by their predecessors and decided to correct the labels. Revising labels is a normal part of curatorial work. It was also a normal part of reopening the museum in 2013 after a ten-year-long renovation. The curators were able to get a few new labels on the wall for the reopening, but really that was just the beginning of this project.

The goal of the project is to eliminate terms that refer to the race, religion, or disability of the subjects in artworks in a negative way. The first term the curators chose to revise was the Dutch term "Neger" (descendant from the old Dutch term "Nikker"). They changed this word to "zwart," the word for the color black. In the English labels in the museum, "Neger" was translated as "Negro," but that isn't its connotation in Dutch. Really, it is the Dutch equivalent of " $N^{\star}$ gger." Upon digging into the presence of that term in the texts, many other terms and phrases came to the attention of the curators, who met together and planed replacements with their peers in other departments as necessary. For example, just as the Dutch term "zwart," the color black, is used to refer to skin color when necessary, so too is the Dutch "wit" or "white." Previously, the term on labels for light-skinned people was "blanc," which carries connotations of purity as well as color. Changing terms across the board denaturalizes the value judgments embedded in the names for racial categories in the Netherlands.

The sociopolitical background for this linguistic shift is significant. When I spoke with Sint Nicolaas and Archangel, the Netherlands was on the brink of an election wherein many feared that the candidate from the isolationist "freedom party" would come to power. (He did not.) At the same time, a "Black emancipation" movement has been taking hold in the Netherlands and the colonies since the early 2010s. Choices about language, which words are acceptable or offensive, are changing rapidly. The curators recognize that they will need to struggle to 
stay abreast of changes as they occur. But now that they are in this project, they are committed to remaining involved. They see it as a permanent fixture rather than a project that will be complete once they have reviewed records for the whole collection. And that is precisely the mindset that contributes to ongoing decolonization at a museum.

The changes are taking place on the descriptions of works on the museum's website as well as on labels accompanying artworks. The collection of the Rijksmuseum contains 1.2 million objects. The whole collection is digitized, though not all of the digital records are complete. As of 2017, the curators have worked through revisions for roughly a third of the collection. However, most of these objects are not on view. The experience in the galleries is that the objects with revised labels are concentrated in two or three of the museum's eighty galleries.

The curators never imagined, perhaps naively, that their project would garner so much attention or controversy, both from those who agree that the language is offensive and those who do not. Criticism of the project has come from at least two camps. Some people resist the notion that the language is offensive and simply view it as part of the culture. As Archangel pointed out to me, this is a culture in which Santa Claus has a clumsy, bumbling, Black helper called "Zwarte Piet," usually represented by a person in blackface. Defending this cultural feature is much like Mexicans arguing that Memín Pinguín (discussed in Chapter 2; see Figure 2.10) is not offensive but rather simply part of Mexican culture, as if the two were mutually exclusive. Each year in November and December the Netherlands erupts in controversy regarding whether Zwarte Piet should be retired. As Archangel put it, "society was ready to hear about change" when the Adjustment of Colonial Terminology project came along. ${ }^{44}$

Some people involved in the Black emancipation movement resist the notion that changing offensive language in the museum obscures ongoing Dutch racism, hiding it by eliminating inside the museum the language that many Dutch people still use outside the museum's walls. Relatedly, some object to the notion that curators are whitewashing history. The revisions, though, never change titles artists have given works. In the instance of offensive original titles, the tombstone for the piece indicates a title given by the museum as well as a "title on object." I can envision one possible solution to these latter two criticisms.

According to Sint Nicolaas, the curators have not signaled on the labels or elsewhere in the museum which labels have been changed or why because it is "too cumbersome." Word counts are important and the curators wish to reserve the whole length of the label for content. The project is explained on the museum's website. However, the Rijksmuseum may sell itself short by not making a bigger public example out of its brave and unusual project. The museum could choose to prominently advertise the project in its gleaming front hall by stating simply that there are terms that are unacceptable in contemporary use and that the museum is working on replacing them. The museum could go so far as to apologize for the use of such terms in the past. Another iteration of the museum's map (it already offers at least ten versions at the information desk) that is color-coded to signal to the changes could be a useful tool to help disseminate information about the project and raise interest. The signage, the map, and color-coding the labels themselves is all that would be needed to stand behind this project as an institution, rather than burying it in the website. No additional text would be necessary on the labels. This kind of visibility might draw more controversy, or it might not. It would surely assuage the critics from the Black emancipation movement by demonstrating that the museum is not trying to hide its prior role in Black subjugation, but rather to make amends and lead by example the way toward more respectful language. It would also assist with a problem Sint Nicolaas sometimes encounters.

Labels can become too sanitized during the revision process, as with the label for "Bathsheba at Her Toilet" by Cornelius van Haarlem (1594). In the painting, two naked maidservants, one 
Black and one White, assist Bathsheba as she bathes outdoors. Bathsheba gazes at the other White woman who washes Bathsheba's foot. The Black woman reaches between Bathsheba's thighs to hold up her leg for their companion, gazing into Bathsheba's face as she does. The new label no longer contains the sentence "Because Bathsheba's maidservant is black, the subtly erotic painting takes on an exotic tinge." ${ }^{45}$ By simply eliminating this language, the revision does not allow the uninitiated visitor to appreciate how exotic and sexual the Black maidservant in the picture appeared when the painting was made and how this eroticization of Black femininity has persisted through the centuries.

The Rijksmuseum presents the Adjustment of Colonial Terminology Project in one other way, though it is also unadvertised. The museum offers a number of audio tours, one of which is a ninety-minute tour on the "Colonial Past." The tour highlights newly interpreted objects, including some with labels that have been revised through the project. In general, the tour is a frank and useful introduction to Dutch colonialism that is also presented in a fun way, rather like a scavenger hunt through the labyrinthine Rijksmuseum. In any national colonial museum like the Rijksmuseum, the truths of colonialism are probably hidden in plain sight, or perhaps concealed by the portrayals of colonialism that the colonizers commissioned. Many seasoned museumgoers and museum professionals will have felt this in museums around the US and Europe. This tour looks beyond the visible in specific objects and tells the history between the lines of the one the colonizer presented. It also draws attention to things the visitor can see, but might miss.

No matter the type of museum or colonial relationship, decolonizing the museum is a broad process, so extensive that it will become a new way of being for the museum that undertakes it. The claim to being a decolonized or decolonizing museum is a bold one that invites scholarly and public critique of a museum's practices. For the museum truly committed to this path, that is an excellent tool for keeping the museum honest in its quest for the worthy goal of decolonization. When a museum takes on the mantle of decolonization, it is necessarily starting the process of breaking the silence, as Lonetree suggests. It must name the colonization that preceded the decolonization and publicly explore the wrongs in which the museum has been complicit. In this way, simply setting that process in motion by claiming to decolonize the museum helps the museum to actually do the work itself. Likewise, once the museum takes that brave step, others - perhaps especially those who suffered from subjugation - will be eager to help creatively subvert the colonial practices of the museum from within. ${ }^{46}$

\section{Three stances: participation, inclusion, and shared authority}

Thinking through which of the models for spaces above best fits your organization will help you decide which of the practices below to test in your gallery. Another part of this process is considering the stances with which your institution approaches visitors. At the end of this chapter, you will find charts and worksheets that help you analyze the models and stances of your workplace and plan ways to experiment with your curatorial practices.

Though participation, inclusion, and shared authority are certainly related, they are not the same thing. Simon's The Participatory Museum discusses several levels of participation that are possible in the museum setting and inspired me to think participation and inclusion as precursors to sharing authority. Visitors' participation does not always end up with visitors sharing in the authority of the museum. But, when it's successful, participation begins with visitors feeling welcomed and included in the museum's process. Simon is a proponent of audience-centered museum work as a precondition for participation. If the museum's work is 
structured around the visitors, the visitors will be more likely to want to participate in it. They will also be more likely to feel welcomed and included. (Audience-centered museum work is also not the same as sharing authority, but it is on the path.) Participation is a two-way street. It can begin in person or digitally, before, during, or after the visit. One common entry point to participation is when visitors are willing to take instructions inside of the museum in order to participate in activities or other initiatives.

Inclusion is an ongoing stance in the relationship between museum and visitor. There are many efforts that can foster inclusion, such as making sure that visitors of all backgrounds and identities see themselves reflected in exhibitions (depending on the type of museum) or designing with people of all abilities in mind. Efforts to be inclusive are also quite locally specific. In an area such as Chicago, for example, an inclusive museum should have bilingual or multilingual labels. But these efforts only work if all those who visit or might want to visit feel welcomed and valued. Overall, the inclusive museum sets out to discover who is not being served or included and why and then dismantles barriers not only to participation but also to feeling welcomed and included. As with decolonizing the museum, this effort must reach into every area of museum operations and programming in an ongoing way to have a meaningful effect.

As visitors become comfortable participating, museums can then share authority with visitors by engaging them in more depth. As mutual trust develops, one possibility is that visitors may finally begin to act as "friendly adversaries," as discussed above in Model 5: contact zones. ${ }^{47}$ But in order to act in this way, one must feel that dissent will not be silenced or ignored. Once again, all of the norms of hospitality that we employ in our homes also come to bear in the museum. Take, for example, the Dan Savage vs. Brian Brown Dinner Table Debate. Savage, a prominent writer and proponent of queer rights, invited Brown, President of the National Organization for Marriage (an organization that promotes the idea that marriage should be between one man and one woman) over to the home that Savage shares with his husband and son for dinner and discussion. ${ }^{48}$ The context of the event changed the discussion the two men had. It was more civil and also more substantive than their previous interactions. The adversarial nature of the relationship between Savage and Brown is an extreme example. I don't wish to imply that the relationship between visitors and the museums they visit is quite so fraught. However, the tension is rising between institutions, such as museums, that have benefited from White supremacy, even unintentionally, and the growing global majority that people of color comprise. This tension extends to museums that merely exist in the White supremacist cultures of the Western world, even those that are engaged in change and the hard work of decolonization. Museums can reap the benefits of the Savage vs. Brown Dinner Table Debate - making interactions with visitors more respectful and substantive - when the invited collaborators feel welcomed at the table as equals, experts, and valued participants. Museums can change as they change who is at the table.

\section{Sharing authority with visitors}

Sometimes museums share authority with communities because they want members of those communities to be comfortable visiting the museum and they want voices from those communities in the stories the museum tells. Other times, museums start with the visitors they have and bring them closer to the institution by sharing authority with them. In Bill Adair, Benjamin Filene, and Laura Koloski's book on the subject, Letting Go, the editors define museums' role in sharing authority with visitors: 
Museum staff members lay the groundwork for visitors to participate successfully: they identify multiple pathways through the content; build bridges that visitors can cross between the stories from the past and their own experiences; and offer tools visitors can use to make new discoveries, cut new pathways, and build new bridges. ${ }^{49}$

Simon emphasizes that sharing authority with visitors will only have the desired effect of further engaging them with the institution when they understand that they are performing authentically useful work for and with the institution.

\section{Alternative labeling}

Hull-House museum uses a curatorial intervention called the Alternative Labeling Project. This project is a way for the museum to "address visitors as citizens engaged in the process of creating meaning" in homage to the participatory democracy of the Hull-House Settlement. In addressing visitors this way, the staff of the museum also hope to address the visitor in such a way as to invite her to "step out of [her] prescribed role as consumer." 50 The making of one particular alternative label demonstrates how visitors take seriously the task of making meaning in the museum when they perceive that they are providing invaluable input. Early on in the project, which is ongoing, the museum crowd-sourced a label in the permanent exhibition, Re-Defining Democracy (2010). It is a label for the portrait of Mary Rozet-Smith, Addams's longtime intimate partner, which hangs in Addams's bedroom (Figure 4.1).

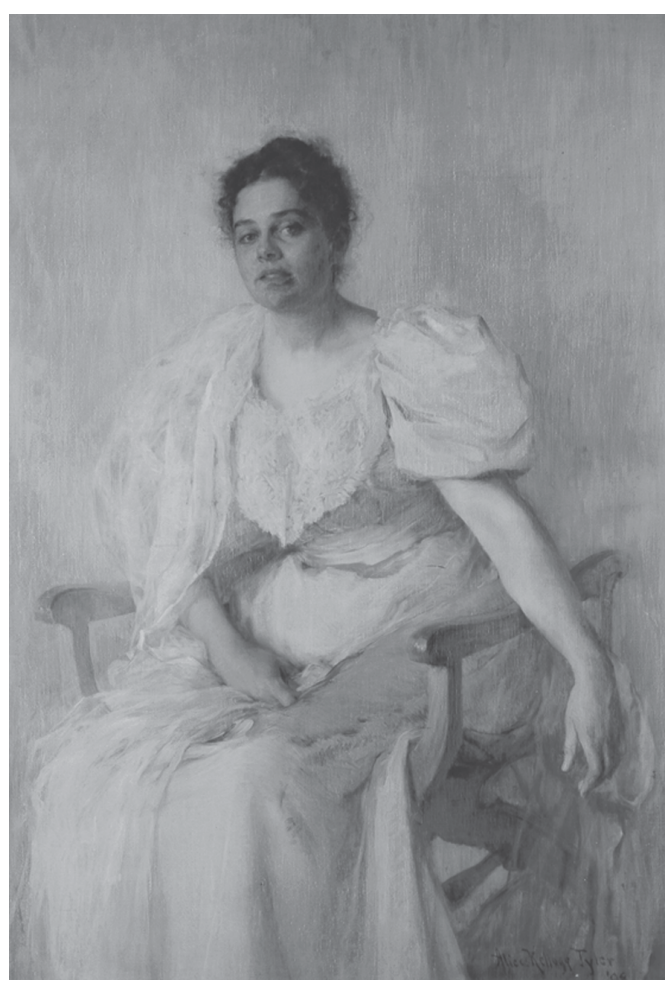

FIGURE 4.1 Alice Kellogg Tyler, Portrait of Mary Rozet Smith, 1898, oil on canvas. Image courtesy of Jane Addams Hull-House Museum, University of Illinois at Chicago. 
The museum had felt resistance to exhibiting the portrait of Rozet-Smith, and especially to interpreting it part of the material legacy of a romance. Crowd-sourcing the label would create the necessary content for the label and involve visitors in the discussion that went into deciding how to interpret an important and potentially divisive object. The process allowed the museum to show by example how and why decisions are made in the museum, while giving visitors a stake in the process. Having seen and participated in the process, they would be less likely to balk if the final label did not represent their views.

First the museum gathered ideas from the public inside the bedroom. Then, the museum produced three versions of the label and asked the public to vote on which one to use. Finally, the museum produced a label for the piece. ${ }^{51}$ The label turned the bedroom into a counterpublic space. ${ }^{52}$ The museum relinquished some authority through crowd-sourcing the label, and, in exchange, offered an opportunity for the museum and visitors to collaborate on the creation of knowledge. ${ }^{53,54}$

\section{Tone}

Tone is another, much simpler and more passive way of fostering the agency of visitors. At the NMMA, many staff members have described the importance of tone.

Davalos noticed it as well, writing that the museum acknowledges the authority of Mexican visitors and treats them as experts. "This authority brings with it a sense of ... ownership because the objects are presented to Mexicanos in the first person: they are ours/ nuestra cultura." ${ }^{55}$ A chain reaction takes place in the museum, beginning with this vision of Mexican visitors as cultural experts.Visitors transform from viewers to doers as they engage the exhibitions with their own authentic cultural experiences and memories and begin to see themselves and their compatriots as subjects of the exhibitions. ${ }^{56}$ Finally, as Davalos puts it, the "third eye" closes and the visitor no longer feels the discomfort of being looked at by others. "The new gaze provides integrity to those in diaspora ... This is a counterhegemonic move." 57 According to Davalos, the empowerment of Mexican visitors does not fall into the trap of disempowering others, however. Placing Mexicans at the center moves European-Americans toward the margins. But European-Americans have so much power in our society already, and so many venues for their voices, that this de-centering does not result in a tangible loss for them, though the loss may be felt. Most importantly it allows Mexican visitors to see themselves as part of a diverse national story. ${ }^{58}$

\section{"Thick description"}

Though every word on a label matters, complication is also valuable. This is one way in which a museum can invite many different kinds of visitors to relate to a story. As Lee put it, a history with multiple points of entry - places where all kinds of visitors can find resonance with their own experiences - is going to be accessible to the greatest variety of visitors. ${ }^{60}$ Thick description can also result in sharing authority over the space of the museum with the visitor. Sometimes, more is more. The anthropologist Clifford Geertz coined the term "thick description" to describe his ethnographic method. ${ }^{61}$

The Alternative Labeling Project provides thick descriptions. In them, additional voices speak from the museum to a range of kinds of visitors. Because of the longer form of the labels, the alternative labels are thicker descriptions - more nuanced, more detailed, and ultimately more 
memorable. (Traditional labels are 50-75 words, and these labels often exceed 250 words.) One of the Alternative Labels is the thickest of thick description, a lengthy "prosepoem" by Terri Kapsalis about, as Lee put it, "health, sickness, war and peace." 62 It is the label for Addams's traveling medicine kit. The museum created a physical experience for the visitor that contained within it, for some, embodied emotional responses. The experience blurred the line between a program and a label, and perhaps made the label into an object unto itself. But it also provided the kind of scaffolding necessary for visitors to deeply engage with an object and a historical figure.

During the winter of 2014, visitors could reserve a half-hour to read the label while drinking tea served to them by a staff member. In Lee's introduction to the label, she states that one of the goals of the Alternative Labeling Project is creating an embodied experience. ${ }^{63}$ The physical experience of the gallery may be quiet and contemplative - or loud and filled with students - but the experiences Kapsalis's label brings on are different: surprise and revulsion at the thought of the painful boils on the buttocks of Karl Marx; anger at the cruel and misogynistic Dr. Mitchell. He treated both Charlotte Perkins Gilman and Jane Addams, imposing on Gilman, at least, his hideous "rest cure" for women's nervousness wherein he confined otherwise healthy women to bed and forbade them to sit up, engage in any activities, or eat normally. They were served four ounces of milk every two hours by a nurse.

The label, filled with seemingly small questions to the reader, offers many opportunities for meditation: Did Addams know that "cure" and "care" share a Latin root? Kapsalis's style leads the mind to wander and explore. Ultimately, Kapsalis's story becomes the story of how Addams found the cure for her ailments in the Hull-House Settlement. The question from Kapsalis comes sixty-five pages into reading the label: “Are we closer to understanding Addams' travel medicine kit?” The answer is yes, but more importantly we are closer to understanding Addams in all her humanity and to understanding her project at Hull-House. These multilayered understandings are the benefit of thick description. The museum's Alternative Labeling Project is valuable because it gives visitors the necessary authority and an authentic reason to linger in the gallery space. If we felt that way more frequently in the spaces of museums, we would certainly learn more and remember better.

\section{Sharing authority with communities}

Sharing authority with stakeholding communities or source communities is what people most often mean when they discuss "sharing authority" in the museum setting. Museums want and need to engage local communities, communities represented in the museum, and underserved communities. Whether temporarily for specific projects or permanently as part of the institution's mission, museums need these groups to share in the ownership of their process and product. They need these connections in order to operate ethically, to have the fullest interpretation possible, and for economic reasons of audience development and fundraising. In the rest of this chapter, I will discuss four methods of sharing authority with communities and their relative merits for curatorial work for social justice. These methods are: Indigenous museology, the steering committee, the museum effect, and the visitor panel.

\section{Appropriate museology in action: Mestizo museology at the NMMA}

The local management of cultural needs requires what Kreps calls "appropriate museology," using culturally appropriate solutions with local materials that are economically sustainable. ${ }^{64}$ 
This museological philosophy comes to bear on everything from large-scale concerns such as what to show and when, to seemingly small details such as wall color, lighting, and labeling. When appropriate museology is in place, local stakeholders can use the authority of the museum to further their own agendas, including cultural preservation. Museums such as the National Museum of the American Indian (NMAI) and Te Papa Tongarewa have protocols around who can access sacred collections and how they may interact with the collections. The research of scholars such as Kreps shows how locals flip the power of institutions born of their colonizers to serve local needs. Public perceptions around this type of institution might not always be favorable. Overall, however, as Kreps put it, community museums gain ownership and authority by creating the information that surrounds objects and intangible cultural heritage. "People realize their right to their own regional and local identity, taking possession of their world and gaining control over it." 65

In Mexico, Mexican identity is still mainly described using the term mestizo, indicating the mixture of Spanish and Indigenous (discussed further in Chapter 2). So, for a Mexican institution to use mixture intentionally in its structure is one example of Indigenous curation and appropriate museology. ${ }^{66}$ Mestizo museology at the NMMA includes everything from the curatorial choices of color, vocabulary, and sound to the organization of the museum's annual cycle of exhibitions.

Entering the NMMA offers two sensory experiences at once: the professional, clean, cool atmosphere that we associate with museums and the colors, sounds, and, during a party, even the smells of Mexican culture. Ochre, turquoise, and gold colors grace the entryway, peopled with the brown faces of staff members and visitors. In the hallway, children are often gathered, chatting, laughing, and horsing around.

The NMMA is known for presenting a diverse cycle of exhibitions throughout the year. Each September, the NMMA opens the largest annual celebration of the Day of the Dead in the US. It is often the first introduction visitors have to the museum and draws roughly 50,000 visitors each year, nearly a third of the 160,000 annual visitors. A social history exhibition may come next. The NMMA presents a contemporary art exhibition each year, and the Chicago Gallery always features the work of local artists. Last, exhibitions from the Permanent Collection are a mainstay type of exhibition along with Nuestras Historias: Stories of Mexican Identity from the Permanent Collection, the permanent exhibition. According to Davalos, the cycle of exhibitions keeps the museum's range of exhibitions, and their disciplines, hanging in a free-floating order, never placing one genre above the others. ${ }^{67}$ For her, the way the NMMA constructs its schedule is also an example of mestizo museology. The schedule is shifting and recurrent. It includes a variety of different kinds of exhibitions without creating a hierarchy within the schedule. The cycle of exhibitions creates, unto itself, a "visual mixture, a mestizaje." 68

The annual exhibition celebrating el día de los muertos offers a special example of mestizo museology. For Davalos, the installation for the Day of the Dead transforms both the space of the museum and the ofrendas themselves. The ofrendas ${ }^{69}$ take on a dual meaning as both religious objects and public art installations. The museum takes on a new role as the location where a religious celebration, though secularized, is being practiced. ${ }^{70}$ This is a mestizo version of the museum as a temple, a moment of Indigenous museology that flips the power of the museum as institution into the hands of the Mexican community. Here, far from being a temple where the content is off-limits and exists to be worshipped in a sterile environment, the celebratory mess of a real temple infuses the space and enhances the participatory nature of the museum. 
Each year, many families make the pilgrimage to the museum to view the exhibition and add contributions to the "community ofrenda" where all visitors can honor their own loved ones.

The vocabulary of the museum is part of its mestizo museology. The term "fine art" normally elevates the status of mainstream fine art museums. "Folk art" lowers the status of culturally specific museums. But Davalos argues that these terms "take on new meanings when invoked from the margins." This is especially true, she writes, when the terms are invoked in a first-voice manner, by a community to that community, rather than to a hegemonic mainstream. ${ }^{71}$ The museum fits into a landscape of fine art museums within Chicago's cultural sector. But the museum actively upsets the racial and ethnic hierarchies we find in other fine art museums. ${ }^{72}$ By integrating and blending the categories of fine and folk art, the museum, like Chicano artists themselves, makes new meanings for "fine art."'73 (The museum's use of a whole range of terms in addition to "fine art" produces this mestizo museum practice, as discussed in Chapter 1.)

Regardless of one's cultural background, it would have been hard not to notice the strangely beautiful green of the walls of the Center Gallery for Risking the Abstract (2004). The color brought out the best in the many compositions of Gunther Gerzso. In the African Presence in México the walls were a deeply regal purple that felt at once ancient and contemporary. In the sister exhibition, Who Are We Now?, the walls were a light teal. When I worked at the museum, these colors were the genius of Angelina Villanueva, then the museum's Graphic Arts Director. She worked individually with curators, learning about the exhibition and the evolving checklist before finding the color that would make every work of art pop. But the tactic goes beyond making the art look best. These colors are not always, or even usually, the rich, dark colors that began to become fashionable in museums during the 1990s. Rather, they are often the bright chillantes that Tomás Ybarra Frausto describes as a hallmark of rasquachismo. ${ }^{74}$

Rasquachismo is a first-voice language, by and for a grassroots cultural cohort, not directed toward a powerful mainstream. A museum is not the same as an artist, however, and implements this technique in its own way. Though the NMMA has never really hewed firmly to this over-the-top aesthetic, some of its most recognizable curatorial techniques demonstrate its presence. Rasquachismo is an important example of Indigenous museology that affects the way in which Mexicans and others are welcomed into the museum differently. Davalos describes rasquachismo this way:

Rasquache sensibility rejects polish, order, and simplicity, because they control experience and package it for consumption. The rasquache strategy subverts hierarchies and legitimates the perspective of those on the margins by anchoring the ordinary, the everyday, and the routine. ${ }^{75}$

The brightness and variation of the colors the NMMA uses immediately signal to Mexican visitors that they can feel at home. This is their museum, not a white box designed to appeal to an elite sensibility. Yet it would be easy to imagine the loud colors as a simple trick if not for the intention that goes into their selection. Rather, they are an authentic, culturally appropriate tool. To those Mexicans who have never been in a museum before, the colors are welcoming. And to White visitors, well-versed in visiting museums, they also say, subtly: This is a new kind of place, and you are a welcome visitor. The colors, in other words, are an effective leveling tool that allows many different visitors to apprehend important messages early in their visits. 
Flipping the power of museums to turn them to work for local communities is one connection between non-Western museums abroad and culturally specific museums in the US. In the US, culturally specific curatorial work often takes place inside of Western museum settings. But Indigenous curation serves the same power-flipping function. Marginalized communities in the US tailor the museum's tools to send culturally appropriate messages. Lights, color, words, spatial organization, and many more elements can speak in any language when they are assembled in a culturally relevant way.

\section{The Steering Committee}

The NMMA will also be the site of the main example in this section. Working with a steering committee is a method by which museums can engage communities in a particular project and share authority. In this model, a museum invites spokespeople and decision makers from a stakeholding community to plan and execute a project with decision makers at the museum. There may be a fact-finding period of time during which staff members seek the right members for the committee. Staff members need to gain insight into how the community they wish to involve is organized, what its basic subgroups are, and who the leaders of those subgroups are. Who is being left out of these groups? Who is being left out of the decision making process within the community? These are difficult questions, and much may rest on the personal connections of individual staff members at the museum. If the staff members don't have helpful relationships, that is a challenge to the process. Simon addresses different ways to find and involve "outsider guides" in The Art of Relevance. ${ }^{76}$

The model of the steering committee is an entry-level way of sharing authority with communities. Simon suggests bringing a steering committee to the next level by ensuring that the collaboration does necessary work for the outsider advisors as well. Even in its most traditional incarnation, the steering committee or advisory group often fails for a number of reasons. The community members may have been brought in too late in the process. Or they don't feel welcomed as equals or experts and, as a result, don't participate in the process. Or, perhaps the museum chose the wrong representatives of the community, or simply inadvertently excluded members of the community. The process can fail because of simple logistical hurdles. For example, do all of the appropriate committee members share a language? If not, is there a translator? Sometimes this process fails simply because the museum (either at the executive or departmental level) doesn't listen to the committee members. Sharing authority does mean giving up at least some authority and sometimes that means completely giving up authority altogether, letting someone else take the wheel temporarily.

To borrow George Lipsitz's powerful turn of phrase, we can think of museums as having a possessive investment in authority. The many tangible benefits of being in charge are so great that it is extremely difficult to intentionally give that up. Of course, there is also nothing wrong with a museum's leaders and staff protecting its institutional interests. At the end of the day, they are responsible for the institution's well-being, continued operation, and reputation. Nevertheless, the benefits of sharing authority are many, and they begin with keeping the institution in good ethical stead. From there, benefits include important interpretive ones as well as, ultimately, economic ones. Furthermore, authority is not a zero-sum game. Many scholars, including Kreps, agree that sharing authority does not make museums or the expertise of specialists obsolete. On the contrary, sharing authority increases the need for the contributions of a museum and its staff. ${ }^{77}$ 
Bernadette Lynch's essay, "Collaboration, Contestation, and Creative Conflict: On the Efficacy of Museum/Community Partnerships," offers an important reminder of the hidden powers of the sharer in the partnership of shared authority. Even when it has the best intentions of sharing authority, there are all kinds of powers that the representatives of the museum might not notice or be aware that they have. The power to set the agenda in meetings and the power of the veto are chief among these. In a partnership with a marginalized community or where power relations seem unequal, it's worth looking at arrangements to see what uncommon steps could level the playing field in the conversation: could the location of the meeting change? Could someone from outside the museum set the agenda? Is there a safe space for partners that is veto-free? In the event of a veto, are there steps the museum can take to make collaborative changes or otherwise not make a top-down decision?

For the museum that is willing and able to negotiate the challenges, the steering committee can be a highly effective tool. It can build the credibility of the museum and increase its visitor base permanently. It can open the door to many new fruitful collaborations. And it can benefit the stakeholding community materially as well as culturally. (Of course, benefits of cultural capital and cultural rights also have real material effects.)

The story of sharing authority in The African Presence in México, a large, complex project that opened at the NMMA in 2006, will demonstrate how successful the steering committee can be as a tool for sharing authority generally and, specifically, how it can be a useful tool for curators. A steering committee of 17 people, nine staff members from the museum and eight representatives from arts organizations and foundations across the city, led the planning of The African Presence beginning in $2004 .^{78}$ The committee was formed for the purpose of sharing authority with the African-American community in Chicago. The outside members of the committee were Jacqueline Atkins, former Director of Museums in the Park, Amina Dickerson, then Director of Corporate Contributions for Kraft Foods, a major funder in Chicago, Joan Gray, President of Muntu Dance Theater of Chicago, Maria-Rosario Jackson, a researcher for the Urban Institute, Tracye Matthews, then Associate Director for the Center for the Study of Race, Politics, and Culture, Philip Thomas of the Chicago Community Trust, Kristina Valaitis, then Executive Director of the Illinois Humanities Council, and Sagrario Cruz-Carretero, Anthropologist for the Instituto de Antropología de la Universidad Veracruzana. The museum's president and other departmental directors chose these outside members based on extant relationships - Gray, for example, had been involved in the museum's first exploration of the African presence in the 1990s. The museum's leaders were also seeking thinkers who could speak to the experiences of Afro-Mexican people (Rosario-Jackson) and those who were deeply immersed in Black history and stories in Chicago (Matthews). With the exception of Valaitis and Cruz-Carretero, all of the external committee members were African-American or of African descent.

Prior to The African Presence, the museum's attendance was roughly 50 percent Latino, 35 percent non-Latino European American, 10 percent African-American, and 5 percent a mix of Asian, American Indian, and others. During the run of The African Presence, the attendance figures flipped so that the attendance was roughly 50 percent African-American, 30 percent Latino, 15 percent non-Latino European American, and 5 percent others. This shift stayed in place for over a year following the end of the exhibition.

The committee met frequently for the year preceding the opening of the exhibitions. Initially the group met every two months. As the opening date approached it met monthly and then every two weeks. Committee members coordinated the logistics of the many components of the projects. It did not have voting rights on label copy or didactic panels, 
but the committee members were a sounding board for the staff as to what issues needed to be addressed, especially in Who Are We Now? The museum approached the committee as needed to review specific works of art. External committee members were also important in helping the museum to craft a vocabulary that would feel welcoming and inclusive to African-American visitors. Changing the term "slaves" to "enslaved people" was just one example of this. The NMMA remained in charge of the project, though it routinely took recommendations from the committee.

It was the Steering Committee that first suggested expanding the project to include not one but three exhibitions. In order for African-American visitors to relate to The African Presence, the Steering Committee argued, there needed to be a component that was north of the border. ${ }^{79}$ The second exhibition, Who Are We Now? Roots, Resistance, and Recognition, covered the relationships between Mexicans and African-Americans in the US as well as between African-Americans and the country of Mexico. The third, Common Goals, Common Struggles, Common Ground, addressed the relationships between Mexicans and African-Americans in the city of Chicago. The Chicago Gallery Committee commissioned a muralist, Rahmaan "Statik" Barnes, to create a piece for the gallery. Barnes is an African-American artist who lived in Pilsen and worked out of the studio of a Mexican muralist across the street from the museum. Barnes was also teaching "Analyzing Stereotypes" at Yollocalli Arts Reach, the museum's afterschool program for teenagers and young adults. ${ }^{80}$ Barnes's mural was ultimately the finishing touch for the project. It took up nearly the entire gallery space with a painting of a DNA double helix (Figure 4.2).

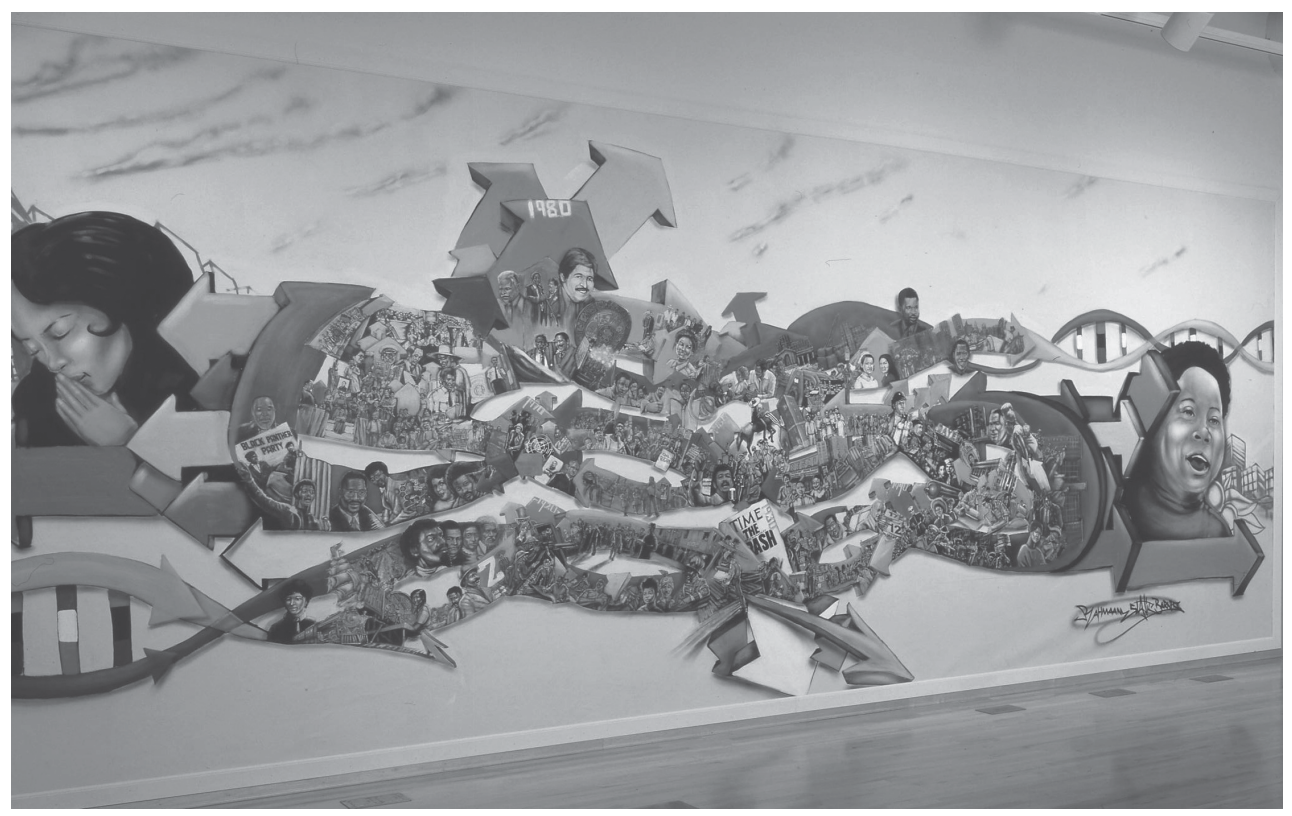

FIGURE 4.2 "Common Goals, Common Struggles, Common Ground (100 year time line on the African American and Mexican migration into Chicago)" by Rahmaan "Statik" Barnes, installed at the NMMA, 2006, spray paint and acrylic on canvas, $10^{\prime} \times 26^{\prime}$. Courtesy of Rahmaan "Statik" Barnes and the National Museum of Mexican Art. 
One strand was Mexican history in Chicago and one was African-American and the painting illustrated the divergences and connections between the two in a plainly legible yet complex and visually compelling statement.

Each of these three exhibitions brought the visitor closer to examining the lived social reality in Chicago. As they did so, they built the everyday relevance of The African Presence for the visiting publics. This is precisely the kind of guidance that makes the NMMA accessible and welcoming for visitors who don't typically go to museums. And it was the commitment to sharing authority that made this accessibility and welcome possible in The African Presence.

Another important element of the committee's work was building the civic dialogue that accompanied the three exhibitions in Chicago and on tour. Matthews was working with African-American artists in Bronzeville, a predominantly Black neighborhood in Chicago, who had studied or sought refuge in Mexico. She was making a film that PBS (Public Broadcasting Services - the American public broadcaster and distributor of television programs) planned to air in the tour cities as a conversation-starter before the exhibition arrived. The museum's then Vice President, Juana Guzmán, brought Rosario-Jackson onto the committee to facilitate the civic dialogue at tour venues. Rosario-Jackson's topics for the civic dialogue also guided the internal plans for the Education Department. Thomas and Rosario-Jackson were at the forefront of the group's discussions of how to handle challenging racist imagery from Mexico, such as el negrito and Memín Pinguín, discussed in Chapter 2.

There were limits to the ways in which the NMMA shared authority on The African Presence, however. The Steering Committee was designed to share authority with only one group. Other groups that had a stake in the outcome of the project were not included in the same way. For example, Afro-Mexicans were not decision makers in the project. In the Main Gallery, a large section toward the end of the exhibition was reserved for discussing the Afro-Mexican movement itself and introducing Afro-Mexican artists. Though this did not amount to sharing authority with the artists, it was an important opportunity for them to be visible and to be recognized in a way they still are not in Mexico. For Cesáreo Moreno, Chief Curator and Director ofVisual Arts of the NMMA and Co-Curator of The African Presence, the responses of the Afro-Mexican communities in Costa Chica and Veracruz were indicators of the success of the exhibition. Moreno cited the large turnout of Afro-Mexican artists whose work was featured in the exhibition at the opening in Veracruz. They had to travel more than twenty-five hours by bus to the event, a testament to the importance the artists saw in viewing their work in this nationally significant venue. ${ }^{81}$

During The African Presence, the NMMA never abdicated authority, even temporarily. This project was not about creating "friendly adversaries." It was about acknowledging and building genuine kinship. In any case, the NMMA was not known, in the early 2000s, for sharing authority. It had been known for nearly two decades as fiercely independent, a maverick institution, willing to dissent and unwilling to conform for love or money. So, the success of the Steering Committee and the process of sharing authority in this process was doubly significant. Though the NMMA is still very independent, the process of sharing authority through The African Presence may have paved the way for the larger collaboration that came next with Declaration of Immigration, the only exhibition at the museum to feature artists with no connection to Mexico. The next level of sharing authority involves offering the resources of the museum directly to a community of participants. 


\section{Sharing the "museum effect"}

From a curatorial standpoint, the most involved and intensive method of sharing authority with a community is to involve that community as curators in an exhibition. This involves a great deal of trust on both sides as well as a significant outlay of human resources on the part of the museum, beyond that of hosting a committee. It can create problems for the museum. If, for example, community members who are curating in the museum don't meet deadlines, the staff must still make it to the opening. But, real risks offer the possibility of real rewards. Communities that are successfully involved in a curatorial process where they actually have control can become permanently empowered within that, and even other museums, and can gain expertise in advocating for themselves in ways that spill over into their quotidian organizing efforts. For the museum and curator committed to working for social justice, sharing the museum effect is an outstanding choice.

In varying degrees, depending on the curatorial arrangement, the museum confers the museum effect onto the objects on view. This can function to further entrench power relations or curators can use it to upend things. In her essay, "The Museum as a Way of Seeing," Svetlana Alpers argues that the museum effect turns all objects into works of art. ${ }^{82}$ Marcel Duchamp's "readymades," and, in particular, Fountain of 1917 (Figure 4.3), illustrate succinctly how this process works.

When a museum invites community members to become curators, and even to bring objects into the museum, the museum is offering to lend the community the museum effect for specific instrumental and even political purposes. This can be quite powerful. We have all

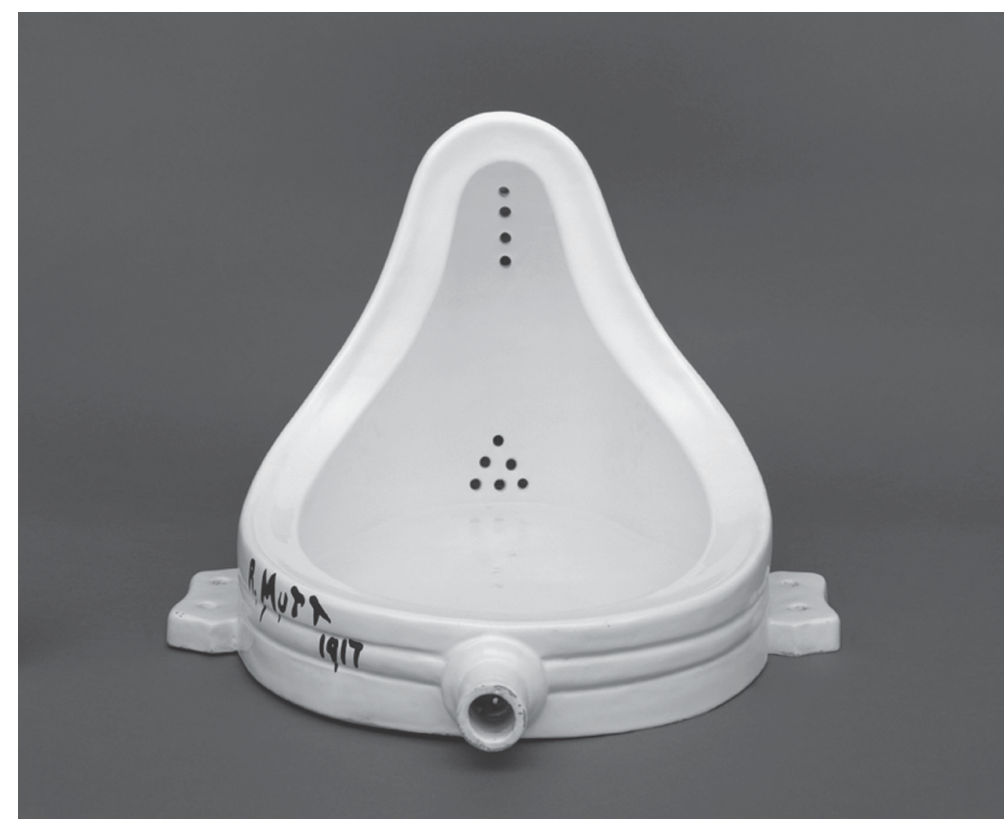

FIGURE 4.3 Fountain, 1917, replica 1964; Marcel Duchamp 1887-1968; Tate, purchased with assistance from the Friends of the Tate Gallery 1999; (C) Succession Marcel Duchamp/ADAGP, Paris/Artists Rights Society (ARS), New York 2017 and DACS, London 2017; photography: (C) Tate, London 2017. 
experienced the effect a museum setting can have on otherwise ordinary-seeming objects. On the one hand, no one other than an expert would ever recognize the difference between, say, Abraham Lincoln's top hat and another like it were it not for the vitrine, the lighting, the label, and the rest of the exhibition at the National Museum of American History that enables us to see the object, reverently, for what it is.

The interesting thing about the museum effect is that knowing it is happening does not prevent it from happening. We can know all about plays on authenticity, authorship, and the ways in which presentation in space affects our emotions. And yet we are affected in real, physical ways in the gallery. I know that the railcar at the Illinois Holocaust Museum may or may not have actually carried people to concentration camps, but my body still responds the way the museum's design demands. Spaces afford diverse ways of being and experiencing, and the way we construct them is another tool for curators working for social justice and sharing authority.

The story of an exhibition at the Hull-House Museum demonstrates how a museum can lend the museum effect to objects outside its typical purview and, by extension, lend the museum's authority to communities. Unfinished Business: Home Economics (2012-2013) was about invisible labor, "the work that makes all work possible," as the slogan of the Chicago Coalition of Household Workers proclaims. The Coalition, comprised of domestic workers employed in a variety of jobs, co-curated the exhibition with Heather Radke, then Exhibitions Coordinator at Hull-House. ${ }^{83}$ At the most basic level, Radke, Lead Curator of the exhibition, wanted visitors to understand invisible labor. "It's actually work. It's necessary. We all do it. It's not considered part of the GDP,' Radke said. In 2012, the law did not provide domestic workers with basic protections that many Americans take for granted, such as a minimum wage, protection from discrimination, time off to eat while working, paid sick days, the right to overtime pay, and a weekly day of rest. ${ }^{84}$

When Radke began collaborating with the Chicago Coalition of Household Workers on Home Economics, she and the Coalition created a mission for the exhibition that "blended" the missions of the museum and the Coalition. ${ }^{85}$ This, Radke and others hoped, would help ensure that the Coalition didn't just provide content for someone else's project. Rather, Radke described the relationship as one in which the Coalition and the museum co-created content based on shared goals that allowed the Coalition to then have a space to bring others and teach visitors about their work in a visual way that was not previously available to them. As a group, they made invisible work visible. Conversely, the members of the Coalition who participated in the project became ambassadors for the history Hull-House teaches. ${ }^{86}$ Together, the two groups - community partners and museum professionals - combined their expertise to create something new and valuable for both parties.

For Radke, and for me, the exhibit within Home Economics that involved domestic workers was the most successful part of the exhibition. Radke asked them to bring in objects that represented their work and write labels for them. To do so, the domestic workers collaborated with Young Chicago Authors. The group does creative writing and spoken word in Chicago. Crucially, this helped workers' labels to be authentic to their own voices while also telling succinct stories that would resonate with visitors. Among the many objects were an adult diaper, a sponge, foreclosure documents, and a pillbox. The details of the workers' experiences charge their stories with emotion. A caregiver named Lisa Thomas wrote this label for a yellow sponge:

I wake up at 5:30, I leave home at 6:00 take that long ride ... when I walk in the door Sutter says "Lisa is that you? I was so worried you would not come. I'm ready to eat." 
These were her first words every day. She weighed 450 pounds ... Her stomach was so big that it took me and her three sons to lift it. We put pillows under the arm. Pillows under the stomach. Rolled sheets between the legs to make it easier to wash. I would use a large sponge ... First it took about an hour to wash her hair. Her hair was long and grey and it could touch her feet. The pillows underneath her arms because they were so big one person could not lift them. As I began to wash her with the sponge she would tell me, "the hot water feels so good." After the arms we washed her stomach. We had three pillows under her stomach. I washed it in sections. She would thank me the whole time. It took two hours to bathe her and then change the sheets ... I cover her with a sheet because she doesn't have anything big enough to wear. After I fix her breakfast. She gets 4 waffles, 6 eggs, and 7 sausages ... While I'm cleaning she moans. She is still hungry. She cries for more food. The doctors have her on a strict diet. Before I leave I would give her two hot dogs. ${ }^{87}$

Radke wrote about her experience of working with domestic workers on an exhibition that purposely employed the "museum effect." Curators achieve this effect by successfully manipulating a complex set of visual tools in the museum. Radke's purpose was drawing visitors' attention to the ways in which we value stories. In particular, the objects the curators chose called visitors to empathize with their owners. "This empathetic response was one of the key goals of the exhibition." 88 Radke moved visitors from empathy to solidarity and eventually to action on a three-part path.Visitors had empathetic responses to objects. Their responses caused the exhibition to resonate with their own personal experiences with domestic labor. The stories from the Coalition directed visitors' empathy toward a relevant, contemporary situation with concerns that could be acted on immediately, a process I discussed in Chapter 3.

Sharing authority is an ethical museum practice, but it is also an important way of building resonance with groups of people who may not yet feel a connection to the museum. Most particularly, this includes those who see historical reasons to remain distant from the museum. Through shared authority, people come to be represented and heard inside the museum, and the resonance this creates can ramify throughout their communities. Because this process can take years, it can be helpful to think of the institutional commitment to sharing authority as a global one rather than one that applies only to a specific exhibition or program. Furthermore, it is unethical to use a community for a project and then move on. Many museums do this as they hunt for funding and seek to demonstrate that they are serving diverse communities. Long-term relationships will benefit the institution and stakeholding communities.

\section{The visitor panel}

The visitor panel is another way of sharing authority with an external community of stakeholders. The goal of visitor panels is to create exhibitions with the experience of the visitor in mind. Like focus groups, this method is highly structured and managed by external consultants who arrange the process, help find participants, and compile data for the museum. These panels differ from focus groups in that they gather specific suggestions for environments that promote informal learning. The museum identifies what the staff needs to learn and builds prototypes that will elicit that kind of information from the panelists. ${ }^{89}$ Each panel 
is recorded so that the staff may plan for the next session. This structure builds the investment of the staff members in the evaluation process. ${ }^{90}$ The panelists are experts on the experience of visiting rather than on content during these meetings.

Slover Linett Audience Research managed the visitor panels for Chicago History Museum (CHM). When CHM and Slover Linett organized the visitor panels for Out in Chicago, they assembled one queer panel and one panel of straight allies, each with eleven to twelve panelists. The panelists were a mix of members and those without memberships to CHM, as well as those who had not visited the museum. The involvement of the panelists was not extensive, though they did address important topics. They met with staff three times for ninety minutes each over five months during the latter portion of the planning process for the exhibition. The first meeting dealt with the big idea of 150 years of queer history in the city as well as the narrative of the exhibition. The panelists participated in cognitive mapping - plotting their thinking in visual ways - to discern whether the exhibition should be organized chronologically or thematically. In the next two meetings, the panelists' previous decisions guided the museum's plans. This created a positive chain of events, inspiring the trust of the panelists who then provided more and better feedback.

The most crucial decision resulting from the panels was to organize the exhibition thematically. One important reason for this was that if it were organized chronologically it would be a long time before people of color appeared in the exhibition. Brier had been the proponent of a chronological organization. She needed to hear that argument, motivated by equity, in order to understand why the thematic choice was right. ${ }^{91}$ It ultimately helped to distinguish Out in Chicago. Other queer histories in Chicago at that time were exclusively White, according to Brier. The thematic choice also allowed the curators to delve deeply into the themes they chose rather than skimming larger swaths of content in the interest of coverage.

The visitor panels for Out were meant to ensure that the queer communities in Chicago were fairly included in the planning and to gather opinions from other kinds of potential visitors. It was important to create an exhibition that would play well in mainstream Chicago. While gathering opinions in and of itself is not sharing authority, sharing authority with some visitors through the visitor panels helped the museum achieve its goal. For Brier, the visitor panels constituted the "true shared authority" for Out even though they differ substantially from more usual forms of outreach, which attempt to involve communities in exhibitions after the openings. ${ }^{92}$

If curators hope to share authority with a community, then some level of first-voice involvement by that community in the interpretation is important. But can a process produced by an outside company actually produce this? In a diverse community, how representative can a panel of twelve people be? How well do the organizers know the dynamics within the community when they curate the panel? Jennie Brier, one of the co-curators for Out, sometimes a critic of the processes at CHM, praised Slover Linett for finding a very representative group of panelists. She said that panelists frequently disagreed, but not so much that the conversation couldn't move forward. This proved that the panelists didn't just represent one part of the community.

The degree to which the visitor panels constituted the museum sharing authority with queer communities is an open question. Certainly, the museum shared authority with visitors, both queer and straight, as well as those who had not visited the museum. Brier said the curators' willingness to change labels when panelists asserted that they had misinterpreted certain objects proves that they truly were sharing authority. The presence of queer people on the panels constituted, for the museum, sharing authority with queer communities. But, within the panels, queer panelists carried an extra burden of expertise. This is a common problem for 
a person from an underrepresented group in the setting of a mixed group. Nevertheless, it's difficult to know: would more productive work emerge from segregated panels where queer panelists did not feel singled out as representatives of their communities? Or is it more useful to have mixed panels where difference is one fulcrum of the conversation itself?

As with the NMMA and the model of the Steering Committee, CHM retained the ability to veto suggestions by community members and make choices that people in queer communities and members of the visitor panels would have disliked. The degree to which the curators preserved their ability to represent sex in the exhibition was one of these areas. Neither the curators not the queer panelists were happy with minimizing sex. In the Radical History Review, the curators described how the goal of the long-running public programming series "Out at CHM" had been "to engage questions of how sex and sexuality mattered to urban public history." 93 This would have been a fitting topic for the exhibition as well, but they write about the difficulty for the institution. External pressures on the museum made it challenging for CHM to show any imagery of sexuality at all, let alone anything other than heteronormative images. The institution's concern about offending those who were uncomfortable with queer sexuality "became one of the bases for decisions to keep or remove materials from Out in Chicago." 94 Brier said she had been telling administrators "you can't take sex out of this exhibition," and they had not believed her. Then the panelists were "a room of 12 people [saying] "um, don't be talking about us like we're just like you." 95 As Austin et al. wrote, it was clear from the outset of the visitor panels that the queer group and the heterosexual group had opposite desires about the narrative. The heterosexual group wanted a narrative about how the two groups were similar, while the queer group wanted to tell a story of the difference and specificity of queer sexualities. ${ }^{96}$

Toward the end, the section of the exhibition called "In the Life" discussed cruising as well as more private sexual encounters such as the annual Capricorn Party for lesbians in Chicago. The administration chose to curtail the inclusion of sex in the exhibition along at least two lines - one was public/private. Whereas the museum's president was willing to advocate for the inclusion of photographs of men having intimate moments at the Belmont Rocks, a wellknown cruising location, the details of the "Wheel of Debauchery" game from the Capricorn Party were unacceptable. ${ }^{97}$ This object was made by lesbians for the Capricorn Party. The wheel is a grown-up version of that ubiquitous middle-school game, Spin the Bottle, with "funny, naughty, playful tasks (suck someone's nipple, moon someone, do a lap dance) written on it." 98 One reason why the curators were thrilled to find the Wheel was that it provided what they saw as a compliment to the many examples of gay male cruising and sexuality in the gallery. Austin described the Wheel as looking "ordinary from afar and ... very rich up close." Objects such as this, that reward close inspection, are valuable because they provide a pause in the visitor's movement through the exhibition during which resonance can begin to take shape. Ultimately, however, the object was not accepted for exhibition in any permutation.

The other boundary along which the museum curtailed the inclusion of sex in the exhibition related to the degree to which content was legible to a heterosexual audience. Often, content that wasn't legible to the straight audience was either excluded or coded for queer visitors. One example of this was the section called "Are You Family?" 99 The title signaled to the way in which the heterosexual family has been made normal and to the way in which heterosexuals see the traditional hetero family structure as being the model for queer families. Many queer families include two moms, two kids, and a dog. But many others are about shared sexual culture and have nothing to do with raising children. Austin et al. tell the story, for example, of Chuck Renslow, "the founder of leather culture in Chicago," who 
"expressed a sense of family based on shared sexual and social practices." ${ }^{100}$ Materials that allowed straight visitors to understand that they were missing part of the conversation were not included. The museum displayed media about sex that had been produced by and for queer audiences from pulp fiction to literature, theater, and visual art. For example, the label on one cartoon encouraged viewers to "Look closely and you'll see same-sex pairs enjoying the debauchery." ${ }^{101}$ In the places where the administration did allow the inclusion of sex in the exhibition, the museum made the valuable statement that "these sexual practices and themes need not be considered illicit or taboo," as Austin et al. write. ${ }^{102}$

Even though there are challenges that come with the process of visitor panels and ways for communities to feel marginalized within the process, the evidence is that CHM was successful in sharing authority. In 2012, the Committee on Lesbian, Gay, Bisexual, and Transgender History awarded CHM the Allan Bérubé Prize for outstanding "communitybased" queer history. ${ }^{103}$ In 2013, the museum won the Excellence in Exhibitions award from the National Association for Museum Exhibition with a special distinction in community engagement. ${ }^{104}$

\section{Conclusion}

Sharing authority is a crucial element of curatorial work for social justice that does two jobs at once. It works against the negative, cliquish ways in which humans tend to form exclusive groups. This ancient survival trait is often ill-suited to contemporary social life. Sharing authority also makes museums more hospitable to a broader range of people. But, there is a chicken-and-egg problem around the issues of sharing authority and inclusion. Marginalized communities may not visit a museum unless they can see the institution working against their marginalization. And it can be hard to share authority with a group the museum does not already "know" as visitors. Simon's The Art of Relevance lays out an elegant process for connecting museums with the people they don't yet know. ${ }^{105}$ One of the issues at the heart of Simon's book is our intersectionality as individuals. Each of us might find many different doors through which we are comfortable walking - to which, as she would put it, we hold the key. The techniques in this chapter are meant to support museum professionals as they explode categories that hinder empathy and solidarity and retain those that band groups and individuals together. This is about using intersectionality intentionally for practical purposes - exposing relationships visitors may not have known they had, helping to build new ones, and helping to dissolve group identities that do not support work for social justice. Sharing authority supports museums' work for social justice. It builds the equitable distribution of voice and representation in the museum. Table 4.1 can help you discover the frameworks and methods of sharing authority that are most appropriate to your museum or project.

Based on your museum's model of sharing authority, it is possible to select relevant techniques that could be a good fit with your institution. In Table 4.2, I've charted the techniques and tools discussed in this chapter alongside the different frameworks for sharing authority discussed above. This is certainly not the only way to determine fit. Many elements of institutional personality and function are idiosyncratic and must be considered as part of this process. Rather, my intention is to provide useful scaffolding for brainstorming within your institution.

The final tables (4.3 and 4.4) are blank worksheets, meant to help you brainstorm practices for your own institution. 
TABLE 4.1 Quick guide to types of spaces

\begin{tabular}{|c|c|c|c|c|c|c|}
\hline & Congregant space & Cosmopolitan canopy & Dialogic museum & First-voice & Contact zone & Decolonizing museum \\
\hline $\begin{array}{l}\text { What kind of } \\
\text { museum do } \\
\text { you have? } \\
\text { (Art, history, } \\
\text { universal, etc.) }\end{array}$ & $\begin{array}{l}\text { Any subject } \\
\text { matter, but } \\
\text { this museum } \\
\text { values social } \\
\text { experiences }\end{array}$ & $\begin{array}{l}\text { This museum is } \\
\text { interested in } \\
\text { fostering civic } \\
\text { engagement }\end{array}$ & $\begin{array}{l}\text { This model comes from } \\
\text { a setting of culturally } \\
\text { specific history, but } \\
\text { could be applied } \\
\text { elsewhere }\end{array}$ & $\begin{array}{l}\text { This is a culturally } \\
\text { specific museum } \\
\text { with any subject } \\
\text { matter }\end{array}$ & $\begin{array}{l}\text { This museum } \\
\text { could have any } \\
\text { subject matter, } \\
\text { but values lively } \\
\text { debate and } \\
\text { process }\end{array}$ & $\begin{array}{l}\text { This could be a } \\
\text { tribal or hybrid } \\
\text { tribal museum } \\
\text { or it could be } \\
\text { a history or art } \\
\text { museum }\end{array}$ \\
\hline $\begin{array}{l}\text { What is the } \\
\text { desired } \\
\text { relationship } \\
\text { between the } \\
\text { museum and } \\
\text { social justice? }\end{array}$ & $\begin{array}{l}\text { The relationship } \\
\text { is open-ended } \\
\text { - people make } \\
\text { what they will } \\
\text { of content in } \\
\text { these spaces }\end{array}$ & $\begin{array}{l}\text { Varies dramatically; } \\
\text { the relationships } \\
\text { of importance to } \\
\text { this institution are } \\
\text { to the city and the } \\
\text { civic }\end{array}$ & $\begin{array}{l}\text { Varies; the focus may } \\
\text { be on creating } \\
\text { conversation among } \\
\text { visitors, between } \\
\text { academics and } \\
\text { community members, } \\
\text { or on discussion } \\
\text { around a particular } \\
\text { topic }\end{array}$ & $\begin{array}{l}\text { Advocacy for } \\
\text { the first-voice } \\
\text { community! The } \\
\text { museum may also } \\
\text { be interested in } \\
\text { making society } \\
\text { more equitable } \\
\text { for others }\end{array}$ & $\begin{array}{l}\text { Active! This } \\
\text { is a space } \\
\text { where knotty } \\
\text { problems are } \\
\text { met head-on } \\
\text { by people who } \\
\text { want to work } \\
\text { on them. }\end{array}$ & $\begin{array}{l}\text { The focus is } \\
\text { on equitably } \\
\text { distributing } \\
\text { historical voice and } \\
\text { righting historical } \\
\text { wrongs; this includes } \\
\text { the truth-telling of } \\
\text { naming the wrongs }\end{array}$ \\
\hline $\begin{array}{l}\text { How much } \\
\text { conflict is } \\
\text { acceptable in } \\
\text { the space? }\end{array}$ & $\begin{array}{l}\text { Some conflict } \\
\text { is ok; the } \\
\text { emphasis is on } \\
\text { this being a } \\
\text { safe space }\end{array}$ & $\begin{array}{l}\text { Some conflict is } \\
\text { ok if it's framed } \\
\text { in friendly } \\
\text { conversation }\end{array}$ & $\begin{array}{l}\text { Lots! As long } \\
\text { as discussion } \\
\text { is respectful, } \\
\text { disagreement is totally } \\
\text { acceptable }\end{array}$ & $\begin{array}{l}\text { Little; this space } \\
\text { is more about } \\
\text { fostering in-group } \\
\text { connections }\end{array}$ & $\begin{array}{l}\text { Lots! Conflict is } \\
\text { the cornerstone } \\
\text { of democracy; } \\
\text { it must still } \\
\text { happen } \\
\text { respectfully }\end{array}$ & $\begin{array}{l}\text { Little; between truth- } \\
\text { telling and healing, } \\
\text { fostering conflict is } \\
\text { rarely on the table }\end{array}$ \\
\hline $\begin{array}{l}\text { What is the } \\
\text { museum's } \\
\text { goal for the } \\
\text { visitor? }\end{array}$ & $\begin{array}{l}\text { Co-existing in } \\
\text { the civic space, } \\
\text { gathering, } \\
\text { casual } \\
\text { encounters } \\
\text { with strangers } \\
\text { that build } \\
\text { social capital }\end{array}$ & $\begin{array}{l}\text { Co-existing in the } \\
\text { civic space, relaxing, } \\
\text { folk ethnographies, } \\
\text { unexpected } \\
\text { encounters }\end{array}$ & $\begin{array}{l}\text { The visitor must be } \\
\text { able to choose to } \\
\text { contribute her voice } \\
\text { to the content in the } \\
\text { museum }\end{array}$ & $\begin{array}{l}\text { Empowerment! } \\
\text { And joining in } \\
\text { advocacy for the } \\
\text { community }\end{array}$ & $\begin{array}{l}\text { Visitors speak } \\
\text { their minds } \\
\text { as friendly } \\
\text { adversaries }\end{array}$ & $\begin{array}{l}\text { Reeducation for } \\
\text { colonized and } \\
\text { colonizers alike is } \\
\text { based on new rules } \\
\text { of engagement with } \\
\text { Indigenous/former } \\
\text { colonized subject } \\
\text { voices at the fore }\end{array}$ \\
\hline
\end{tabular}




\begin{tabular}{|c|c|c|c|c|c|c|}
\hline & Congregant space & Cosmopolitan canopy & Dialogic museum & First-voice & Contact zone & Decolonizing museum \\
\hline $\begin{array}{l}\text { Does the } \\
\text { museum hope } \\
\text { the audience } \\
\text { will change? }\end{array}$ & $\begin{array}{l}\text { This museum } \\
\text { hopes the } \\
\text { audience will } \\
\text { accurately } \\
\text { reflect the } \\
\text { local area, and } \\
\text { that strangers } \\
\text { will feel less } \\
\text { alienated. } \\
\text { Perhaps } \\
\text { their public } \\
\text { practices will } \\
\text { change as a } \\
\text { result }\end{array}$ & $\begin{array}{l}\text { This museum hopes } \\
\text { the audience will } \\
\text { accurately reflect } \\
\text { the local area, and } \\
\text { that strangers will } \\
\text { feel less alienated. } \\
\text { Perhaps their public } \\
\text { practices will } \\
\text { change as a result }\end{array}$ & $\begin{array}{l}\text { Varies depending on the } \\
\text { approach to dialogue } \\
\text { the museum chooses }\end{array}$ & $\begin{array}{l}\text { Maybe - varies for } \\
\text { each program/ } \\
\text { exhibition. }\end{array}$ & $\begin{array}{l}\text { This museum } \\
\text { wants } \\
\text { underserved } \\
\text { and } \\
\text { marginalized } \\
\text { groups to have } \\
\text { a voice and } \\
\text { power in the } \\
\text { museum }\end{array}$ & $\begin{array}{l}\text { In some cases. For } \\
\text { mainstream } \\
\text { museums, } \\
\text { decolonizing } \\
\text { is a message to } \\
\text { marginalized groups } \\
\text { that it is now safe } \\
\text { to support this } \\
\text { organization }\end{array}$ \\
\hline
\end{tabular}


TABLE 4.2 Which tools fit which spaces?

\begin{tabular}{|c|c|c|c|c|c|}
\hline Congregant space & Cosmopolitan canopy & Dialogic museum & First-voice & Contact zone & Decolonizing museum \\
\hline Good fit & Good fit & $\begin{array}{l}\text { Excellent fit! } \\
\text { Creates dialogue } \\
\text { within the } \\
\text { exhibition }\end{array}$ & $\begin{array}{l}\text { This can be a rich way } \\
\text { for diverse points } \\
\text { of view on a shared } \\
\text { cultural referent to } \\
\text { emerge }\end{array}$ & $\begin{array}{l}\text { Diverse points of } \\
\text { view will emerge, } \\
\text { but more conflict } \\
\text { will arise with } \\
\text { crowd-sourced } \\
\text { labeling }\end{array}$ & Excellent fit \\
\hline $\begin{array}{l}\text { This sets a low bar for } \\
\text { participation, and } \\
\text { is therefore a good } \\
\text { entry point into } \\
\text { blending voices }\end{array}$ & $\begin{array}{l}\text { This sets a low bar for } \\
\text { participation, and is } \\
\text { therefore a good entry } \\
\text { point into blending } \\
\text { voices }\end{array}$ & $\begin{array}{l}\text { Excellent fit! Creates } \\
\text { dialogue within the } \\
\text { exhibition }\end{array}$ & $\begin{array}{l}\text { This can be a rich way } \\
\text { for diverse points } \\
\text { of view on a shared } \\
\text { cultural referent to } \\
\text { emerge. It's also a } \\
\text { nice way to share a } \\
\text { cultural tradition as } \\
\text { a community (ex. } \\
\text { community ofrenda for } \\
\text { Day of the Dead at the } \\
\text { NMMA) }\end{array}$ & $\begin{array}{l}\text { This will be a rich } \\
\text { opportunity for } \\
\text { conflict to arise and } \\
\text { democratic debate to } \\
\text { take shape }\end{array}$ & $\begin{array}{l}\text { Good fit for building new } \\
\text { voices into the museum } \\
\text { and demonstrating to } \\
\text { visitors that the museum is } \\
\text { changing/has changed }\end{array}$ \\
\hline $\begin{array}{l}\text { Know your audience's } \\
\text { preferences for } \\
\text { quantity of text }\end{array}$ & $\begin{array}{l}\text { Know your audience's } \\
\text { preferences for quantity } \\
\text { of text }\end{array}$ & $\begin{array}{l}\text { Good fit! Multiple } \\
\text { points of view in } \\
\text { labels can create a } \\
\text { dialogic narrative }\end{array}$ & $\begin{array}{l}\text { Know your audience's } \\
\text { preferences for quantity } \\
\text { of text. } \\
\text { Specificity of vocabulary } \\
\text { will also be important. } \\
\text { Where is the pitch } \\
\text { that speaks to the } \\
\text { community? What } \\
\text { words are coded? }\end{array}$ & $\begin{array}{l}\text { Know your audience's } \\
\text { preferences for } \\
\text { quantity of tex; this } \\
\text { tool can be paired } \\
\text { with questioning } \\
\text { to spur debate or } \\
\text { conversation }\end{array}$ & $\begin{array}{l}\text { Know your audience's } \\
\text { preferences for quantity } \\
\text { of text; in this setting, it } \\
\text { also allows for the essential } \\
\text { naming of perpetrators and } \\
\text { details of colonialism that } \\
\text { short labels might hamper }\end{array}$ \\
\hline
\end{tabular}




\begin{tabular}{|c|c|c|c|c|c|}
\hline Congregant space & Cosmopolitan canopy & Dialogic museum & First-voice & Contact zone & Decolonizing museum \\
\hline $\begin{array}{l}\text { This will depend } \\
\text { on what kind of } \\
\text { museum the space } \\
\text { is, but it could work } \\
\text { well here }\end{array}$ & $\begin{array}{l}\text { This will depend on what } \\
\text { kind of museum the } \\
\text { space is, but it could } \\
\text { work well here }\end{array}$ & $\begin{array}{l}\text { Excellent fit! This } \\
\text { tool will invite } \\
\text { visitors who might } \\
\text { otherwise feel } \\
\text { marginalized into } \\
\text { the dialogue in the } \\
\text { gallery }\end{array}$ & $\begin{array}{l}\text { Crucially important. What } \\
\text { colors, presentation } \\
\text { techniques, storage/ } \\
\text { collections care, and } \\
\text { other environmental } \\
\text { details and ways } \\
\text { of communicating } \\
\text { are native to your } \\
\text { community? }\end{array}$ & $\begin{array}{l}\text { Excellent fit } \\
\text { - "contact" } \\
\text { opportunities } \\
\text { are all over the } \\
\text { museum (collections } \\
\text { management, } \\
\text { curatorial, etc.) }\end{array}$ & $\begin{array}{l}\text { Excellent fit - the best } \\
\text { way to counter colonial } \\
\text { museologies might be } \\
\text { with appropriate use of } \\
\text { Indigenous ones; consider } \\
\text { first-voice curators }\end{array}$ \\
\hline $\begin{array}{l}\text { Could be a good fit } \\
\text { - great structure for } \\
\text { fostering mutual } \\
\text { respect }\end{array}$ & $\begin{array}{l}\text { Could be a good fit - great } \\
\text { structure for fostering } \\
\text { mutual respect }\end{array}$ & $\begin{array}{l}\text { Good fit - } \\
\text { stakeholders co- } \\
\text { create; doesn't } \\
\text { necessarily produce } \\
\text { a dialogic exhibition }\end{array}$ & Good fit & $\begin{array}{l}\text { Good fit, but be } \\
\text { cautious to ensure } \\
\text { that there is a level } \\
\text { playing field for } \\
\text { committee members; } \\
\text { balance power }\end{array}$ & $\begin{array}{l}\text { Good fit for a multivocal } \\
\text { presentation }\end{array}$ \\
\hline $\begin{array}{l}\text { This will depend } \\
\text { on what kind of } \\
\text { museum the space } \\
\text { is, but it could work } \\
\text { well here }\end{array}$ & $\begin{array}{l}\text { This will depend on what } \\
\text { kind of museum the } \\
\text { space is, but it could } \\
\text { work well here }\end{array}$ & $\begin{array}{l}\text { Excellent fit! Shining } \\
\text { the museum's light } \\
\text { on non-traditional } \\
\text { objects invites } \\
\text { conversation }\end{array}$ & $\begin{array}{l}\text { Good fit! This will work } \\
\text { particularly well for } \\
\text { changing perceptions } \\
\text { around folk art, } \\
\text { popular art, craft, and } \\
\text { other underprivileged } \\
\text { cultural forms }\end{array}$ & $\begin{array}{l}\text { Good fit! } \\
\text { Opportunities to use } \\
\text { this tool will emerge } \\
\text { in conversation }\end{array}$ & $\begin{array}{l}\text { Good fit! This can work } \\
\text { particularly well for } \\
\text { changing perceptions } \\
\text { around folk art, popular } \\
\text { art, craft, and other } \\
\text { underprivileged cultural } \\
\text { forms }\end{array}$ \\
\hline Could be useful & Could be useful & $\begin{array}{l}\text { Doesn't go far enough } \\
\text { to constitute } \\
\text { dialogue }\end{array}$ & $\begin{array}{l}\text { Probably not applicable } \\
\text { unless the stakeholders } \\
\text { are not already } \\
\text { represented by the } \\
\text { museum's voice }\end{array}$ & $\begin{array}{l}\text { Probably too limited an } \\
\text { approach }\end{array}$ & $\begin{array}{l}\text { Could be a good fit, but } \\
\text { possibly not enough of a } \\
\text { partnership }\end{array}$ \\
\hline
\end{tabular}


TABLE 4.2 (Cont.)

\begin{tabular}{|c|c|c|c|c|c|}
\hline Congregant space & Cosmopolitan canopy & Dialogic museum & First-voice & Contact zone & Decolonizing museum \\
\hline Good fit & Good fit & $\begin{array}{l}\text { Good fit; dialogue } \\
\text { is present in the } \\
\text { process, but not } \\
\text { necessarily in the } \\
\text { product }\end{array}$ & $\begin{array}{l}\text { May not be applicable, } \\
\text { but could be a good } \\
\text { way to involve specific } \\
\text { artists, historians, } \\
\text { or leaders of the } \\
\text { community }\end{array}$ & $\begin{array}{l}\text { May not be a good } \\
\text { fit because the co- } \\
\text { curator may lack the } \\
\text { autonomy that this } \\
\text { model demands }\end{array}$ & $\begin{array}{l}\text { May not be a good fit } \\
\text { because the co-curator } \\
\text { may lack the autonomy } \\
\text { that this model demands } \\
\text { for the "community" }\end{array}$ \\
\hline $\begin{array}{l}\text { Could work well in a } \\
\text { round-robin format } \\
\text { where different } \\
\text { groups/interests } \\
\text { are represented } \\
\text { throughout a single } \\
\text { exhibition or over a } \\
\text { schedule of several } \\
\text { exhibitions }\end{array}$ & $\begin{array}{l}\text { Could work well in a } \\
\text { round-robin format } \\
\text { where different groups/ } \\
\text { interests are represented } \\
\text { throughout a single } \\
\text { exhibition or over a } \\
\text { schedule of several } \\
\text { exhibitions }\end{array}$ & $\begin{array}{l}\text { Good fit; dialogue } \\
\text { is present in the } \\
\text { process, but not } \\
\text { necessarily in the } \\
\text { product }\end{array}$ & $\begin{array}{l}\text { Could be a good way to } \\
\text { involve specific artists, } \\
\text { historians, or leaders } \\
\text { of the source/local } \\
\text { community }\end{array}$ & $\begin{array}{l}\text { Good fit - the } \\
\text { protected autonomy } \\
\text { of the guest-curated } \\
\text { elements allows for } \\
\text { disagreement }\end{array}$ & $\begin{array}{l}\text { Good fit - the protected } \\
\text { autonomy of the guest- } \\
\text { curated elements ensures } \\
\text { the integrity of previously } \\
\text { marginalized voices }\end{array}$ \\
\hline Could be a good fit & Could be a good fit & $\begin{array}{l}\text { Good fit; dialogue } \\
\text { is present in the } \\
\text { process, but not } \\
\text { necessarily in the } \\
\text { product }\end{array}$ & $\begin{array}{l}\text { Could be a fit, especially } \\
\text { if the stakeholders are } \\
\text { not already represented } \\
\text { by the museum's voice }\end{array}$ & $\begin{array}{l}\text { Good fit - the } \\
\text { curatorial autonomy } \\
\text { of the outsider helps } \\
\text { balance the museum's } \\
\text { power }\end{array}$ & $\begin{array}{l}\text { Good fit - the curatorial } \\
\text { autonomy of the outsider } \\
\text { helps balance the museum's } \\
\text { power }\end{array}$ \\
\hline Good fit & Good fit & $\begin{array}{l}\text { Good fit - creates } \\
\text { a platform for } \\
\text { exploring memory } \\
\text { and meaning; doesn't } \\
\text { necessarily produce a } \\
\text { dialogic exhibition }\end{array}$ & $\begin{array}{l}\text { Could be useful if the } \\
\text { museum was interested } \\
\text { in diversifying the } \\
\text { audience }\end{array}$ & $\begin{array}{l}\text { Probably not a rich } \\
\text { enough environment } \\
\text { for disagreement, but } \\
\text { possibly a fit }\end{array}$ & $\begin{array}{l}\text { Could be useful for } \\
\text { seeking input from } \\
\text { underrepresented groups }\end{array}$ \\
\hline
\end{tabular}


TABLE 4.3 Brainstorming on models of spaces

$\begin{array}{lllll}\text { Which type of } & \text { Which type of } & \text { Which type of } & \text { Which } & \text { Which type of } \\ \text { space models our } & \text { space facilitates } & \text { space supports } & \text { type of } & \text { space supports } \\ \text { goals for inclusion } & \text { serving our } & \text { our relationship space relates the kind of } \\ \text { and sharing } & \text { goals for } & \text { to issues of } & \text { well to } & \text { environment we } \\ \text { authority with } & \text { visitors? } & \text { concern for our our subject want to foster? } \\ \text { communities? } & & \text { stakeholders? } & \begin{array}{l}\text { matter and } \\ \text { content? }\end{array} & \\ & & & \end{array}$

Congregant space

The museum values social experience.

Visitors make what they will of content.

Emphasis is on this being a safe space.

The goal is casual encounters with strangers in the civic space

Cosmopolitan canopy

This museum is interested in fostering civic engagement. It values its relationship to the city and the civic. The goal is co-existing in the civic space, having unexpected encounters.

\footnotetext{
Dialogic museum

Dialogue is a feature of all institutional practices. This museum wants audiences and stakeholders to co-create meaning, evaluation mechanisms, and more. All visitors may choose to collaborate in documenting/discussing memories
} 
TABLE 4.3 (Cont.)

$\begin{array}{lllll}\text { Which type of } & \text { Which type of } & \text { Which type of } & \text { Which } & \text { Which type of } \\ \text { space models our } & \text { space facilitates } & \text { space supports } & \text { type of } & \text { space supports } \\ \text { goals for inclusion } & \text { serving our } & \text { our relationship space relates the kind of } \\ \text { and sharing } & \text { goals for } & \text { to issues of } & \text { well to } & \text { environment we } \\ \text { authority with } & \text { visitors? } & \text { concern for our our subject } & \text { want to foster? } \\ \text { communities? } & & \text { stakeholders? } & \begin{array}{l}\text { matter and } \\ \text { content? }\end{array}\end{array}$

\section{First-voice}

This is a culturally specific museum. Advocacy for the first-voice community is the primary connection to social justice. The space fosters in-group connections and empowers visitors to join the advocacy efforts

\section{Contact zone}

This museum values lively debate. The museum dives into trying to solve knotty contemporary problems. Respectful conflict is the cornerstone of democracy and is valuable in this environment

Decolonizing museum

This museum focuses on equitably distributing historical voice and redressing the wrongs of the museum/history establishment. Truthtelling and healing are vital mechanisms for this. The museum works to reeducate colonized and colonizers alike based on narratives that keep the voices of the colonized at the fore 
TABLE 4.4 Brainstorming on use of tools

$\begin{array}{ll}\text { Which tools } & \text { Which tools Which tools support Which tools Which tools } \\ \text { serve our goals serve our goals our relationship to relate well to support the kind } \\ \text { for inclusion and for visitors? issues of concern for our subject of environment we } \\ \text { sharing authority } \\ \text { with communities? }\end{array}$

Alternative
labeling
The museum uses
the label to
incorporate more
and different
voices into the
exhibition

\section{Crowd-sourced} labeling

Visitors propose content for labels. Staff makes decisions as to how to use it

Thick description

Whether in labels or elsewhere, thick description allows multiple points of view and entry into a topic. This can make content more inclusive and welcoming

Indigenous
museology,
empowering
vocabularies
Indigenous ways of
working in the
museum, in texts
and beyond, are
inclusive, welcoming,
protective, and
empowering to
stakeholding
communities and
underrepresented
groups


TABLE 4.4 (Cont.)

Which tools $\quad$ Which tools Which tools support Which tools Which tools
serve our goals serve our goals our relationship to relate well to support the kind
for inclusion and for visitors? issues of concern for our subject of environment we
sharing authority
with communities?

Steering committees
Staff and external
advisors determine
goals and potentially
methods and content
together

Sharing the

museum effect

Exhibiting an object in a museum can change the way visitors see it, and the people who produced or used it. First-voice labeling enhances this tool

Curated

community voices

In-house curators carefully select community members whose voices will be heard in limited ways
community
co-curator
Community member(s)
works with staff to
co-determine goals,
content, and form of
the exhibition

Guest-curated elements

Community member(s) is invited to have autonomy over one or more elements within an exhibition otherwise curated by staff 
TABLE 4.4 (Cont.)

\begin{tabular}{|c|c|c|c|c|}
\hline $\begin{array}{l}\text { Which tools } \\
\text { serve our goals } \\
\text { for inclusion and } \\
\text { sharing authority } \\
\text { with communities? }\end{array}$ & $\begin{array}{l}\text { Which tools } \\
\text { serve our goals } \\
\text { for visitors? }\end{array}$ & $\begin{array}{l}\text { Which tools support } \\
\text { our relationship to } \\
\text { issues of concern for } \\
\text { our stakeholders? }\end{array}$ & $\begin{array}{l}\text { Which tools } \\
\text { relate well to } \\
\text { our subject } \\
\text { matter and } \\
\text { content? }\end{array}$ & $\begin{array}{l}\text { Which tools } \\
\text { support the kind } \\
\text { of environment we } \\
\text { want to foster? }\end{array}$ \\
\hline
\end{tabular}

Community curator
The museum invites a
member of the source
community to act as
curator

Visitor panel

The museum seeks structured input in a focus-group like setting

\section{Notes}

1 Nina Simon and Jon Moscone, The Art of Relevance (Santa Cruz, CA: Museum 2.0, 2016).

2 Though ubiquitous now, "sharing authority" developed after Michael Frisch wrote A Shared Authority (1990). Frisch used the construction "shared" instead of "sharing" for philosophical reasons of authorship that he discusses at length in his book as well as in "From A Shared Authority to the Digital Kitchen and Back" in Bill Adair, Benjamin Filene, and Laura Koloski, eds, Letting Go?: Sharing Historical Authority in a User-Generated World, 1st edn (Washington, DC: Pew Center for Arts \& Heritage, 2010), 127. While I agree with Frisch that authority should be shared, and should be inherent in the process of a dialogue or interview, for example, I do not believe that that balance is inherent. Instead, the cultural sector and the creation of public memory is rife with power imbalances. Institutions such as museums often have more power to shape agendas, narratives, and relationships, direct funds, etc. When this is the case, it is up to those with power to engage in active sharing. So, I use that term instead of "shared authority."

3 Elaine Heumann Gurian, Civilizing the Museum: The Collected Writings of Elaine Heumann Gurian, 1st edn (London; New York: Routledge, 2006), 90.

4 Gurian, 88-89.

5 Ibid.

6 Ibid., 90.

7 Ibid., 112.

8 Ibid., 112, 113.

9 Ibid., 109.

10 Elijah Anderson, "The Cosmopolitan Canopy," The ANNALS of the American Academy of Political and Social Science 595, no. 1 (September 1, 2004): 15,

11 Anderson, 14.

12 Ibid., 21.

13 Ibid., 25.

14 Ibid., 17

15 Ibid., 17.

16 Ibid., 21 
17 Betty Farrell et al., "Demographic Transformation and the Future of Museums," Center for the Future of Museums (Washington, DC:American Association of Museums, 2010), 20.

18 Karen Mary Davalos, Exhibiting Mestizaje: Mexican (American) Museums in the Diaspora, 1st edn (Albuquerque, NM: University of New Mexico Press, 2001), 115.

19 I use the term "stakeholding communities" to create as neutral as possible a designation for communities that are represented in museums via their stories or objects, or should be so represented. While this follows Chandra Frank's recommendation in the section of this chapter entitled "Decolonizing Museums," it also addresses James Clifford's concern that museum structures and museum professionals create the sense that the museum is the "center" to which objects and stories flow from the "periphery" of communities. James Clifford, Routes: Travel and Translation in the Late Twentieth Century (Cambridge, MA: Harvard University Press, 1997), 193-194.

20 This sounds like a less formal and perhaps more sustained version of the visitor panels discussed in the section of this chapter entitled "The visitor panel."

21 John Kuo Wei Tchen in Ivan Karp, Christine Mullen Kreamer, and Steven Levine, eds, Museums and Communities: The Politics of Public Culture (Washington, DC: Smithsonian Books, 1992), 298.

22 Tchen in Karp, Kreamer, and Levine, 308.

23 Ibid., 310.

24 Ševčenko in Bill Adair, Benjamin Filene, and Laura Koloski, eds, Letting Go?, 84-85.

25 John Kuo Wei Tchen in Bill Adair, Benjamin Filene, and Laura Koloski, eds, 89.

26 The history of this term is difficult to trace. Scholars and curators such as Rosa Cabrera and Cesáreo Moreno generally agree that the term originated around commemorations of the quincentennial of the encounter between Europeans and people of the Americas. And there is an association between the term and terms such as "First Nations" and "First Peoples." However, the earliest specific attribution of "first voice" that I have seen comes from Amareswar Galla, "The First Voice in Heritage Conservation," International Journal of Intangible Heritage 3 (2008): 23. In it, Galla notes the same murkiness around the term's origin, but cites several early uses. The earliest is from the workshops in Victoria British Columbia, Canada, during the International Year of Worlds Indigenous Peoples in 1994. More research is needed on the subject.

27 Fath Davis Ruffins discusses the shift from "ethnic" to "culturally specific" in "Culture Wars Won and Lost: Ethnic Museums on the Mall, Part I: The National Holocaust Museum and the National Museum of the American Indian,' Radical History Review 68 (1997): 79-100.

28 Diane Grams, Producing Local Color: Art Networks in Ethnic Chicago (Chicago; London: University of Chicago Press, 2010), 54.

29 Christina Kreps, Liberating Culture: Cross-Cultural Perspectives on Museums, Curation, and Heritage Preservation, 1st edn (London; New York: Routledge, 2003), 13.

30 Mary Louise Pratt, Imperial Eyes: Travel Writing and Transculturation, 2nd edn (London; New York: Routledge, 2007), 6.

31 Pratt, 7.

32 Clifford, Routes, 192-193.

33 Lynch in Janet C. Marstine, ed., The Routledge Companion to Museum Ethics: Redefining Ethics for the Twenty-First Century Museum, 1st edn (London; New York: Routledge, 2011), 154-155.

34 Lynch in Marstine, 160.

35 The terms "decolonize" and "post-colonial" get at similar ideas, but one is more active than the other. While "post-colonial" assumes that the museum is in a state of being that is, itself, postcolonial, "decolonizing" is a process that must be undertaken by workers in the museum.

36 Amy Lonetree, Decolonizing Museums: Representing Native America in National and Tribal Museums, 1st edn (Chapel Hill, NC:The University of North Carolina Press, 2012), 5.

37 “Towards A Decolonial Curatorial Practice," Chandra Frank, 2-3, www.chandrafrank.com/towardsa-decolonial-curatorial-practice/.

38 “Towards A Decolonial Curatorial Practice," 5-7.

39 “Oppression: A Museum Primer," The Incluseum (blog), February 4, 2015, http://incluseum.com/ 2015/02/04/oppression-a-museum-primer/. 
40 “Rijksmuseum Press Kit - Press," Rijksmuseum, 8, www.rijksmuseum.nl/en/presskit.

41 "Rijks Museum Jaarverslag 2016," Annual Report (Amsterdam, the Netherlands: Rijksmuseum, 2016), 26.

42 Nina Siegal, "Rijksmuseum Removing Racially Charged Terms From Artworks' Titles and Descriptions,"ArtsBeat,1449760605, http://artsbeat.blogs.nytimes.com/2015/12/10/rijksmuseumremoving-racially-charged-terms-from-artworks-titles-and-descriptions/; Carey Dunne, "Why the Rijksmuseum is Removing Bigoted Terms from Its Artworks'Titles," Hyperallergic, December 22, 2015, http://hyperallergic.com/263180/why-the-rijksmuseum-is-removing-bigoted-terms-fromits-artworks-titles/.

43 Eveline Sint Nicholaas and Stephanie Archangel, interview with Eveline Sint Nicolaas and Stephanie Archangel, curators of history at the Rijksmuseum, Personal, January 23, 2017.

44 Sint Nicholaas and Archangel.

45 Eveline Sint Nicolaas, "Bathseba oud en nieuw" (Rijksmuseum, January 23, 2017).

46 One successful example of this would be Mining the Museum by Fred Wilson at the Maryland Historical Society.

47 Bernadette Lynch in Marstine, The Routledge Companion to Museum Ethics, 2011, 154-155.

48 DinnerTableDebate, Dan Savage vs. Brian Brown: The Dinner Table Debate, www.youtube.com/ watch? ${ }_{\mathrm{v}}=\mathrm{oG} 804 \mathrm{t} 0 \mathrm{WG}-\mathrm{c}$.

49 Bill Adair, Benjamin Filene, and Laura Koloski, eds, Letting Go?: Sharing Historical Authority in a UserGenerated World, 1st edn (Washington, DC: Pew Center for Arts \& Heritage, 2010), 13.

50 Lee in Janet C. Marstine, ed., The Routledge Companion to Museum Ethics: Redefining Ethics for the Twenty-First Century Museum, 1st edn (London; New York: Routledge, 2011), 180.

51 Lisa Lee explains the process in detail in Marstine, The Routledge Companion to Museum Ethics, 2011, 179-181.

52 The museum used Michael Warner's term from Michael Warner, Publics and Counterpublics (New York: Zone Books, 2002).

53 Lee in Marstine, The Routledge Companion to Museum Ethics, 2011, 181.

54 Lee in Janet C. Marstine, The Routledge Companion to Museum Ethics: Redefining Ethics for the TwentyFirst Century Museum, 1st edn (Routledge, 2011), 181.

55 Karen Mary Davalos, Exhibiting Mestizaje: Mexican (American) Museums in the Diaspora, 1st edn (Albuquerque, NM: University of New Mexico Press, 2001), 124.

56 In Nuestras Historias, Euro-Americans are still not given a voice. But that group has a new point of entry into the topics of the museum.

57 Ibid., 183, 185-187.

58 Davalos, 184.

59 Clifford Geertz, The Interpretation of Cultures (New York: Basic Books, 1973), 5-10.

60 Lisa Lee, “Opening of Excavating Others" (exhibition opening, November 30, 2011).

61 Geertz drew on the lecture "What is le penseur Thinking" by the British philosopher Gilbert Ryle in developing the term. Since Geertz made it popular in the 1970s, it has gained popularity among the social sciences and, in particular, in literary criticism.

62 Terri Kapsalis, “Jane Addams' Traveling Medicine Kit," www.uic.edu/jaddams/hull/_museum/_ exhibits/Alternative\%20Labeling/alternativelabeling.html.

63 Kapsalis.

64 Her concept comes from the field of international development, its participatory approaches to development, and the concept of appropriate technology. Christina F. Kreps, "Appropriate Museology in Theory and Practice," Museum Management and Curatorship 23, no. 1 (2008): 23.

65 Christina Kreps, Liberating Culture: Cross-Cultural Perspectives on Museums, Curation, and Heritage Preservation, 1st edn (London; New York: Routledge, 2003), 10.

66 Christina Kreps, "Appropriate Museology in Theory and Practice," Museum Management and Curatorship 23, no. 1 (2008): 23-41; Kreps, Liberating Culture.

67 Davalos, Exhibiting Mestizaje, 174.

68 Davalos, 175. 
69 Ofrendas are often called "altars" in English, but literally, and more accurately, they are "offerings." They are special installations in homes, businesses, and other locations that honor those who have died. Ofrendas feature many common elements across different areas of Mexico and the US: sugar skulls, decorative papel picado (cut paper flags), flame-colored marigolds that light the way home for the deceased, candles, photos, and objects that remind the family of its loved one(s), and the favorite foods and drinks of the departed. The dead are famously debaucherous, so ofrendas always include sweets, alcohol, and other indulgences.

70 Davalos, Exhibiting Mestizaje, 145.

71 Davalos, 112.

72 Ibid., 110-112.

73 "Chicano" designates a specific political orientation. The Chicano Movement positioned itself against the assimilationist politics of the Mexican American fight for civil rights. (Maria Raquel Casas in Patricia Sullivan and Waldo E. Martin Jr., Civil Rights in the United States, 1st edn (New York: Macmillan Reference USA, 2000), 125.) Though the movement began by reclaiming the American Southwest as Aztlán, Chicano identity exists all over the US. Tortolero has stated that the NMMA is not a Chicano museum, and it has never used the term Chicano to identify itself, but it does share some practices with the Chicano movement and Chicano artists, as I discuss.

74 Tomás Ybarra-Frausto, "Chicano Movement/Chicano Art" in Steven D. Lavine and Ivan Karp, Exhibiting Cultures: The Poetics and Politics of Museum Display (Washington, DC: Smithsonian Institution Press, 1991), 134.

75 Davalos, Exhibiting Mestizaje, 131-132.

76 Nina Simon and Jon Moscone, The Art of Relevance (Santa Cruz, CA: Museum 2.0, 2016), 76-77.

77 Kreps, Liberating Culture, 155. Bill Adair, Benjamin Filene, and Laura Koloski, eds, Letting Go?

78 Maria-Rosario Jackson shares similar recollections to mine about the steering committee in Andrew Grant-Thomas and Gary Orfield, Twenty-First Century Color Lines: Multiracial Change in Contemporary America (Philadelphia, PA:Temple University Press, 2008), 227-228.

79 Elena Gonzales, “The African Presence in México Steering Committee Meeting Minutes” (meeting minutes, February 23, 2005).

80 Elena Gonzales, “The African Presence in México Steering Committee Meeting Minutes” (meeting minutes, December 13, 2005).

81 Cesáreo Moreno, interview with the Chief Curator and Director of Visual Arts at the National Museum of Mexican Art, personal, August 1, 2012.

82 Svetlana Alpers in Lavine and Karp, Exhibiting Cultures.

83 Heather Radke and Chicago Coalition of Household Workers, "The Work That Makes All Work Possible. Organizing for Basic Labor Rights for Household Workers,” AREA Chicago, http:// areachicago.org/the-work-that-makes-all-work-possible-organizing-for-basic-labor-rights-forhousehold-workers/.

84 Radke and Chicago Coalition of Household Workers.

85 Ibid.

86 Heather Radke,"Unfinished Business," Museum magazine, www.aam-us.org/resources/publications/ museum-magazine/unfinished-business.

87 Thomas, Lisa, "Label for a Yellow Sponge in Unfinished Business: Home Economics at the Jane Addams Hull-House Museum," 2012.

88 Radke, "Unfinished Business."

89 Jill Austin, "Making and Remaking Visitor Panels" (conference panel, July 26, 2011).

90 Daryl Fischer from Musynergy in Austin.

91 Jennifer Brier, interview with Co-Curator, Out in Chicago; Associate Professor of Gender and Women's Studies and History, University of Illinois at Chicago, personal, September 6, 2011.

92 Jill Austin, interview with Co-Curator, Out in Chicago, Chicago History Museum, personal, October 4, 2011.

93 Jill Austin et al.,"When the Erotic Becomes Illicit," Radical History Review, no. 113 (Spring 2012): 188.

94 Austin et al., 188. 
95 Brier, interview with Co-Curator, Out in Chicago; Associate Professor of Gender and Women's Studies and History, University of Illinois at Chicago.

96 Austin et al.,"When the Erotic Becomes Illicit," 192.

97 Jill Austin, interview with Co-Curator, Out in Chicago, Chicago History Museum, personal, August 10, 2011.

98 Austin et al.,"When the Erotic Becomes Illicit," 189.

99 Jennifer Brier, interview with Jennie Brier, Co-Curator, Out in Chicago, Chicago History Museum, phone, August 7, 2014.

100 Austin et al., "When the Erotic Becomes Illicit," 194-195.

101 Jill Austin and Jennie Brier, "Out in Chicago Labels, Section 3, Draft 6; Section 3: In the Life; Object Label: 'When Harrison Was Mayor,' Undated, by John T. McCutcheon" (exhibit texts, ND - final label).

102 Austin et al.,"When the Erotic Becomes Illicit," 188.

103 Nicholas Glenn, "Out in Chicago Exhibition Wins Allan Bérubé Prize: Outstanding Work in Community-Based LGBTQ History" (press release, March 23, 2012).

104 "NAME: National Association for Museum Exhibition - Awards \& Fellowships," http://nameaam.org/about/past-winners.

105 The whole book really deals with this topic, but see especially Simon and Moscone, The Art of Relevance, 51-87.

\section{Bibliography}

Anderson, Elijah. "The Cosmopolitan Canopy." The ANNALS of the American Academy of Political and Social Science 595, no. 1 (September 1, 2004): 14-31.

Austin, Jill. Interview with Co-Curator, Out in Chicago, Chicago History Museum. Personal, August 10, 2011 .

—. Interview with Co-Curator, Out in Chicago, Chicago History Museum. Personal, October 4, 2011.

_. "Making and Remaking Visitor Panels." Conference Panel presented at the Association of Midwest Museums and Visitor Studies Association, Chicago, July 26, 2011.

Austin, Jill, Jennifer Brier, Jessica Herczeg-Konecny, and Anne Parsons. "When the Erotic Becomes Illicit." Radical History Review, no. 113 (Spring 2012): 187-197.

Bill Adair, Benjamin Filene, and Laura Koloski, eds. Letting Go?: Sharing Historical Authority in a UserGenerated World, 1st edn. Washington, DC: Pew Center for Arts \& Heritage, 2010.

Brier, Jennifer. Interview with Co-Curator, Out in Chicago; Associate Professor of Gender and Women's Studies and History, University of Illinois at Chicago. Personal, September 6, 2011.

Clifford, James. Routes: Travel and Translation in the Late Twentieth Century. Cambridge, MA: Harvard University Press, 1997.

Davalos, Karen Mary. Exhibiting Mestizaje: Mexican (American) Museums in the Diaspora, 1st edn. Albuquerque, NM: University of New Mexico Press, 2001.

DinnerTableDebate. Dan Savage vs. Brian Brown: The Dinner Table Debate. www.youtube.com/ watch? ${ }_{\mathrm{v}}=\mathrm{oG} 804 \mathrm{t} 0 \mathrm{WG}-\mathrm{c}$.

Dunne, Carey. "Why the Rijksmuseum Is Removing Bigoted Terms from Its Artworks' Titles." Hyperallergic, December 22, 2015. http://hyperallergic.com/263180/why-the-rijksmuseum-isremoving-bigoted-terms-from-its-artworks-titles/.

Eveline Sint Nicolaas. "Bathseba oud en nieuw." Exhibition labels. Rijksmuseum, January 23, 2017.

Farrell, Betty, Maria Medvedeva, Cultural Policy Center, and NORC and the Harris School of Public Policy at the University of Chicago. "Demographic Transformation and the Future of Museums." Center for the Future of Museums. Washington, DC: American Association of Museums, 2010.

Galla, Amareswar. "The First Voice in Heritage Conservation.” International Journal of Intangible Heritage 3 (2008): n.p.

Geertz, Clifford. The Interpretation of Cultures. New York: Basic Books, 1973. 
Gonzales, Elena. “The African Presence in México Steering Committee Meeting Minutes.” Meeting minutes. Mexican Fine Arts Center Museum, Chicago, February 23, 2005.

—. "The African Presence in México Steering Committee Meeting Minutes." Meeting minutes. Mexican Fine Arts Center Museum, Chicago, December 13, 2005.

Grams, Diane. Producing Local Color: Art Networks in Ethnic Chicago. Chicago; London: University of Chicago Press, 2010.

Grant-Thomas, Andrew and Gary Orfield. Twenty-First Century Color Lines: Multiracial Change in Contemporary America. Philadelphia, PA:Temple University Press, 2008.

Gurian, Elaine Heumann. Civilizing the Museum: The Collected Writings of Elaine Heumann Gurian, 1 st edn. Routledge, 2006.

Jennifer Brier. Interview with Jennie Brier, Co-Curator, Out In Chicago, Chicago History Museum. Phone, August 7, 2014.

Jill Austin and Jennie Brier. "Out in Chicago Labels, Section 3, Draft 6; Section 3: In the Life; Object Label: 'When Harrison Was Mayor,' Undated, by John T. McCutcheon.” Exhibit texts. Chicago History Museum, Chicago, ND - final label.

Kapsalis, Terri.“Jane Addams’Traveling Medicine Kit.”www.uic.edu/jaddams/hull/_museum/_exhibits/ Alternative\%20Labeling/alternativelabeling.html.

Karp, Ivan, Christine Mullen Kreamer, and Steven Levine, eds. Museums and Communities: The Politics of Public Culture. Washington, DC: Smithsonian Books, 1992.

Kreps, Christina. “Appropriate Museology in Theory and Practice.” Museum Management and Curatorship 23, no. 1 (2008): 23-41.

- Liberating Culture: Cross-Cultural Perspectives on Museums, Curation, and Heritage Preservation, 1st edn. London; New York: Routledge, 2003.

Kreps, Christina F."Appropriate Museology in Theory and Practice.” Museum Management and Curatorship 23, no. 1 (2008): 23.

Lavine, Steven D. and Ivan Karp. Exhibiting Cultures:The Poetics and Politics of Museum Display. Washington, DC: Smithsonian Institution Press, 1991.

Lee, Lisa. "Opening of Excavating Others." Exhibition opening, School of the Art Institute, Chicago, November 30, 2011.

Lonetree, Amy. Decolonizing Museums: Representing Native America in National and Tribal Museums, 1 st edn. Chapel Hill, NC:The University of North Carolina Press, 2012.

Marstine, Janet C. The Routledge Companion to Museum Ethics: Redefining Ethics for the Twenty-First Century Museum, 1st edn. London; New York: Routledge, 2011.

- ed. The Routledge Companion to Museum Ethics: Redefining Ethics for the Twenty-First Century Museum, 1st edn. London; New York: Routledge, 2011.

Moreno, Cesáreo. Interview with the Chief Curator and Director ofVisual Arts at the National Museum of Mexican Art. Personal, August 1, 2012.

"NAME: National Association for Museum Exhibition - Awards \& Fellowships." http://name-aam.org/ about/past-winners.

Nicholas Glenn. "Out in Chicago Exhibition Wins Allan Bérubé Prize: Outstanding Work in Community-Based LGBTQ History.” Press release. Chicago History Museum, Chicago, March 23, 2012.

“Oppression: A Museum Primer.” The Incluseum (blog), February 4, 2015. http://incluseum.com/2015/ 02/04/oppression-a-museum-primer/.

Pratt, Mary Louise. Imperial Eyes: Travel Writing and Transculturation, 2nd edn. London; New York: Routledge, 2007.

Radke, Heather. "Unfinished Business.” Museum magazine. www.aam-us.org/resources/publications/ museum-magazine/unfinished-business.

Radke, Heather and Chicago Coalition of Household Workers. "The Work That Makes All Work Possible. Organizing for Basic Labor Rights for Household Workers.” AREA Chicago. http://areachicago.org/ the-work-that-makes-all-work-possible-organizing-for-basic-labor-rights-for-household-workers/.

“Rijks Museum Jaarverslag 2016." Annual report. Amsterdam, the Netherlands: Rijksmuseum, 2016.

"Rijksmuseum Press Kit - Press.” Rijksmuseum. www.rijksmuseum.nl/en/presskit. 
Ruffins, Fath Davis. "Culture Wars Won and Lost: Ethnic Museums on the Mall, Part I: The National Holocaust Museum and the National Museum of the American Indian." Radical History Review 68 (1997): 79-100.

Siegal, Nina. "Rijksmuseum Removing Racially Charged Terms From Artworks'Titles and Descriptions." ArtsBeat, 1449760605. http://artsbeat.blogs.nytimes.com/2015/12/10/rijksmuseum-removingracially-charged-terms-from-artworks-titles-and-descriptions/.

Simon, Nina and Jon Moscone. The Art of Relevance. Santa Cruz, CA: Museum 2.0, 2016.

Sint Nicholaas, Eveline and Stephanie Archangel. Interview with Eveline Sint Nicolaas and Stephanie Archangel, curators of history at the Rijksmuseum. Personal, January 23, 2017.

Sullivan, Patricia and Waldo E. Martin Jr. Civil Rights in the United States, 1st edn. New York: Macmillan Reference USA, 2000.

Thomas, Lisa. "Label for a Yellow Sponge in Unfinished Business: Home Economics at the Jane Addams Hull-House Museum," 2012.

"Towards A Decolonial Curatorial Practice." Chandra Frank. www.chandrafrank.com/towards-adecolonial-curatorial-practice/.

Warner, Michael. Publics and Counterpublics. New York: Zone Books, 2002. 


\section{CONCLUSION}

There are 80,000 museums in the world. ${ }^{1}$ For comparison, consider the fact that this number is 25-percent greater than the combined total of McDonald's and Starbucks outlets. Museums are beyond ubiquitous. They work everywhere on every topic imaginable. Large and small, these institutions are poised to be important catalysts of significant changes. If museums work together they can shift our societies to be more just for all. From championing human rights, such as healthcare and housing, to building a diverse historical record replete with voices of every color, creed, and tax bracket, museums can make a difference.

This is already happening. In many nations and fields of study, museum workers are refusing the elitist, colonial histories of their institutions and creating change from within. With varying degrees of success and support, all kinds of educators, including curators, are writing new narratives. Curators are mining their collections with fresh eyes, looking for faces that might once have hidden in the shadows of paintings, and they are telling their histories.

This book is a call to continue and expand this effort. In support of curatorial work for social justice, I have sought new and interesting practices to inspire and fuel our work. In particular, I have highlighted those practices that visitors' own bodies and brains will help boost into utility. I have offered visions for inspiring visitors to take action and practical advice for museum workers at all levels who wish to do the same.

In Chapter 1, I examined the difficult task of building bonds across groups, first from person to person and then from group to group. If we can tackle the first task, the second becomes easier. Museums have a special ability to encourage visitors to think their way into new groups they did not perceive that they were a part of. Museums' special environments and experiences give them an advantage in helping a visitor walk in the shoes of a truly different other. Museums are unique among our institutions for their capacities in these areas. Cultivating empathy between individuals is essential to building solidarity among groups. Both are crucial to curatorial work for social justice. Luckily, museums have the tools to do this work.

Since there is such a strong relationship between the material in Chapters 1 and 4, I am bringing them together here in the conclusion to discuss lessons from them. This book begins and ends with the subject of hospitality in the museum. Chapter 1 asks how to help 
visitors empathize and build solidarity. One answer is to make the museum a hospitable place where visitors feel that people are empathizing with them. Chapter 4 asks how to make all visitors feel welcome and bring diverse stakeholding communities into relationships of shared authority with the museum.

It is impossible to do justice to critical topics such as inclusion and sharing authority in a single chapter. ${ }^{2}$ Nevertheless, I tried to retain a tight focus in Chapter 4 on the crucial ways in which these areas support and underpin curatorial work for social justice. In Chapter 4 this book moves from focusing on the world a curator creates in the gallery to focusing on the world of the museum, from whence exhibitions arise. Though this whole book is meant for museum professionals, researchers, and students, this chapter in particular is about how staff and leaders can plan and take action themselves, at a higher level than that of exhibitions. The chapter analyzes the barriers that exist for many visitors and the ways in which museums can lift those barriers. It also explores possibilities for rupturing prejudices by offering diverse communities a chance to speak through the voice of the museum. Museums are one of the gatekeepers to history, to the stories we tell about ourselves and pass down to future generations. Museums have the opportunity to shape that collection of stories to make it more diverse and representative of our societies. The chapter ends with takeaway tools designed to help museums' staff and boards put the practices in this book to work.

Here is a brief overview of some of the related lessons and curatorial practices in Chapters 1 and 4. The first points of contact between the museum and the visitor are the museum's first opportunities to welcome all visitors with hospitality. Carefully considering advertisements, front-of-house staff, and security are all efforts that can support and reflect a sense of welcoming to all audiences and visitors. Learn why "outsiders" truly are like family and advertise that. Rehearse this knowledge inside the organization and with allies. Take the institutional commitment to welcome to the highest level. And use staff training to get everyone on the same page.

When someone from the museum shows empathy to a visitor, the visitor is more likely to empathize with subjects of exhibitions. Consider how this knowledge can inform the actions of staff, whether front-of-house or educators. Once the visit begins, free admission without strings attached is the simplest way to welcome visitors of all kinds and ensure that everyone is able to attend. Being generous with the museum's public areas will also give the museum a reputation as a good neighbor, community member, and beloved third space. Of course, students should just stop by and walk in after school! Of course, passerby should feel that they can enter simply to use the restroom, get a drink of water, or get out of the weather. Can there be spaces that are open to the street? Can there be non-binary bathrooms? Can there be space for nursing mothers? Take steps to ensure that your physical space embodies your goals for social justice as much as possible.

As the visitor enters the galleries, the visit begins in earnest. This is the museum's moment to demonstrate that its materials are accessible and inclusive. Ensure that the language and tone throughout the museum's texts is welcoming to all audiences. Likewise, thick description enables empathy and offers multiple points of entry that welcome different visitors. Diverse materials also help create multiple points of entry. Data visualization and maps can be knitted together with objects. Art can allow us to consider ideas we ordinarily might not by starting in a place without words. Stories of specific individuals and local stories inspire one-to-one human bonding. When protagonists are unsympathetic, artful presentations of information can provide a point of entry. Specificity of details and scale in the exhibition better enable visitors 
to empathize with subjects. Use interactives that place the visitor in the narrative momentarily (when appropriate). Within exhibitions, including spaces that give visitors positive gutlevel reactions will improve their overall feeling of enjoyment at the museum. Offering haptic experiences embraces the old-fashioned, yet authentic, currency of touch as a sign of hospitality.

Consider closely your curatorial goals for the visitor. What do you want your audience to know? How do you want her to feel? What do you want her to do? Address the next steps toward systemic change on a given issue as a way of moving from empathy between individuals to solidarity between groups. Making concrete plans to address problems also inspires a vote of confidence from visitors who may be on the fence about the museum. Use prosthetic memories to connect distant generations.

As you consider how to make your institution more welcoming and hospitable, it is crucially important to ensure that narratives within the museum are inclusive of those whose communities have been affected by colonialism, mass violence, and racist or bigoted systems. Luckily, the tools for doing this are straightforward, even if they involve difficult conversations. First, acknowledge the difficult history. Call perpetrators and their actions by name. Do not use euphemisms. If the museum itself was involved in the past wrongs being discussed, acknowledge the museum's role, apologize, and state the museum's position moving forward. Make aesthetic and narrative choices that destabilize and decentralize patriarchy, White power, wealth, and the hegemony of Western cultures. Use appropriate museology. Evaluate the museum's vocabulary to search for unintended forms of marginalization, and change them. When changing offensive terminology, take care to retain nuanced descriptions, in labels for example. It may mean that when certain terms are changed or eliminated, more information needs to be added. Mine the museum's collection for subject matter that is undiscussed and whenever you hope to better represent an underrepresented group. The content may be there, hidden in plain sight. Find ways throughout the museum to draw attention to things the visitor might miss, and expose the history between the lines of the objects. (Use creative labeling, maps, audio guides, and signage, for example.) Ensure that partnerships benefit all partners in the ways that matter to them. Commit to decolonizing your museum, and band together with institutions and partners that can help.

The museum can work in an important social capacity as a disabler of negative groupness. Connecting groups in positive ways is one component of this work. Build and participate in networks of visitors, stakeholders, and institutions. Encourage positive groupness (the building of groups that does not exclude or exploit, but does encourage relationships of solidarity that are productive for social justice). Use visitors' intersectionality to connect them. Forms of address consolidate groups, so use the texts in the museum to call connections into being. Use existing online communities to connect more people together within the exhibition. How can the online community participate in the show? What opportunities will encourage members to come to the museum? How can the museum connect visitors and non-visitors with "their people"?

One way for museums to build group alliances in a positive way is to find productive ways to help visitors tinker with their identities. Museum can help visitors amplify their sense of who is related to them and how and can break down walls between supposed "us" and "them," by illuminating cross-cultural histories. Museums can validate visitors' existing knowledge to build trust. Then build on visitors' existing knowledge. Key objects and people that act as cultural touchstones can transfer trustworthiness from themselves to the topic of expanded identity. Culturally specific/appropriate vocabulary can embrace groups and band them together. 
Culturally specific/relevant imagery can band groups together in a similar way. Museums can build on existing first-voice organizing - whether or not they are first-voice institutions - to build empathy and solidarity and work for social justice.

As museums plan new projects or look for new ways of shaping and maintaining the institution, researching stakeholding communities and discovering ways to share authority with them is an excellent way to increase the museum's inclusivity and hospitality. Consider a community that could be better represented in the museum. Who are the leaders? Who is being left out of the leadership in that community? (If there is productive disagreement among the community representatives you're working with, that is one sign of a diverse group that may better represent the community as a whole.) How can you work together in a way that is mutually beneficial? (Spell out how each party benefits from collaboration.) Engaging partners from the beginning of a project rather than late in the game is a sign of respect. Think of these collaborations as investments in long-term relationships.

Once you have identified a partner and laid the groundwork for collaboration, it's time to consider the logistical elements that can determine whether a partnership feels fair or exploitative. What language do you share? Do you need a translator? Listen to your partners. Value their expertise. Consider equity when setting the meeting point and agenda.

Chapter 2 explored practices that help visitors build strong memories, particularly combining physical and intellectual experiences in the gallery. Building strong, long-lasting memories is important to curatorial work for social justice because they give visitors a platform from which to think and act over time. An exhibition may not inform the decisions visitors make on the day they visit, nor even in the time shortly thereafter. But if visitors have strong memories of the exhibition, then those memories can live for decades, like a good book or a movie, and be available when they most resonate with contemporary concerns.

One way to think about the findings from this chapter is to break them down into efforts to engage the visitor intellectually - to create resonance with that visitor's own life - and efforts to create meaningful physical experiences, including emotional ones. I spend less time on making exhibitions relevant, because that subject has been well treated elsewhere. However, a few concepts bear repeating: the more an exhibition relates to contemporary concerns, the more relevant it will be. Often this means simply drawing historical lessons into the present or connecting with current affairs in a thoughtful way. Offering multiple points of entry to the visitor - as many as possible - helps use the visitor's own intersectionality to build resonance with the exhibition. Questioning is a good tool for helping visitors connect the exhibition to their lives or the present. Direct, specific questions can linger and help visitors build memories as well as inspire visitors to actually answer the questions.

Physical experiences, including emotional ones, help us make lasting and detailed memories. And, while our memories are changing and fallible, visitors with strong memories are a good channel for moving the content of the exhibition forward into the future. Exhibitions that allow touch help build memories, but other multisensory experiences are also useful. Make sure to scaffold these experiences for visitors to encourage thoughtful participation and a memorable experience. Give the visitor the opportunity to do a physical activity: dance, play, move in a particular way, taste something, smell something. If it's relevant and fun or interesting, it can do the trick. And if it encourages laughter, so much the better. Exhibitions that involve intentional pleasure can build memories and a sense of kinship with the institution. Furthermore, laughter is an embodied emotional response, like tears, fear, revulsion, or awe - and, as such, helps make memories. 
Many other strategies can also lead to visitors having emotional experiences. They can encounter emotionally freighted objects. Objects that create wonder (large, interesting, beautiful, devastating, awe-inspiring) can stop a visitor long enough to allow her to enter a resonant experience.

Once you have a plan in place within your exhibition for building emotion, ensure that it is properly modulated so that it does not overwhelm visitors. Create an ebb and flow of intense emotional experiences. Returns from difficult content create tiny emotional highs that are rewarding for the visitor, even subconsciously. Use resting places and safe spaces to punctuate difficult content. Offer lines of sight through difficult content. Make particularly disturbing emotional experiences optional. Provide an alternate route. Immersive spaces can work well or feel inauthentic or overwhelming. Use a narrative path as an alternative to immersion. Some objects are environments all on their own. These can also offer an alternative to a fully immersive environment. Immersive art installations can be an effective way to address difficult histories. Immersive environments need not recreate. But good ones will inspire conversation and thought - rehearsal.

Visitors' memories of their visits can be bolstered significantly by rehearsing the visit before, during, and after it occurs. As visitors plan their visits, they begin to talk to themselves and others about what they anticipate. During the visit, there may be opportunities to promote rehearsal, which will also take place naturally. For example, when visitors can take actions at the museum that are interesting enough, these actions promote rehearsal and can inspire additional actions. Museums can take other steps at the end of the visit and after the visit to promote additional rehearsal. For example, the museum can offer staged contact after the visit at several intervals (weeks, months, and years later, for example). If there is contact after the visit, it should go without saying that it needs to be meaningful and interesting to the visitor to not be simply an annoyance. Specificity about that visitor's own visit helps. A surprise element can provide one incentive to the visitor to open/accept further communication. One example of this is the visitors' postcards to themselves in Prisons Today at Eastern State Penitentiary. The visitor answers some questions, but does not view the full text of the postcards in advance. In addition to building memory through rehearsal, this particular activity was also an opportunity for visitors to both take action in the museum and also potentially be inspired to take further action later.

Chapter 3 was an investigation, informed by Chapters 1 and 2, of the many ways visitors can and do take action as a result of their experiences in exhibitions. Though museums are only one element of our informational environments, studies have shown that they are more trusted than most other sources. ${ }^{3}$ When visitors are invited to take action during their visits, they often do. One way to encourage this is by strategically scaffolding the invitation to participate so that the visitor feels confident about the steps she needs to take and about the likelihood of her success. As visitors' memories develop over time, they also take action relating to their experiences in museums. Often, visitors' actions snowball across their social networks and gain momentum as more people take related actions. Although much more study is needed on this topic, this initial exploration of visitors' actions revealed stories of over 36,500 visitors taking action (mostly in only 2016 and 2017) as a result of visits to roughly five museums. This is only a drop in the bucket of what is happening already as well as what is possible.

However, the stories from these museums yield practices that can encourage visitors to take action and support the museum's programming around this topic. Set a low bar for taking action. Action begets action. Offer opportunities to act in which the visitor does something 
she would normally do anyway, but with a twist. One example of this is relevant selfie stations. Taking and passing on collateral material is another easy action. Make sure your takeaway collateral is worth taking, and sharing. Offer actions that show other visitors how many people have already acted. Art installations where visitors contribute and change the work over time are one example that also can encourage repeat visits. Offer opportunities for action that are memorable, physical, and useful - to the museum and the visitor. Give visitors a stake in the museum's process.

Offer clear steps to action at the moment of building empathy. Consider who is calling visitors to act. Make sure they embody the brand you most want to project to your target audiences. Give visitors freedom to do things you might not normally allow: In one good example, Lincoln Cottage enabled visitors to pick up books of information and walk around with them. In another, staff members from Hull-House served tea to visitors in the gallery. These opportunities can result in action and in helping visitors feel more comfortable in the museum and even feel ownership over the museum.

Another lesson from Lincoln Cottage: rather than offering newspaper clippings or unattractive binders of ancillary materials for visitors to "learn more," brand those pieces of information with the exhibition, simplify them visually, make them bold and attractive. Make them a centerpiece. Often the grittier content relating to action can be accidentally cloaked in a boring or uninviting exterior. Use attractive, highly visible, consistent messaging across the institution or exhibition.

Use social media (but don't let it overwhelm the encounter in the museum). One good method came from the Brookfield Zoo: using the content in your museum, create special characters who can have a presence online. Pick a specific issue or topic for the character to address. Mix humor, information, and practical tips for action.

Plan and study your efforts to inspire action. Integrate your planning for action to planning the exhibition from the beginning. Experiment with evaluations that work for your institution, not just funders. Ally your work with existing issues: collaborate with partners working in these areas. Consider working around existing legislative efforts or other ongoing actions occurring outside the museum. Partners can provide resources and help keep the institution honest.

It is time for us to retrain ourselves for the challenges our societies face, from unfair labor practices to unfair distribution of healthcare, from deep animosity along political lines to prejudice based on race, age, class, gender, and immigration status. We need training in specific areas such as these - education on issues, as well as opportunities to take action and make change. We also need venues in which to explore different modes of relating to one another socially hospitality, listening, radical transparency, compassion, and empathy. Museums can help disable systemic prejudices. Museums can help illuminate new solutions for distributing nourishment, environmental protection, healthcare, and education globally and locally. Museums can foment change and inspire innovation. What are you working on?

\section{Notes}

1 Richard Florida in Gail Dexter Lord and Ngaire Blankenberg, Cities, Museums and Soft Power (Washington, DC:American Alliance Of Museums, 2015), 2.

2 Numerous practitioners and scholars are creating excellent resources for the field in this area today. Here are a few of my favorites: Anniessa Antar, Camille Erickson, and Sarah Winter, eds, "MASS 
Action Toolkit," 2017; Alyssa Machida, "The Dreamspace Project: A Workbook \& Toolkit for Critical Praxis in the American Art Museum," 2018, https://incluseum.files.wordpress.com/2016/ 10/thedreamspaceprojectworkbook.pdf; "Social Justice \& Museums Resources List," Google Docs, https://docs.google.com/document/d/1o_rUpYGLVOhrsgfwXbnAWjoE3N3bpv6zDbFDLLs_ iCE/edit?usp=embed_facebook.

3 This fact has been cited for decades, beginning with Roy Rosenzweig, The Presence of the Past: Popular Uses of History in American Life (New York: Columbia University Press, 1998). Here is a discussion of controversy on whether or not the public's trust of museums is well informed about the work museums do: "Center for the Future of Museums: Trust Me, I'm a Museum," Center for the Future of Museums (blog), February 3, 2015, http://futureofmuseums.blogspot.com/2015/02/trust-me-immuseum_3.html.

\section{Bibliography}

Alyssa Machida."The Dreamspace Project:A Workbook \& Toolkit for Critical Praxis in the American Art Museum,” 2018. https://incluseum.files.wordpress.com/2016/10/thedreamspaceprojectworkbook. pdf.

Anniessa Antar, Camille Erickson, and Sarah Winter, eds."MASS Action Toolkit," 2017.

"Center for the Future of Museums: Trust Me, I'm a Museum." Center for the Future of Museums (blog), February 3, 2015. http://futureofmuseums.blogspot.com/2015/02/trust-me-im-museum_3.html.

Lord, Gail Dexter and Ngaire Blankenberg. Cities, Museums and Soft Power. Washington, DC: American Alliance Of Museums, 2015.

Rosenzweig, Roy. The Presence of the Past: Popular Uses of History in American Life. New York: Columbia University Press, 1998.

"Social Justice \& Museums Resources List." Google Docs. https://docs.google.com/document/d/1o_ rUpYGLVOhrsgfwXbnAWjoE3N3bpv6zDbFDLLs_iCE/edit?usp=embed_facebook. 


\section{INDEX}

Note: The page numbers in bold refer to tables and the page numbers in italics refer to figures.

96 Acres $71-72$

Abernathy, Ralph 101

accessibility $6-7,66,82,108,125,150,157,181$; see also inclusion; "thick description"

Adair, Bill 148

Addams, Jane 30, 149, 151; see also Jane Addams

Hull-House Museum (Chicago)

agency $3-4,6,28,143,150$

Akeley, Carl 125

Allan Bérubé Prize 163

Alpers, Svetlana 158

Alternative Labeling Project 30, 149

American Alliance of Museums (AAM) 6-7

Ames, Michael 111

Anderson, Elijah 6,140

Anne Frank House (Amsterdam): generally 76; exhibitions, Free2Choose 28-29

Aono, Kristine 119-120

apartheid 4

Applebaum, Ralph 28, 76

aquariums 8, 103-107, 134n24-27

Archangel, Stephanie 145-146

art 11, 18, 21, 37-38, 46-49, 80, 84, 127, 146, 152-153, 163, 164-173; difficult history 2 , $70,78,96,110,184$; inspiring action 96, 110, 116-119, 185; resonance and wonder 87-88; see also immersive environments; Jane Addams Hull-House Museum Unfinished Business: Arts Education

Art, Museums and Touch (Candlin) 65

The Art of Relevance (Simon) 91n65, 121, 139, 154, 163

Atkins, Jacqueline 155 attendance $21,42,105,109,111,119-120,124$, $126,145,155,185$

Austin, Jill 63, 66, 162-163

authenticity $6,23,68,75,77,107,124,149,151$, $153,159,182,184$

Ayer, Edward 125

Babi Yar massacre 67

Baggesen, Lise Haller 113

Barnes, Rahmaan "Statik" (artist) 156, 156

Batmanglij, Rostam 96

Beardon, Romare 47

Beltrán, Aguirre 54n84

Benavides, Jose Luis 96

Bennett, Tony 5, 28

Berenbaum, Michael 67, 77

Berger, John 87

Bermudez, Julio 109

Berry, Amanda 108-109

bias 41; implicit, 99; see also agency; transparency

Bielak, Susannah 117

"Bike Dream" (song) 96

Bivins, Joy 35, 79

"Black is Beautiful" 47

Black Panthers 47

Blumberg, Naomi 62

Boda, Simone 19

Borer, Tristan Anne 2

Boriquez, Chaz (artist) 48, 48

Boyd, Neva 113

The Brain Scoop (YouTube channel) 125-126

Brave Heart, Maria Yellow Horse 144

Brier, Jennifer 63, 65-66, 161 
Brookfield Zoo (Chicago) 8, 104-107, 110, 134n21 and 23, 185

Brown, Beverly 111-112

Brown, Brian 148

Brown, Pam 111

Brown, Roger 62

Brown, Wendy 27

Burroughs, Margaret 47

"butterfly effect" 98-101

Cabrera, Rosa 174n26

Cameron, Catherine 61

Cameron, Duncan 6-7

Canada Truth and Reconciliation

Commission 111

Candlin, Fiona 29, 65

Caravaggio, Michelangelo Merisi da (artist) 18,18

Carter, Kevin 73

Casa Memoria José Domingo Cañas (Santiago) 40-42

Cashier, Albert 64

casta system, 42-46

Castro, Ariel 109

Catlett, Elizabeth 47-49

Center for Holocaust and Humanity

Education 98

The Changing Face of Public History: The Chicago Historical Society and the Transformation of an American Museum (Lewis) 35

Chanin, Clifford 37-38, 87

Chicago 8-9, 35, 68, 85, 142, 153, 155-157, 161; Bronzeville 157; La Villita 71; Pilsen 142, 156

Chicago Coalition of Household Workers (CCHW) 102-103, 159; see also Thomas, Lisa

Chicago Historical Society (CHS) $4-5$

Chicago History Museum (CMH): generally 8-9, 49, 78-79; exhibitions, Out in Chicago 49, 63-66, 90n36, 161-163; Without Sanctuary 35,79

Chicago Zoological Society 104

Chicano Movement 176n73

children / childhood $6,11,33,40,42,54 \mathrm{n} 84$, $100,111,112,120,122,124,132,152$, 162; exhibitions for 22-28, 69-70, 96, 98, 106,110

Chopik, W.J. 49

Christiano, Michael 127-128

"civic seeing" 28

Classen, Constance 29

Clifford, James 6, 143, 174n19

Cohen, Danny 67

Collins, Lizetta Le-Falle 47

comfort 19-31; see also enjoyment; hospitality; pleasure

Committee on Lesbian, Gay, Bisexual, and Transgender History 163 community $3,12,15,42,46,82,109,112,139$, 141, 152, 154, 164-173, 181-183; African American 21, 38; Afro-Mexican 21, 44, 88; Chinese 122; curators 158-159; digital 125, 128 (see also digital); First Voice see First Voice; Holocaust 36; queer 65, 161-163; Jane Addams Hull-House Museum 71-73, 102, 114, 116; Mary and Leigh Block Museum of Art 119; Mexican 20-21, 54n84, 153; stakeholders 6, 10, 15, 141-143, 152, 155, 160, 167-173, 174n19,

182 ; visitor panels see visitor panels communities of memory 37-38

community museum movement 7

compassion fatigue $31,36,52 \mathrm{n} 45,77$

Compean, Juan (artist) 83, 84

Compean, Ricardo (artist) 83, 84

congregant spaces 139-140, 164-169

contact zones 143, 164-168, 170

Cooper, Rich 99

Corrin, Lisa 117-118

Cortéz, Carlos (artist) 47-48

cosmopolitan canopies 140-141, 164-169

Coyle, Kat 128

Creation Museum (Petersburg) 6

criminal justice 31-33, 52n48, 52n49, 71, 121

Cruz-Carretero, Sagario 54n84, 155

Cuéllar, Julieta 15, 39

culturally specific $4,7,20-21,46,49,51 \mathrm{n} 18$, 140-143, 153-154, 164-173, 174n27, 182-183; see also First Voice

Cumbo, Katie $91 \mathrm{n} 64$

Curating Difficult Knowledge (Lehrer) 96

curatorial work 1-10, 12, 16, 18, 20-21, 28-32, $35,38-39,42,45-46,49-50,58,60-63,66-68$, 77-79, 81-84, 85, 87-89, 96-97, 102, 104, 108, 111, 117, 123, 126, 128-129, 133, 139, 141-147, 149, 151-155, 157-173, 180-183

Damasio, Antonio 17, 58-60, 77

Davalos, Karen Mary 88, 141, 150, 152-153

DeBruyn, Lemyra 144

decolonizing museums 144-147, 164-168, 170, $174 n 35$

Decolonizing Museums (Lonetree) 144

DeJesus, Gina 108-109

Denver Art Museum: exhibitions, Mi Tierra: Contemporary Artists Explore Peace 71

design $2,5,8,19,23,28,45,49-50,65-68,70,74$, 76-78, 85, 90n48, 102, 105, 108, 110, 113, 122, 153,159

dialogic museums 141-142, 164-169

Dickerson, Amina 155

Dierking, Lynn 18, 97

Diettes, Erika (artist) 39

Digital, resources 41, 124, 146; visitors 123-132, 148

distributive justice 2 
diversity 1, 3, 5-6, 8-9, 19-20, 35, 38, 81-82, 88, 139-140, 150, 160-161, 180-181, 183

Doron, Edith 19

The Dreamspace Project: $A$ Workbook and Toolkit for Critical Praxis in the American Art Museum (Machada) 41

Dubin, Steven 3

Duchamp, Marcel (artist) 158, 158

Duffek, Karen 111

DuSable Museum of African History (Chicago) 47,142

Eastern State Penitentiary (Philadelphia): generally 8, 31-34; work, The Big Graph 32, 32-33; exhibition, Prisons Today 32-34, 34, 121,184

Ebony Museum (Chicago) 142

Elkins, James 19

El Museo de la Memoria y los Derechos Humanos (Santiago) 40

Emmett, Peter 62

emotions: generally 2, 7-8, 11-12, 16-18, 31, 34, 36, 58-59, 135n39, 184; inspiring action 7-8, 12, 36, 58-62, 67, 69, 73-74, 97, 101-102, 110, 113, 184; learning, role in 7, 59-63, 69, 102; memory 7-8, 25, 59-63, 65, 67, 69, 74, 77, 87, 97, 101, 112, 183-184; overload / overwhelming emotions 24-25, 52n45, 67, 73-74, 77-79 (see also compassion fatigue); physicality 66, 68-69, 101, 151, 159 (see also immersive environments); resonance 11-12, 58-61, 64, 68-69, 73, 77-78, 81, 85, 87-88, 102, 110, 112-113, 183-184; space 17, 24-25, 60-61, 65-67, 73-74, 77-79, 85, 151, 159, 184

Empathetic Museum 40-41

empathy: generally $1,7,10-12,14 \mathrm{n} 36,15$, 18-19, 40-41, 48-50, 77, 96, 180-183; comfort 30-31, 65, 185; emotion and resonance $58-61,81-82,88,113$; groupness 15-17, 20, 60, 182; hospitality 10, 12, 19-29, 180-181; individual stories $10,22,25,31-34$; inspiring action $1,7,10,36-37,58-59,61$, 69, 67, 82, 104-107, 113, 160, 180-181, 185; intentional welcoming 12, 20-29, 50, 82, 181; intergenerational communities of memory 37-38, 76; institutional solidarity 38-42; key objects $11,45-46,61,77,160,181-182$; local stories 10, 15, 35, 69, 181; memory see memory; personal identities 42-45; physical experiences and see physical experiences; regional networking 15, 38-42; shared vocabularies 16, 46-49; social media 15, 40-41, 107, 185; solidarity and see solidarity; systemic change $27,33,35-37,71,182,185$; touching of exhibits 7, 29-31, 182; "universe of obligation" 17-19 engagement 24-25, 29, 60, 65, 81, 85, 102, 110, 114, 117, 127-128, 135n56, 163, 164-170; see also resonance

enjoyment $19,24,30-31,62,163,182$; see also pleasure

equity 1-2, 7, 20, 44, 142, 144, 161, 163-164, 183

Europe / European 31, 39, 41, 49, 76, 78, 144, 145, 147, 150, 155, 174n26

Excellence and Equity (AAM) 7

Exhibiting Mestizaje (Davalos) 88

Facing History and Ourselves 17

facts and figures, use of 84-85; see also logic

Falk, John 6, 18, 97

feelings $1,5,12,15,18,50,58-61,66,77$, 105,114

Field, Marshall 125

Field Museum of Natural History (Chicago): generally 69; Project Hyena Diorama 124-126; exhibitions, Inside Ancient Egypt 69-70, 70; Traveling the Pacific 69, 69

Filene, Benjamin 148

First Nations see indigeneity

first-voice 142-143, 164-168, 170, 174n26

"flashbulb memories" 62-63

folk ethnography 140

forum (temple vs. / museum as) 6-7, 141

Foster, Chris 36

Foucault, Michel 5

Fountain (Duchamp) 158, 158

Frank, Chandra 144, 174n19

Frausto, Tomás Ybarra 153

Freedberg, David 2

Freedom Writers 98

Friendly adversaries 143, 148, 157, 164

Frisch, Michael 173n2

funding / fundraising 6, 8, 10, 39, 83, 102-104, $125,126,151,155,160,185$

Galla, Amareswar 174n26

Gallace, Alberto 87

Gao, Yang 135n56

Garcia, Jesús “Chuy” 85

Garfield Park Conservatory (Chicago) 66

Gaspar, Maria (artist) 71-72, 71-73

Gass, Alison 126, 128

Gatewood, John 61

Geertz, Clifford 150

genocide 2, 31, 36-38, 40, 67, 81, 144; (see also Holocaust compassion fatigue)

Gerzso, Gunther 153

Ghosts in the Gulch (Hawke) 122

Gilman, Charlotte Perkins 151

Global Networks Team 15, 38

Goldman, Shifra 47

Gonzales, Laurence 99-101 
Graham, Anderson, Probst \& White (architectural firm) 105

Graslie, Emily 125-126

Gray, Joan 155

Greenblatt, Stephen 59-60

Griffiths, Allison 6, 60, 66

groupness 15-17, 20, 60, 81, 142, 182

Gurian, Elaine Heumann 6, 139-140

Guterl, Matthew 79

Guzmán, Juan 157

Han Sifuentes, Aram 113-118

Haptic see tactile experiences, enabling

Harlem Renaissance 47

Harness, John 128, 132

Harriet Beecher Stowe House (Cincinnati) 37

Hawke, Sangye 121-122

Heap, Jane (aka Richard) 64

Hein, Hilde 6

Henderson, Harry 47

Hinman, Mary Wood 62-63

Hirschhaut, Rick 67, 77

History Wars 5

Holocaust 24, 35-36, 38, 67-69, 76, 81, 123; museums 10, 19, 27-28, 40, 66, 74, 76-77, 91n67; resting places 78, (see also overstimulation); (see also Center for Holocaust and Humanity Education; compassion fatigue; genocide; Illinois Holocaust Museum \& Education Center; Museum of Tolerance; United States Holocaust Memorial Museum; Verzetsmuseum)

The Holocaust in American Life (Novick) 67

Holocaust Memorial Foundation of Illinois (HMFI) 36

Hooper-Greenhill, Eilean 5

hospitality $1,10,12,19-31,67,128-129,140$, 142, 163, 180-183, 185; comfort 30-31; intentional welcoming 12, 19-29, 49, 82, 126-132, 139-163; sharing authority 180-183; touching of exhibits 29-31

House of Pain (Gonzales) 101

Hughes, Langston 54n92

Hull-House see Jane Addams Hull-House Museum (Chicago)

humor 25, 46, 113, 185 (see also emotions; tone)

identity $6,16,20,37,42-45,47,67,76,81$, $83,91 \mathrm{n} 66,123,142,152,176 \mathrm{n} 73$ (see also groupness; intersectionality)

Illinois Domestic Workers' Bill of Rights 102-103

Illinois Holocaust Museum \& Education Center (Chicago): generally 8-9, 76, 78; exhibitions, The Act of Art 38; Karkomi Permanent Exhibition 66-67, 78; Legacy of Absence 37-38; Make a Difference! 110; railcar 74-75, 75, 159 immersive environments 7-8, 11, 26, 58, 61-62, 66-74, 76-77, 184

Imperial Eyes: Travel Writing and Transculturalism (Pratt) 143

Incedulità di San Tommaso (Caravaggio) 18, 18

inclusion 2, 10, 12, 19, 31, 41, 44-45, 51n37, 127-128, 147-148, 156, 169-173, 181-182

indigeneity, 45-47, 79, 99, 122-123, 143-144, 151-154, 164-173, 174n26; Coast Salish 122;

Musqueam 122, 123, 136; residential schooling 111 (see also Speaking to Memory); see also casta system; decolonizing museums

individual stories 7, 10, 12, 22-29, 31-34, 36-38, $42,49,50,68,81,102,163,180-181$; see also intersectionality

inner conversation, fueling 63-65; see also questioning

inspiring action: generally 11-12, 96-98, 132-133, 184-185; aquariums 103-107; "butterfly effect," 98-101; digital visitors, see digital and visitors; during visit 111-120; at endof visit 120-121; evaluating for action 107-110; far beyond visit 121-123; influence of evaluation on thinking 101-110; social media, use of 107; types of action 110; zoos 103-107

institutional solidarity 15, 17, 38-42, 163, 180, 181

intentional welcoming 20-29; see also hospitality Inter-American Court of Human Rights 39

intergenerational communities of memory 37-38

International Coalition of Sites of Conscience (SoC) 3, 8, 15, 38-42, 141

internment 38, 119

Interpreting Art in Museums (Whitehead) 3

Ivey, Bill 135n56

Jaar, Alfredo (artist) 73-74

Janes, Robert 1, 17

Jane Addams Hull-House Museum (Chicago): generally 5, 8-9, 11, 20, 30, 30-31, 49, 185; Alternative Labeling Project 149; exhibitions, Into Body Into Wall (Gaspar) 71-72, 71-73; Official Unofficial Voting Station; Voting for All Who Legally Can't 113-114, 114-115; Re-Defining Democracy 110, 149; Tuttle Clog 64, 65; Unfinished Business:Arts Education 113; Unfinished Business: Home Economics 102-103, 113, 159; Unfinished Business: Juvenile Justice 121; Unfinished Business: The Right to Play 62, 63-64, 82, 87; US Citizenship Test Samplers 114, 116, 116-118

Janes, Robert 1

Jaramillo, Alfonso 47

John G. Shedd Aquarium (Chicago) 8, 105-106 Johnson, Gary 35 
Johnston, Juanita 111

Jones, Jennifer 85, 96

Kant, Immanuel 19

Kapsalis, Terri 151

Karp, Ivan 6

Kelley, Sean 32

key objects 45-46

King, Martin Luther 99-101

Kinnick, Katherine 52n45

Kinsley, Rose Paquet 41, 145

Kiser, Kathy 106

Knight, Michelle 108-109

Kohan, Mark 98-99

Koloski, Laura 148

Konrath, S.H. 50

Kreps, Christina 143, 151-152, 154

Kulik, James 62

"La Bamba" (song) 88

La Caze, Margeurite 50n16

Lair, liam 64

Landsberg, Alison 37

The Land We Are:Artists and Writers Unsettle the Politics of Reconciliation in Canada (Mccall) 96

Latham, Kiersten 61

Latin America 15, 39-42, 83

Lavine, Steven 6

Layman, David 66, 68

LeDoux, Joseph 59

Lee, Lisa 22, 102, 110, 143, 150-151

Lehrer, Erica 96

Letting Go (Adair, Filene, and Koloski) 149

Leubke, Jerry 104-105

Levent, Nina 29-30

Lewis, Catherine 35

Lincoln, Abraham 107 (see also President Lincoln's Cottage)

Lincoln Park Zoo (Chicago): generally 8 , 105-106; exhibitions, Wild Horizons 98

Lipsitz, George 154

local stories 35

logic, appealing to 83-85; see also facts and figures

Lonetree, Amy 144, 147

Lorraine Motel (Memphis) see National Civil Rights Museum

Lower East Side Tenement Museum (New York) 3

Lynch, Bernadette 143, 155

Machada, Alyssa 41

Mais,Yitzchak 67, 77

Maldonado, Lindsay 105

Mann, Stacey 67

Marshall, Kerry James 73

Mary and Leigh Block Museum of Art (Evanston): generally 8-9; exhibitions, If You'll Remember, I'll Remember 119, 119-120
Maryland Historical Society (Baltimore): exhibitions Mining the Museum 117

Mashantucket Pequot Museum and Research Center: exhibitions, Understanding Implicit Bias 99

mass incarceration 31,121

Mast, Erin 108-110

Matthews, Tracye 155-156

Mccall, Sophie 96

McCarthyism 47

McKee, Yates 96

McRainey, Lynn 29-30

Memory 3, 10, 140-141, 144, 166-173; action 59-60, 67; art 63, 64, 87; emotion (see emotions); empathy $14 \mathrm{n} 36,25,71$, 89; learning 61, 69; physicality $62,65,74$; rehearsal 82,97 , $112,121,184$; resonance 101 ; stress 77 ; visitor studies 97; (see also communities of memory; Holocaust; Memory Jar; Speaking to Memory)

Mestizo museology 151-154

methodology of study 8-9

Mexican Fine Arts Center Museum (Chicago) see National Museum of Mexican Art

Mexicanidad 42-44

Milgram, Stanley 16-17

Miller, Cindy 28

models of space: congregant spaces 6, 139-141, 164-169; contact zones 6, 140, 143 ,

164-168, 170 (see also friendly adversaries); cosmopolitan canopies 6,140-141, 164-169; decolonizing museums 4, 139, 144-148,

164-168, 170, 174n35; dialogic museums 141-142, 164, 169; first-voice 142-143, 164-168, 170, 174n 26

Montoya, Malaquías (artist) 48, 48

Moreno, Cesáreo 21, 45, 79, 81, 83, 87-88, 157, $174 \mathrm{n} 26$

multiculturalism 7

Museo de Antioquía (Medellin): exhibitions, Relicarios 39

Museum 2.020

"museum effect" 151, 158-160, 171-173

The Museum Experience Revisited (Falk and Dierking) 97

Museum of Anthropology (Vancouver): generally 8; exhibitions, 'casna?am, The City Before the City 122-123; Speaking to Memory: St. Michael's Indian Residential School 111-112, 112

Museum of Chinese in America (New York): exhibitions, Memories of New York Chinatown 141

Museum of Contemporary Art (MCA) (Chicago): generally 73-74; exhibitions, Kerry James Marshall: Mastry 73; Witness 73

Museum of Tolerance (MoT) (Los Angeles) 5, 22, 27,76

Museum of Vancouver 122 
Museums as a Site for Social Action (MASS

Action) 41

Musqueam Cultural Centre Gallery (Vancouver) $122-123$

Nakamura, Jeanne 19

narrative path 74-77

National Air and Space Museum (Washington) 96

National Association for Museum Exhibition 163

National Center for Civil and Human Rights (Atlanta) 35

National Civil Rights Museum (Memphis) 6, 99-101

National Human Trafficking Resource Center 108

National Museum of African American History and Culture (Washington) 8

National Museum of Mexican Art (NMMA)

(Chicago): generally 5, 8-9, 42-49, 77;

commemorative postage stamps 80 ;

Mestizo museology 152-154; sharing authority 141-142, 149-151; Steering Committee 154 157; exhibitions, The African Presence in México: From Yanga to the Present 20-21, 42, 44-45, 47, 49, 83, 85, 87-88, 96, 153, 155-157; Common Goals, Common Struggles, Common Ground 156, 156; Declaration of Immigration 83, 157; Día de los Muertos 110, 152-153; El Jugete Popular Mexicano/ Popular Toys of Mexico 88; Nuestras Historias: Stories of Mexican Identity from the Permanent Collection 152; Risking the Abstract 153; Who Are We Now? Roots, Resistance, and Recognition 45-46, 48, 48, 84, 86, 96, 153, 156; works, Copa inmigración AKA Deport a Mex Football (Compean and Compean) 83, 84; Draftees of the World Unite! (Cortéz) 47; Español y Negro produce Mulato 43, 43; La Raza Kózmika (Quiroz) 46, 79, 80, 81; Malcolm as the Phoenix (Boriquez) 48, 48; Steven Biko and Malcolm X (Montoya) 48, 48; War Targets Poor People of Color (Rodriguez) 47, 47

National Museum of the American Indian (NMAI) (Washington) 123

National September 11 Memorial \& Museum 37,87

National Underground Railroad Freedom Center (Cincinnati): generally 8, 98-99; Action Library 123-124; Open Your Mind learning lab 99; exhibitions, End Slavery Now 124; Invisible: Slavery Today 123; Slavery to Freedom 123; Understanding Implicit Bias 99

neuroscience 7-8, 12, 17-18, 50n9, 58-60, 66, 77, 109-110

neutrality 3, 4; see also agency; bias; transparency New York Model 31

Norris, Linda 15, 38-39
Novick, Peter 67, 92n68

objectivity see bias; see agency; see transparency

Obregón, Álvaro 44

O'Brien, E. 50

Oceja, Luis V. 7

ofrendas 152-153, 176n69

On the Object of the Museum and its Architecture (Stead) 70

outcomes-based evaluation 12,101-102

Ow, George 122

participation 10, 19, 30, 38, 96, 114, 116, 120-122, 135n56, 147-149, 153, 166-173, 175n64, 183

The Participatory Museum (Simon) 14n26, 50n15, $51 n 38,121,147$

Pearce, Susan 3

Pekarik, Andrew 101-102

Perry, D.L. 61

physical experiences: generally $7,11,18-19,58$, 89, 101, 107, 113, 151, 159, 181, 183-184; emotions (see emotions); empathy 7,11 , $17,18,31,58-59,61,63,65,67,71,113$, $181,183,185$; facts and figures use of 84-85; getting visitors moving 62-64, 70-71, 74 (see also narrative path); immersive environments 7-8, 11, 26, 58, 61-62, 66-74, 76-77, 184; inner conversation, fueling 63-65 (see also questioning); inventive interactives 62-65; logic, appealing to 83-85; narrative path 74-77; political appeals 31,85 ; resonance and (see resonance); rest 77-81; tactile experiences, enabling (see tactile experiences, enabling); taking position 82-83; wonder (see wonder) Pictures and Tears (Elkins) 19

Pinochet, Augusto 40

Pleasure $31,61,65,77,78,183$; see also comfort; enjoyment

political appeals $21,27,42-45,82-87,90$ n36, 110, 124

The Power of Images (Freedberg) 2

Pratt, Mary Louise 143

Pratt, Richard Henry 111

prejudice, 1-3, 5, 12, 16, 20-21, 27, 29, 35-36, 44, 140, 142, 181, 185; see also racism

President Lincoln's Cottage (Washington): generally 8, 185; exhibitions, Can You Walk Away? 107-110, 109

Presiosi, Daniel 90n48

prosthetic memory 38,182

purposes of museums 3, 5-7, 19-20, 29

"Pussy Hat" 127, 127

queer, Chicago see Out in Chicago; transsexual 64-65; use of term 51n37; violence 28; see also community and queer; Savage, Dan 
questioning 5, 28-29, 166-168, 183

Quinn, Therese 96

Quiroz, Alfred (artist) 46, 79, 80, 81

Rabkin, Nick 113

race, 21, 32, 35, 38, 41-49, 73, 79, 83, 85, 88, 91n66, 96, 98-100, 142, 145-147, 152, 155-157, 185; see also Adjustment of Colonial Terminology Project; casta system racism 11, 29, 35, 44, 54n85, 79, 91n64, 98-99, 146, 157, 182; and violence 35, 43, 79, 91n66, 100 ; see also prejudice

Radke, Heather 62, 102, 159-160

Ramachandran, V.S. 87

Rasquachismo 153

Ravelry 128

Ray, James Earl 100, 100-101

Redress of wrongs see retributive justice

Regarding the Pain of Others (Sontag) 36

regional networking 15, 38-42

Re-Imagining the Museum (Witcomb) see Andrea Witcomb

relevance $1-4,10,27,35,37-39,41,76,81-82$, 87, 91n65, 96-98, 105, 119-121, 139, 154, 157, $163,183,185$

Renslow, Chuck 162

resonance $41,68,78,81-88,91 \mathrm{n} 65,119$, 150, 160, 162, 183; defined, 59-60; art see art and resonance; empathy see empathy and resonance; emotions see emotions and resonance; exclusion 11, 82; facts and figures, use of 83-85; logic appealing to, 81, 83-85; political appeals $85-87$; taking position 4 , 82-83; welcome 82; wonder see wonder and resonance

rest $77-81$

restorative truth $4,5,13 \mathrm{n} 3,141,164,170$ (see also decolonizing museums)

retributive justice $2,12,13 \mathrm{n} 1,15,186$ (see also decolonizing museums)

Rijksmuseum (Amsterdam): generally 5, 8; Adjustment of Colonial Terminology Project 145-147; work, Bathsheba at Her Toilet (van Haarlem) 147

Rivera, Diego 46

Rochet, Pablo 40

Rodriguez, Favianna (artist) 47, 47

Rosario-Jackson, Maria 155-157

Rothstein, Edward 4

Routes: Travel and Translation in the Late 20th Century (Clifford) 143

Rowley, Susan 123

Rozet-Smith, Mary 149, 149

Sacks, Oliver 11, 132-133

St. Louis Zoo 8

Sandell, Richard 29
Santa Cruz Museum of Art and History: exhibitions, Memory Jar 121-122

Sapolsky, Robert 59, 77

satiric misspelling 91n64

Saunders, Carol 104

Savage, Dan 148

Schacter, Daniel 82

Schieffelin, Bambi 46

scope of study 9

Scott, Jennifer 113

Ševčenko, Liz 141

The Seven Sins of Memory (Schacter) 82

shared vocabularies 16, 46-49

sharing authority: generally 5-6, 12, 139, 163,

169-176; alternative labeling 149-150;

with communities 151-163; congregant spaces 139-140, 164-169; contact zones 143,

164-168, 170; cosmopolitan canopies

140-141, 164-169; decolonizing museums

144-147, 164-168, 170, 174n35; dialogic

museums 141-142, 164-169; first-voice

142-143, 164-168, 170, 174n26; hospitality

19, 180-183; inclusion 147-148, 183;

"museum effect," 158-160; participation

147-148; steering committees 154-157;

"thick description," 150-151; tone 150; tools

171-173; use of term 173n2; visitor panels

160-163; with visitors 148-151; Seeing Race in

Modern America (Guterl) 79

Shivers Down Your Spine: Cinema, Museums, and the Immersive View (Griffiths) 6, 60

Silkes, Liz 3

Silva, Teresa 82

Simon, Nina 4, 6, 20, 22, 29, 91n65, 121, 139, 147-148, 154, 163

Simon, Roger 110

Simon, Sibley 122

Sint Nicolas, Eveline 145-146

site selection 9-10

Sloan, Andrew Jackson 122

Slover Linett Audience Research 161

Slovic, Paul 31

Smart Museum of Art (Chicago): generally 8; exhibitions, Feast: Radical Hospitality in Contemporary Art 128-129; Welcome Blanket 126-132, 129-132

Smith, Manda 105-106

Snyder, Timothy 92n68

social justice see criminal justice; distributive justice; see retributive justice; see transitional justice

Social Justice Alliance of Museums (SJAM) 41 social media, 15, 40-41, 98, 107, 124, 126, 128 , 145, 185 (see also digital)

solidarity: generally 10-12, 15, 58, 160, 163, 180-183; institutional solidarity 38-40; intentional welcoming 20-21; intergenerational 
communities of memory 37-38; personal identities 42; regional networking 39-42; relationships between Mexicans and AfricanAmericans 21, 44-49, 84, 85, 88, 96, 100, 155-157; systemic change 37

somatic markers 60-61, 66

Sontag, Susan 36

South Africa Truth and Reconciliation

Commission 4

Spence, Charles 87

Sperber, Dan 82

Spolin,Viola 113

Stafford, Barbara 87

stakeholders see community and stakeholders

Stanford Prison Experiment 16

Starr, Ellen Gates 30

Stead, Naomi 70

steering committees $81,151,154-158,162$,

166-173, 176n78

Strike Art (McKee) 96

subjectivity see agency

sustainability 152; environmental 1, 38, 104, 107; museological 10, 38

systemic change 27, 33, 35-37, 44, 145, 182, 185

Szany, Kelly 31

tactile experiences, enabling 7, 29-31, 61, 65-74, $87,182,183$

Tajfel, Henri 16

taking positions see transparency

Taller de Gráfico Popular (TGP) 47

Tchen, Jack (John Kuo Wei) 141-142

Te Papa Tongarewa (Wellington) 152

Tepper, Stephen 135n56

"thick description" 150-151

third place 17,19

Thomas, Lisa 159-160

Thomas, Philip 155-157

Tigerman, Stanley 66

Till, Emmett 35

tolerance 5, 10, 19, 20, 22, 27

tone 4,150, 181 (see also humor)

Tortolero, Carlos 21, 44, 176n73

touch see tactile experiences, enabling

transitional justice $2-3$

transparency 3-6, 82, 185 (see also agency; tone)

Trump, Donald 127

truth, kinds of see restorative truth; see South

African Truth and Reconciliation Commission
Underground Railroad 45-46, 49

United States Holocaust Memorial Museum

(Washington) 28, 76-78

universalism 5, 9, 139, 164-173

"universe of obligation" 17-19

University of Connecticut 98-99

Valaitis, Kristina 155

van Haarlem, Cornelius (artist) 146

Vasconcelas, José, 44, 80

Verzetsmuseum (Amsterdam): generally 8; exhibitions, Verzetsmuseum Junior 22-28, 23-26

Villanueva, Angelina 85, 153

Villaraigosa, Antonio, 85

visitors, actions of see inspiring action; attendance, see attendance; as social actors 6 , 11, 29, 96-97; panels, see visitor panels; stances toward 10, 19-31, 140-141, 149, 157, see also hospitality; welcome; studies 12, 97, 104, 109, 184

visitor panels 160-163, 171-173

Warhol Foundation 83

Warner, Michael 65

Washington, Harold 85

White, Charles 47

Whitehead, Christopher 3

Wiesel, Elie, 76

Wiesenthal, Simon 92n68

Williams, Kimberlé Crenshaw 91n66

Wilson, Dierdre 82

Wilson, Fred 117

Wilson, Jordan 123

Wing Luke Asian Museum (Seattle) 20

Witcomb, Andrea 5-6, 27, 62, 65, 69, 76

Wittman, Aletheia 41, 145

Women Hold Up Half the Sky (exhibition) 116, 119-120

wonder 50n16, 59-61, 70, 87-88, 105, 184

Yasuoka, Matthew 96

Young Chicago Authors 159

Zimbardo, Philip 16-17 (see also Stanford Prison Experiment)

Zite-Stumbris, Jamie 104

zoos xi, 8, 98, 103-107, 110, 134n21, 185

Zweiman, Jayna 126-128 